Violence and Trolling

on Social Media 


\section{MediaMatters}

MediaMatters is an international book series published by Amsterdam University Press on current debates about emerging and transforming cultural practices that engage with (new) media technologies. Contributions to the series critically analyse and theorise the materiality, spatiality, mobility and performativity of these practices in book projects that engage with today's dynamic digital media culture.

MediaMatters focuses on objects and practices such as: installation art; (digital) performance; site-specific theater; time-based art; experimental film and video; digital and new media art; motion capture; telematics; looping media and digital GIFs; glitch media; cybernetics, robots and AI; virtual reality, augmented and mixed reality; screen media; interactive media, haptic/tactile media; mobile media; tactical media; ecological art and media; media architecture; new museum and exhibition practices.

Key themes are:

- situatedness and site-specificity of media, art and performance;

- transformations and (re-)configurations of materials, spaces, movements, and bodies in media, art and performance;

- visuality and visibility in the age of the digital interfaces;

- media ecologies;

- media and the environment;

- participatory practices, interactive engagements, and transforming publics in contemporary screen and performance culture;

- the role of media technologies in (urban) public spaces;

- the materiality and performativity of digital technologies.

\section{Series Editors}

Nanna Verhoeff, Utrecht University, the Netherlands

Maaike Bleeker, Department of Media \& Culture Studies, Utrecht University, the Netherlands

Jennifer Peterson, Woodbury University Department of Communication, USA

Sally-Jane Norman, Victoria University of Wellington, New Zealand 


\title{
Violence and Trolling on Social Media
}

History, Affect, and Effects of Online Vitriol

\author{
Edited by \\ Sara Polak \\ and Daniel Trottier
}


Cover illustration: designed by Nils Michael Weishaupt Source: GCSC

Cover design: Coördesign, Leiden

Typesetting: Crius Group, Hulshout

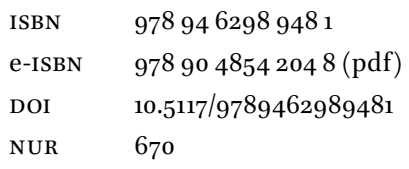

\section{(C) $(1) \Theta \Theta$}

Creative Commons License CC BY NC ND (http://creativecommons.org/licenses/by-nc-nd/3.o)

$\circledast$ All authors / Amsterdam University Press B.V., Amsterdam 2020

Some rights reserved. Without limiting the rights under copyright reserved above, any part of this book may be reproduced, stored in or introduced into a retrieval system, or transmitted, in any form or by any means (electronic, mechanical, photocopying, recording or otherwise). 


\section{Table of Contents}

Acknowledgements

Introducing Online Vitriol

Sara Polak and Daniel Trottier

\section{Dynamics of Online Vitriol}

1 Mediated Visibility as Making Vitriol Meaningful Daniel Trottier, Qian Huang and Rashid Gabdulhakov

Social Media and the Limits of Free Speech

Tom Clucas

3 '\#Unpresidented'

The Making of The First Twitter President Sara Polak

\section{Histories of Online Vitriol}

4 Historical Prefigurations of Vitriol

Communities, Constituencies and Plutocratic Insurgency Frans-Willem Korsten

5 White Femininity and Trolling

Historicizing Some Visual Strategies of Today's Far Right Ewelina Pepiak

6 The Case of Telefilm De Punt's Online Discussion Forum Participatory Space for Societal Debate or Echo Chamber for the Polemical Few?

Gerlovvan Engelenhoven 


\section{Affects of Online Vitriol}

7 Love and Hate Online

Affective Politics in the Era of Trump

Greta Olson

8 Satire and Affect

179

The Case of Stefanie Sargnagel in Austria

Ann-Marie Riesner

9 Ethical Implications of Onlife Vitriol

Katleen Gabriels and Marjolein Lanzing

\section{Activism and Online Vitriol}

10 'I Wasn't Chastised Properly'

On Trolls and Misogyny

Sophie Schwarz

11 r/ChokeABitch

Feminist Tactics Against Hate Speech in Capitalist Social Media Platforms

Penelope Kemekenidou

Index 


\section{Acknowledgements}

The initial groundwork for this book was laid at a conference in 2017 around the theme of Online Vitriol, organized at the Graduate Centre for the Study of Culture (GCSC), with additional support from the Zentrum für Medien und Interaktivität (ZMI), of the Justus Liebig Universität Giessen. We are very grateful to both institutes, and particularly thank Ann-Marie Riesner and Rahel Schmitz for their organizing talent; Greta Olson, Jutta Hergenhan, and Dorothée de Nève for their support in thinking through the conference, and Jens Kugele and Ann Van De Veire for their logistic support.

We thank Monica Williams and Tina Olteanu for their contributions to the early conceptualization of the book, Elizabeth Losh for helpful feedback on

the first version of the full manuscript, Wouter Woltering for his assistance in copy-editing, and Maryse Elliott and Jaap Wagenaar for their editing at AUP. We are very grateful to Josje Calff and Menno Polak for their final editing.

This work was supported by the Netherlands Organisation for Scientific Research (NWO), project numbers 446-16-0o2 and 276-45-004. Leiden University Centre for the Arts in Society (LUCAS) provided funding for the indexing and Open Access fees. 



\title{
Introducing Online Vitriol
}

\author{
Sara Polak and Daniel Trottier
}

In 'How One Stupid Tweet Blew Up Justine Sacco's Life' (New York Times Magazine, 12 February 2015) Welsh journalist Jon Ronson investigated the effect on victims of public shaming through social media platforms and compared it to the history of public shaming as a form of punishment. Such punishments (the stocks, the pillory, the whipping pole) have gone out of practice, in part because they were considered too humiliating and socially annihilating for the person undergoing the punishment. Ronson finds a clear parallel in the effects of online public shaming in the victims of the present. He both interviewed victims, including Justine Sacco (famous for being shamed online by thousands of people as a racist by the malicious retweet of her 'funny' joke tweeted just before going offline on an intercontinental flight in 2013), and people who had been important in setting off such processes, like Sam Biddle, who initially retweeted Sacco's tweet and posted it on Valleywag, with the hashtag \#hasjustinelandedyet. Biddle was unapologetic in his interview with Ronson about the harm done to Sacco as a result of the Twitter storm (she was let go from her job, received numerous death threats, was socially isolated, and trauma-

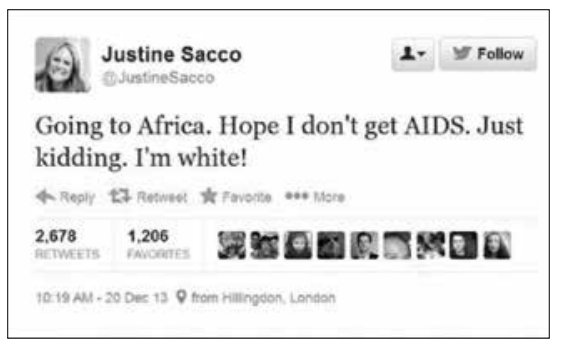
tized by the ordeal - all effects that have come to be seen as fairly typical for public shaming). ${ }^{1}$ However, Biddle later became victim of such a shitstorm himself, and a year after the initial denunciation publicly apologized to Sacco.

Ronson reflects how he himself was initially a keen actor in such processes:

1 For more research on these 'typical' effects of online shaming see e.g. Jackson et al., ‘\#GirlsLikeUs; Vaidhyanathan, Anti-Social Media; Losh and Wernimont, Bodies of Information; Lovink, Social Media Abyss.

Polak, Sara, and Daniel Trottier (eds), Violence and Trolling on Social Media. Amsterdam, Amsterdam University Press 2020 DOI: 10.5117/9789462989481_INTRO 
In the early days of Twitter, I was a keen shamer. When newspaper columnists made racist or homophobic statements, I joined the pile-on. [...] It felt as if hierarchies were being dismantled, as if justice were being democratized. As time passed, though, I watched these shame campaigns multiply, to the point that they targeted not just powerful institutions and public figures but really anyone perceived to have done something offensive. I also began to marvel at the disconnect between the severity of the crime and the gleeful savagery of the punishment. It almost felt as if shamings were now happening for their own sake, as if they were following a script. ${ }^{2}$

Sacco herself worked in PR, and Ronson and Biddle too are both journalists, writers and people who are professionally involved in communication online. Yet even as professionals they are clearly as little in control of the 'gleeful savagery' of online shaming as anyone else. At most they may be said to have a bit more agency or influence than others, ${ }^{3}$ which only underscores how unprepared and outmatched other targets might be when facing an angered online mob. ${ }^{4}$

Events like this have become very common in recent years and they raise many questions. For instance, do trolling, 'doxxing' (publicizing someone's personal details such as home address and phone number without consent), or contributing to public shaming as in the above cases constitute a form of violence? Who are its victims? And how are victims, bystanders, societies and platform owners to deal with it? Is it something that can be controlled, and if so by whom? And what is the genealogy of online vitriol? How, does it interact with embodied violence offline? While online and offline worlds seem separated, the consequences of online media expressions also occur offline, and many online dynamics have offline equivalents in past and present. Beyond comparisons to the pillory, there are many other ways in which this phenomenon resembles the online equivalent of age-old enactments of violence. Ronson, for instance, reports getting one jarring response to having set off a shaming campaign on Twitter ('amid the hundreds of congratulatory messages I received') - a question: 'Were you a bully at school?'.

2 https://www.nytimes.com/2015/02/15/magazine/how-one-stupid-tweet-ruined-justinesaccos-life.html. Accessed 21 February 2020.

3 As in Biddle's case because he had a larger platform; or as in Sacco's case because she should presumably have been better able to estimate the potential consequences of making a joke that could be understood as racist on a public platform.

4 Lovink, Social Media Abyss. 
The link between bullying and trolling on social media has often been made, for one thing because a great deal of bullying in the context of school nowadays also occurs online, but also because the setting in which trolling happens is similar to that of bullying. ${ }^{5}$ If we consider trolling to mean 'sowing discord on the internet by starting quarrels or upsetting people, by posting inflammatory, extraneous, or off-topic messages in an online community with the intent of provoking readers into an emotional response or of otherwise disrupting normal, on-topic discussion', some of the intentions and effects are obviously similar to those of bullying. In terms of social psychology the aim of either is to disrupt the communication of real or randomly selected 'enemies', in order to strengthen a sense of power within one's own group. Social media platforms like Twitter, Facebook or Reddit are especially fertile environments for this, because conversation there, even if it seems to be between two people, is really also a performance for the benefit of perhaps very many invisible onlookers, who may or may not express themselves through likes, retweets, or by adding comments. ${ }^{6}$ Thus, such a conversation, which might have been entirely civil if it happened face to face between two people, or even in a series of one-on-one direct messages, can easily become like a schoolyard fight. The function most of the comments serve is rather to show off one's acerbic wit or cool to people on one's own side, rather than to arrive at mutual understanding or appreciation. As in offline bullying then, the function of such 'debates' is often rather to strengthen one's own 'ingroup' by means of excluding and humiliating the opponent. Thus, the 'normal on-topic discussion' is often less the logical function of social media exchanges, than the disruption itself, which may have a range of secondary purposes, such as entertainment, silencing political opposition, a sense of power for those doing the targeting, or of safety for those not targeted.

Many social media platforms through their design - the publicness of communication, the possibility to share, like, and comment on earlier statements, the imposed brevity of such statements - facilitate processes of group formation through bullying and exclusion more easily than they facilitate conversation that brings insight into the content of what is being discussed. This is also why two factions clashing on social media platforms can often both come away from the exchange feeling that they are being trolled by the others. Similarly, there are various cases where the person who

5 Wright (ed), A Social-ecological Approach to Cyberbullying; Horowitz and Bollinger, Cyberbullying.

6 Settle, Frenemies. 
(is perceived to have) started the public shaming of someone, is later targeted in the same way and with the same effects by anonymous wrath. And while this wrath seems volatile, and online abuse may happen to anyone, there is ample evidence that misogyny and other forms of vitriol aimed at minorities thrive online both in terms of quantity and sheer bluntness of such utterances.

This book is motivated by a series of urgent questions surrounding online vitriol. Even in a deeply polarized political climate, one common experience across the spectrum is the sense of simultaneous empowerment and powerlessness in response to prolific and persistent digitally mediated communications. We are wondering how to evaluate, and what to do with, the overwhelming amount of such activity, much of which can be considered violent. What is online vitriol, as we have termed it throughout the book? What does it mean? What is its intent? In what ways is this phenomenon new compared to forms of violence or vitriolic texts in the broadest sense from the past? How productive, in this context, is the dichotomy of online and offline? And how can individuals, organizations, (media) companies and governments respond to it? ${ }^{7}$

These important and urgent questions bring together scholars in the social sciences and humanities, as well as activists and media professionals who through their work are regularly confronted with online vitriol. Their discussions are reflected in this book, which seeks to bridge academic research and everyday practice. We take this approach since online vitriol arguably has an impact on all of us, even those who choose not to participate in online social networking. And many professionals, for instance in journalism, communications or politics, no longer have the luxury of being able to avoid social media altogether.

The notion of online vitriol is a complicated one. When can online sociality be considered as violence, and to what extent can this be determined objectively? Whitney Phillips and Ryan Milner in their book The Ambivalent Internet explicitly embrace the notion of ambivalence here, arguing that what can be offensive to one reader is funny to another. ${ }^{8}$ Of course this is true, and their appreciation of the ambivalence and the sliding scale of what is possible or acceptable is an essential element of a great deal of online sociality. However, we position ourselves on the side of those negatively affected by online expressions in a way that can be construed as violent. In

7 Several strategies for doing this are discussed in Sunstein, \#Republic and in Caplan et al., 'Algorithmic Accountability'.

8 Phillips and Milner, The Ambivalent Internet. 
other words, our primary focus is precarity and relative powerlessness in the face of online vitriol, which characterizes the experience for instance of a trans activist whose home address and/ phone number are publicized online, or of the female critics who were victimized by GeenStijl (a Dutch online news website that posted photos of critical columnists, asking their readers to respond in the comments to the question 'Would you do her?'). However, the business models driving such sites' editors and the affective or political motivations of their anonymous posters are also considered.

The first question to answer is how we should read potentially violent messages on social media. Throughout its chapters this book is committed to showing that these are speech acts, in the sense that they are in various ways performative. By saying or showing something, they do something. This is not new to social media networks: a threat exists only in words, yet it can profoundly alter the reality of safety of the person threatened. This is true whether the threat is uttered on Twitter or a handwritten letter, but the difference is that on social media, users are typically less inhibited by social norms and practical viability to utter threats, which to them may seem silly or trivial, but not to the receiver, in the characteristic ambivalence that Phillips and Milner analyze. Nonetheless, a threat, however ephemeral in the eyes of the sender, remains performative in J.L. Austin's sense of the term: ${ }^{9}$ like speech acts such as 'I promise', it changes the reality. Online speech acts can also be performative in a considerably more aggressive way, for instance, when they serve to retweet or otherwise spread nude photos without the consent of the (often famous) person photographed. A share or retweet may seem inconsequential enough to the user clicking the button, but it is precisely the massive spread of such images that actually constitutes and continues the abuse implicit in the non-consensual spread of the image.

\section{What is online vitriol?}

Various terms are in use to describe violent, bullying, demeaning, or otherwise antagonistic expressions on social media platforms. Hate speech is common, but also not limited to the online world. While it does signal that these expressions are speech acts, and therefore, as we maintain, performative, the reference to 'hate' does not always seem justified. While many different motivations and affects can be involved, and hatred on the part of the sender is surely one of them, other motivations exist too 
(as considered for instance in chapters two, three and seven). The term is thus both too broad and too narrow in its seeming attribution of motives. Feminist scholar Emma Jane has introduced the term 'e-bile', which is useful, but particularly designed for the specific category of misogynist and objectifying comments addressed to women online. ${ }^{10}$ We propose online vitriol as a term to think about this phenomenon, because it stresses both the violent and the uncontrollable aspects of the phenomenon and its typical excesses, such as shitstorms, and speech acts that silence, threaten, or harm others.

Etymologically vitriol derives from the Latin 'vitriolum' which means sulphuric acid, and is akin to the Latin word 'vitrum', glass. In common usage it means bitter or abusive speech or malice. Vitriol does tend to be acidic and acerbic, and the metaphor of splintering glass is apt in this context. Moreover, vitriol is a word as well as a phenomenon with long cultural roots in the Western world. Vitriol has been expressed and documented in historical contexts, as Frans-Willem Korsten and Ewelina Pepiak show in Section Two.

Online vitriol seems to be a particular product of the Web 2.0, the 'participatory' or 'social web' that has evolved since the early twenty-first century, and that revolves around 'user-generated content' and conceives of the web as a space of interaction, rather than a collection of static sites where one can read information. The term 'Web 2.0' was coined in 1999 by Darcy DiNucci in an article prophetically titled 'Fragmented Future.. ${ }^{11}$ Fragmentation does indeed seem to be one of the key aims and effects of online vitriol enabled by the interactive structure of social media platforms. In recent years particularly, online vitriol has come to serve political powerplay, with actors often operating from a stance of victimhood and supposed powerlessness, while at the same time attracting considerable attention, visibility and influence. This becomes manifest for instance in the context of political strife, between political actors, but also between political and press actors (Donald Trump's lashing out at mainstream media networks comes to mind as an obvious example). These are well-documented instances of vitriolic exchanges between public figures. We may consider whether these shape individuals' understandings of what is possible and what is appropriate in public discourse, though social platforms and mobile devices users can also reproduce and exceed the kinds of vitriol they encounter in public. 
Vitriol is a fruitful and troubling term to invoke when discussing the problematics of contemporary communication practices. Seemingly, the purpose is not only to cause offence or harm towards the interlocutor. Whether discussing a spat between political rivals or a heated exchange between cultural influencers on Twitter, the intention is simultaneously to communicate a disregard for that target - as well as the categories and communities to which they may belong - to a wider audience. Contemporary mediated vitriol is always a public affair that is usually meant to challenge the social standing of the other, and to reassert one's own. The cases considered in this book vary in terms of political, cultural and historical contexts. Yet throughout them we may consider some common tendencies that provide insight about the harms and other consequences of vitriolic practices.

Online vitriol is weaponized: vitriol is deliberately leveraged to target political opponents, or groups that may face categorical and systemic forms of oppression. It is thus possible to consider vitriol as purpose driven: as a form of expression in which the speaker/author seeks to harm or assert one's self over someone else. This can but does not necessarily stand in contrast to an understanding of vitriol as primarily affect-driven. ${ }^{12}$ While the author of vitriolic content may be fuelled by their own disgust or hatred, perhaps of greater concern is their ability, and apparent desire, to foster and mobilize the disgust and hatred of their audience. This may be evident when assessing polarized political landscapes, but can also be observed within subcultures such as among authors and fans of young adult literature. ${ }^{13}$

Online vitriol is also prominent: the intention and effect of vitriolic statements is often to grab attention, to get clicks, to direct media focus towards oneself, and/or a target. Social media platforms are often complicit in this, as their business models depend on a steady flurry of user engagements and disclosures. The purpose is not simply to speak to the person deemed worthy of vitriol, but rather to make that denunciation visible and legible to a broad audience. In other words, vitriol is directed towards a target, but is also keenly aware of the broader public it is attempting to influence. This extends from the weaponized nature of vitriol: it's not just that the words cause harm on their own, but rather harm is yielded in making those words so visibly linked to the reputation of a targeted victim. Online vitriol can often be mobilized at remarkable speed, and thus can spread 
far and wide in little time. This does not only intensify the harm caused, but simultaneously divides responsibility for this harm among so many, often anonymous, participants, that it becomes very difficult to attribute responsibility to individuals.

Finally, online vitriol is retained: by operating through social media platforms it forms a kind of public record that may lead to unanticipated consequences. Vitriolic statements are uttered in particular contexts, and despite their seeming ubiquity, are not necessarily meant to transcend and endure beyond these contexts. Yet as digital content, vitriol can potentially (and following default settings on platforms, by default) be retained indefinitely. Produced and retained in such conditions, they will surely leak beyond their intended audience, and new standards of acceptability may inform how they are received by temporally and spatially dispersed publics. For this reason, researchers and other professionals must remain attentive to prominent and routinized forms of vitriol, especially as these become acceptable practices both within and beyond particular contexts.

\section{Purpose of the book and overview of the sections and chapters}

This book considers online vitriol in a context of significant mediatization in a new and rapidly changing media ecosystem, in which data are collected and processed in ways that are difficult for individual users to oversee, but also difficult for lawmakers to regulate and enforce. This book brings together disciplines, such as digital media studies, cultural history, and literary studies. It both uses the tools and analytical apparatus from older disciplines to understand new developments in their historical and cultural context, and it offers new terminology and case studies to think through the ways in which online vitriol functions in ways fundamentally different from older structures and dynamics of vitriol. This book also brings together perspectives and contributions that go beyond a purely scholarly interest, including activist and journalistic engagements. This contributes in particular to a consideration of vitriol's societal importance, and steps that readers can take when encountering it. We hope that this book is also, or perhaps primarily, of interest to people who do not necessarily study online vitriol, but who are in their daily work and life confronted with its practices.

This book is comprised of four sections, each providing various perspectives on one of the book's guiding questions. The first part on the dynamics 
of online vitriol concerns the question how online vitriol works in ontological and medial terms. How do social media networks lend themselves to digital vigilantism, or to the spreading of 'scares', and how should one respond to trolls? The second section is dedicated to the historical precursors of online vitriol and to the online life of cultural memory. Where in the offline past does online vitriol find its roots? And how is it new? The third section is dedicated to the affects of online vitriol. How does online sociality and vitriol incite waves of strong affective responses? How does this 'economy' of affect work for and in online platforms and carry over into traditional tabloid media? What sensibilities drive online activism from the Alt-Right? And to what extent must online vitriol be considered 'onlife' in the sense that it has tangible effects in the offline world? The final section is dedicated to activism, and is written by activists, with academic backgrounds, who explain how they personally and collaboratively deal with the vitriol aimed at them in response to their work, what initiatives exist to protect users, by users themselves, governments, platforms, and other organizations and collectives. This section clearly shows the inextricability of the online and the offline.

How are social dynamics in the public sphere different if that public sphere is largely moved to an online environment? The opening chapter by Trottier, Gabdulhakov and Huang discusses the issues of citizens' vigilantism (watching and calling out each other's real and perceived impolite or uncivil behaviour in public space) when this happens in the online world. The chapter addresses case studies in three different countries (the UK, Russia, and China), showing how these are each culturally specific yet escalate the impact for those who are at the receiving end of this 'digilantism'.

Tom Clucas's chapter addresses practices of YouTube users calling each other out in the comments for racist or trolling behaviours. The chapter gives historical and philosophical context to the longstanding dilemma whether one should 'feed the trolls' or not. While the common wisdom is not to give attention to trolling - because attention is exactly what trolls presumably want - Clucas argues that many trolling comments do merit clearly denunciatory responses, and providing these is a kind of labour that the online public sphere needs.

In the third chapter Sara Polak zooms in on the early formation of political constituencies online. Some such groups, formed and mobilized through online platforms, started to become politically active well before they were easily visible a such to a larger public. The case study developed in the chapter is that of Donald Trump's and others' alarmist tweeting about the Ebola epidemic in West Africa (2013-2015) which was one of the moments Trump 
and online constituencies around him came into their own as a group and learned to hone and employ massive influence through Twitter and other online platforms that later came in handy for the formation of collectives such as Trolls for Trump (active in the 2016 Presidential campaign).

The fourth chapter, by Frans-Willem Korsten, opens the section on the histories of online vitriol, and thus attends mainly to offline dynamics and characteristics of vitriol, locating the god Momus and his daughter Rumor as European cultural forebears. Korsten makes clear that the speed with which online vitriol can spread, creates a kind of surplus value usually directed towards disrupting the process of political agonism. Thus, he argues, using the example of rapidly mass-printed pamphlets in the Dutch Republic in the $17^{\text {th }}$ century, as well as 'Alt-Right' memes of more recent date, have a crucial role in firing up political escalations beyond what is manageable in a democratic context.

Ewelina Pepiak's chapter focuses on the history of the visual rhetoric used in nationalist and racist memes employed to frame the attacks on women in Cologne on New Year's Eve 2016-7 as a reason to exclude and criminalize refugees and non-white men in general. The chapter shows that such 'memes', although they are image-text hybrids of a kind specific to social media contexts, come out of a long tradition of visual culture with stock figures and tropes to stress the danger of the colonial other as a sexualized threat to white femininity.

The sixth chapter, by Gerlov van Engelenhoven, focuses also on the presence of colonial inheritances, but rather the other way around: it studies how social media communities (Facebook groups and online fora), respond to a documentary film that has effectively become a site of memory for postcolonial trauma. Perhaps counterintuitively, Van Engelenhoven notes that the documentary allows for more nuance and a broader variety of perspectives than the social media discourse following it. Social media, despite their interactive nature, seem to allow more easily for an echo chamber of congealed memories than for actively working through a contested past.

Part three, on the affects of online vitriol, opens with Greta Olson's introduction to affect theory in general, explaining its genealogy as a preverbal visceral response, followed by her analysis of the functions of vitriolic misogyny in certain US American 'meninist' circles. Olson analyzes the meanings and implications of misogynist social media vernacular such as 'basic bitch' and concludes that this does not indicate a genuine hatred for women, so much as a collective sense of nostalgia and loyalty among men. 
The more Trump, for instance, is criticized the more fervent his supporters become in their defence of him, because he reflects their own affective experience of being beleaguered.

Ann-Marie Riesner's chapter, then, traces the affects, turning into full-blown shitstorms, that Austrian author Stefanie Sargnagel arouses through her provocative blogposts. Riesner analyzes how Sargnagel as part of her artwork manipulates her readers to expose the affective networks of vitriolic hatred that span both the online and the offline world. The analysis uses methods originating in literary studies to untangle the dynamics of online vitriol and elucidate the functioning mechanisms of online hate speech.

This notion of affect 'flowing' between the online and offline world and destabilizing any dichotomy between the two that may or may not have existed in the past, is then further explored in Katleen Gabriels and Marjolein Lanzing's chapter on 'onlife' vitriol. This chapter explores three case studies from different contexts in which online bullying and vigilantism have very tangible effects on people's lives (including suicide and being forced to move homes). Gabriels and Lanzing make a clear case that online and offline practices and sociality are so intertwined and interdependent that the online/offline binary really collapses and should be considered an 'onlife' dynamic, rejecting any notion that online vitriol can be dismissed as something limited to a specifically virtual sphere that is voluntarily entered.

The final two chapters are dedicated to activism and practice. They essentially each offer experiences and advice from activists. The first is Sophie Schwarz's reflection on her project at Justus Liebig Universität Giessen 'Why I Need Feminism' - unlike the original project that inspired this one, a specifically offline invitation to people in the university to leave their thoughts about why they need feminism. This drew serious reactions but also attracted a considerable deal of abuse, online as well as offline, surprising perhaps if one considers the offline design of the project.

In the last chapter, Penelope Kemekenidou discusses her extensive experience with online and offline feminist activism, and particularly the ways in which she and her peers protect themselves against threats and sexist violence directed against them. While this contains a wealth of rules of thumb for individual and collective self-care on social media, it also dissects how and why the corporations who own the platforms are uninterested in making them safer by setting and policing clearer boundaries of what is acceptable. 


\section{Works cited}

Austin, J.L. How To Do Things With Words. Oxford: Clarendon Press, 1976.

Caplan, Robyn, Joan Donovan, Lauren Hansen, and Jeanna Matthews. 'Algorithmic Accountability' Report. Data and Society, 18 April 2018, https://datasociety.net/ library/algorithmic-accountability-a-primer/. Accessed 1 March 2020.

DiNucci, Darcy. 'Fragmented Future'. Print Magazine, vol. 53, no. 4, 1999, pp. 32 [and] 221-222.

Gregg, Melissa. 'On Friday Night Drinks: Workplace Affects in the Age of the Cubicle', in The Affect Theory Reader, edited by Melissa Gregg and Gregory Seigworth. Durham (NC): Duke University Press, 2010, pp. 250-268.

Horowitz, Merle, and Dorothy Bollinger. Cyberbullying in Social Media within Educational Institutions: Featuring Student, Employee, and Parent Information. Lanham: Rowman \& Littlefield, 2014.

Jackson, Sarah J., Moya Bailey, and Brooke Foucault Welles. ‘\#GirlsLikeUs: Trans Advocacy \& Community Building Online'. New Media \& Society, 2017, https:// journals.sagepub.com/doi/10.1177/1461444817709276.

Jane, Emma Alice. "Your a Ugly, Whorish, Slut': Understanding E-Bile'. Feminist Media Studies, vol. 14, no. 4, 2014, pp. 531-545.

Losh, Elizabeth, and Jacqueline Wernimont (eds). Bodies of Information: Intersectional Feminism and Digital Humanities. Minneapolis: University of Minnesota Press, 2018.

Lovink, Geert. SocialMedia Abyss: Critical Internet Cultures and the Force of Negation. Cambridge (UK): Polity Press, 2016.

Phillips, Whitney, and Ryan Milner. The Ambivalent Internet: Mischief, Oddity, and Antagonism Online. Malden (MA): Polity Press, 2017.

Settle, Jaime. Frenemies: How Social Media Polarizes America. Cambridge (UK): Cambridge University Press, 2018.

Sunstein, Cass. \#Republic: Divided Democracy in the Age of Social Media. Princeton: Princeton University Press, 2017.

Vaidhyanathan, Siva. Anti-Social Media: How Facebook Disconnects Us and Undermines Democracy. Oxford: Oxford University Press, 2018.

Wright, Michelle F. (ed). A Social-ecological Approach to Cyberbullying. New York: Nova Publishers, 2016. 


\section{About the authors}

SARA POLAK (Leiden University Centre for the Arts in Society) is assistant professor in American Studies, focusing on US presidents and their media. She wrote "This is Roosevelt's World" - FDR as a Cultural Icon in American Memory (Johns Hopkins University Press, 2021) and co-edited Embodying Contagion: The Viropolitics of Horror and Desire in Contemporary Discourse (University of Wales Press, 2021). She currently focuses on Trump's Twitter use. Polak teaches American literature, culture and history, and regularly comments on US politics and culture in Dutch media.

Daniel Trottier is an Associate Professor of Global Digital Media in the Department of Media and Communication at Erasmus University Rotterdam, the Netherlands. His current research considers the use of digital media for the purposes of scrutiny, denunciation and shaming. Daniel is the PI of a five-year NWO-funded project on this topic, entitled "Digital Vigilantism: Mapping the terrain and assessing societal impacts". He has authored several articles in peer-reviewed journals on this and other topics, as well as Social Media as Surveillance (Ashgate, 2012), Identity Problems in the Facebook Era (Routledge, 2013), and Social Media, Politics and the State (co-edited with Christian Fuchs; Routledge, 2014). Daniel completed a PhD in Sociology at Queen's University in Kingston, Canada. 



\section{Dynamics of Online Vitriol}





\title{
$1 \quad$ Mediated Visibility as Making Vitriol Meaningful
}

\author{
Daniel Trottier, Qian Huang and Rashid Gabdulhakov
}

\begin{abstract}
When engaged in vitriol through digital media, users harm their peers not only through the caustic nature of their words, but also by the way in which they can make their targets visible to public scrutiny. Social platforms and mobile devices enable individuals to author commentary about their targets, but also compel other types of actors to join in (or to contest, appropriate or derail) malicious exchanges. By focusing on highly visible yet comparatively mundane forms of denunciation in China, Russia and the United Kingdom, this chapter considers how vitriol can be manifest as a form of civic engagement. These cases provide insight about a more prevalent form of vigilantism that may be located at the margins of what is considered acceptable in their respective social contexts.
\end{abstract}

Keywords: vigilantism, denunciation, digital media, social media, public space

\section{Situating vigilantism and visibility in relation to the study of vitriol}

When engaged in vitriol online, users harm their peers not only through the caustic nature of their words, but also by the way in which they can make their targets visible to public scrutiny. In addition to denunciatory and hateful language, it is important to consider the conditions in which these utterances are produced and circulated, especially in determining the severity of their social impact. Mediated visibility, notably the strategic and multi-actor manipulation of a targeted individual's visibility features prominently in vitriolic practices.

Polak, Sara, and Daniel Trottier (eds), Violence and Trolling on Social Media. Amsterdam, Amsterdam University Press 2020 DOI: 10.5117/9789462989481_CHO1 
Contemporary vitriol is primarily expressed through digital media. Social platforms and mobile devices enable individuals to author commentary about their targets, but also to compel other types of actors to join in (or to contest, appropriate, or derail) malicious exchanges. These other users, who we can tentatively consider as an audience, may simply view the content in question, a seemingly passive act that will be registered by the platform as a popularity metric, in turn contributing to the broader imagined community of judging onlookers. Technical features of social platforms and mobile devices, such as the ability to 'share' or 'retweet', as well as algorithms that sort and re-arrange volumes of user-generated content, extend the scope and range of vitriolic practices. Though some platforms might have been designed with particular professional or demographic contexts in mind, they can be adopted for any number of purposes, especially if these purposes end up serving the platform's business model of commanding attention and collecting personal information. As such, many sites have become gathering points for populist interventions. For example, in the context of Brexit, Facebook groups such as South East Alliance and Pie \& Mash Squad serve as venues for nationalist and anti-immigrant sentiment. ${ }^{1}$ This involves posting news articles and links to other extremist websites, as well as publishing vitriolic comments about targeted politicians, criminal suspects as well as entire categories of individuals in and beyond the United Kingdom. Such activities go far beyond Facebook's original and long-abandoned purpose of socialization among Ivy-league university students. While Facebook has expressed its commitment to removing such content, the platform remains one of several means for denunciatory and vitriolic coordination. ${ }^{2}$

Alongside more coordinated and politicized gatherings social media also offer citizens the opportunity to express frustration about everyday concerns, for example in the context of shared public spaces. In response to incivilities witnessed on a train, a bystander may digitally intervene by uploading evidence of the offending act, along with denunciatory words that capture their dismay. Such denunciations may be spontaneous, and one can imagine that they may be driven by civic motivations (for example, the desire for a safe and orderly daily commute) as opposed to furthering struggles between hegemonic and subaltern communities. Yet other users with diverging intentions can join in such denunciations by adding their own comments, sharing the footage with their social networks, and even supplementing it with additional details about the targeted individual or

$1 \quad$ Poulter, 'The Far Right Are Uniting'.

2 Thompson, 'How Facebook Checks Facts'. 
broader community. As a result, such denunciations can be co-opted for other purposes. They can also have a lasting impact on the lives of those targeted, as well as those belonging to the same (often disadvantaged) communities.

This kind of crowdsourced vitriol is a global phenomenon. Silicon Valley platforms such as Reddit and Twitter play a far-reaching role in denunciations and harassment in countless non-Western countries. Yet mediated vitriol is equally a local and nationalized phenomenon, with users in countries like China and Russia making either exclusive (in the case of the former) or preferred (in the case of the latter) use of national-origin platforms. In addition to national divergences, there are also instances of parallel online communities emerging along ideological lines. As conventional social media platforms have begun to monitor and curtail hate speech, ideologically bespoke platforms such as Voat and Gab have each gained prominence as Alt-Right equivalents to Reddit and Twitter, while Hatreon emerged as an alternative to the fundraising site Patreon. ${ }^{3}$

By focusing on highly visible forms of denunciation, this chapter considers how vitriol can be manifest as a form of civic engagement. These cases may amount to a reassertion of moral boundaries, which typically also carry identity-based dimensions. For this reason civic-led denunciations can become discriminatory and exclusionary, especially when this becomes a crowdsourced effort (which they are designed to be). Fleeting and situated moments of frustration may lead to a singular moment of mediated denunciation, which in turn may culminate into something much more impactful. Vitriolic words may - knowingly or otherwise - mobilize journalists, populist organizations, and politicians along with their respective followers. This chapter considers a particular form of digitally mediated harassment that relies on the denunciation and sustained visibility of others. In the cases considered below, the image of the target is made accessible to an amorphous and volatile audience. By editorializing an event, users invoke a moral compass that can garner further attention and harm. Moreover seemingly 'online' interactions are not distinct from offline consequences, but rather are intimately connected, and can create and exacerbate problems in embodied contexts.

Previous scholarship considers online mobilizations from the lens of (digital) vigilantism. ${ }^{4}$ This refers to instances in which digital media users are offended (or feign being offended) by the words or actions of others, and seek to make both the offence and the targeted individual visible for 
punitive measures. Recent cases vary greatly in terms of offending acts, ranging from minor incivilities to criminal acts that capture public attention such as child exploitation and participating in riots. Likewise, public sentiment about the appropriateness of these denunciations may also vary significantly. A common feature in such cases is the inclusion of vitriolic discourse, which can be observed both in the initial denunciations, as well as in the ensuing commentary by a wider audience. However, the caustic nature of these words cannot be assessed in isolation. Rather, social harm is brought about through the manner in which these statements are seamlessly joined together with description of someone (including images and audio-visual footage) and their associations (including family, workplace, and communities to which they belong). An amplification of the target's visibility leads to an amplification of any potential abuse.

Such developments speak to the ambivalence many users share about being visible online. On the one hand, digitally mediated visibility is partially self-asserted, and can be understood as a reasonably accessible form of self-expression and self-actualization. After all, in the vast majority of cases users knowingly decide to upload information about themselves to social media platforms. Even from a surveillance-studies perspective, being under the watchful eye of others can be understood as participatory and even empowering. ${ }^{5}$ Yet the sharing and subsequent circulation of that content may exceed the target's expectations. In cases where digital media users denounce and coordinate against a target in response to statement or photograph that the target uploaded themselves, we may imagine that they were willingly engaging in some kind of self-expression, for example, to a group of peers. This speaks to how digitally mediated visibility is a collaborative and decentralized endeavour, with several types of actors sharing no institutional or ideological alignment recirculate content originally posted to a social media account. Vitriolic discourses also act as a mobilizing force that invokes a broader audience either in support or against the denunciation. Yet either way it prompts a reaction, and ensures further visibility of the target and the initial message. Such efforts typically culminate in a targeted individual being rendered excessively visible as an object of discussion, without a reasonable opportunity to provide a response.

Unless the digital vigilante chooses to remain anonymous, their exposure and denunciation of a target can lead to themselves becoming the target of a potential counter-denunciation. This possibility reflects the fact that acceptable norms about filming and denouncing others are still being 
negotiated in the mediated public sphere. It bears noting that cases of digital vigilantism cover a moral gamut, and as such include offending acts that trigger widespread condemnation (such as the sexual abuse of children), as well as actions not necessarily considered objectionable by a broader audience (such as eating on public transit). Even in cases of widely condemned offences, public opinion may not support such interventions. For these reasons, scholarship must continue to focus on the public shaping of the perceived acceptability of digital vigilantism. Of particular concern here is the role of the state. By definition it remains excluded from participation in vigilante activities. Yet states may endorse or even financially support citizen-led initiatives, and make use of media channels to attempt to shape public perception of such movements.

The following sections provide an overview of contemporary vitriolic and vigilante landscapes in three national contexts: the United Kingdom, China and Russia. For each country we consider a recent case, and make use of press representations as well as other publicly available data about the event. In contrast to immediate responses to high-profile criminal acts that have been covered in other research, these cases are centred on comparatively banal incidents occurring in public spaces. ${ }^{6}$ These cases provide insight about a more prevalent form of vigilantism, one that may be located at the margins of what is considered acceptable in their respective social contexts. The purpose in juxtaposing them is not purely comparative, but rather to identify commonalities and divergences as topics for subsequent in-depth analysis.

\section{United Kingdom: Disability and disregarded train seat reservations}

While it would be impossible to provide an exhaustive account of UK-based mediated shaming and vigilantism in this chapter, what follows is a case study that provides both recent developments as well as historic antecedents. As such, we do not seek to establish causal links between any single media format, and user activity. Although online shaming may be considered as a product of digital media cultures, a cursory overview of punitive technologies in the UK reveals an array of embodied devices such as the pillory or the scold's bridle, which restrained the targeted individual's movement as well as speech. These served not only to punish transgressions, but in particular

6 Nhan et al., 'Digilantism'; Schneider and Trottier, 'Social Media'. 
to do so in a public manner that disciplined both the target as well as those belonging to the same category, such as 'quarrelsome women' in the case of the scold's bridle. ${ }^{7}$ Likewise, citizen-led interventions such as charivari and rough music had a distinctly public and performative character, in that they served to convey to a broad array of actors both the nature and the consequence of a transgressive act. ${ }^{8}$ The emergence and establishment of tabloid press furthered the scope and visibility of such denunciatory acts. In particular, these facilitated the circulation of imagery of a target of scorn, as well as vitriolic accounts of the target that had a broader and more lasting public reach.

We might think of digitally mediated shaming and its co-construction with British tabloids as a recent development. Yet as far back as 1998 the articles described how '[c] omputer hackers' were 'becoming cyber vigilantes' in order to combat paedophilia, a social problem that received substantial media coverage at the time. ${ }^{9}$ Such anti-paedophile vigilantes have consistently been presented in public discourse, often in conjunction with legal mechanisms. For example, Sarah's law sought to enable the UK public 'to find out if an individual in contact with a child has a record of child sexual offences' through formal legal means. ${ }^{10}$ Other prominent cases include responses to animal abuse, such as the outrage that a Coventry woman received in 2010 when placing a cat into a garbage bin. Women have also been on the receiving end of online scrutiny for a range of other reasons in the UK, such as eating on public transit. ${ }^{11}$ In such cases, the press and tabloid media in particular served as prominent accounts of developments. In recent years there have been a number of cases in which digital media users have witnessed antisocial behaviour in public settings, and have uploaded photographs and their own accounts to their personal social media profiles. We consider one such case below.

In September 2016, a woman took a rush hour train from London to her hometown. She had a seating reservation in order to cope with a disability that left her in great discomfort if left to stand. Upon arriving at her seats (one of which was reserved for her caretaker), she encountered two men who occupied them and refused to move. She took a photograph of the men, and uploaded it to Facebook with her description of what transpired.

8 Johnson, 'Charivari/Shivaree'.

9 Blackstock, 'Hackers Make War', p. 10.

10 Sarah's Law.

11 Sanghani, 'Why This Man Takes Photos'. 
Several aspects of this post are worth noting. First, she identifies herself as a disabled passenger, explaining the additional necessity of the reserved seat, and further explaining why the offence in question is so actionable. She also includes the train time as well as destination, making the incident not only legible but also locatable to an undetermined audience, which may include journalists as well as representatives from the rail company. While avoiding explicitly vitriolic language, she makes extensive use of sarcasm, referring to the targets as 'gentlemen' and 'charming fellows', noting that their 'wives and mothers would be proud.' The latter is especially relevant, as through these words this statement not only appears to invoke a broader social network to bear witness to this offence, but in particular names the female members of the targets' families for additional scrutiny and shaming (potentially of and by these women). Further categories are invoked in this denunciation, as the author notes that the two men were discussing luxury holidays. This, combined with the business attire that both men are wearing in the accompanying photograph, characterized the targets as socially aloof businessmen.

The first news articles reporting this incident were published the following day, mostly in national and regional tabloids. These articles provided coverage of both the offending act as well as the mediated denunciation. Indeed, these initial reports relied heavily on the Facebook post and photograph, often quoting its text in article titles as well as throughout the copy. Previously invoked categories such as 'disabled woman' and 'businessmen' also featured prominently. These journalists take some steps to distance their reporting from the initial denunciation, for example, through the use of quotation marks and terms such as 'it is claimed'. ${ }^{12}$ Yet this press coverage largely serves to reproduce the discourse of the Facebook post. In the following days, subsequent articles provided additional perspectives of the incident on the train. This included one of the targets along with his father, as well as a friend of the disabled woman. Full names were often included, though reports also indicated when people (such as one of the two targets) wished to remain unnamed. These additional perspectives provided some nuance to the original incident, for example, by revealing that seat reservations had allegedly been cancelled on the train, and that the two targets claimed that they did not know the woman in question had a disability. These perspectives also served to extend coverage of the incident by an additional two days. Later articles also featured quotes from spokespeople of the rail network, who provided insight regarding the company's 
reservation policies. Articles appeared in these newspapers the following week that made passing reference to the incident. They included comments from readers either supporting or condemning the initial denunciation, as well as journalists' own editorializing. Here, authors often scaled up their denunciation to target broader societal conditions such as entitlement culture and 'the nature of our violent society'. ${ }^{13}$

This reporting provides a pattern that can be found in other UK-based cases, in which a citizen uploads a denunciatory post on social media, and the press pick up on it over the course of the following days. In doing so the press call further attention to the cases, and the people implicated in them. Their framing of these cases may also shape public perception of the offending incident and response. As the original posts may be deleted or hidden through privacy settings, press coverage allows for a wider and more enduring audience. This audience may provide vitriolic comments when speaking to journalists, commenting online, or sharing links of these articles on their own social media accounts.

\section{'Unqualified as a mother and teacher': Vitriol against a female passenger on a high-speed train in China}

In Chinese history, policing has been conducted by the state through nonphysical coercion in addition to physical violence. This combined method is partly due to the influence of Confucian philosophy that the best way to maintain order is to establish intrinsic morality instead of strict rule, regulations and laws. The self-policing that is required by such a principle was practiced by people in a form of 'village pacts' in the Zhou Dynasty and became prevalent in the Song Dynasty. ${ }^{14}$ The village pact was essentially a form of neighbourhood surveillance and mutual warnings in response to breaches and transgressions that were regarded as harmful for the public welfare. The punishment to such breaches and transgressions were mostly non-physical spectacle of the dishonoured family, such as posters on the door, social isolation, expulsion from the pact and the registration of evil deeds. ${ }^{15}$

In contemporary China, vitriol is used as a tool of self-policing as well. On social media platforms, such punitive policing follows the exposure of illegal behaviours of various severities, from minor violations of traffic 
regulations, physical conflicts between individuals, to child abuse and paedophilia. Citizens also express their disappointment with the current Chinese legal system for not being comprehensive enough to govern the wide range of social activities. These issues are mostly immoral but legal or legally unclear, such as animal abuse, marital disputes and incivilities on public transportation. There are also denunciations reflecting an emerging online nationalism, which support state narratives and discipline those who challenge the state by rendering them visible online and shaming them with vitriolic statements.

Participants typically initiate vigilantism on private-owned social media platforms, such as Sina Weibo, Baidu Tieba, Douban, Tianya, among others. ${ }^{16}$ After its establishment in 2009, Sina Weibo in particular has become the major platform where most influential online incidents take place, including vigilantism. ${ }^{17}$ Government accounts (including local police agencies and state ministries) post their own content and interact with net-citizens (netizens) on a daily basis according to a 2017 statistical report. ${ }^{18}$ State-controlled and commercial media are highly active on Sina Weibo. Individual users, including civilians, celebrities and public opinion leaders also routinely produce, consume, and disseminate information on this platform.

Mass media and state institutions perpetuate the mediated visibility of vitriol. In China, state-owned and commercial media have different roles, characteristics and relations with the state. Commercial media are private companies and enjoy a relatively greater degree of freedom in terms of topic choices and editing. ${ }^{19}$ Some commercial media, such as Pengpai News Agency, Xinjingbao, Caixin, and Phoenix benefit from the reputation of keeping up with trending societal issues. They report on and provide dedicated columns for hotly debated incidents. On the contrary, state-owned media started as part of the state propaganda apparatus from the establishment of People's Republic of China to the Opening and Reform in 1978, and their administrative and staffing issues are still directly controlled by the state even though they enjoy relative freedom in terms of their daily operation.

16 Sina Weibo is a microblogging platform, usually regarded as the 'Chinese Twitter'. Baidu Tieba is a bulletin board system established in 2003 that aims to provide a platform where people with the same interests can find each other by keyword searching. Douban is a website established in 2005 that provides user generated content of films, music, books etc. Tianya is a social networking site established in 1999 that focuses on life and emotions in forms of user generated forums and blogs.

17 Sullivan, 'A Tale of Two Microblogs'.

18 CNNIC, '2016 China Statistical Report'. 
In addition, reports from state-owned media usually feature government announcements and responses. When an incident is regarded as a threat to social stability, however, state-owned media also produce articles of greater length to analyze the issue and provide a state-desired perspective and conclusion. In addition to state-owned media, the government has furthered the involvement of law enforcement in online matters. From 2015, Internet Police in fifty cities started their own Weibo, WeChat, and Baidu BBS accounts, in order to deter and stop cybercrime, harmful speech and behaviours, and to act on netizens' reports about illegal behaviours on the Internet. ${ }^{20}$ The Internet Police is a state police division that is solely responsible for policing various Internet crimes, including online threats, spamming, pornography, terrorism, hacking and fraud. While the Internet Police encourages citizens to provide information in order to fight crimes, the exposure of individuals' personal information acquired illegally is outlawed. The establishment of such systems encourages citizens' online self-policing. For this reason, Chinese citizens engage in vigilantism on even minor transgressions with firm denunciations. Facilitated by a widely networked platform - Sina Weibo - and perpetuated by the broader media landscape, such visibility and vitriol tend to amplify and prolong the impact on individuals. We may consider a recent case about a minor transgression on public transportation.

In January 2018, a woman impeded a train's departure because her husband was denied entry at the boarding gate. A passenger recorded and shared the conflict and the video went viral. The woman was given a penalty of 2 , ooo yuan (roughly $300 \mathrm{USD} / 255$ Euro) and later suspended from her job as a deputy dean in a primary school. She appeared in two interview videos before and after the punishment was announced. In the first interview for a privately-owned short-video streaming website, she insisted that it was just a matter of ten seconds so that her husband could make it to the train and wondered why her behaviour was so poorly regarded. In the second interview on the CCTV (China Central Television) News Channel, she admitted that she was overreacting and caused troubles for both the railway staff and passengers, and wished to apologize, hoping that netizens would forgive her.

In the video that shows the transgression, the person behind camera constantly reminds the woman of the illegality of her behaviour: 'Do you know it is illegal to do so?' The shared video on Weibo provoked netizens' denunciation with vitriol against the woman. There are between 4000 and 7000 comments under each post from five major media Weibo accounts. Four 
types of vitriolic utterances can be observed among the above-mentioned comments. The first type is normative evaluations of her behaviour. She is regarded as a person who 'has no respect of punctuality', 'has a horrible public manner', 'is unreasonable and making a scene', and 'endangers others' safety', which are concerning the qualities that a good citizen should have. In addition to direct negative evaluation of her behaviour, there are comments referring to her identity and social roles, including teacher, mother, and woman. Netizens show disgust by expressing concerns about her students and daughter: 'I can't imagine what kind of people/person her students/ daughter will become'. She is regarded as 'unqualified as a teacher/mother', and having 'tarnished the occupation/the title 'mother". She also received gender-specific vitriol such as 'shrew', and comments that emphasize her gender with terms like 'as a woman...'. These utterances imply that a higher moral standard should be required for teachers, mothers, and women. Insulting and vulgar language are also observed in comments, such as calling the woman 'psycho', 'trash', regarding her as 'despicable', 'disgusting', asking her to 'fuck off', and wishing for her to suffer in the future through 'getting a divorce', 'being beaten up', and 'losing her job forever'. Sarcasm is a common strategy. For example, 'dear teacher, ... you taught us a valuable lesson that anything can be sacrificed for our own good...' is an instance of vitriol disguised in praise. Netizens' responses target law enforcement for being too soft when forcing out the woman and giving her a penalty: 'The law enforcements treat their own rules as shit; no wonder people keep breaking it.'

The woman's apology also attracts vitriol later. Netizens regard her apology as insincere because 'She kept finding excuses for her behaviour' and conclude that 'she's only apologizing because her life was ruined'. They accuse her of lying in order to gain sympathy: 'she has her ID card in her hand on the video (she claimed her husband had her ID card in the apology video). How dare she lie about such obvious thing! Does she think that all the netizens are retarded and have no common sense?'. They decide that they would not forgive her: 'she deserves it!' 'NEVER!' 'We won't need police if apology works'. These responses reveal an intention to socially exclude an individual who has misbehaved. User-led policing through vigilantism and can greatly harm a targets' social standing, perhaps more so than through other policing mechanisms because an opportunity for rehabilitation is not provided. Instead, social exclusion for an undetermined period of time appears to be the desired outcome.

Commercial media play an essential role in perpetuating such long lasting visibility. Most commercial media provide the offender's name or last name, 
her job, and the school that she works for in their coverage. By mentioning the target's occupation, commercial media implicitly echo netizens' assumption of a higher moral standard for teachers. While state-owned media refer the target as 'a female passenger' most commercial media and social media articles refer the target as 'a female teacher'. ${ }^{21}$ Some commercial media divert discussion in order to focus on the occupation. A journalist posted a special column entitled 'How can directors of discipline avoid becoming monsters who stop the high-speed train' on Tencent News, in which he emphasizes that teachers and other authority figures are easily 'alienated by the power they have at schools.'. ${ }^{22}$

The majority of commercial media reports reproduce netizen vitriol in criticizing the offender's lack of citizenship. They point out the potentially severe outcome of the offender's behaviour, stressing that any disruption of train schedules might affect the dispatching of trains in different routes, and conclude that the offender lacks awareness of regulations and laws. There are also commercial media such as Xinjingbao, which have a reputation of reporting from different perspectives, giving the offender an opportunity to explain herself and questioning the punishment and online vitriol. However, netizens denounce the newspaper's editors and reporters for 'trying too hard for attention'. In contrast, state-owned media comment mainly on the general social implications of this incident. Beijing Daily emphasizes the necessity of citizenship training in terms of respecting the rule of law and the contract spirit. Guangming Daily criticizes the commercial media and some netizens for putting occupational labels on the offender, diverting the discussion and fanning the flame. ${ }^{23}$

\section{Smile douchebag-you are on camera: Collectively mediated vitriol in Russia}

It can be argued that current digitally mediated cases of collective denunciation and vitriol in Russia are largely influenced by the country's Soviet past, where the public's involvement in exercising justice over fellow comrades was a prevalent and encouraged practice. ${ }^{24}$ In cases of minor mischief, the delinquent was confronted through a system of comrades' courts where 
judge and jury were comprised of colleagues and neighbours. The severity of the shameful impact of such collective justice could be amplified through display of the target's portrait on special boards of shame and through exposure in the local paper. ${ }^{25}$ Nowadays, mediated vigilantism in Russia still principally takes place as an encouraged, organized and systematic practice with an issue-specific retaliatory focus.

This section of the chapter seeks to provide a general overview of cases and trends related to mediated vitriol in contemporary Russia. From a seemingly universal practice of exposing alleged paedophiles to rather unique engagements with drivers and merchants, active citizens in Russia have been finding offence in fellow citizens, retaliating, and exposing them across global and domestic social media platforms. Soviet boards of shame have been replaced with YouTube, Facebook, and VKontakte; ${ }^{26}$ while traditional media outlets continue to widely report on 'loud' cases, rendering additional layers of visibility and exposure.

In Russia, organized acts of retaliation by citizens against fellow citizens share a common scenario where targets are confronted over offences while the process is filmed and the footage is spread widely. Vigilantes across the country have formed movements focused on specific offences. Some of these formations turn into recognizable brands. Among such brandlike vigilante groups are StopXam [Stop a Douchebag] and Hrushi Protiv [Piglets Against],${ }^{27}$ specializing in combating traffic violations and exposing 'unscrupulous' merchants respectively. Founded in 2010 by members of Russia's state-organized youth movement Nashi [Ours $],{ }^{28}$ both formations were endorsed ${ }^{29}$ and funded by the government. ${ }^{30}$ Given this unique scenario where the state encourages an etymologically citizen-organized practice of vigilantism, it is important to consider, among other factors, the motives behind both organization and participation.

In widely available videos that have been viewed by millions, StopXam members approach the drivers and ask them to re-park their cars. If the driver does not comply, a sticker that reads 'I Spit on Everyone I Drive Where I Want ${ }^{\prime 31}$ is placed on the windshield of the vehicle, usually sparking hostility accounts of the groups.

28 Kurochkin and Nikoforov, 'Civic Initiatives'.

29

Kurochkin and Nikoforov, 'Civic Initiatives'.

Original translation orthography used by StopHam is preserved. 
as well as verbal and physical confrontations between participants and targets. The shameful signs are difficult to remove and are intended to serve a 'disciplinary purpose, as the driver should think about their behaviour while scratching off the sticker'. ${ }^{32}$ Some drivers receive several stickers during a single confrontation, which will impede their ability to drive off due to their restricted visibility.

Dressed in full-body piglet costumes, Hrushi Protiv target allegedly unscrupulous merchants and expose them online. Participants raid markets and grocery stores with the aim of disclosing expired products. Seeing a dozen 'piglets' browsing the aisles, the personnel confronts the selfproclaimed auditors, sparking verbal and physical assaults between both parties. All raids are filmed, and edited footage is spread across social media. Content analysis of video material produced by Hrushi Protiv reveals a bias against merchants of non-Russian descent. The group frames people from the Caucasus ${ }^{33}$ and labour migrants from the former-Soviet Central Asian republics as responsible for expired produce on the shelves of Russia's stores. In 2014, Hrushi Protiv called on its audience to sign petitions to 'condemn migrants from working in retail'. 34 Though it received marginal online support, this call for action is suggestive of a political stance of the group. Along with proportionality of retaliation, questions concerning political instrumentalization of digital vigilantes inevitably arise.

Virtually every video produced by StopXam and Hrushi Protiv contains cases of violent verbal or physical confrontations and shaming of the drivers and the merchants. These confrontations and mediated public shaming serve as both entertainment and disciplinary show for the passer-by, for the online audience, and for traditional media consumers when featured on TV and in newspapers. Both groups publish several videos per month and possess editorial powers, which grant them the ability to frame the target and the process of retaliation. ${ }^{35}$ Unless they are famous people with a large social media following, targets have limited options to generate a counter-narrative. If a digital vigilante group has an audience of millions, their target with a few hundred friends on social networks cannot compete with such social outreach. ${ }^{36}$

33 Some Republics in the Caucasus are part of the Russian Federation. Nevertheless, due to ethnic biases, Russian citizens from the Caucasus are sometimes perceived as alien migrants not only by Russian nationalists, but also by immigration and law enforcement officers.

34 Russia's Public Initiative, 'Call for a legislative ban'.

35 Gabdulhakov, 'Citizen-led Justice', p. 327.

36 Gabdulhakov, 'In the Bullseye of Vigilantes', p. 233. 
Videos produced by vigilantes are actively commented on by the viewers. While some viewers question the acts of participants, the majority express solidarity and condemn targets in a biased fashion. Videos where drivers and merchants are framed as non-Russians are commented on in the following manner: 'this is a zoo, not a store', or 'as always, the mountain folk is acting like animals', 'they are used to riding donkeys in their villages, and here they have to abide the rules'. Comments also bring up speculations about the targets' legal status in Russia: 'they are afraid of cameras because they do not have a registration', 'why is every other Central Asian so afraid of cameras? Are they illegals? I suggest our immigration forces look closely at this group'.

While traditional media could theoretically serve as a platform for targets to deliver their side of the story, media analysis reveals that Russia's mainstream broadcasters rely on participants' footage as evidence, which is an explicitly subjective representation of events. Traditional media coverage leads to greater exposure of targets and profile raising of vigilantes, making the latter appear as an omnipresent eye of the public. Words such as 'activists', 'youth', 'public movement', and 'volunteers' have been used by Russia's mainstream media outlets to define StopXam and Hrushi Protiv. In reference to the targets, media reports tend to use phrases such as 'aggressive' and 'inadequate'. A number of media reports make direct references to the targets' ethnic and national backgrounds through use of othering wording such as 'the Chechens', or 'people from the Caucasus', or 'the Tajiks', thus copying vigilantes' biases and prioritizing ethnic origins and nationality as identity markers for the 'bellicose' targets.

What is distinguishable in digital vigilantism is the severity and longevity of retaliation. For instance, for grocery stores, an inspection by state consumer protection services could lead to investigations and any shortcomings would end in fines for the concerned retailor, without the public necessarily getting involved in mob justice, chanting and pointing out the ethnic origin of the manager or other employees. In current practices of mediated vitriol and exposure, the concerned retailer's reputation can be severely damaged without any legal investigation, but by means of edited video reports produced by self-proclaimed auditors. These circumstances grant peculiar powers to participants, as, theoretically, they can be hired by competitor stores as 'reputation assassins'. Some large retailers in Russia even went as far as signing special collaboration agreements with Hrushi Protiv, ${ }^{37}$ which grants further legitimacy to otherwise unsanctioned raids. 
Social media platforms play a unique role as providers of a stage for vigilante practices. This role is not a passive one, as terms of use as well as state legislation in which platforms operate govern harmful and inappropriate content. Platforms can rate certain videos as $18+$, remove them, filter commentary, and otherwise censor users. Arrests over 'likes' and 'shares' on social media have sprawled across Russia in recent years. ${ }^{38}$ However, sometimes no action is taken against users. ${ }^{39}$ YouTube, in this regard, is successfully instrumentalized by both StopXam and Hrushi Protiv, with millions of viewers and income generated through advertisements. Videos with obscene content freely circulate the web, which reflects the default involvement of platforms in disseminating vitriolic confrontations and exposure of targets. Global circulation of videos grants recognition to participants far beyond their local communities. Both StopXam and Hrushi Protiv have branches in other former Soviet republics and in the case of the former, even on other continents. ${ }^{40}$

The combination of social justice practices and political agendas reproduces a convoluted dynamic between the state, participants, targets, media platforms (both traditional and social), as well as the audience. ${ }^{41}$ In such a setting, the boundaries of power division are blurred, proportionality and legality of retaliation become questionable, and citizen-on-citizen retaliation takes on a totalitarian and pervasive mode.

\section{Discussion}

While these three examples of mediated vigilantism concern different political and cultural contexts, some common features stand out. Each case is a response to incivilities that take place in (quasi-)public spaces such as grocery stores, shared roadways and train carriages. We can imagine these to be contested terrains due to external factors such as the edacity of markets, a scarcity of seating/parking, or a surfeit of passengers or vehicles. In addition to witnessing laws and regulations being violated, we may

38 Bevza, 'To Fabricate a Case'.

39 Although StopXam was officially liquidated in 2018, Ministry of Justice of Russia made the decision over the group's violation of accounting procedures, and not over video content or vigilante practices.

40 StopXam prototype Mal Estacionado [Bad Parking] was opened in Lima, Peru, upon approval of the original group in Moscow.

41 Manifested through a hierarchy of power, from the highest ranks of policymakers to police officers on the ground and other state entities whose functions are performed by digital vigilantes. 
also speculate whether a sense of entitlement to these spaces may further compel citizens to denounce those who are deemed to breach a moral order. Furthermore, we can speculate whether such a sense of moral order may also be sought in quasi-public digital spaces when vigilantes retaliate against online incivilities.

These cases also raise the question of who is entitled to speak out against their peers. In order to succeed in openly denouncing someone, digital media users depend not only on an audience for support, but also on the press to provide further coverage of the incident. In all three cases we see that mediated vitriol is above all else a collaborative effort. In turn, newspapers source quotes from online posts, reach out to friends and family of those who are implicated, and invite readers to comment and share reports as well. This is partly out of necessity, in order for journalists to produce a news-story out of what often begins as a social media post. Yet it also demonstrates one manner in which media assemblages work: through temporary partnerships and collaborations with a range of actors. As such, even toxic and anti-social discourse may become a core component of routine news cycles.

A further commonality to these cases is that even when a single individual is being targeted, the denunciation itself also mobilizes social categories. Offensive conduct in trains and on streets is rhetorically coupled to broader representatives of a particular ethnic group or nationality, groups like the wealthy, as well as professions such as teachers, with all the social expectations that are bundled with such a position. Shaming and vitriol are typically gendered as well, with denunciations serving as an opportunity for citizens to air grievances against 'shrews' and those deemed to be unfit mothers.

All three cases demonstrate how vitriol and mediated visibility are related: afforded by digital platforms, denunciation accompanied by vitriolic discourse makes individuals visible online, which provokes further translocal denunciations against them. Such vitriol and visibility are most likely to be amplified by traditional media, which adds to the layered harm inflicted on individuals. Therefore, the contemporary study of vitriol in media needs to consider how targets are rendered visible. Mediated visibility may serve as a kind of force multiplier for leveraging harm against a target or a community. In particular, these mechanisms further serve to persecute and marginalize women and members of disadvantaged communities. Religious, ethnic, gender, and other prejudices come to surface in cases of citizens' collective response to perceived infraction committed by target. In a recent incident in Russia surrounding a public discussion of sexual assault the common narrative in response to the female victim of sexual violence is 'you should 
not have seduced the man' and 'what were you doing at a party anyhow'. ${ }^{2}$ This narrative is backed with legislation decriminalizing some domestic violence and softening punishment for first offence in sexual assault. ${ }^{43}$ In many cases, targets of digital vigilantism are limited in their options of seeking justice. Going public with the case can lead to an ever-greater exposure, shaming, and societal condemnation. Gender, sexual, national, ethnic, religious and other flaws and biases set ground for layers of vulnerabilities among some members of the society. ${ }^{44}$ In the aftermath of terrorist attacks in Russia's major cities, the promptly identified suspects tend to be 'Muslim-looking' males from the Caucasus. In one such instance the wrongly accused target reported themselves to police, in order to prove their own innocence and restore a damaged reputation. While police confirmed the person's innocence, the mediated exposure turned out to be difficult to revert. When attempting to travel back to his hometown, the target was forced off the plane by other passengers and faced perpetuated instances of questioning by police and short-term arrests. 45

It is therefore important to take a scholarly and societal approach towards mediated harassment that recognizes that while potentially anybody can be targeted by collective scorn and denunciation, these mediated practices typically reproduce and even aggravate existing disparities. In terms of directions for subsequent research, scholars should further consider links between media studies and criminological accounts of vitriol in denunciatory contexts. In particular, they should consider vitriolic denunciation as a chain of mediated events, rendered meaningful through networks of decentralized actors. The above cases suggest that press coverage of denunciations may significantly contribute to the exposure and harassment of a targeted individual, and this is a topic scholars should continue to examine. Yet we should also be mindful of our own potential contribution to mediated exposure and shaming through our analysis of prominent as well as relatively obscure cases. We can take steps to attempt to protect the identities of those involved, yet our reliance on press coverage may still render them identifiable. And while the readership of an academic text may pale in comparison to a viral social media post or tabloid article, it may remain archived and potentially accessible to a wider audience. 
When searching for remedies to online vitriol, one cannot simply mute the so-called 'court of public opinion'. ${ }^{46}$ From a practical standpoint, mediasavvy audiences can take advantage of multiple platforms, and spill out into the comments sections of any online newspaper, or the reply function of any social platform. The fact that such visible opinions (in the forms of comments and replies) can either be fuelled by strategically constructed (fake) news, or itself the product of a Twitter bot, remains a pressing concern. As well, self-erasure or self-censorship is neither sufficient to prevent receiving online vitriol, nor is it a desirable state of existence for potential targets. As the examples above demonstrate, other individuals and institutions make use of one's social visibility. Remedies for specific instances of vitriolic harassment, as well as more general strategies for prevention, need to prioritize the autonomy of the person being targeted.

\section{Works cited}

Albrechtslund, Anders. 'Online Social Networking as Participatory Surveillance'. First Monday, vol. 13, no. 3, 2008, https://firstmonday.org/article/view/2142/1949.

BBC. 'Russian MPs Pass Bill to Soften Domestic Violence Law'. BBC.com, 27 January 2017, https://www.bbc.com/news/world-38767873. Accessed 26 October 2018.

Beijing Daily. 'Lan Gaotie Shijian Shitang Guize Yishi Gongkaike'. Beijing Daily, 12 January 2018, https://www.weibo.com/ttarticle/p/show?id=2309404195357461480177. Accessed 20 March 2018.

Bevza, Dmitry. 'Narisova's Delo: Kak v Rossii Sazhayut za Reposti'. [To Fabriate a Case: How Russia Arrests for Shares]. Gazeta.ru, 19 August 2018, https://www.gazeta. ru/tech/2018/08/18/11899507/two_years.shtml?updated. Accessed 15 July 2019.

Blackstock, Colin. 'Hackers Make War on Net Paedophiles'. The Independent, 6 September 1998.

Chandler, Mark. 'Disabled Woman Posts Facebook Photo of Businessmen 'Refusing to Give up Her Reserved Seats' on London Train'. London Evening Standard, 21 September 2016.

Chinese Ministry of Public Security. 'Jianli Wangjing Changtaihua Gongkai Xuncha Zhifa Jizhi', 2015, www.mps.gov.cn/n2255079/n4876594/n497459o/n4974592/ n5116794/index.html. Accessed on 20 March 2018.

CNNIC. '2016 China Statistical Report on Internet Development'. http://www. cnnic.net.cn/hlwfzyj/hlwxzbg/hlwtjbg/201708/Po20170807351923262153.pdf. Accessed 20 March 2018. 
Dobash, Russel P., and R. Emerson Dobash. 'Community Response to Violence Against Wives: Charivari, Abstract Justice and Patriarchy'. Social Problems, vol. 28 , no. 5 , 1981. pp. 563-581.

Dowle, Jayne. 'Why We Must Not Stand for Selfish People Who Disregard the Disabled'. Yorkshire Post, 26 September 2014.

Dutton, Michael R. Policing and Punishment in China: From Patriarchy to 'the People'. Cambridge (UK): Cambridge University Press, 1992.

Gabdulhakov, Rashid. 'Citizen-led Justice in Post-Communist Russia: From Comrades' Courts to Dotcomrade Vigilantism'. Surveillance \& Society, 16, no. 3, 2018, pp. 314-331, doi:10.24908/ss.v16i3.6952.

-. 'In the Bullseye of Vigilantes: Mediated Vulnerabilities of Kyrgyz Labour Migrants in Russia'. Media and Communication, 7, no. 2, 2019, pp. 230-241, doi:10.17645/mac.v7i2.1927.

Gabowitsch, Mischa. 'Are Copycats Subversive? Strategy-31, the Russian Runs, the Immortal Regiment, and the Transformative Potential of Non-Hierarchical Movements'. Problems of Post-Communism, vol. 65, no. 5, 2016, pp. 1-18.

Guangming Web Critic. 'Weiguan Gongong Shijian, Shaoyidian Biaoqian'. Guangming Daily, 14January 2018, http://guancha.gmw.cn/2018-01/14/content_27345819. htm. Accessed 20 March 2018.

Johnson, Loretta. 'Charivari/Shivaree: A European Folk Ritual on the American Plains'. The Journal of Interdisciplinary History, vol. 20, no. 3, 1990, pp. 371-387.

Kremlin. 'Rasshirennoe Zasedanie Kolleggii MVD Rossii'. [Extended Meeting of the Board of the Ministry of Internal Affairs of Russia], 2017, http://kremlin.ru/ events/president/news/54014. Accessed 13 August 2018.

Kupfer, Mathew. 'How Russia Turned on a Teenage Rape Victim'. The Moscow Times, 8 March 2017, https://www.themoscowtimes.com/2017/03/o8/how-russia-turnedon-a-teenage-rape-victim-a57368. Accessed 13 August 2018.

Kurochkin, Alexander, and Alexander Nikoforov. 'Civic Initiatives under Conditions of Network Society: New Challenges and Possibilities'. Modern Research of Social Problems, vol. 145, 2015.

Li, Duoyu. 'How Can Directors of Discipline Avoid Becoming Monsters Who Stop the High Speed Train'. Tencent Sage, 12 January 2018, http://dajia.qq.com/original/ category/ldy20180112.html. Accessed 20 March 2018.

Nhan, Johnny, et al. 'Digilantism: An Analysis of Crowdsourcing and the Boston Marathon Bombings'. The British Journal of Criminology, vol. 57, no. 2, 2017, pp. 341-361.

Poulter, James. 'The Far Right Are Uniting Around Their Right to 'Free Speech". Vice.com, 20 March 2018, https://www.vice.com/en_ca/article/j5axgd/the-farright-are-uniting-around-their-right-to-free-speech. Accessed 13 August 2018. 
Roose, Kevin. 'The Alt-Right Created a Parallel Internet. It's an Unholy Mess'. New York Times, 11 December 2017, https://www.nytimes.com/2017/12/11/technology/ alt-right-internet.html. Accessed 13 August 2018.

Russia's Public Initiative. “Zakonodatel'no Zapretit' Rabotu Migrantov v Sfere Torgovli'. [Call for a Legislative Ban on Migrant Employment in Retail], 2014, https://www.roi.ru/8873/. Accessed 13 August 2018.

Russia Today. “Leave Me Alone!': Misidentified St. Petersburg Bombing Suspect Says Life Has Turned into Nightmare'. RT.com, 5 April 2017, https://www.rt.com/ news/383619-petersburg-suspect-muslim-police/. Accessed 13 August 2018.

Sanghani, Radhinka. 'Why This Man Takes Photos of 'Women Who Eat On Tubes'. He Promises He Isn't a 'Weird Deviant”. Telegraph.co.uk, 7 April 2014, https:// www.telegraph.co.uk/women/womens-life/10749681/Why-this-man-takesphotos-of-Women-Who-Eat-On-Tubes.-He-promises-he-isnt-a-weird-deviant. html. Accessed 13 August 2018.

Sarah's Law. https://www.sarsas.org.uk/sarahs-law/. Accessed 13 August 2018.

Schneider, Christopher J., and Daniel Trottier. 'Social Media and the 2011 Vancouver Riot', in Denzin, Norman K. (ed). 4oth Anniversary of Studies in Symbolic Interaction, Studies in Symbolic Interaction. Bingley (UK): Emerald, 2013, vol. 40, 2013, pp. 335-362.

Stephenson, Matthew C. 'Court of Public Opinion: Government Accountability and Judicial Independence'. The Journal of Law, Economics, \& Organization, vol. 20, no. 2, 2008, pp. 379-399.

Sullivan, Jonathan. 'A Tale of Two Microblogs in China'. Media, Culture \& Society, vol. 34, no. 6, 2012, pp. 773-783.

Thompson, Nicholas. 'How Facebook Checks Facts and Polices Hate Speech'. Wired. com, 6 July 2018, https://www.wired.com/story/how-facebook-checks-facts-andpolices-hate-speech/. Accessed 13 August 2018.

Trottier, Daniel. 'Digital Vigilantism as Weaponisation of Visibility'. Philosophy \& Technology, vol. 30, no. 1, 2017, pp. 55-72.

Vigilantes. 'Hrushi Protiv', http://vigilant.myverdict.org/files/pigs. Accessed 13July 2019. Winfield, Betty Houchin, and Zengjun Peng. 'Market or Party Controls? Chinese Media in Transition'. International Communication Gazette, vol. 67, no. 3, 2005, pp. $255^{-270 .}$

\section{About the authors}

Daniel Trottier is an Associate Professor of Global Digital Media in the Department of Media and Communication at Erasmus University Rotterdam, the Netherlands. His current research considers the use of digital media for 
the purposes of scrutiny, denunciation and shaming. Daniel is the PI of a five-year NWO-funded project on this topic, entitled "Digital Vigilantism: Mapping the terrain and assessing societal impacts". He has authored several articles in peer-reviewed journals on this and other topics, as well as Social Media as Surveillance (Ashgate, 2012), Identity Problems in the Facebook Era (Routledge, 2013), and Social Media, Politics and the State (co-edited with Christian Fuchs; Routledge, 2014). Daniel completed a PhD in Sociology at Queen's University in Kingston, Canada.

QIAN HuANG is a Ph.D. Candidate at the Department of Media and Communication of Erasmus University Rotterdam The Netherlands. Her current research considers digital vigilantism on the Chinese Internet. Qian completed her master's study at the Chinese University of Hong Kong.

Rashid Gabdulhakov is a Ph.D. Candidate at the Department of Media and Communication, at Erasmus University Rotterdam, the Netherlands. As a member of an international team of scholars, he is researching the phenomenon of digital vigilantism and its manifestation in Russia and other former Soviet republics. Rashid has authored several articles in peerreviewed journals on this topic. 


\title{
2 'Don't Feed the Trolls'
}

\author{
Social Media and the Limits of Free Speech
}

\author{
Tom Clucas
}

\begin{abstract}
This chapter examines 'comment culture' using examples from social media platforms and the tabloid press. It explores the shift from a model of free speech as a collective responsibility to one that presents it as an absolute individual right. The chapter examines the consequences of this shift by analyzing a series of vitriolic exchanges on its chosen platforms. Three main trends emerge: furst, social media have developed a unique comment culture focussed on combat, disinhibition and the contest for popularity. Second, online platforms are governed by their own distinctive 'thread logic', which disdains rational argument in favour of passionate display. Third, the conventional rules of conversation and argumentation have been disapplied, with consequences for communities both on- and offline.
\end{abstract}

Keywords: online vitriol, social media, free speech, comment culture, public sphere

This chapter examines 'comment culture' using examples drawn from the comment sections on YouTube, Twitter, and Facebook, as well as in the British tabloid press. These comment sections aim to make the websites more interactive by enabling individuals to post comments on other users' content (e.g. YouTube videos, tweets, Facebook posts, or news articles). The comments are generally gathered beneath the original post in a thread that often also allows users to respond to one another's comments. The chapter argues that these comment sections develop their own particular cultures - sets of generally established rules and practices about the content, tone, and format of comments - which are tacitly agreed between the community of users on the platform. However, there is also a tendency for certain

Polak, Sara, and Daniel Trottier (eds), Violence and Trolling on Social Media. Amsterdam, Amsterdam University Press 2020 DOI: 10.5117/9789462989481_CHO2 
individuals to flout these conventions by posting deliberately provocative, aggressive, or hate-filled material. As a result, the comment sections are often particularly rife with examples of online vitriol, as individuals take advantage of anonymous posting options and/or disguised user names to post vitriolic comments that would not be tolerated in face-to-face conversation.

The chapter begins by briefly surveying modern debates about free speech, from John Milton's Areopagitica to Timothy Garton Ash's Free Speech. In the process, it posits a recent shift from a model of free speech as a collective responsibility to one that presents it as an absolute individual right. This strong model of free speech, coupled with users' ability to post anonymously online, helps to shape the cultures that evolve in the comment sections of various online platforms. Although each platform has its own unique community of users and set of rules governing the comments section, three broad trends can be seen to emerge. First, social media have developed a unique 'comment culture', in which largely self-regulating communities of users reach a consensus about what forms of expression are or are not available. Recent research by Jude P. Mikal and others suggests that:

As individuals learn the generally accepted rules of conduct associated with the site, their online interactions will shift to reflect their social rather than individual - identities. The result will be a common voice emanating from the website: a generally cohesive tone, characterized by overall consistent responses, and overt behaviour correction. ${ }^{1}$

Partly, this comment culture is established by the host of the site, through moderation and rules governing the site's usage. However, the culture is also the product of communities of users responding to one another's posts with praise or blame. Often, it is the site's users who decide whether or not to report a particular comment to the moderators. As a result, the community of users has a large say over the extent to which hate speech and online vitriol are tolerated.

The second trend is that online platforms are governed by their own distinctive 'thread logic', in which traditional models of debate are supplemented by appeals to humour and the popular phenomenon of 'trolling'. In his study of this phenomenon, Whitney Phillips observes that:

Engaging in racism or sexism or homophobia, disrupting a forum with stupid questions, or generally being annoying does not automatically make 
one a subcultural troll. Trolling in the subcultural sense is something a self-identifying troll sets out to do, as an expression of his or her online identity. $^{2}$

Real trolling aims to disrupt accepted practices of online debate and conversation for the sake of 'lulz', which Phillips defines as 'a particular kind of unsympathetic, ambiguous laughter'.3 As discussed below, the phenomenon of trolling is problematic because internet users often conflate it with hate speech. When forms of online vitriol (including those that relate to racism, sexism, or homophobia) are mislabelled as 'trolling', there is a tendency for users to downplay or ignore them.

The third trend is that the conventional rules of conversation and human interaction are often modified online, with some users being more willing to resort to insult and abuse when they have the ability to appear anonymously. This is reinforced by the fact that online users are often hesitant to 'feed the trolls' by calling out examples of hate speech or online vitriol: such displays of aggression are often mislabelled as trolling and allowed to remain on the site without being censured or removed. The chapter concludes by considering the implications that these recent developments might have for offline modes of communication.

The effects of online vitriol were powerfully demonstrated during the 2017 General Election campaign in the UK. During this campaign, the Shadow Home Secretary Diane Abbott Member of Parliament (MP) was subjected to extensive scrutiny by the mass media and the electorate. Abbott became the first black woman elected as a UK MP when she won her seat in 1987. However, in an article published in The Guardian on 14 February 2017, she revealed that her role had become harder in recent years due to the daily racist and sexist abuse she receives online. Abbott wrote that 'I have received rape threats, death threats, and am referred to routinely as a ***** and/or ${ }^{* * * * * *}$, and am sent horrible images on Twitter.' The death threats include an English Defence League-affiliated account with the tag 'burn Diane Abbott'. ${ }^{4}$ It is likely that some of these comments constitute hate speech and can be reported under the UK hate speech laws in Part 3 of the Public Order Act 1986. However, the sheer scale of hate speech on the internet makes it impractical to place the burden solely on victims to report each incident. On a cultural level, it is important to understand the 
possible causes of this epidemic of online vitriol. This chapter proposes two interrelated factors: first, a strong model of free speech as an absolute, individual right and second, a rapid rebalancing of the equilibrium between the private and public spheres encapsulated by YouTube's catchphrase: 'Broadcast Yourself'.

\section{The right to hate}

Recently, there has been a shift from a model of free speech as a collective responsibility to one that presents it as an absolute individual right. This marks a significant departure from the model of free speech that prevailed from the early modern period into the twentieth century. In an often-quoted formulation from his prose polemic Areopagitica; A Speech [...] for the Liberty of Unlicenc'd Printing (1644), the poet John Milton exclaimed: 'Give me the liberty to know, to utter, and to argue freely according to conscience, above all liberties. ${ }^{.5}$ What is remarkable in this quotation is its emphasis on 'conscience'. Milton stresses that the right to speak freely comes with the attendant burden of accountability for what is said. Similarly, John Locke argued in 'A Letter Concerning Toleration' (1690) that:

[N]o private person has the right to attack or diminish another person's civil goods in any way because he professes a religion or ritual differing from his own; all of that person's human rights as well as his civil rights are to be scrupulously observed. ${ }^{6}$

Locke wrote his 'Letter' centuries before the European Convention on $\mathrm{Hu}$ man Rights came into force in 1953 and before the US enacted the Civil Rights Act in 1964. His conceptions of 'human rights' and 'civil rights' inevitably differ from those in the present, yet they remain expansive in encompassing life, liberty, physical integrity, and freedom from pain, as well as external possessions, such as land, money, the necessities of everyday life, and so on'? 7 What unites these two early texts is their interpretation of free speech as a collective responsibility as well as an individual right. In order for free speech to function, Milton and Locke contend that it must be moderated by individuals respecting one another's mutual rights. 
In principle, this model of free speech as a collective responsibility remains inscribed in European law. Article 10 of the European Convention on Human Rights, which governs 'freedom of expression', provides that 'Everyone has the right to freedom of expression', but that the

exercise of these freedoms, since it carries with it duties and responsibilities, may be subject to such formalities, conditions, restrictions or penalties as are prescribed by law and are necessary in a democratic society. ${ }^{8}$

With the advent of the internet and the growth of the tabloid press, however, the popular conception of free speech appears to have departed from this model. Tracing the western history of free speech since the French Revolution, Elizabeth Powers argues that the debates foreshadowed in the eighteenth century have intensified since the fall of the Berlin Wall in $1989 .{ }^{9}$ One reason for this, she argues, is that the 'western liberal order would seem to have become a victim of its own success, so long without competition that it has forgotten the source of the freedoms it enjoys.' ${ }^{10}$ As a result, arguments for free speech in western societies have tended to be expressed in stronger terms in recent years, giving rise to the strong model of free speech on which this chapter focuses.

In his 2016 book Free Speech: Ten Principles for a Connected World, the journalist and academic Timothy Garton Ash argues that 'free speech has never meant unlimited speech - everyone spouting whatever comes into his or her head, global logorrhea'. ${ }^{11}$ Despite this, the ten principles that Ash proceeds to outline adopt a relatively laissez-faire approach to free speech. The second principle states that 'we neither make threats of violence nor accept violent intimidation', but under the fifth heading Ash argues that 'mature democracies should move beyond hate speech laws'. Rather than simply abandoning laws, Ash implies the need to replace them with more robust social mechanisms for dealing with hate speech. However, the examples of online comment sections show that communities of users are often peculiarly hesitant or reticent to deal with hate speech, due to the belief that calling it out will only escalate the conflict and exacerbate the problem. As a result, it is unclear how the

10 Ibid.

11 Ash, Free Speech, p. 4. 
racist, sexist, and body-shaming abuse described by Diane Abbott could be regulated in Ash's system, particularly where it does not constitute a direct 'threat of violence'. Its vitriolic force appears to nestle safely in the realms of opinion. In a study of racist hate speech, Caroline West notes that "[s]ome liberals have argued that the regulation of hate speech should be resisted as a matter of principle because our commitment to free speech must be absolute'. ${ }^{12}$ Yet, as West observes, this model of unregulated free speech is not sustainable, because the 'visceral hostility' of racist hate speech 'forecloses' the possibility of further discussion: 'In the immediate aftermath of a verbal attack, it is rare that victims are able to produce words at all, let alone to gather themselves together to offer a clear-headed and balanced response. ${ }^{13}$ As a result, the strong model of free speech struggles to deal with the problem that one person's unlimited free speech can effectively silence another's.

Despite this, some netizens have defended their 'right to free speech' in absolutist terms. When Katie Hopkins was fired by the LBC radio station for tweeting that 'We need a final solution' after the Manchester terror attack on 22 May 2017, the libertarian commentator Brendan O'Neill defended her in a piece entitled 'The Mob Claims Another Scalp'. Despite suggesting that Hopkins's tweet knowingly echoed one of the most harrowing slogans of the Holocaust, O'Neill argues that:

[I]t's one thing to be offended by something (you can be offended by whatever you like) - it's quite another to mobilise your feelings of offence to the end of getting someone sacked, and by extension warning everyone else in public life that if they say anything like this, if they venture too far from the realm of Acceptable Thought, then they too will face fury, punishment, and potentially the loss of their livelihood. ${ }^{14}$

This argument implies that those who are 'offended' by what O'Neill himself suggests was a call for genocide are exercising the privilege of oversensitivity, while Hopkins's freedom to issue this call stands as an indefatigable right. One might argue that this comment embodies an extreme position in the free speech debate. However, the absolutist approach to free speech has rapidly entered the mainstream. 


\section{'Broadcast yourself': The expanding public sphere}

In addition to the strong model of free speech outlined above, online platforms have been influential in dissolving the traditional boundary between the public and private spheres. With the rise of social media, the distinction between what one would say and do in private and in public has become more porous. The benefits of this development are expressed in the mission statements of various prominent social media platforms, for example YouTube ('Our mission is to give everyone a voice and show them the world'), ${ }^{15}$ Twitter ('Our mission: Give everyone the power to create and share ideas and information instantly, without barriers'), ${ }^{16}$ and Facebook ('Facebook's mission is to give people the power to build community and bring the world closer together') ${ }^{17}$ Social media platforms like these have proved important in democratizing the access to information and the right to self-expression around the world. However, the expansion of the public sphere into the realms of formerly private opinion has also given rise to an increased potential for the clash of beliefs and the uncensored expression of prejudices online. This section examines how the expanded capacity for instantaneous communication inevitably increases the potential for conflict, as well as how prominent online platforms have attempted to the regulate the resulting phenomenon of online vitriol.

In arguing for the transformative power of social expression, social media platforms rely on a model of free speech as a civilizing force which emerged during the Enlightenment. Since the eighteenth century, it has often been suggested that speech should be allowed to function as a free market. In this vein, the eighteenth-century philosopher the Earl of Shaftesbury argued that:
All politeness is owing to liberty. We polish one another and rub off our corners and rough sides by a sort of amicable collision. To restrain this is inevitably to bring a rust upon men's understandings. It is a destroying of civility, good breeding and even charity itself, under the pretence of maintaining it. ${ }^{18}$

Shaftesbury's metaphor of 'amicable collision' implies that social values can only be developed by individuals participating in the conversation of 
culture. In other words, there is a need for individuals to air and discuss their private opinions in public, so that the members of a community can arrive at a consensus through mutual critique and discussion. This model of amicable collision continues to be upheld in a modified form by social media platforms, for example Twitter, which reminds its users that 'as a policy, we do not mediate content or intervene in disputes between users. ${ }^{19}$ Along similar lines to Shaftesbury, the current Twitter policy treats conflict as a potentially productive process in which users regulate one another's posts and arrive at a consensus about what can or cannot be expressed.

However, the hugely increased capability which these platforms offer their users - the opportunity to 'create and share ideas and information instantly, without barriers' ${ }^{20}$ - has also led to an increased capacity for conflict. Hate speech like that aimed at Diane Abbott, including rape threats, death threats, and the Twitter hashtag 'burn Diane Abbott', ${ }^{21}$ shows that the deregulation of speech on the internet does not necessarily lead to 'politeness' and 'amicable collision'. In this respect, it is important to consider the fundamental shift that has occurred with the rise of the internet in the equilibrium between the private and public spheres. In his seminal text The Structural Transformation of the Public Sphere, Jürgen Habermas argued that the 'model of the bourgeois public sphere presupposed strict separation of the public from the private realm'. ${ }^{22}$ Though Habermas recognized that the boundary between these spheres was porous, the rise of social media has almost erased this boundary by encouraging individuals to share their private thoughts and emotions in the public sphere with virtually no mediation. Users of these platforms are invited to project every aspect of their mental experience into the public debate. This approach is illustrated by YouTube's slogan - 'Broadcast Yourself' - which imagines the possibility of superimposing every individual's stream of consciousness in the public sphere. One consequence of this is that public abuse is more likely to occur in this context than in Shaftesbury's model of 'civility', which was developed in a culture where social groups were much smaller and even access to print media was limited.

Like any major cultural change, the rebalancing of the private and public spheres carries both advantages and disadvantages, which will take years if not decades to understand. Writing just before the rise of Twitter, Facebook,

Habermas, The Structural Transformation, pp. 175-176. 
and YouTube, Luke Goode contended that the internet could contribute to greater reflexivity in the public sphere:

[I]n the Habermasian model, the public sphere and its reflexive context must be mutually reinforcing: the public sphere takes on the role of a kind of exemplary space for the considered, deliberative and, as far as possible, egalitarian weighing of competing claims, an ethic that can at least rub off on - though by no means colonise - the more unruly and visceral micro-practices and discourses of everyday life. ${ }^{23}$

To some extent, this prediction has come true, with social media platforms allowing their users to criticize celebrities and those in the public eye for displaying prejudice. This occurred, for example, when the musician Ten Walls posted homophobic comments on his Facebook page in 2015 and was rapidly criticized by fans and dropped by sponsors. ${ }^{24}$ Subsequently, a number of other artists, including UK grime artist Stormzy, have apologized for homophobic posts and tweets made in the past. ${ }^{25}$ While this may hold true for public figures, the proliferation of online content has also made it possible for private individuals, such as the owner of the English Defence League-affiliated hate account aimed at Diane Abbott, to project what Goode calls 'the more unruly and visceral micro-practices and discourses of everyday life' into the public sphere without censorship. While social media platforms can make the public sphere more reflexive of democratic ideals, they also risk transforming areas of the public sphere into an unregulated space where unjustified prejudice and legitimate, reasoned opinion become interchangeable. To this extent, the traditional model of the public sphere as a space in which communities come together to negotiate that shared cultural practices and public opinions becomes less tenable online.

\section{Unruly spaces: The problems of enforcement}

The phenomenon of online vitriol is arguably exacerbated by the sheer scale of online content, which necessitates the relatively non-interventionist and reactive approach to moderation adopted by many online platforms. On its support page, YouTube prohibits 'content that promotes violence or hatred 
against individuals or groups based on certain attributes, such as: race or ethnic origin, religion, disability, gender, age, veteran status, and sexual orientation/gender identity'. ${ }^{26}$ However, the site also instructs its users to 'keep in mind that not everything that's mean or insulting is hate speech', adding: 'If you're upset by content that a specific person is posting, you may wish to consider blocking the user. ${ }^{27}$ Arguably, it is not feasible for platforms like YouTube, Facebook, and Twitter to moderate comments in real-time. However, the reliance on individual blocking and reporting mechanisms once again places the burden on the victims of abuse and risks denigrating their reactions as hypersensitive. Not only does this mean that many instances of online vitriol go unreported, but it also presents the victims of online abuse with the task of deciding whether the comments they have received are severe enough to qualify as 'abuse', 'harassment', or 'bullying'.

Even when the identification of hate speech is unequivocal, there remains a problem of enforcement. On a video of a subway performer covering Fleetwood Mac's song 'Landslide', one person commented: 'As soon as she started singing I got chills, damn'. ${ }^{28}$ Another user, responded: 'Write a

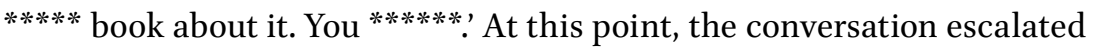
until a user with a pseudonymous and deliberately offensive name made a comment about slavery. When a fellow commenter expressed outrage at this post, they were reprimanded by a third user, who commented: 'Why people try and argue with trolls on this I'll never understand. They just want everyone to be as mad and ignorant as they are! Save your energy bud ;)'. 29

This exchange exemplifies the problem referred to above, where forms online vitriol and actual hate speech are mislabelled as 'trolling', with the result that users agree to ignore rather than denounce them. The sentiment embodied in the phrase 'don't feed the trolls' is now widespread on social media platforms. The problem with this approach is that even if the other users do not sanction such racist and dehumanizing language, they are pressured (as in the example above) into overlooking it. Meanwhile, the perpetrators feel empowered to post sentiments online which they often would not expect to be able to express in person. Furthermore, even if such comments are removed and the users' accounts are suspended, the individual concerned can simply create another pseudonymous account and continue posting.

28 https://www.youtube.com/watch?v=x--yddOolRQ. Accessed 23 June 2017.

29 https://www.youtube.com/watch?v=x--yddOolRQ. Accessed 11 March 2018. 
Arguably, there are limits to the steps that platforms like Facebook, YouTube, and Twitter can take to tackle the epidemic of online vitriol. Following the recent media scrutiny of cyberbullying, these platforms have taken steps to make their stances on online abuse and harassment more robust..$^{30}$ Nonetheless, there is still a dearth of concrete solutions to tackle the scale of the problem. In a recent study of online misogyny, Emma A.Jane observes that 'cyber-harassment such as rape threats and sexualized vitriol [...] have become part of the everyday experience for many women online'. ${ }^{11}$ Not only this, but 'the discourse involved is more rhetorically noxious and is occurring in far broader communities than earlier iterations of gender-based harassment'. $3^{2}$ The current case-by-case approach to regulation cannot help but leave many instances of online vitriol unreported. In addition, it can appear punitive when some individuals are policed more strictly than others. An example of this came in 2017, when Rose McGowan was suspended from Twitter for remarks she made in the wake of the Harvey Weinstein abuse scandal. Believing that McGowan had been unfairly targeted in a draconian instance of enforcement, many women boycotted the platform for a day using the hashtag '\#WomenBoycottTwitter'.33 Though potentially effective, this form of protest also involved women removing themselves from the social platform and therefore renouncing this channel of self-expression. Given the limitations of regulation and enforcement when dealing with online vitriol, there is a strong case for analyzing the conditions which enable it to prevail in the first place.

As discussed in the previous section, social media platforms encourage the expansion of the public sphere into a public hypersphere, in which individuals are invited to share their immediate, emotional responses to every event. This, coupled with the sites' non-interventionist approach to free speech, has enabled the development of a unique comment culture focussed on combat, disinhibition, and the contest for popularity. In the process, the conventional rules of conversation, argumentation, and mutual respect have been disapplied. Between them, these factors make the public hypersphere a revolutionary but vitriolic space, which has far-reaching consequences for language, logic, and the constitution of societies. In the absence of active enforcement by users, online platforms can be governed by the 'unruly and visceral micro-practices' that Goode hoped would be 
transformed in a more reflexive public sphere. ${ }^{34}$ Unless users are willing to enforce the social rules of debate and politeness as they would in an offline space, online platforms develop their own 'thread logic', governed not only by attempts to shock and troll other users, but also in some cases by very real attempts to threaten and intimidate.

\section{Limitless free speech?}

The alternative to ignoring online vitriol and hate speech is for users to call it out by denouncing the content and/or blaming those who post such comments. However, this raises the problem that those who condemn online vitriol risk being accused of being vitriolic themselves, or of attempting to stifle free speech. In this case, perpetrators of hate speech can quickly be transformed to be presented as victims. On 17 April 2015, Katie Hopkins published an article in The Sun in which she referred to migrants as 'cockroaches' and proposed using gunships to prevent them from reaching British shores. At the time, there was widespread condemnation of this article on Twitter and other social media platforms, but the press regulator Ipso found on 1 May 2015 that Hopkins's comments were not discriminatory because they did not refer to a specific individual. This finding arguably reveals the shortfalls of relying on national defamation and libel laws to shoulder the burden of regulating free speech. Clearly, hate speech can be targeted at groups as well as individuals, and it appears significant that the British press regulator in 2015 was not equipped to deal with that fact. Equally significant was the willingness of numerous individuals to defend Hopkins's comments in the name of free speech.

In a blog published by The Spectator on 20 April 2015, Brendan O'Neill argued that 'she's wrong, but Katie Hopkins has a right to call migrants "cockroaches". 35 The problem of the strong model of free speech, based on the fallacy that one person's freedom of expression cannot harm another's, has already been considered. However, O'Neill raised a second point when he described the 'Twitterstorm' which followed Hopkins's remarks:

She's a fascist, they said. She's a Nazi. She's indistinguishable from the authors of the Rwandan genocide. Her comments would have made Hitler blush, said an Independent journalist. Congratulations! You win the war 
of hyperbole, the thesaurus-bombing competition to see who can hate Hopkins the most. ${ }^{36}$

What is significant is O'Neill's recognition that hate speech is often countered with hate on the internet. This raises the question of how to distinguish hate from denunciation: whereas denunciation involves a reasoned rejection of hateful comments, hate involves a more aggressive and/or abusive response to the poster as an individual. Increasingly, those interacting in the public sphere respond to online vitriol in its own vituperative terms, with scorn and vitriol. As O'Neill observes, this leads to a 'war of hyperbole', as the internecine internet hosts a perpetual escalation of anger and resentment.

The contemporary manifestation of anger as a form of critique has a long heritage. No one has done more to understand this heritage than the philosopher Hannah Arendt. In her essay On Revolution, Arendt traced the progress of political violence from Rome to her own time, arguing that:

since the days of the French Revolution, it has been the boundlessness of their sentiments that made revolutionaries so curiously insensitive to reality in general and to the reality of persons in particular, whom they felt no compunctions in sacrificing to their 'principles,' or to the course of history, or to the cause of revolution as such. ${ }^{37}$

Though the reaction to Katie Hopkins's comments on Twitter did not occur in a revolutionary context, it is significant that Hopkins's critics continue to pride themselves on the 'boundlessness of their sentiments'. Due to their vehemence, writers like O'Neill are ultimately able to portray Hopkins as a victim of the debacle, since so many terms of abuse have been levelled at her for exercizing what he and others perceive as her absolute right to free speech. In the process, some of the accusers have become like their target in adopting the same language and logic. In the context of the May 1968 events in France, Arendt argued in her essay On Violence that 'loss of power becomes a temptation to substitute violence for power'. ${ }^{8}$ Arguably, one reason that online posters increasingly adopt anger and vitriol as a means of critique is that they no longer possess the power to set the terms of the debate. As the principles of rationality and compassion lose their hold over the public hypersphere, vitriol begins to seem like the only means 
of expression. Arendt argues that: 'Where violence rules absolutely [...] not only the laws [...] but everything and everybody must fall silent. ${ }^{\prime 9} \mathrm{In}$ adopting anger as a mode of critique, and joining the 'war of hyperbole', those who wish to defend against online vitriol and denounce hate speech risk abandoning the principles of reason and compassion that they seek to uphold. No doubt, there are highly articulate and compassionate forms of anger, but it is important for opponents of social injustice to retain these, rather than surrendering to an expressive but incoherent vitriol.

\section{Conclusion}

This brief survey of 'comment culture' on YouTube, Twitter, and Facebook, as well as in the British tabloid press, has examined how the phenomenon of online vitriol has developed and, to some extent, been regulated on social media. In particular, it suggests that the development of a strong model of free speech, coupled with the expansion of the public sphere into the realm of private and opinion and belief, helps to shape the cultures that evolve in the comment sections of various online platforms. Although each platform has its own unique culture, three broad trends can be seen to emerge. First, social media have developed a unique 'comment culture', in which largely self-regulating communities of users reach a consensus about what forms of expression are or are not available. Second, online platforms are governed by their own distinctive 'thread logic', in which traditional models of debate and conversation are undermined by the phenomenon of trolling and by the confusion of this with more problematic forms of online vitriol and hate speech. Third, the conventional rules of conversation and human interaction are often modified online, with some users being more willing to resort to insult and abuse when they have the ability to appear anonymously and shelter behind other users' unwillingness to 'feed the trolls'.

Ultimately, this chapter considers how the phenomenon of online vitriol begins to influence offline behaviour, as the displays of anger and aggression commonly tolerated and accepted online begin to permeate public life. While it remains difficult for the providers of social media platforms to police every post, the onus of moderation falls on the users of these platforms, who are able to negate and report extreme instances of abuse and prejudice online. In the absence of a consensus and a concerted democratic effort to uphold the principles of debate and mutual respect, the comments sections on even 
the most highly-respected online platforms risk becoming unruly spaces, where the public sphere - rather than becoming a democratic market of opinion - is colonized by 'the more unruly and visceral micro-practices and discourses of everyday life..$^{40}$ The problem for users and operators of these sites is developing a response to online vitriol and hate speech which finds a middle ground between simply ignoring these posts and responding to them in similarly vitriolic terms. A more robust culture of denunciation needs to develop, in which users respond to vitriol with a reasoned rejection of its content rather than with abuse and outrage. Without this, it does not seem possible to realize Ash's ideal that 'mature democracies should move beyond hate speech laws'.

\section{Works cited}

Abbott, Diane. 'I Fought Racism and Misogyny to Become an MP. The Fight Is Getting Harder'. The Guardian, 14 February 2017, https://www.theguardian.com/ commentisfree/2017/feb/14/racism-misogyny-politics-online-abuse-minorities. Accessed 23 June 2017.

Arendt, Hannah. On Revolution. London: Faber \& Faber, 2016.

—, On Violence. New York: Harcourt Brace, 1970.

Ash, Timothy Garton. Free Speech:Ten Principles for a Connected World. New Haven: Yale University Press, 2016.

BBC Newsbeat. 'Stormzy Apologises for Homophobic Tweets'. BBC, 22 November 2017, http://www.bbc.co.uk/newsbeat/article/42078366/stormzy-apologisesfor-homophobic-tweets. Accessed 11 March 2018.

Channel 4. 'Ten Walls Dropped from Festivals after Anti-gay Rant'. Channel 4, 8 June 2015, https://www.channel4.com/news/festivals-drop-ten-walls-followingvicious-homophobic-rant. Accessed 11 March 2018.

Cooper, Anthony Ashley, Third Earl of Shaftesbury. Characteristics of Men, Manners, Opinions, Times, edited by Lawrence E. Klein. Cambridge (UK): Cambridge University Press, 1999.

European Convention on Human Rights, Art. 10. https://www.echr.coe.int/Documents/Convention_ENG.pdf. Accessed 11 March 2018.

Facebook, 'Investor Relations', https://investor.fb.com/resources/default.aspx. Accessed 11 March 2018.

Goode, Luke. Jürgen Habermas: Democracy and the Public Sphere. London: Pluto Press, 2005. 
Griffin, Andrew. 'Boycott Twitter: Women Across the World Abandon Site after it Bans Rose McGowan'. The Independent, 13 October 2017, https://www.independent.co.uk/life-style/gadgets-and-tech/news/boycott-twitter-latest-explainedrose-mcgowan-harvey-weinstein-ben-affleck-ban-a7998341.html. Accessed 11 March 2018.

Habermas, Jürgen. The Structural Transformation of the Public Sphere: An Inquiry into a Category of Bourgeois Society, transl. by Thomas Burger. Cambridge (MA): MIT Press, 1991.

Jane, Emma A. 'Online Misogyny and Feminist Digilantism'. Continuum:Journal of Media \& Cultural Studies, vol. 30, no. 3, 2016, pp. 284-297.

Khommani, Nadia, “Day of Rage' Protestors Demand May's Resignation'. The Guardian, 21 June 2017, https://www.theguardian.com/uk-news/2017/jun/21/ day-of-rage-protest-march-westminster-grenfell-tower. Accessed 23 June 2017.

Locke, John. 'A Letter Concerning Toleration', Locke on Toleration, edited by Richard Vernon. Cambridge (UK): Cambridge University Press, 2010.

Mikal, Jude P., et al. 'Common Voice: Analysis of Behavior Modification and Content Convergence in a Popular Online Community'. Computers in Human Behavior, vol. 35, no. C, 2014, pp. 506-515.

Milton, John. Areopagitica. London, 1644, http://www.dartmouth.edu/ milton/ reading_room/areopagitica/text.html. Accessed 23 June 2017.

O'Neill, Brendan. “Katie Hopkins' Sacking: The Mob Claims Another Scalp'. Spiked, 26 May 2017, https://www.spiked-online.com/2017/05/26/katie-hopkins-sackingthe-mob-claims-another-scalp/. Accessed 23 June 2017.

—, 'She's Wrong, But Katie Hopkins Has a Right to Call Migrants 'Cockroaches.” The Spectator, 20 April 2015, https://www.spectator.co.uk/article/she-s-wrong-butkatie-hopkins-has-a-right-to-call-migrants-cockroaches-. Accessed 23June 2017.

Phillips, Whitney. This Is Why We Can't Have Nice Things: Mapping the Relationship Between Online Trolling and Mainstream Culture. Cambridge (MA): MIT Press, 2015.

Powers, Elizabeth. Freedom of Speech: The History of an Idea. Lewisburg (PA): Bucknell University Press, 2011.

Twitter, 'About', https://about.twitter.com/en_us/company.html. Accessed 11 March 2018.

—. 'About Offensive Content', https://help.twitter.com/en/safety-and-security/ offensive-tweets-and-content. Accessed 11 March 2018.

—. 'Clarifying the Twitter Rules', 3 November 2017, https://blog.twitter.com/official/ en_us/topics/company/2017/Clarifying_The_Twitter_Rules.html. Accessed 11 March 2018.

West, Caroline. 'Words That Silence? Freedom of Expression and Racist Hate Speech' in Speech and Harm: Controversies over Free Speech, edited by Ishani Maitra and Mary Kate McGowan. Oxford: Oxford University Press, 2012, pp. 222-247. 
YouTube. 'About', https://www.youtube.com/about/. Accessed 11 March 2018.

YouTube Help. 'Hate Speech', https://support.google.com/youtube/answer/2801939. Accessed 23 June 2017 .

\section{About the author}

Tom Clucas completed his B.A., M.St. and D.Phil. in English Literature at the University of Oxford, where he also taught at several of the Colleges. Subsequently, he worked as a researcher at the International Graduate Centre for the Study of Culture and Deputy Professor of English and American Literature and Culture at Justus Liebig University, Giessen. He has published articles on Romantic Poetry in journals including Notes and Queries, The Wordsworth Circle, The Cowper and Newton Journal, Textual Cultures, The Review of English Studies, European Romantic Review and The Coleridge Bulletin. He now lives and works in London. 



\title{
3 '\#Unpresidented'
}

\author{
The Making of The First Twitter President
}

Sara Polak

\begin{abstract}
This chapter examines the dynamics of US American Twitter responses to the Ebola epidemic in West Africa of 2013-5. Particularly, it focuses on Donald Trump's role in the 'Ebola scare' - he tweeted more than a hundred times about Ebola late in 2014 and early in 2015 - in order to gauge how Trump found his feet as a social media agitator. The chapter argues that Trump and activists/social media marketeers around him learned from the Birther movement and the Ebola scare how to act as 'superspreaders' of viral content by employing the racialized contagions they were virtually engaging with.
\end{abstract}

Keywords: Ebola, Donald Trump, Twitter, contagion metaphors, Ebola scare, Patient Zero

\section{The retweetable inarticulacy of Trump's language}

On December 17, 2016, just over a month after his general election victory, and briefly before being inaugurated as $45^{\text {th }}$ president of the United States, Donald Trump made a spelling error in a tweet that immediately went viral. In what could be read as a Freudian slip betraying his unconscious, and millions of people's not-so-unconscious desires, he wrote of an 'unpresidented' act (referring to China's capture of a US drone). ${ }^{1}$ Although the tweet was quickly deleted, the hashtag \# unpresidented continued to linger on social

1 https://www.theguardian.com/us-news/shortcuts/2016/dec/19/trump-spelling-error-actjoycean-virtuosity-carelessness. Accessed 1 March 2020.

Polak, Sara, and Daniel Trottier (eds), Violence and Trolling on Social Media. Amsterdam, Amsterdam University Press 2020 DOI: 10.5117/9789462989481_CHO3 
media, and The Guardian adopted it as 'the word of the year'. ${ }^{2}$ It is an apt example of the oft-noted fact that Donald Trump himself is the one who forges the language for his opponents to resist him with. Other examples are the many varieties of Trump's campaign slogan 'Make America Great Again' ('Make America Sane Again', 'Make America Gay Again') and 'grab them by the pussy' from the Hollywood Access tapes ('pussy grabs back'). ${ }^{3}$

Donald Trump's tweets have become a specific, unique and rapidly expanding body of literature. The media, particularly the 'traditional' media, in the US and elsewhere, have had a hard time deciding how to deal with them. There are numerous pro- and anti-Trump responses to controversial Trump tweets on the platform itself and on other social media platforms, but mass media such as television news and newspapers also report and respond to most of his tweets, which are regularly front-page news inside and outside of the United States. Trump himself has often stressed that he uses Twitter to be able to address Americans directly, without the 'interference' of media networks, which he deeply mistrusts and systematically tries to delegitimize. At the same time Trump, also explicitly, often uses Twitter to divert the attention of the mainstream media, away from other politically perhaps more important topics, by tweeting. ${ }^{4}$

Journalists have a hard time measuring their responses to Trump's tweets. They cannot be ignored because they are messages from the President. Although of course these are not laws or executive orders or memos, Trump himself often seems to believe they have that status, and in a sense they have that effect. For instance, on 26 July 2017 Trump sent three tweets in which he 'banned' transgender people from the military. ${ }^{5}$ While the tweeted ban had no legal power - a month later the White House issued a

2 https://www.theguardian.com/us-news/2016/dec/19/unpresidented-trump-word-definition. Accessed 1 March 2020.

3 https://www.theguardian.com/commentisfree/2017/jan/17/resist-donald-trump-vocabularyresistance-rhetoric. Accessed 1 March 2020.

4 E.g. on 1 July 2017 Trump tweeted: 'The FAKE \& FRAUDULENT NEWS MEDIA is working hard to convince Republicans and others I should not use social media - but remember, I won the 2016 election with interviews, speeches and social media. I had to beat \#FakeNews, and did. We will continue to WIN' https://twitter.com/realdonaldtrump/status/881271748280365056. Accessed 1 March 2020.

5 'After consultation with my Generals and military experts, please be advised that the United States Government will not accept or allow Transgender individuals to serve in any capacity in the U.S. Military. Our military must be focused on decisive and overwhelming victory and cannot be burdened with the tremendous medical costs and disruption that transgender in the military would entail. Thank you.' https://twitter.com/realDonaldTrump/status/890193981585444864. Accessed 1 March 2020. 
memo which did - the tweets were the real bombshell that sparked a huge amount of confusion and discussion in the media, to some extent as a result of their unclarity. They could not be ignored, yet coming at a time when Trump clearly felt the heat of the investigation into Russian interference in the elections, many journalists expressed a worry that this was a diverting manoeuvre from a President who is perhaps in the first place a talented show master, highly adept at redirecting the public's attention. ${ }^{6}$

Similarly, although the now-deleted tweet 'Despite the constant negative press cofveve' (31 May 2017) was obviously unintentional, the 'affair' was hilarious news for days in a fashion that was hardly at Trump's expense. Indeed, later the same day he tweeted 'Who can figure out the true meaning of 'covfefe' ??? Enjoy!"7 Clearly, he or his team realized that the hilarity about the typo worked in his favour. Even his most fanatical opponents had a relatively harmless laugh about it, and many adopted the word, to the extent that it became not just a popular hashtag, but a word, denoting a tongue-in-cheek version of 'coffee', 'coverage', 'kerfuffle' or the newly coined word for the concept of 'sending a text or publishing a tweet prematurely and with egregious spelling errors'. ${ }^{8}$ Even more than the 'Unpresidented' tweet, this tweet generated a kind of cult of using, usually in benevolent jest, a vocabulary introduced in Trump tweets, that arguably extended his control over the public discourse. What these cases share, is the way in which they weaponize Trump's disarming inarticulacy to contribute to a discourse that would not be legitimate if it were not so vague. That such Trumpian discourse works disarmingly is not to say that it succeeds in getting opponents' political support, but it does work to acquire their linguistic support. Any joke - even if it is at Trump's expense - that employs this discourse helps to establish his position of seeming sheepishness. This is a purely cultural 'soft' power, that does not begin to address equally relevant related questions, such as what Twitter's responsibility as a company is in policing expressions on the platform, and whether it matters legally if a tweet comes from Trump's personal account (@realdonaldtrump) or from the official White House presidential account (@POTUS).

Although 'unpresidented' and 'covfefe' were presumably not intentionally coined, both have the apparently irresistible attraction of so many of his expressions - irresistible even to those who set out to do just that. This chapter interrogates why so many Trump tweets are so irresistible. What

6 E.g. Kendzior, 'First They Came for Trans Americans, Who Will Be Next?'.

7 https://twitter.com/realDonaldTrump/status/869858333477523458. Accessed 1 March 2020.

8 https://www.urbandictionary.com/define.php?term=covfefe. Accessed 1 March 2020. 
makes Twitter so peculiarly conducive to Donald Trump's messages? How does it make his inarticulacy a peculiar strength? How does it spread them, and how have Trump and his supporters learned to employ the contagious nature of both language and medium?

\section{History of Trump as a Twitter president}

There is a long history of symbioses between presidents and their favourite media. What radio was for Franklin D. Roosevelt and television for John F. Kennedy is what Twitter is for Donald Trump. In virtually none of these cases was the particular president actually the first president to employ that medium. Calvin Coolidge and Herbert Hoover were broadcast over the radio before Franklin Roosevelt developed his famous intimate radio style for the Fireside Chats; Dwight Eisenhower appeared on television well before John Kennedy became famous as the first president to master the medium. ${ }^{9}$ Barack Obama's electoral success in 2008 was largely ascribed to his campaign's astute use of social media - Facebook, mainly - in acquiring large-scale popular support and a record-breaking number of small donations. ${ }^{10}$ Donald Trump, however, was an avid Twitter user years before Barack Obama became a personal Twitter user as president. ('Hello, Twitter! It's Barack. Really! Six years in, they're finally giving me my own account.' 18 May 2015).${ }^{11}$ While Obama has always remained a sparse tweeter, Trump has tweeted using the @realdonaldtrump handle over 37,0oo times between his registration in March 2009 and March 2018. Moreover, Trump has used the medium to conduct large-scale campaigns for - and against - a number of issues, mostly in direct or indirect criticism of President Obama.

The best-known example is perhaps the cluster of conspiracy theories around Barack Obama's American citizenship, promoted intensely by a group which later came to be called the Birther Movement. This group of right-wing activists, in which Trump had a prominent role, claimed or suggested that President Obama was not a 'natural-born' citizen of the United States, and therefore, under Article Two of the Constitution, had no right to serve as US President, in order to delegitimize Obama's presidency. In an interview with Ashleigh Banfield on Good Morning America he both expressed his seriousness about running for president himself, and his concurrence with 
the Birther Movement's doubts about Obama's Americanness. ${ }^{12}$ When, a month later, Obama released his long-form birth certificate in response to the pressure, Trump credited himself for having forced the President's hand, but did not drop the accusation. Early in 2016, with the Republican primary in which he himself was a candidate underway, Trump used the same tactic against Ted Cruz, another candidate for the Republican nomination, for example in a tweet on 12 February 2016: 'If @TedCruz doesn't clean up his act, stop cheating, \& doing negative ads, I have standing to sue him for not being a natural born citizen. ${ }^{13}$ In this case particularly, the formulation 'I have standing to sue him for not being a natural born citizen', suggests that not being born in the United States is in itself a crime, which is then compounded by lying about it, as Trump falsely alleges. There were actual court cases about Obama's country of origin, which the birthers lost, but the real power of these narratives lies in their attractiveness for the media, particularly social media.

More than ever, the 2016 US General Elections seem to have been decided in the realm of online social media. Hillary Clinton's 'ground game' - campaigning in the offline world, through flyers, canvassing, grass roots organizing and other traditional means - which was widely acclaimed and understood as far superior to Donald Trump's, by pollsters and analysts of both political leanings, appears not to have mattered as much as Trump's big campaign rallies, rabid tweets, and the online trolling and alleged cybercrime committed in support of his candidacy. Some of the key characteristics of Twitter as a medium - the brevity, the habitual omission of reference to sources - seem to have been particularly important for the Trump campaign, because they are well-suited to his style of communication and intentions. To a large extent, Trump and his circle of supporters benefit not only from the algorithmic characteristics and implications of the medium, but also from its reputation of being unfiltered, democratic, and to-the-point. I will argue that Trump learned to use the tactics to undercut opponents and take charge of the discourse which he used in the campaign and employs as president through social media during earlier social media storms such as the Birther Movement. I will specifically unpack the discourse and metaphors developed during the US American Ebola Scare on Twitter in which Trump was also a key player. 


\section{The contagiousness of the Ebola scare}

Between September 2014 and April 2015 hundreds of millions of tweets in English have used the word 'Ebola'; most of these are US American. ${ }^{14}$ It is not always possible to determine the geographical origin of a tweet, but if the subsection of 'Ebola'-tweets that does have geographical metadata is representative, the majority of the Anglophone tweets that mention Ebola originate from the US. Many are from non-governmental organizations, news networks, or from the various involved American federal agencies, but a large subsection is from individuals who are seemingly not directly involved. Neither do they have clear links with Ebola-affected people or areas, nor are they engaged in the effort to combat the disease. A large number of these tweets bespeak genuine or pretend outrage at the risks involved in addressing the outbreak, and fear of the virus infecting Americans in the United States. This fear was reflected in mainstream American media around the same time, particularly after the discovery of a Liberian patient (on 30 September 2014), and three more cases in the course of October 2014, and later after the discovery of a medical doctor who had contracted the virus in New York. ${ }^{15}$ While some of the mainstream media reports about the disease threat to Americans was definitely alarmist, ${ }^{16}$ the scare took on its own life on social media, where it 'went viral' in a far more aggressive manner.

This case is revealing for several reasons: first of all because it is rich in racist 'lulz' (social media parlance for jokes) and fascinations that often draw on pre-existing narratives and conceptual metaphors regarding disease and (West) Africa. Whether or not actual fear was involved, objectification of victims who are fascinating because they are scary and abject offers a perfect vehicle for individual users to become cliques and organized collectives. Donald Trump, then still a business tycoon and reality star, but not yet president or candidate - although he did have well-known ambitions to become that - happened to be a very active participant in this process on Twitter. In so doing, I argue, he laid some of the groundwork, both for his later campaign and for under-the-radar groups, who came to his support strongly in the course of his presidential campaign.

14 Established using the Digital Methods Initiative's tool T-CAT, and the database [Africa], searched for 'Ebola' in English-language tweet text, and where available, geolocation.

15 https://www.cdc.gov/vhf/ebola/outbreaks/2014-west-africa/united-states-imported-case. html. Accessed 1 March 2020.

16 Hasian, Representing Ebola, p. 137. 
In a perceptive analysis of anti-Semitic Alt-Right YouTube star Felix Kjellberg, Jacob Clifton discusses the phenomenon of online Alt-Right groups that seem to appear from nowhere:

We're conditioned to distance ourselves from Reddit dorks, anime-avatar trolls, and suddenly Nazi-identifying furries, and so they stay invisible - until they aren't. They become collectives, at which point it feels like they came from nothing. ${ }^{17}$

Clifton argues that these collectives of self-identifying 'dorks', 'trolls' and 'edgelords' tended for a long time to remain invisible to a larger public, because they are most active on platforms like Reddit and 4 Chan. There they developed, often from gamers or comics fans, into Alt-Right activist collectives. They only became visible, also to audiences beyond Twitter, when they started to 'feed' Twitter, which is primarily a circulation platform. On the feeder platforms, out of sight of the rest of society, online communities evolve in which the members radicalize one another in part as a result of a continued wish to shock one another. ${ }^{18}$ While it might seem that many of such extreme messages do not greatly matter, because they hardly reach any audience, this is missing the point. Edgelords do not usually aim to address their messages to everyone, but to a small group of likeminded users, which is why the term 'edgelord' is used with ironic pride. These expressions can easily move from ironic non-pc jokes that are intended to draw in-group laughs to hatred genuine enough to motivate group action against specific objects (be they Jews, non-Whites, women or any other group).

Apart from the fact that they tend to be active on platforms most users of mainstream platforms like Facebook and Twitter rarely use, another reason why edgelords and their evolving group dynamics are invisible, is because most social media users do not want to see them. They are, to most users' tastes and sensibilities simply gross, even as badass jokes. To give one example a joke that went around on Reddit and Twitter in early 2015 went along the lines of 'Mom: what did your last slave die of? Me: Ebola'.19 Such jokes, more recognizable as deliberate provocations than as jokes, are rife on message boards like 4 Chan and 8 Chan and some subreddits

17 https://www.buzzfeednews.com/article/jacobclifton/pewdiepie-isnt-a-monster-hessomeone-you-know\#.nfNVPxKqv\%20(16\%20February\%202017). Accessed 1 March 2020.

18 Nagle, Kill All Normies.

19 E.g. https://twitter.com/Emoly28/status/566oo1752198373376. Accessed 1 March 2020. 
(Reddit threads around a specific theme or group of users). They seem to rely on casual racism, which remains soft or borderline by virtue of being syntactically or practically incomprehensible. However unseen, though, these groups, and their organizing and radicalization tactics have been around for about a decade. While there are many examples (the Birther movement is one, but the most famous is perhaps Gamergate), the 2014 Ebola scare on US American Twitter is a case that has not been scrutinized in depth so far.

\section{Trump as a superspreader of the Ebola scare}

Donald Trump, however, did, during the Ebola crisis, lead a very specific and seemingly deliberate response to Ebola on Twitter, which politicized the Ebola scare. He incessantly attacked the Obama administration for its supposedly 'weak' handling of the crisis, repeating that the only way to stop Ebola from infecting Americans on a large scale was to stop all flights from Africa. He also argued that Americans going to the affected areas to help affected communities, should not be allowed back into the country, and suggested that those who entered the US with the virus, did so with malignant intentions. In doing so, Trump politicized the crisis, roping the presumed risk into his white nationalist agenda, which, like the birther movement, contributed to the long process that propelled him into the Republican nomination, and the presidency. But simultaneously, and perhaps more importantly, his tweets reflected, interacted with, and spurred on a trend among the evolving Alt-Right on Twitter to dress narratives of white supremacy in very basic and familiar narremes and memes.

Throughout October 2014, Trump tweeted just under eighty times about Ebola (using either 'Ebola' or ‘\#Ebola' in tweets), up to eight, though often two or three times a day - a significant section of his average of 11 tweets per day. To give a sense of the kinds of tweets Donald Trump (@realdonaldtrump) posted about Ebola in October 2014, here are some examples. ${ }^{20}$

Here we go! I stated long ago that we should cancel all flights from West Africa. Now we have Ebola in U.S., AND IT WILL ONLY GET WORSE! (@ realdonaldtrump,1 October 2014)

20 The examples are selected to be representative, but the entire collection of 'Ebola'-tweets can be found here: http://www.trumptwitterarchive.com/archive (search for 'Ebola'). 
Ebola is much easier to transmit than the CDC and government representatives are admitting. Spreading all over Africa-and fast. Stop flights (@ realdonaldtrump, 2 October 2014)

The Ebola patient who came into our country knew exactly what he was doing. Came into contact with over 100 people. Here we go-I told you so! (@realdonaldtrump, 3 October 2014)

This Ebola patient Thomas Duncan, who fraudulently entered the U.S. by signing false papers, is causing havoc. If he lives, prosecute! (@realdonaldtrump, 4 October 2014)

Despite the ever increasing Ebola disaster, Obama refuses to stop flights from West Africa. It's almost like he's saying F-you to U.S. public (@ realdonaldtrump, 7 October 2014)

The CDC chief just said Ebola is spreading faster than Aids. Marines are preparing for a pandemic drill. Stop all flights from West Africa! (@ realdonaldtrump, 10 October 2014)

China is ripping wealth out Africa and yet, as usual, refuses to put anything back to help with Ebola. 'Let the stupid Americans do it!' SAD (@ realdonaldtrump, 10 October 2014)

As ISIS and Ebola spread like wildfire, the Obama administration just submitted a paper on how to stop climate change (aka global warming). (@realdonaldtrump, 14 October 2014)

President Obama has a personal responsibility to visit \& embrace all people in the US who contract Ebola! (@realdonaldtrump, 15 October 2014)

If this doctor, who so recklessly flew into New York from West Africa, has Ebola, then Obama should apologize to the American people \& resign! (@realdonaldtrump, 24 October 2014)

The Ebola doctor who just flew to N.Y. from West Africa and went on the subway, bowling and dining is a very SELFISH man-should have known! (@realdonaldtrump, 24 October 2014) 
President Obama has a major meeting on the N.Y.C. Ebola outbreak, with people flying in from all over the country, but decided to play golf! (@ realdonaldtrump, 24 October 2014)

Many of these messages accord perfectly with the tendencies and mechanisms Priscilla Wald analyzes in Contagious: Cultures, Carries, and the Outbreak Narrative (2008). As Wald notes 'Disease emergence dramatizes the dilemma that inspires the most basic human narratives: the necessity and danger of human contact.' She offers a cultural history and analysis of the role of the narratives in which communicable disease is framed, in addressing the outbreak on a medical and political level. She analyzes narrative framings of communicable disease in the context of religion, the rise of nationalism, globalization, and other cultural trends, as well as the interface with race, class, and sexual orientation.

The outbreak narrative - in its scientific, journalistic, and fictional incarnations - follows a formulaic plot that begins with the identification of an emerging infection, includes discussion of the global networks throughout which it travels, and chronicles the epidemiological work that ends with its containment. ${ }^{21}$

Contagious is both a cultural history of outbreak narratives and a strong plea for taking such narratives seriously, not as implicit 'truths' that might be reproduced in addressing epidemics, but as stories that '[affect] which social structures and whose beliefs, poverty, prejudices, and personalities become the focus of analysis, as well as who is included in the "we" who might have been better off had the virus not been identified'. ${ }^{22}$

Donald Trump, however, is interested exactly in 'reproducing the epidemic's terms', or rather, in using the actual epidemic to fire up the social epidemic of fear and objectification of Africans and migrants in general as infectious and contaminating. This outbreak narrative - like most, Wald shows - reinforces national belonging: 'indeed typically in outbreak narratives, the effort to contain the spread of a disease may involve international cooperation, but is cast in distinctly national terms, especially in the United States'. ${ }^{23}$ Thus, many outbreak narratives foster 'medicalized nativism,' a term coined by the historian Alan Kraut 'to describe how the stigmatization 
of immigrant groups is justified by their association with communicable disease; it implies the almost superstitious belief that national borders can afford protection against communicable disease.. ${ }^{24}$ Trump's repeated call for closing the borders and stopping all flights from Africa imply the notion that a virus cannot travel across a 'closed' border, closely matches that idea. Clearly, in Trump's wilfully dramatic rendering, Ebola is 'like wildfire', that can be contained and sealed off from reaching the United States through borders.

It is obvious that Trump in his Ebola tweets espouses a classic outbreak narrative, with all the basic ingredients. For example, he forcefully buys into the 'Patient Zero' myth - the idea, central to most outbreak narratives, that there is an 'original virus carrier' who is perpetrator rather than victim of the disease, and who knowingly and cunningly infects others. ${ }^{25}$

The Ebola patient who came into our country knew exactly what he was doing. Came into contact with over 100 people. Here we go-I told you so!

Trump implies that the man who was discovered to carry Ebola, although he only became ill after he had entered the United States, did so with a predetermined plan, and aim to infect as many as possible. Trump's final half-triumphant, half hand-wringing exclamation at the end suggests the event is part of a detailed scenario - the outbreak narrative - which he already knows in detail. In that sense, the Ebola epidemic and the medial versatility of the outbreak narrative come in handy for him to promote a narrative he was already campaigning to get others to buy into as well.

\section{The inarticulacy of Ebola rhetoric}

However, virus metaphors, and the infectious cultural fascination around the threat of disease epidemics are not the same as an outbreak narrative. Rather, those metaphors and fascinations are circumstances that facilitate the development of a real structured narrative, in which time and characters play a role, evolves. Many of the hints about the Ebola epidemic together with frames and implications of virus metaphors on social media together suggest an underlying outbreak narrative, which however hardly surfaces as an actual narrative. When Trump on 1 October 2014, after the discovery 
of the first Ebola case in the US tweeted 'Here we go! [...] AND IT WILL ONLY GET WORSE!', his remarks were at once vague - what does 'it' refer to? Where are 'we' going? - and well-tuned into pre-existing cultural notions of what a disease pandemic is like. As such Trump does not offer an outbreak narrative but uses one that can be intuited, and at the same time remains very elusive.

As such, 'the' Ebola outbreak narrative as it evolves on Twitter is especially hard to capture. The outbreak narratives Wald analyzes are outlined in non-fiction books, novels, magazine stories and other more or less longform mainstream media stories, which can be taken to represent the most prevalent or most widely understood outbreak narrative, but in a world in which hypes happen largely on social media this is harder to do (for most researchers studying narratives - although prominent tweets others find by Donald trump are a good start - especially if these are the artefacts that endure over time).

The inarticulate terms in which the outbreak narrative he promotes is framed, is helpful in obfuscating its internal inconsistencies and logical and factual flaws. The vague language ('Here we go!') and the uncompleted thoughts and sentences allow for various interpretations. The narrative is hardly a real narrative, but rather a jumble of loosely connected 140-character messages that invoke a range of pre-existing popular narratives and images, which invite the reader to fantasize along using narremes from popular culture (small narrative units, e.g., the notion of the impending apocalypse).

A tweet like 'This Ebola patient Thomas Duncan, who fraudulently entered the U.S. by signing false papers, is causing havoc. If he lives, prosecute!' explicitly names the victim, and then falsely accuses him of fraud and 'causing havoc', as if these two, fraud and causing havoc were equally illegal. The implication is that being ill with Ebola in the United States is in itself illegal. Next to the obvious medicalized nativism here, Trump invokes another classical convention of outbreak narratives: the 'super-spreader': the idea that there are patients (often 'Patient Zero') who infect a disproportionate number of others, but also: 'the archetypal stranger, both embodying the danger of microbial invasion, and transforming it into the possibility for rejuvenation and growth'. ${ }^{26}$

Trump's 'super-spreader' tweets, like the one above, clearly speak to fear of 'the archetypal stranger' as well as more general anxieties about mobility in a shrinking world, but not explicitly to the possibility of rejuvenation or growth. However, these are present, not in Trump's explicit words, but in his 
own positioning as a largely social-media-driven presidential candidate. The notion of a 'global village' in which health must be treated on a global scale is a prominent part of Wald's analysis, however, she does not specifically address how the Web 2.0 and social media have influenced or changed this dynamic. Writing in 2008, Wald addresses historically recent outbreaks such as HIV/AIDS, avian influenza, and SARS, without attending to their social lives and outbreak narratives in social media.

\section{Dynamics of Twitter and other platforms}

So what does the seemingly open, border-free, and transnational nature of social media interaction present that is new in the dynamics of narrating communicable disease?

While on the one hand these tweets presume (and construct) a nation that can function as a healthy bulwark against corrupting and debilitating disease, it simultaneously attacks its president, Barack Obama. Obama's failure to stop flights from West-Africa in Trump's rendering seems to bear a relation to his race. Coming after the long birther movement campaign in which Trump and a well-organized group of Tea Party supporters planted the notion that Obama was not born in the United States, the suggestion that his foreignness causes Obama to play a malignant role adds to a pre-existing tradition of racist insults. When Trump tweets 'It's almost like he's saying F-you to U.S. public' the direct implication is that Obama himself is part of the problem, indeed of the attack on the nation Ebola represents. Similarly, attacking Obama for 'play[ing] golf' plays in to pre-existing stereotypes of black laziness, and the racist notion that it is inappropriate for a black man to play golf.

Such suggestions of Obama's complicity in the outbreak simultaneously contribute to the idea that the bordered nation can function as a bulwark against the invasion of the Ebola virus, and imply that Obama's identity in itself represents a fracture in the texture of that border. If one accepts the fabrication of Obama as an intruder and impostor himself - a notion strengthened by the idea that a black president should always be working and has by definition no business playing golf - then the extension of that implication is that he is the vehicle for the entrance of the virus into the US. Trump may support his accusations with criticism of Obama's policies (or policies he falsely attributes to Obama), but in essence the message is that Obama's identity 'naturally' causes the leak. This can be observed also in the tweets in which Trump connects Obama's allegedly conscious choice 
to make the US porous to its own detriment, to Obama's own body, as in: 'President Obama has a personal responsibility to visit \& embrace all people in the US who contract Ebola!'

While Trump does not explicitly move beyond claiming that Obama's body politic is at fault in allowing Ebola to enter the US, implicitly it is clear that Obama's body natural is at fault. The idea that he be punished on the body natural is appealing in part because Obama's body natural, and his African roots in the birther movement's racist frame of reference have enabled the nation's porousness. There is a long tradition of seeing the president as an embodiment of the United States, that facilitated the superficial conflation of Obama's allegedly alien status with his alleged complicity in bringing Ebola into the country. Neither allegation is correct but they support each other in a narrative that weaponizes the fear of the other, while using vagueness about the precise meaning and implications of the claims to deny racism, in a way that is fairly usual for outbreak narratives.

Twitter, because of its accessibility and instantaneity, tends to suggests it is both democratizing and, literally, im-mediate, direct, both in terms of speed and transparency. As the company itself asserts in advertisements: 'People use Twitter to gush, geek out, and get informed. Use our tools to target every type of tweet'. ${ }^{27}$ Twitter is, in reality used for far more, and more pernicious, ways of doing things with words. Some of the key 'types of tweet' indeed are performative: they harass, silence misinform, or scapegoat, often in a collective and organized fashion.

The birther movement - and particularly Trump's way of employing it - exemplifies how narratives that appear to gain attention on the strength of their entertainment value, gather very concrete political traction. Twitter, with its classification of 'types' of tweets suggests that tweets may be believed to be authentic expressions of thoughts and feelings. This misunderstands what kinds of messages tweets can be employed for, and also, how messages can evolve, work on several levels, and operate in a context that is not always visible, and leads all too easily to the tendency to take tweets too much at face value.

Since the rise of social media platforms such as Facebook, Twitter, YouTube and Instagram, the concept of virality has taken on a new set of meanings. Of course virality - not even necessarily online - has over the last decades come to be understood to pertain to computer 'viruses' (malware, spyware) that spread through infected data carriers, email, scams, unsecured WiFi networks and other 'carriers', but I limit my discussion here to material that 
is deliberately shared on social media platforms. For something to 'go viral' online means that it succeeds in attracting attention, clicks, shares, likes, or whatever specific platforms enable, far beyond its own direct environment.

The metaphor of digital content 'going viral' relies on the tendency of actual viruses to spread to others who are in contact with the already infected. However, unlike with disease (or malware), in the case of a YouTube video that goes viral, this is usually seen as positive. Indeed, viral videos have the potential to generate large sums of advertising revenue. Online virality is thus close to a connotation of contagiousness that has long been around in marketing and sales: the idea that human longing or need to have or be part of something works like a virus. If your neighbour has it, you are likely to acquire it too. One difference with online virality is that anyone, anywhere in the world can spread the object with incredible ease, and at - seemingly - no cost.

Such viral objects - video footage, photos, memes, tweets - often spread more aggressively than any real virus would, whether airborne or otherwise. Indeed, Trump seems to have discovered that he himself was able to act as a kind of superspreader of the medial Ebola scare, in part through the generic dynamics of social media, and in part through the specific properties of his language. While the very discursive notions of super-spreaders and Patient Zeros often work to unduly incriminate individuals, Trump seems to relish his role as metaphorical superspreader of online fears and trends more broadly. His entire candidacy, of course, could be framed in 'superspreader' terms: he positioned as an archetypal 'stranger' or outsider candidate (more than was justified in fact for a long-time political donor, and potential candidate), and he rhetorically posed as a political promise who embodied not just the danger (to the establishment) of invasion, but also the possibility of 'rejuvenation and growth'.

Thus, Trump seems to have realized the potential power of virus metaphors as a kind of metaphorical virus in and of itself, during and through the Ebola epidemic, although of course without the sophisticated discourse in which Wald analyzes it. James Peacock and Tim Lustig have identified what they term the 'Syndrome Syndrome' - in the current-day Western culture one needs some kind of syndrome to retain a right to human imperfection socially and economically. In a similar fashion one can speak of a 'Contagion Contagion' - the virus metaphor itself enjoys a cultural popularity only too easily considered in its own terms. ${ }^{28}$

If the Alt-Right, and Donald Trump, can be credited with one thing, it is to discover and learn to employ the tremendous power of metaphorical virality 
to implicitly or explicitly make an argument, and particularly to ridicule, inspire fear, collectively enjoy, and shame, often using the latter strategies to achieve the former. Theoretically the power of fear as metaphorically contagious was already well known. Wald notes: 'Morrow was one of many cultural observers who worried that the fear generated by the epidemic was more socially disruptive than the virus. ${ }^{29}$ However, something that existed primarily as a worry, and which is among other things central to the response to epidemics of the Centers for Disease Control, this fear can also be employed to disrupt society or mobilize groups for political gain. While the 'Ebola scare' did not actually disrupt life in the US to a great extent, it did influence the lives of people who were somehow involved directly, and in any case the disruptive intention of these tweets (for instance to interrupt flights from African countries to the US) is clear.

\section{From the Ebola scare to the presidential campaign}

Such social disruption in general is indeed what Trump, and a great many of the Alt-Right's online activists are aiming for. In an extensive interview with New Yorker's Andrew Marantz, Mike Cernovich, 'an expert at using social media to drive alt-right ideas into the heart of American political discourse', ${ }^{30}$ explained how he became leader of the 'Trolls for Trump' movement that aggressively campaigned against Hillary Clinton in the 2016 elections. Although it does not mention any literal virus or epidemic, both interviewer and interviewee are clearly acutely aware of the relevance of the virus metaphor:

Rush Limbaugh had just mentioned \#ZombieHillary on his radio show. The hashtag, referring to Clinton's supposed frailty, had trended the previous day on Twitter, after Cernovich encouraged his followers to use it. 'I would like to claim credit for it, but I can't,' Limbaugh had said. 'Somebody on Twitter did it.' Cernovich told me, 'He'll never mention me by name, but he's at least listening to the periphery.'

People have always expressed extreme views online, but for many years there was no easy way for such opinions to spread. The Internet was a vast landscape dotted with isolated viruses. The rise of social networks was like the advent of air travel: a virus can now conquer the world in a day. ${ }^{31}$ 
If there is one striking trend in many American tweets about Ebola, it is their tendency to compare it to a 'zombie virus' - perhaps because of Ebola's gruesome effects on the body. While Trump does not literally use the word zombie in his Ebola tweets, he does dehumanize Ebola sufferers, suggest that they 'feed' on spreading the disease, and refer to the epidemic as if it were an impending Walking Dead-style zombie apocalypse. For Cernovich then to employ ‘\#ZombieHillary’ as a hashtag to jeer at illness, contributes to the narrative frame in which being ill is a reason to be blamed and suspected of wanting to spread disease. In the same movement, Cernovich himself uses online virality to influence the mainstream discourse from the fringe, a possibility, as Marantz notes, that results from the internet's shift towards an environment that encourages the spread of such 'viruses' like air travel does with actual viruses.

Not only do Cernovich and others use online virality to troll others, and push content into the mainstream that without social media never would make it into the public arena. Since becoming president, but also already before that, Donald Trump himself had a role in mainstreaming Alt-Right messages. Or more specifically, there is a large machine producing pro-Trump memes, often in response to Trump's tweets, which he then retweets, so that they reach a mainstream, mass audience. Thus, many messages that are not seen beyond very specific Alt-Right marginal communities on platforms like Reddit, on the one hand respond to Trump and on the other are made visible by him. One example concerns a video clip in which Trump beats to the ground a person whose head is replaced by the CNN logo. Trump retweeted it on 2 July 2017 (' $\#$ FraudnewsCNN \#FNN') ${ }^{32}$, but it was first made and shared by a Reddit user. Although Trump denies taking the video from that platform, this is its source, and the video became world news after he had shared it, as part of a general campaign to discredit and delegitimize media that are critical of him, particularly CNN.

The original maker of the video pastiche who had pasted the CNN logo into the clip quickly removed it from Reddit when he saw the upheaval it caused, but at that point it had already spread far and wide, both geographically and across different platforms and media. There was no going back. Trump has learned to use such materials, which are on the one hand clear in their message, that Trump wins the battle in and with the media, and on the other imprecise and inarticulate. The metaphor is obviously silly and it is unclear what it refers to exactly, but that is also what produces its comical effect. Trump, time and again, manages to create 
a perfect storm out of something that is 'going around'. He already had experience in that before the Ebola epidemic, but cheering on the Ebola scare also taught him how to employ the dynamics of outbreak narratives in his own resounding yet disjointed manner. Simultaneously Trump's functioning in turning news of the Ebola epidemic into a veritable scare far away from the sites of the epidemic shows how Wald's theory could be 'updated' to include the shape and politics of outbreak narratives in a social-media ecosystem.

\section{Works cited}

Anderson, Benedict. Imagined Communities: Reflections on the Origin and Spread of Nationalism. London: Verso, 1983.

Arthur, P. and K. Bode. Advancing Digital Humanities: Research, Methods, Theories. London: Palgrave, 2014.

Baym, Nancy K. Personal Connections in the Digital Age: Digital Media and Society Series. Malden (MA): Polity Press, 2015.

Booth, Wayne C. A Rhetoric of Irony. Chicago: University of Chicago Press, 1974.

Boyd, D.M., and N.B. Ellison. 'Social Network Sites: Definition, History, and Scholarship'.Journal of Computer Mediated Communication, vol. 13, no. 1, 2008, pp. 210-230.

Buhite, Russell D. and David E. Levy. FDR's Fireside Chats. Norman (OK): University of Oklahoma Press, 2010.

Chadwick, Andrew. The Hybrid Media System: Politics and Power. Oxford: Oxford University Press, 2013.

Clifton, Jacob. 'The Downfall of YouTube's Biggest Star Is a Symptom of a Bigger Illness'. Buzzfeed, 16 February 2017.

Cogburn, Derrick, and Fatima Espinoza-Vasquez. 'From Networked Nominee to Networked Nation: Examining the Impact of Web 2.o and Social Media on Political Participation and Civic Engagement in the 2008 Obama Campaign'. Journal of Political Marketing, vol. 10, no. 1-2, 2011, pp. 189-213.

Dijck, José van. The Culture of Connectivity: A Critical History of Social Media. Oxford: Oxford University Press, 2013.

Fuller, Matthew. Media Ecologies: Materialist Energies in Art and Technoculture. Cambridge (MA): MIT Press, 2005.

Goriunova, Olga. 'The Force of Digital Aesthetics: On Memes, Hacking, and Individuation'. The Nordic Journal of Aesthetics, vol. 47, 2014, pp. 54-75.

Hasian Jr, Marouf A. Representing Ebola: Culture, Law, and Public Discourse about the 2013-2015 West African Ebola Outbreak. Lanham: Rowman \& Littlefield, 2016. 
Jane, Emma Alice. "Your a Ugly, Whorish, Slut': Understanding E-Bile'. Feminist Media Studies, vol. 14, no. 4, 2014, pp. 531-545.

—. "Back to the Kitchen, Cunt': Speaking the Unspeakable about Online Misogyny'. Journal of Media and Cultural Studies, vol. 28, no. 4, 2014, pp. 558-570.

Kendzior, Sarah. 'First They Came for Trans Americans, Who Will Be Next?'. The Globe and Mail, 27 July 2017, https://www.theglobeandmail.com/opinion/firstthey-came-for-trans-americans-who-will-be-next/article35817888/. Accessed 1 March 2020.

Lakoff, George and Mark Johnson. Metaphors We Live By. Chicago: The University of Chicago Press, 2003.

Lauro, Sarah Juliet. The Transatlantic Zombie: Slavery, Rebellion, and Living Death. New Brunswick: Rutgers University Press, 2015.

Levine, Lawrence and Cornelia Levine. The People and the President: America's Conversation with FDR. Boston: Beacon Press, 2002.

Losh, Elizabeth. Hashtag - Object Lessons. London: Bloomsbury Academic, 2019.

-. Virtualpolitik: An Electronic History of Government Media-Making in a Time of War, Scandal, Disaster, Miscommunication, and Mistakes. Cambridge (MA): MIT Press, 2009.

Lustig, T.J., and James Peacock (eds). Diseases and Disorders in Contemporary Fiction. The Syndrome Syndrome. New York, London: Routledge, 2013.

Marantz, Andrew. 'Trolls for Trump: Meet Mike Cernovich, the Meme Mastermind of the Alt-Right'. The New Yorker, 31 October 2016.

Nagle, Angela. Kill All Normies: Online Culture Wars from 4 Chan and Tumblr to Trump and the Alt-Right. New York: Zero Books, 2017.

Neiwert, David. Alt-America: The Rise of the Radical Right in the Age of Trump. New York: Verso Books, 2017.

Parikka, Jussi. Digital Contagions: A Media Archaeology of Computer Viruses, 2nd. updated edition. New York: Peter Lang, 2016.

Phillips, Whitney, and Ryan Milner. The Ambivalent Internet: Mischief, Oddity, and Antagonism Online. Malden (MA): Polity Press, 2017.

Poell, T., and J. van Dijck. 'Social Media and Activist Communication', in The Routledge Companion to Alternative and Community Media, edited by C. Atton. London: Routledge, 2015, pp. 527-537.

Schaefer, M.T. Bastard Culture! How User Participation Transforms Cultural Production. Amsterdam: Amsterdam University Press, 2011.

Shifman, Limor. Memes in Digital Culture. Cambridge (MA): MIT Press, 2013.

Shildrick, Margrit. Leaky Bodies and Boundaries: Feminism, Postmodernism and (Bio)Ethics. London: Routledge, 1997.

Sunstein, Cass R. \#Republic:Divided Democracy in the Age of Social Media. Princeton, Oxford: Princeton University Press, 2017. 
Thibodeau, Paul H., and Lera Boroditsky. 'Metaphors We Think With: The Role of

Metaphor in Reasoning'. PLoS ONE, vol. 6, no. 2, 2011.

Trottier, Daniel. Identity Problems in the Facebook Era. New York: Routledge, 2013.

-. Social Media as Surveillance: Rethinking Visibility in a Converging World.

Farnham: Ashgate, 2012.

Tufecki, Zeynep. Twitter and Tear Gas: The Power and Fragility of Networked Protest.

New Haven: Yale University Press, 2017.

Wald, Priscilla. Contagious: Cultures, Carriers, and the Outbreak Narrative. Durham

(NC): Duke University Press, 2008.

\section{About the author}

SARA POLAK (Leiden University Centre for the Arts in Society) is assistant professor in American Studies, focusing on US presidents and their media. She wrote "This is Roosevelt's World" - FDR as a Cultural Icon in American Memory (Johns Hopkins University Press, 2021) and co-edited Embodying Contagion: The Viropolitics of Horror and Desire in Contemporary Discourse (University of Wales Press, 2021). She currently focuses on Trump's Twitter use. Polak teaches American literature, culture and history, and regularly comments on US politics and culture in Dutch media. 


\section{Histories of Online Vitriol}





\title{
4 Historical Prefigurations of Vitriol
}

\author{
Communities, Constituencies and Plutocratic Insurgency
}

Frans-Willem Korsten

\begin{abstract}
The historical pivot of this chapter is the baroque 17 th-century Dutch Republic where the rapidly developing printing press facilitated new forms of masking and of speed. Masked speaking allowed an anonymity in which communities came to intermingle with constituencies. In the current situation, the often used phrase of 'online communities' needs scrutiny, for there is little that makes such groups communities. They are entangled with social businesses and lack a complicated texture. Vitriolic online collectives are much like the religious constituencies in earlier times, in that they depend on iconic figures or platforms that attract and form groups and that vilify one another. Vitriol has become a form of socio-symbolic capital, partaking in neoliberal insurgencies that superimpose constituencies over communities.
\end{abstract}

Keywords: rhetorical maskedness, vitriol's speed, community, constituency, neoliberal insurgency

'Fascism attempts to organize the newly proletarianized masses while leaving intact the property relations which they strive to abolish. It sees its salvation in granting expression to the masses - but on no account granting them rights. The masses have a right to change property relations; fascism seeks to give them expression in keeping things unchanged. The logical outcome of fascism is an aestheticizing of political life. [...] All efforts to aestheticize politics culminate in one point. That one point is war.' - Walter Benjamin, Epilogue to The Work of Art in the Age of Mechanization

Polak, Sara, and Daniel Trottier (eds), Violence and Trolling on Social Media. Amsterdam, Amsterdam University Press 2020 DOI: $10.5117 / 9789462989481$ CHO4 
Figure 1 Pepe the Frog, 'This is what the most important memes used by extremists mean'

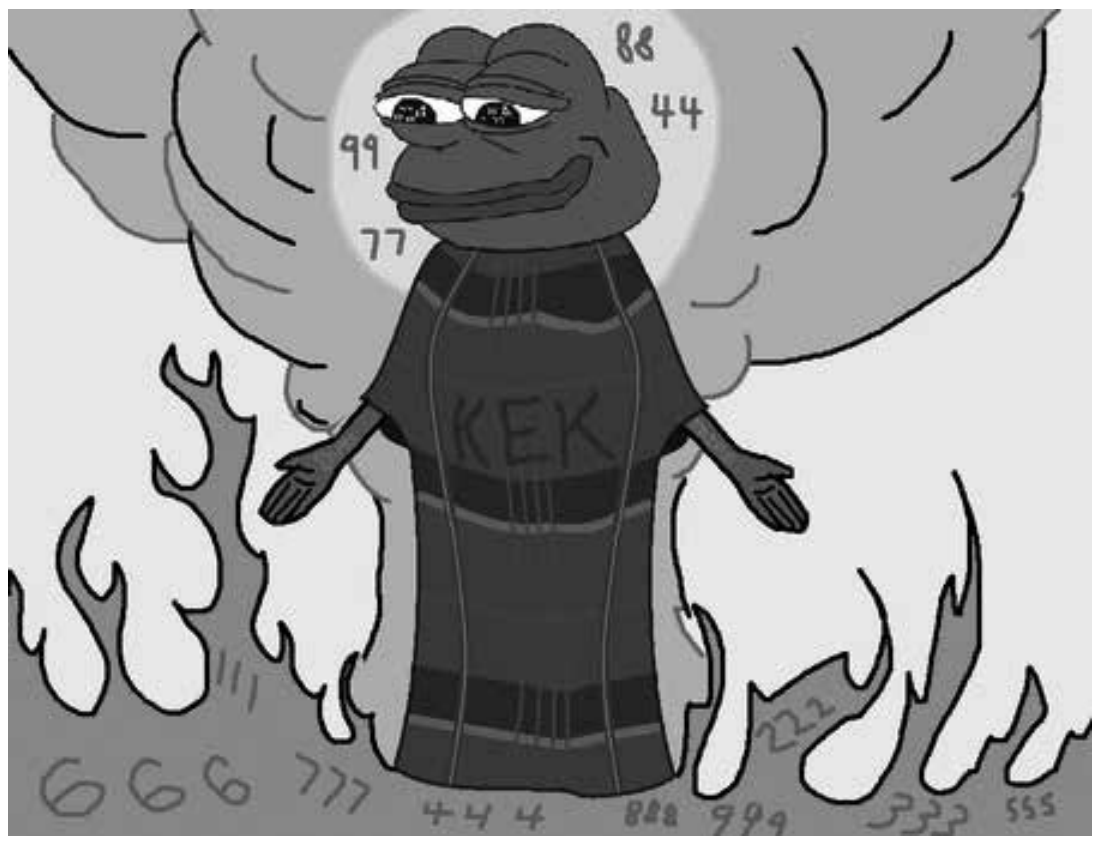

De Correspondent, 30 May 2018

This chapter looks at some pivotal historical prefigurations of vitriol, with a focus on vitriol's use of masks and need of speed - its 'going viral' - in relation to either communities or, better, constituencies. Nasty, masked speech was paradigmatically embodied first by the classical Greek god Momus, who would use masks to mislead or counter divine power and to create chaos. Not coincidentally, he also happened to father Rumor. ${ }^{1}$ There are other historical prefigurations, to be sure. The Dutch online news medium De Correspondent, for instance, reproduced the image above in a contribution titled 'This is what the most important memes used by extremists mean'.

In this case the infamous Pepe the frog is clothed as the god Kek, Egyptian god of chaos, who watches the world burn. ${ }^{3}$ It might be an allusion to Steve Bannon, at some point the dominant voice of Alt-Right, who propagated

1 I will be using Rumor to indicate the god, rumour to indicate its everyday manifestation.

2 Tokmetzis, 'Dit betekenen de belangrijkste memes'.

3 Pepe the frog has real historical resonances, here. The Egyptian god Kek of Kekui was sometimes depicted with the head (not the mask) of a frog. 
the total destruction of the political system so that a new one might arise. ${ }^{4}$ As De Correspondent explains, Kek is also a term used in circles of fervent gamers, indicating fun or lol ('laugh out loud'), and it is at the basis of a virtual world: Kekistan. Still, Kek has been given a mask here, namely of Pepe. It is the both destructive and aggressively comical play with masks that is so characteristic of vitriol, and this play starts with Momus.

The functional aspect of memes, if one knows how to read the masks used, is double: they spread easily, with speed, and their message is both informative and suggestive, connoting rumour. With respect to these, I will first be looking at specific aspects of historical prefigurations of online vitriol connected to Momus, like his fathering Rumor. Its speed in classical antiquity was rather a metaphor for something else: rumour's uncontrollable spreading. Via a short detour on how medieval rumour was positively defined as talk that offered vital and valuable information to communities, I move to a qualitatively different form of masked-ness and speed in the early modern period, when vitriol's speed was technically made possible by a rapidly developing printing press. Here, people's talk came to be orchestrated in the service of powers that aimed to vectorize public debate antagonistically. In that context communities came to intermingle with constituencies and masked speaking came to facilitate an anonymity that worked to cook up political struggles. A third phase brings us to the current situation in which masks and speed have acquired an independent value in relation to forms of public talk that serve as both symbolical gratification and distraction. Here, vitriol will be considered as a form of socio-symbolic capital, partaking in neoliberal insurgencies that superimpose constituencies over communities.

\section{Defying sovereign power: The functions of masks and rumour's force}

Between 1443 and 1450 the Italian artist Leon Battista Alberti wrote a satirical story in Latin titled Momus. ${ }^{5}$ Existing as a manuscript first (it would be published after Alberti's death, in 1520), it was probably meant to be told or read at the court of one of Alberti's protectors: a prince. The text played with the rather popular medieval and early modern genre of the speculum principes, the Fürstenspiegel or mirror of princes, which was a genre that 
specifically told princes or leaders how to behave. ${ }^{6}$ Yet, only at the very end of the story the prince, as the symbol of political harmony and order, is addressed and given advice. Before that the text is a paradigm of what in modern times would come to be called a negative aesthetics, presenting a continuing series of nasty or dirty tricks performed by the protagonist Momus. The latter is a classical Greek god who would be taken up as an important character in the renaissance and baroque. From the eighteenth century onward he would disappear from view, but can still be traced in the English word 'mummer', a mime player, derived from French momer: to disguise oneself. Indeed, Momus is the god of masks. As a son of Nyx, goddess of the Night, he is a dark force. He would be the perfect patron saint for online vitriol, for he was the god of taunting, flouting and unfounded criticism.

This is how the most recent translator and editors, Sarah Knight and Victoria Brown, summarize the first part of Alberti's story in their introduction. ${ }^{7}$ After Jupiter has commissioned the gods to provide the Earth with useful objects, Momus 'criticizes the efforts of other deities, and unleashes a plague of biting insects upon the world. Momus' duplicitous lover, the goddess Mischief, plots to have him exiled from Olympos, and tricks him into treacherous statements about Jupiter's regime. Jupiter discovers Momus's disloyalty and the other gods demand that he be punished.' Fleeing to earth, Momus 'poses first as a poet, then as a philosopher to spread slander against the gods and foment atheism.' So the gods send Virtue, together with her children Praise, Trophy and Triumph, to get Momus back on the right path. Yet being the god of deceit, Momus can change into anything he wants, and now he changes himself into the ugly Thersites, who then turns beautiful because of relentless prayer. Momus's tactic, here, is to make all women pray so that the gods will be overwhelmed with prayer, 'making them cantankerous,' because they now are forced to work. Then he goes to the temple of Justice, where Virtue holds sway, and rapes her daughter Praise. Out of this enforced union a child is born: Rumor. The goddess Fortune immediately realizes what a dangerous force has now come into being and 'urges Hercules, Praise's suitor and Momus's enemy, to capture Rumor'. Yet

6 For an overview, see Bejczy and Nederman. Princely Virtues in the Middle Ages. Peter Stacey builds forth on Quentin Skinner's analysis of Macchiavelli's The Prince and its indebtedness to the genre, by pointing to its classical prefigurations: Stacey, Roman Monarchy and the Renaissance Prince, pp. 4-5.

7 Brown and Knight, 'Introduction'. 
Rumor 'flies up to heaven dragging Hercules with her' and deposits him in the house of Mars' ('Introduction', viii-ix).

Alberti's story illustrates a dominant characteristic of vitriol throughout the ages, which is not only that it prefers to appear masked, but that it can easily swap masks and positions. Moreover, Momus is not only a figure of multiple masks, but he also turns into an allegorical meta-mask, one that speaks to Alberti's time in terms of a classical other. Due to the character's mask and its allegorical doubling, Momus may invoke laughter. It is a form of laughter, however, that has little to do with humour because there is always pain involved, the pain of others and that inflicted on others. A specific case is when Momus rapes Virtue's daughter, Praise. The result is Rumor. With respect to this, one function of the masks is that without them the infliction of pain would be too real. The other function is that the masks work in a carnevalesque context, in which divine or sovereign powers are being defied and defiled, or temporarily subverted. ${ }^{8}$

Momus's carnevalesque behaviour and unreliability confuses the gods and they are not inclined to invite Momus in their tent to have him take a piss out, though as a result they run the risk of his pissing in from the outside (I am referring here to a phrase by US president Lyndon Johnson on J. Edgar Hoover, first director of the FBI, that he had rather have him piss out than piss in; quoted in The New York Times of $3_{1}$ October 1971). This is why the gods want Momus out of the vicinity of their tent. Still, at some point he suddenly appears to have his uses. He makes people pray more than they did before. So Jupiter invites him back. Then Momus starts to plant the idea in Jupiter's head that the world, especially mankind, should be destroyed in order to make it craftily anew again, an idea that will keep the gods busy for most of the rest of the story. Here Momus loses his carnevalesque nature of playfully subverting order and turns into a demiurge or some sort of engineer; a chilling prefiguration of modern figures. The crafty, playing, both masked and masking, carnevalesque Momus comes to prefigure a political actor that we know from futurist manifestos with their fiat ars - pereat mundus: let art rule even if the world perishes. Or Momus manifests himself in line, here, with what Dutch philosopher Hans Achterhuis defined as the key marker of utopian thinking: the world that is has to be destroyed first before we can get to the ideal situation of a new world (also Steve Bannon's favourite

8 Probably the Netherlands' first carnevalesque society, founded in Maastricht in 1839, named itself Momus; see http://www.mestreechtersteerke.nl/paggebmomus.htm. Last accessed March 2018. 
scenario, as we saw above). ${ }^{9}$ That is to say: Momus may prefigure all those that find 'anything better' than current circumstances, or all those types that want to destroy the status quo by organizing chaos, so that the world can be built anew.

Considering Momus as a possible prefiguration of vitriol, I found the following aspects to be of interest: 1. Momus wants to destroy order or harmony. Yet would he be living in disorder he would start to promote order, just to be able to destroy it again. In this sense he is not a truly political actor that wants to build or make worlds but one that wants to destroy worlds. Making one anew serves only the purpose of its possible destruction. 2. Accordingly, he may act rhetorically but he lacks a proper, rhetorically convincing goal. One could, for instance, ethically defend an actor who strategically wants to unveil the hypocrisy of gods. Yet Momus does not mind hypocrisy for ethical reasons nor does he have a true strategy to counter such hypocrisy. He works mostly through tactics, 'acts of arrangement'. He is much like a stage director setting up his own theatrical scenes. 3. As senseless as it is to ask what motivates Venus to be the goddess of love or Mars the god of war, as senseless is it to ask what motivates Momus's actions. In a classical frame of mind, in the context of an honour and shame culture, his lacking understandable intentions and motivations imply that Momus will not, and cannot, be brought to justice. He only can be fought. 4 . When he has fled to Earth, Momus poses as poet or philosopher. One could consider these two as the epitome of hypocrisy, in their capacity to say whatever one wants, yet Momus's impersonation also symbolizes the radically open potential in language. If literature's task and aim, in the end, is 'to say all' as Derrida wanted it, this also implies the possibility of a relentless production of filth. 5 . His being a poet/philosopher, finally, leaves open the possibility that Momus embodies the radical potential in and of critique. This, at least, is why he was considered positively by humanists such as Erasmus and Giordano Bruno.

The latter, in The Expulsion of the Triumphant Beast, used Momus to criticize the corruption and perversion of ruling elites, especially the allpowerful Catholic church. ${ }^{10}$ At the same time Momus was also considered negatively, as when Martin Luther compared Erasmus to a modern Momus because of what Luther considered to be Erasmus' sacrilegious standpoints. ${ }^{11}$

9 Achterhuis, De Utopie van de Vrije Markt.

10 Giordano Bruno, The Expulsion of the Triumphant Beast.

11 Arnoud Visser states it as follows, quoting from Luther's Tischreden (book 1, no. 811): 'It confirmed his image of Erasmus as a new Momus, the ancient god of satire, who 'ridicules and plays with everything, the entire faith and Christ.' To this end, Erasmus was 'thinking up 
The mask of Momus, and by implication vitriol, has a double function, then, in relation to power. The Momus mask serves those who speak against power; or helps those who run a risk. Yet Bruno's using Momus as a mask did not avoid his dying on the stake. The reason may be that the Momus mask can also serve those in power to accuse a speaker of being a Momus. Or, whereas on the one hand Momus can be used as a mask to hide from ruling powers in order to look for some form of freedom of speech, on the other hand he can be used as a mask that serves to vilify those to whom the mask is applied. As Luther's attack on Erasmus illustrates, the name of Momus worked as a meme that was functional in what would later become shaming, or a shitstorm.

Using Momus as an easily readable meme to attack others with, introduces the aspect of speed and of suggestion. Both are addressed in Alberti's text when Momus rapes Praise as a result of which a new creature comes to life: Rumor - a semi-divine creature with wings. Ovid, in the $12^{\text {th }}$ book of the Metamorphoses, tells that Rumor has his palace at the connecting point of sky, earth and seas in a palace that is made of brass so that it can amplify and echo everything. This is an index to the kind of speed at stake. Rumor does not surprise or have power because it can move faster than a horse (it cannot, in Ovid's and Alberti's world). Rather, horses can only speed towards one goal and get tired in the course of it, while rumours swerve and swirl to all sides while gaining energy. ${ }^{12}$ Rumours do not have speed, that is, they rather suggest speed, in their uncontrollable spreading to all sides, as a result of which they pop up at unexpected places and come to have a force that has outgrown any original source. Allegorically captured in the figure of Rumor, rumour becomes a separate subject with independent agency that has a powerful and potentially disturbing or destructive function when it can 'fly' to all sides, as it could in Rome or, by extension, in the Roman empire.

Still, rumour also had a positive value in the context of the construction and functioning of medieval communities. In the early $13^{\text {th }}$ century, Pope Innocent III stated: 'It is not so much that the judge is himself the accuser; rather it is as if fama were accusing and clamor denouncing.' Here, fama came to indicate, positively, 'the voice of the injured community' and as such it became immensely important in the medieval honour and shame culture, to the extent that even when no explicit complaint had been brought 
forward, city judges could use fama as a motivation for inquiry. ${ }^{13}$ In other words: fama was valuable information, pronounced by 'a sort of collective voice.' ${ }^{14}$ This is why in The Politics of Talk and Reputation in Medieval Europe Thelma Fenster and Daniel Lord Smail use the term 'talk', to avoid the pejorative term gossip. The latter acquired its bad name in the $18^{\text {th }}$ century, but etymologically means godsibb ('relative in God'), connoting the talk people had at happy or festive events. Happy talk was community talk, then, and fama was pivotal when the community was somehow injured. In this context, fama was informative and had a shaping force: It was the expression of an existing community or something used to restore or establish a community.

Yet when the medieval world changed into the urban mercantilist and legalized culture of early modern Europe, fama, as community talk, also changed in nature. At first it 'was fleeting, aspectual and notoriously protean; it was a process, rather than the fixed, unchanging memory that written records necessarily convey to us. ${ }^{15}$ Yet in the late Middle Ages, 'the capacity of talk to serve as legitimate and widely acknowledged legal, social, and moral agent' came to be taken up by professional agents, operating in the service of bureaucracies. ${ }^{16}$ Fama became an essential component in courts of law where what people said about something or someone, as 'common knowledge', would become fact. ${ }^{17}$ The performative changed into constative as a consequence: talk became fact. In the process fama not only came to replace the ordeal as a mode of proof, ${ }^{18}$ it also lost its suggestion of speed because it was written down and archived. Coincidentally, it changed colour in terms of gender because knowledge was common on the basis of talk or gossip that was predominantly a female affair, while in courts it became a male issue. ${ }^{19}$

The move from fama on the floor of daily society to the legal system implied different functions in the service of cultural homogenization or cultural hegemony and growing state control. It was also intrinsic to a shift from what was an honour and shame culture to a culture that was based, in a fully Christianized Europe, on internalized and

13 Steinberg, Dante and the Limits of the Law, pp. 19-20.

14 Bettoni, 'Fama, Shame Punishment and Metamorphoses'.

15 Fenster and Smail (eds), Fama. The Politics of Talk, p. 6 (Introduction).

16 '...in medieval societies, talk did many of the things that in modern society are handled, officially, by bankers, credit bureaus, lawyers, state archives, and so on', Fenster and Smail (eds), Fama. The Politics of Talk, p. 9 (Introduction).

17 Kuehn, 'Fama as a Legal Status in Renaissance Florence', p. 29.

18 Hyams, 'Due Process versus the Maintenance of Order in European Law', p. 82.

19

Kuehn, 'Fama as a Legal Status in Renaissance Florence', p. 34. 
provable guilt, and by implication liability. This is why 'bad talk' would become punishable, in its being maliciously disinformative. It became a prefiguration, that is of fake news. Now that valuable and trustworthy information had become the domain of experts, the question became what role was left for public, community talk. I move to a second phase in the genealogy of vitriol.

\section{Fuelling antagonism: Communities intermingling with constituency}

In Dutch the genre of the schimpdicht has a rich history, so rich that it has two synonyms: hekeldicht and scheldgedicht. In English satire is the average translation; in German Spottgedicht, in French satire, brocard, flèche. Yet the Dutch verbs beschimpen, hekelen, and schelden are not so much satirical as vitriolic in nature. They mean: to scoff; to jeer; to denounce; to decry; to castigate; to curse; to scold; to swear; to call names. The aggressive and potentially violent type of poetry of the 'hekeldicht' is abundantly present in the $17^{\text {th }}$ century Dutch Republic, in the context of a fierce and decades-long political battle between Dutch Republicans and Orangists, who longed for a quasi-royal ruler for the Dutch Republic. One such ruler was prince William III of Orange (1650-1702), who was behind a flood of vilifying pamphlets, mostly anonymous ones, or written under a pseudonym in the period leading up to a pivotal year in Dutch politics, 1672 , that would definitely end the republican nature of the Republic. ${ }^{20}$

With Momus the mask was functional to subvert power, or to protect the radical speaker against supreme powers. With fama, considered as the collective voice of an injured community, public talk had to appear mask-less even if its original source would not be known. It concerned what one had heard, and one who had appeared masked could be punished for arousal and bad talk. The $17^{\text {th }}$ century masks, however, were used in the context of what one could call free, public speech. Here, masks were used in the service of a power that secretly wanted to close down the public political realm while using that public realm's space of freedom. It is telling that John de Witt, the political, republican leader of the times and proponent of 'the true freedom' had recurrently asked the prince to stop his attempts to rouse the sentiments of the common folk, who for more than a century had supported the house of Orange. 
For this arousal, William of Orange made use of the astounding developments in the Dutch printing press. Pamphlets could be made almost impromptu and spit out in numbers with great speed. The speed of rumour that was formerly only metaphorical, a matter of suggestion, now made way for technically produced real speed, that effectively made public debate as a debate impossible. Speed served forms of arousal, which, most of the time, tapped into earlier moments of disruption (an issue central to the second chapter in this section). For instance, almost half a century before the pivotal year 1672 , stadholder Maurits had organized the execution of another state pensionary, Johan van Oldenbarnevelt, who was, like John de Witt, the Republic's most important public official. This older figure, from 1618 , could easily be fused with de Witt, as in this poem:

The ghost of Oldenbarnevelt, enemy of the land, arch-traitor Come back to life in De Wit, cursed by the common folk As bastard, piece of shit, and son of such progenitor Born only to trample the country's prosperity Is brought here next to him, comparable in virtue and deeds Two enemies of the state (each in turn)

Betraying church and fatherland by perjuries

In such a way that even baby's eyes'd come to burn

Who have nevertheless received their deserved reward One, on the court's scaffold, had his head chopped off first The other was trampled, heart-ripped, hung, and torn apart Because of a rightful revenge, swollen till it burst. ${ }^{21}$

The verbal violence is both performative and constative, here. In 1672 , circles around William III had organized a lynching party in the course of which the bodies of John and Cornelis de Witt had not just been mutilated but had been torn apart, intestines had been eaten raw, their hearts had been ripped out and their naked bodies, or what was left of them, were

21 ' $t$ Leven en Bedrijf van Mr. Jan van Oldenbarnevelt nagevolght van Mr. Jan de Wit.' Knuttel 10433: 'De geest van Barnevelt, 's Landsvyant, aartsverrader. / Herlevende in de Wit, vervloekt van het gemeen, / als Bastaart aterlingh, en Zoon van sulk een Vader: / Gebooren om 's Lantsheyl met voeten te vertrêen; / wort hier by hem gepaart. Gelijk in deuchde en daaden. / Twee vyanden van Staat, (maar ider op sijn beurt:) / om Kerk en Vaderlandt meijneedich te verraden, / Daar noch den Suygelingh sou hebben om getreurt; / Maar hebben (Godt sy dank) hun loon na werk ontfangen, / den een op 't hofschavot ten kosten van zijn Kop. / Den anderen vertrapt, onthart, verscheurt, gehangen, / Van rechtgetergde wraak, gesteegen hoogh in top'. 
hung, publicly, in the centre of The Hague. The poem forgets to mention that body parts were traded.

This brutal violence did not come out of the blue. On the morning of lynching day a text was hammered on the door of The New Church, in the centre of The Hague and close to the prison where de Witt's brother, Cornelis, had been tortured and was still imprisoned. It said:

Belzebub is writing from hell

That Kees de Wit is done for, arrive he shall,

He is waiting for him in the coming day

But first his head should be chopped away

And his brother is a villain too ${ }^{22}$

The one who was probably responsible for this text was preaching a day later, in a church filled to the brim, that the murder on the brothers was the revenge of God: a clear hint of how the political, the religious and the cultural coincided. The Orthodox Protestant desire for a state religion matched the Orangist's longing for the conflation of royal house with state. In contrast, the brothers de Witt belonged to the more tolerant parties, who saw religions flourish in a Republic for all. The battle between the two concerned an irreconcilable difference in the distribution of power and the organization of public space. Were regents in charge and did religion have a subservient place, or was religious rule to be fused with that of the sovereign? Was public space to be like the inner court of a ruler's house of should it be as open as a market? The models were not just different but disparate, and political agonism easily toppled over into antagonism. ${ }^{23}$

As the very term antagonism suggests, one can hardly speak of public debate, in the $17^{\text {th }}$-century context. Rather, radical parties were battling one another, not just Catholics, and radical Protestants or atheists, but also Anabaptists, Coornhertists, David-Jorists, Arminians, Gomarists, Socinianists, or Vorstians, ${ }^{24}$ and others. They all were fighting to have

22 The minister responsible for the text was called Simon Simonides. In the original: 'Belsebub schrijft uit de Hel / Dat Kees de Wit haast komen zel / Hij wacht hem in korte dagen / Maar zijn kop moet eerst zijn afgeslagen / En zijn broer is ook een schelm' See Van Gemert, 'De Haagsche Broeder-Moord: Oranje ontmaskerd'.

23 I am referring here to a distinction made by Chantal Mouffe, with her pivotal distinction between politics and the political in On the Political.

24 For instance, Vorstians were followers of Conrad Vorstius (1569-1622) who was asked to occupy the seat in Leiden University that was left empty after the death of Arminius. 
a voice, to establish a constituency, in an endeavour to establish a new world. The difference between community and constituency is pivotal in this respect. If citizens were tied to existing communities at first, they could also become part now of new entities that depended on leading, often charismatic figures who would parade, explicitly or implicitly, as a new Messiah. In this context, conceptually speaking, 'the Dutch Republic was not the solution to a political problem. It rather posed the problem of the political. Being ruled by a king first, the Low Countries had to solve the problem of how to rule themselves. ${ }^{25}$ In having to rule themselves, the Dutch had to be able to deal with radical cultural diversity in a dynamic that was driven as much by flexible constituencies as by relatively stable communities. A key problem, in this context, was not so much how to choose for one world instead of another, but how to keep the body politic together, either as one homogenized house, or as the complicated texture of peoples with different interests and cultures. As we will see in the next part of this chapter, it is this work to keep the body politic together that is exploited by vitriolic actors.

If vitriol is aiming at antagonizing the body politic, this is indeed the opposite of what one could call a public debate. Moreover, once in play, it is difficult to stop the antagonism. This is evidenced by the fact that, almost a century later, the political split that characterized the Dutch Republic re-materialized in the 'war of the de Witts' in 1757. It was a culture war of public debate in journals, newspapers and pamphlets, defending or attacking the republican brothers. One such pamphlet is shown below (Figure 2) ${ }^{26}$

The print shows men who crush pencils or cut texts with a knife, thus allegorically indicating a war of words. The first line of the poem underneath the etch reads: 'How is fama still roaring with her raw trumpets / about the innocent blood... ${ }^{27}$ Here, fama is informative in pronouncing out loud that innocent victims have fallen by the hands of tyrants. The big book in front is defined as the Bible of the Synod: an index to the Calvinist endeavour to install a monopoly by state religion. The both literal and figural violence comes, then, from the side of the so-called tolerant, republican Arminians who are fighting the texts that were used to legitimate the murder of those who, in their eyes, were innocent.

Korsten, A Dutch Republican Baroque, p. 22.

26 'Spotprent op de strijd tussen arminianen en calvinisten over de geboeders De Witt en de prinsgezinden, ca. 1758, anonymous, 1756-1759', Rijksmuseum Amsterdam; https://www.rijksmuseum. nl/en/collection/RP-P-OB-84.50o. Accessed March 2018.

27 In Dutch: 'Hoe schatert noch de faam met haren rooue trompetten / over het onnoosel bloet $[\ldots]$. 
Figure 2 'Cartoon about the fight between Arminians and Calvinists about the De Witt Brothers and the royalists'

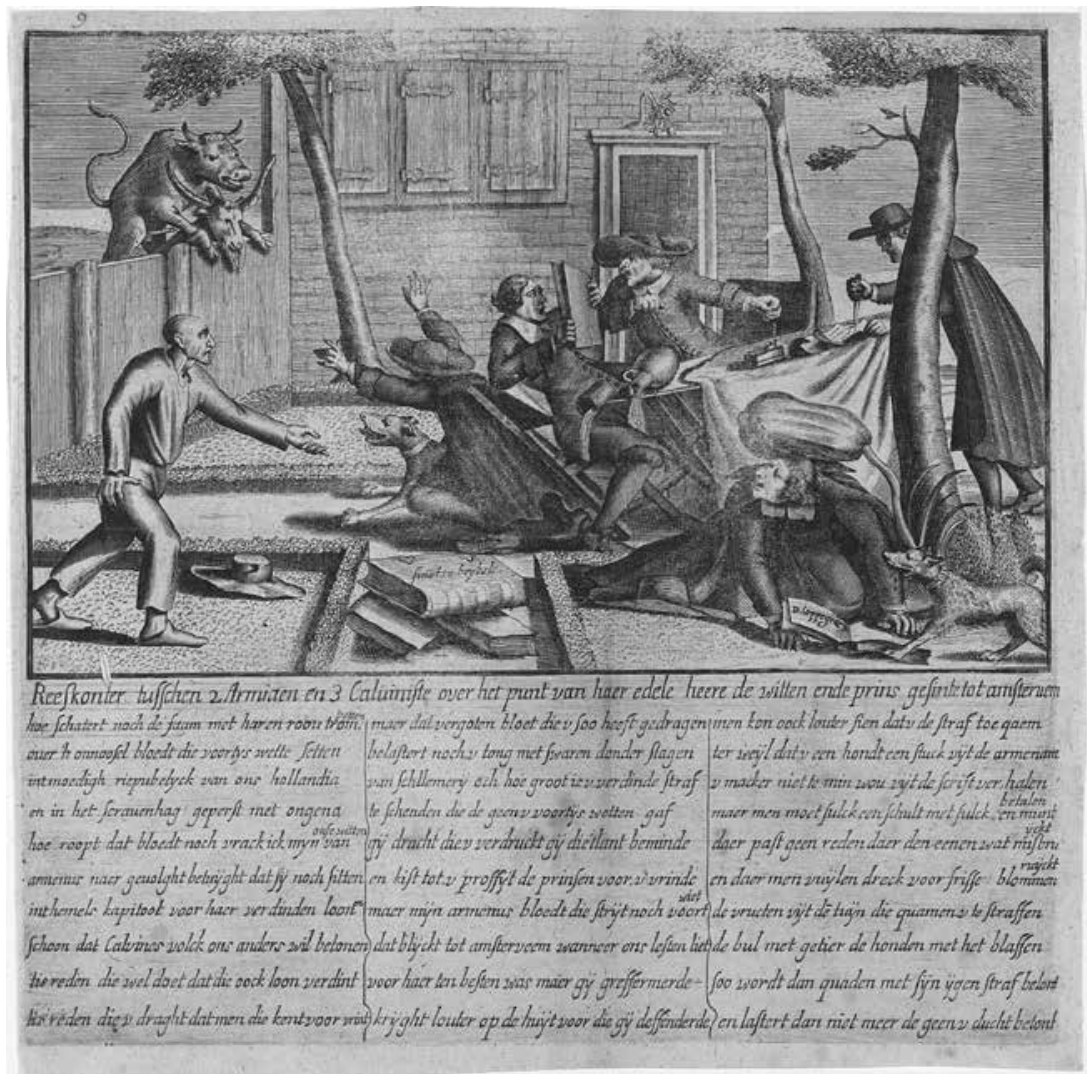

Ca. 1758, Anonymous, 1756-1759, Rijksmuseum Amsterdam

In relation to the previous medieval phase, we see a reversal, here, of the use of fama. When historiography had come to work in the service of political powers, talk became the domain where repressed voices could be heard. Its defining marker was no longer speed but its unstoppable, time transcending potential. Speed had become the prerogative of the printing press. This, in turn, has come to change in our times, now that slow, or time transcending collective talk has acquired a technologically enhanced speed, as a result of which collective talk and writing come to be conflated, and a battle about the informative quality of public talk ensues. Whereas in the medieval context experts had come to take over trustworthy information from fama, claiming it as their domain, nowadays public talk has come to 
target experts as untrustworthy, paradoxically claiming back an informative status while using all the qualities of fictitious rumour.

\section{Online communities as constituencies}

One can pick a paradigmatic case every hour of the day, but let me take one of three Dutch journalists, Rosanne Hertzberger, Loes Reijmer, and columnist Heleen Mees, who addressed the coincidence of vitriol, pornification and misogyny on two online Dutch news media: GeenStijl and Dumpert. The first literally means 'Nostyle'; it is a pun that might be translated as Badform. Dumpert, connotes the English 'to dump'. Both were, in first instance, platforms of TMG Digital, part of the Telegraaf Media Group - part of an official right-wing media group, that is, with a turnover of 35 million euros. Despite its being part of a journalistically oriented media group, the subtitle on the GeenStijl site perverted any journalistic attitude in stating: 'insinuating, unfounded and needlessly offensive. ${ }^{28}$ Perhaps they should have called themselves Momus. Whatever the name, in 2017 the site was visited monthly by 1.9 million visitors, while Dumpert with 8 million visitors got 151 million video views per month. ${ }^{29}$

Especially Loes Reijmer's critical article in the national newspaper De Volkskrant provoked a fierce reaction. On 25 March 2017 at 10:54 a.m., GeenStijl posted her photograph with the text: 'Would you do her?' The first response came at 10:56. Within hours, 254 derogative responses followed, published online, including rape phantasies, some elaborate. There were twenty-five comments on 26 March; the two last ones came in on 27 March; the rest was from the very same day, 25 March. Considering that several texts were repulsive, one wonders what the comments said that were removed, or what the persons who were banned from the site contributed. After years of intimidation, with a growing number of journalists being victim of online threats and insults, and a growing problem of self-censorship, two Dutch national newspapers, NRC Handelsblad and De Volkskrant, decided to publish a pamphlet in which companies that advertise on GeenStijl were asked to withdraw their money. Some of them did. In response GeenStijl published the

28 In Dutch: 'tendentieus, ongefundeerd en nodeloos kwetsend'; http://www.geenstijl.nl/. Tellingly, in June 2017, the new owner of TMG, Het Vlaamse Mediahuis, made public it wanted to buy and then sell GeenStijl, but then didn't.

29 https://www.rtlnieuws.nl/nederland/rel-met-adverteerders-geenstijl-kan-uitgever-tmgmiljoenen-kosten. Accessed July 2017. 
list of those who had signed the pamphlet. These were insulted, threatened or put on what one voice called 'an execution list'.

In terms of style, morality or ethics, the indecencies allowed, provoked, facilitated, or used by GeenStijl call to mind the comment of Joseph Welch when provoked by Joseph McCarthy during the Army-McCarthy hearings in 1954: 'Have you no sense of decency, sir? At long last, have you left no sense of decency?' The very McCarthy period may have been one of the first examples we have in modern times of media driven vitriol, which served the purpose of eliminating communism, the political alternative to capitalist, corporative democracy. The comparison may also serve to highlight how McCarthyism, with its anchors in several cultural currents and undercurrents, was more prominently a matter of producing new forms of constituencies rather than of mobilizing existing communities.

Despite the often used phrase of online communities there is little that makes these groups communities in the proper sense of the term. They are entangled with social businesses and lack the complicated texture of culture: a texture consisting of the nuances or differences that characterize a community not bound by one homogenous culture but consisting of a network of cultures. It may be clear, here, that I am talking about a different kind of community than the one glorified under fascism and Nazism. As Susan Sontag argued in her analysis of fascist aesthetics: "The exaltation of community does not preclude the search for absolute leadership; on the contrary, it may inevitably lead to it..30 Such exaltation is also at work in the attempts of the extreme right to reinvigorate national identities. Yet in the current circumstances it is the combined exaltation of community with the flexibility of constituency that propels neoliberal strategies and tactics. When Pierre Bourdieu defined neoliberalism as a relentless attack on collectives, he meant collectives that are cultural in nature. ${ }^{31}$ In contrast, vitriolic online collectives are much like the religious constituencies in the Dutch Republic, in that they depend on iconic figures or platforms that attract and form groups and that vilify one another. As bodies of constituents - people 'who appoint or elect a representative' - they form flexible and competitive wholes based on personal and stylistic ties. They use certain expressive forms of self-articulation or self-actualization, yet they miss pivotal elements needed for the cultural build-up of communities in the sense of their

31 As for communities in the context of neoliberalism, I follow the analysis of Kelly and Caputo, Community. 
connoting 'society, fellowship, friendly intercourse; courtesy, affability.' They are not cultural at all if we specify culture with Griselda Pollock as 'the imaginative faculty that can grasp multiple life worlds, different experiences, and the nature of change and the function of creativity based on work. ${ }^{32}$

Instead of being cultural in nature, allowing the formation, continuation or establishment of communities, vitriol is rather aesthetic in nature in the sense of an anti-aesthetics. The latter serves what Susan Buck-Morss defined as especially fascism's ability to tap in on a typically modern anaesthetized aesthetics, ${ }^{33}$ using 'media which rob our senses of experiential connection and instead drug us into a blank "aesthetic" enjoyment of self-destruction.' Vitriol's speed partly fits such a form of anaesthetizing aesthetics, yet can be explained differently still.

\section{Speed in the age of plutocracies: The subversion of power revisited}

Online vitriol is not concrete or meaningful in the sense of its having semantic use value. This would fall under the rubric of making sense by means of communication, like talk that holds a community together on the basis of culture. The value of online vitriol consists in how it appears on a market of exchange, much like a discursive commodity. Here, online vitriol's real speed gets another force. If it does not go viral, it means nothing, or has no value. Vitriol only superficially resembles early modern rumour, here, with the printing press spitting out pamphlets. Its desire and ability 'to go viral' within hours, lingering on for some days, but often not much longer, embodies something else. Speed has gained an independent value, in some sense valued higher than content. I read vitriol, here, not so much as an analogy to, but as a symptom of a neo-liberal capitalism that resonates with the first anarchic phase of capitalism in the late $18^{\text {th }}$ and early $19^{\text {th }}$ century, as a form of anarcho-capitalism. ${ }^{34}$

I am following the analysis here of Chrystia Freeland, who before she became minister of Foreign Affairs of Canada wrote Sale of the Century (2000), sketching Russia's transition from communism to anarcho-capitalism, and Plutocrats: The Rise of the New Global Super-Rich and the Fall of Everyone 
Else (2012). Moreover, I follow the analysis of Robert J. Bunker and Pamela Ligouri Bunker in Global Criminal and Sovereign Free Economies and the Demise of the Western Economies: Dark Renaissance (2014). Bunker and Bunker describe two insurgencies that are taking place simultaneously: one plutocratic in nature, embodied in the international elite of the ultrawealthy; one criminal in nature, embodied in the 'deviant globalization's winners', as Nils Gilman (historian in global developments and author of Mandarins of the Future, 2004) defined them in his foreword:

Unlike classic twentieth-century insurgents, who sought control over the state apparatus in order to implement social reforms, criminal and plutocratic insurgents do not seek to take over the state. Nor do they wish to destroy the state, since they rely, like parasites, on the state to provide the legacy goods of social welfare [...] Rather, their aim is simpler: to carve out de facto zones of autonomy for themselves by crippling the state's ability to constrain their freedom of (economic) action. ${ }^{35}$

Online vitriol partly partakes in this double insurgency. It does not speak against real power, but serves the real powers that want to weaken the state. For instance, the multi-billionaire Koch brothers in the United States, of Koch Industries, which made its basic capital with cracking techniques in the thirties and forties of the $20^{\text {th }}$ century, have funded multiple projects of disinformation, which have also produced vitriol..$^{36}$ The 'Competitive Enterprise Institute', for one, and funded in part by the Koch brothers, by mouth of Rand Simberg, targeted climate scientist Michael Mann by comparing him with a child molester. ${ }^{37}$ Much vitriol, moreover, is close to being criminal in the sense that it can be brought to court; some of it is allied to criminal organizations, whether these are political or so-called entrepreneurial in nature.

Those who truly own power, without being responsibly in power, know quite well how to aestheticize politics by means of vitriol, in order to avoid the mobilization of forces that want to change property relations for real. In this context vitriol can be seen as a topsy turvy form of what Pierre Bourdieu and Jean-Claude Passeron coined symbolic capital, with which they

35 Gilman, 'Foreword: the Twin Insurgency - Facing Plutocrats and Criminals', p. xx.

36 See http://www.ucsusa.org/global_warming/solutions/fight-misinformation/global-warmingskeptic.html\#.WT6hVMakLIU. Accessed March 2018.

37 See http://www.ucsusa.org/our-work/center-science-and-democracy/protecting-scientistsharassment/va-ag-timeline.html\#.WT6i_8akLIU. Accessed March 2018. 
indicated the not straightforwardly financial or economic possessions and capabilities of the French elite but a symbolic capital that was the opposite of social capital.$^{38}$ Whereas the first is, indeed, elitist and can be radically anti-social or shamelessly individual, the latter is collective and indeed socio-cultural in nature. With vitriol the two become perversely entangled as socio-symbolic capital: a collective form of anti-social, symbolic capital. And analogous to non-symbolic or concrete capital, it exploits public services, like the internet, and it feeds on something else, namely communal life.

Whereas the political realm consists in and due to conflict, or agon, the work of the body politic at the same time is to keep people together, respecting differing interests and socio-cultural differences. In other words, politics has to facilitate and guarantee a texture of cultures that does not exist as one unity, what one could call the fetish of the nation state, but that defines a political, that is to say internally conflicting, unit. The pivotal political work to accept such conflicts while avoiding dissolution, has become precarious nowadays because neo-liberal actors have succeeded in redefining the work of the body politic as labour, something that can be bought and exploited. In this context, vitriol affectively exploits communal life, using its attention and affective resources for the creation of socio-symbolic surplus value. Since time is of the essence, here, this explains vitriol's need of speed. There is nothing in terms of content, or use value, that needs to come on the discursive market with this speed. The speed is needed only to make a discursive profit. As a consequence, cultural expression gets a different nature and status.

In comparison with medieval talk, vitriol is a hybrid conflation of talk and written language that constantly moves to and from between being a performative and a constative. Talk and fact alternate. And whereas in medieval courts fama came to replace the ordeal as a mode of proof as information, in the case of vitriol fama is used to fuel a public ordeal on the basis of disinformation. Considered as a form of expression per se, vitriol 'talk' is a form of discursive possession and as such the opposite of what Giorgio Agamben defined as 'pure language', the language of a community to come. ${ }^{39}$ In contrast, online vitriol is an attack on culture, with culture defined as the complex texture that both holds together and empowers a communal entity with a living culture. In attacking this culture, vitriol is symptomatic of a neo-liberal capitalist system that has perhaps reached a 
limit, but not the limit of growing inequality. ${ }^{40}$ To avoid any serious dealing with this growing inequality, plutocrats grant peoples expression, while 'on no account granting them rights'. If capitalism celebrates the victory of the desire for possession over that of enjoyment, as Marx wanted it, vitriol should be seen in the light of possession rather than enjoyment. ${ }^{41}$ When Thorstein Veblen talked about symbolic capital, in Theory of the Leisure Class (1899), he indicated how the nouveau riche used displays of wealth to compete with upper classes that previously had been at untouchable social heights..$^{42}$ This dynamic appears now to have been reversed. Those who will never belong to the international elite, and have little money to mirror them because they belong to the parties exploited and marginalized by the processes of globalization, are granted to possess their own digito-discursive, socio-symbolic surplus value. They may feel this gives them some sort of purchasing power. In effect it gives them nothing but a hollow gratification.

In terms of historical comparison they are not part of a newly proletariarized mass, moreover, like in Walter Benjamin's times, for the current masses are split up, in a new kind of Lumpenproletariat and a precariate. Both are struggling to survive, the first by looking for the chance and the moment that they are given some sort of labour, the second by trying to stay desperately in the system. Both are inclined to form constituencies that are granted expression with all sorts of devices as a result of which they tend to forget that they have no real chance to change any property relations. The real financial surplus value owned by the plutocracies of this world, meanwhile, remains untouched, in its swiftly moving wherever it is safe for the time being. This is not to say that vitriol is simply the tool of an international plutocracy, the elite of the ultra-wealthy. Still, it has its function in arousing people's emotion on all sorts of topics, as long as the topic is not the enormous inequality of wealth and property. Any dealing with vitriol that considers it per se, misses the symptomatic nature of vitriol, that is to say: its mediated relation with neo-liberal insurgencies and current plutocracies. Such a dealing per se will mistake vitriol's anger for real whereas it is at best a veil, and more probably an entangled knot of despair and manipulated consciousness.

40 In The Death of a Discipline Gayatri Chakravorty Spivak distinguished between the global as 'the imposition of the same system of exchange everywhere' and the planetary - 'the planet is a species of alterity, belonging to another system; and yet we inhabit it, on loan' (Spivak, The Death, p. 72). This was a way of defining and distinguishing a whole that is marked by respect for difference in contrast with a system that imposes the same logic everywhere.

41 Marx, Economic \& Philosophic Manuscripts.

42 See Veblen, Theory of the Leisure Class. 


\section{Works cited}

Achterhuis, Hans. De utopie van de vrije markt. Rotterdam: Lemniscaat, 2010.

Agamben, Giorgio. Language and Death: The Place of Negativity, transl. by Karen

E. Pinkus. Minneapolis: University of Minnesota, 1991.

Bejczy, István P. and Cary J. Nederman. Princely Virtues in the Middle Ages, 1200-1500. Turnhout: Brepols Publishers, 2007.

Bettoni, Antonella. 'Fama, Shame Punishment and Metamorphoses in Criminal Justice (Fourteenth-Seventeenth centuries)', 24 March 2010, in forum historiae iuris, https://forhistiur.de/2010-03-bettoni/. Accessed 26 October 2018.

Bourdieu, Pierre. 'The Essence of Neoliberalism: Utopia of Endless Exploitation - What Is Neoliberalism? A Programme for Destroying Collective Structures Which May Impede the Pure Market Logic'. Le monde diplomatique, December 1998, https://mondediplo.com/1998/12/o8bourdieu. Accessed 26 October 2018.

— and Jean Claude Passeron. Reproduction in Education, Society and Culture. London: Sage, 1990.

Brown, Victoria, and Sarah Knight. 'Introduction', in Leon Batista Alberti, Momus, edited by Victoria Brown, transl. and edited by Sara Knight. New York: Harvard University Press, 2003, pp. vii-xxv.

Buck Morss, Susan. 'Aesthetics and Anaesthetics: Walter Benjamin's Artwork Essay Reconsidered'. October, vol. 62, Fall 1992, pp. 3-41.

Bunker, Robert J., and Pamela Ligouri Bunker. Global Criminal and Sovereign Free Economies and the Demise of the Western Economies: Dark Renaissance. London: Routledge, 2014.

Burton, Tara Isabelle. 'Steve Bannon Shares a Fascists Obsession with Cleansing, Apocalyptic War. And Now He's in the White House', https://www.telegraph.co.uk/ news/2017/02/07/steve-bannon-shares-fascists-obsession-cleansing-apocalyptic/.

Fenster, Thelma, and Daniel Lord Smail (eds). Fama. The Politics of Talk and Reputation in Medieval Europe. Ithaca-London: Cornell University Press, 2003.

Freeland, Chrystia. Sale of the Century: Russia's Wild Ride from Communism to Capitalism. Crown Business, 2000, London: Abacus, 2005.

-.Plutocrats: The Rise of the New Global Super-Rich and the Fall of Everyone Else. London: Penguin, 2012.

Fulcher, James. Capitalism: A Very Short Introduction. Oxford: Oxford University Press, 2004.

Gemert, Lia van. 'De Haagsche Broeder-Moord: Oranje Ontmaskerd'. Literatuur 1, 1984, pp. 268-276.

Gilman, Nils. 'Foreword: The Twin Insurgency - Facing Plutocrats and Criminals', in Global Criminal and Sovereign Free Economies and the Demise of the Western 
Economies: Dark Renaissance, edited by J. Bunker and Pamela Ligouri Bunker. London: Routledge, 2014.

Giordano Bruno. The Expulsion of the Triumphant Beast, transl. by Arthur D. Imerti. University of Nebraska Press, 1992.

Harms, Roeland. Pamfletten en Publieke Opinie: Massamedia in de Zeventiende Eeuw. Amsterdam: Amsterdam University Press, 2011.

Hyams, Paul. 'Due Process versus the Maintenance of Order in European Law: The Contribution of the Ius Commune'. The Moral World of the Law, edited by Peter Cross. Cambridge (UK): Cambridge University Press, 2000, pp. 62-90.

Kelly, Katherine, and Tullio Caputo. Community: A Contemporary Analysis of Policies, Programs and Practices. Toronto: Toronto University Press, 2011.

Korsten, Frans-Willem. A Dutch Republican Baroque: Theatricality, Dramatization, Moment and Event. Amsterdam: Amsterdam University Press, 2017.

Kuehn, Thomas. 'Fama as a Legal Status in Renaissance Florence', in Fama. The Politics of Talk and Reputation in Medieval Europe, edited by Thelma Fenster and Daniel Lord Smail. Ithaca, London: Cornell University Press, 2003, pp. 27-46.

Leon Batista Alberti, Momus, edited by Victoria Brown, transl. and edited by Sara Knight. New York: Harvard University Press, 2003.

Marx, Karl. Economic \& Philosophic Manuscripts of 1844 , transl. by Martin Milligan. Createspace, 2015 .

Mouffe, Chantal. On the Political: Thinking in Action. London, New York: Routledge, 2005 .

Pollock, Griselda. 'Saying NO!: Profligacy versus Austerity, or Metaphor against Model in Justifying the Arts and Humanities in the Contemporary University', in Against Value in the Arts and Education, edited by Sam Ladkin, Robert McKay and Emile Bojesen. London, New York: Rowman and Littlefield, 2016.

Sontag, Susan. 'Fascinating Fascism'. The New York Review of Books, 6 February 1975, https://www.nybooks.com/articles/1975/o2/o6/fascinating-fascism/. Accessed 26 October 2018.

Spivak, Gayatri Chakravorty. The Death of a Discipline. New York: Columbia University Press, 2003.

Stacey, Peter. Roman Monarchy and the Renaissance Prince. Cambridge (UK): Cambridge University Press, 2007.

Steinberg, Justin. Dante and the Limits of the Law. Chicago/London: University of Chicago Press, 2013.

Tokmetzis, Dimitri. 'Dit betekenen de belangrijkste memes die door extremisten worden gebruikt. De Correspondent, 30 May 2018, https://decorrespondent. $\mathrm{nl} / 8275 /$ dit-betekenen-de-belangrijkste-memes-die-door-extremisten-wordengebruikt/402967675-9cb17685. 
Veblen, Thorstein. Theory of the Leisure Class, http://moglen.law.columbia.edu/ LCS/theoryleisureclass.pdf. Accessed 1 March 2020.

Visser, Arnoud. 'Erasmus, Luther, and the Margins of Biblical Misunderstanding' in For the Sake of Learning: Essays in Honor of Anthony Grafton, edited by Ann Blair, and Anja-Silvia Goeing. Leiden: Brill, 2016, pp. 232-250.

\section{About the author}

Frans-Willem Korsten holds the chair by special appointment 'Literature and society' at the Erasmus University, and is associate professor at LUCAS: the Leiden University Centre for the Arts in Society. He published monographs on the Dutch baroque, theatricality and sovereignty, and published on the relation between literature, art, capitalism and law. He was responsible for the NWO internationalization programme 'Precarity and Post-Autonomia: The Global Heritage' (with Joost de Bloois - University of Amsterdam). With colleagues from Gent, Brussel and Amsterdam he recently finished a NWO/FWO programme on theatrical representations of violence under the acronym ITEMP: Imagineering Techniques in the Early Modern Period. He is currently working on justice and the role of literature and art at the limits of the law under the umbrella of CALL: the Centre for Art, Literature and Law. 


\title{
$5 \quad$ White Femininity and Trolling
}

\author{
Historicizing Some Visual Strategies of Today's Far Right
}

\author{
Ewelina Pepiak
}

\begin{abstract}
This section interrogates historical prefigurations of anti-immigrant online vitriol following sexual assaults that occurred during the 2015 New Year's Eve in Cologne. The study of the post-Cologne inventory of European far-right memes and internet portals draws on anti-miscegenation iconography and narratives that reach back to European imperialisms. Apart from cataloguing fairly well-documented dehumanizing representations of non-white men, it brings about an ambiguous figure of a white woman. While white women typically symbolize national dignity, they, too, have been perceived as unpatriotic traitors and stakes in biopolitical warfare on democratic institutions. After Cologne, online trolling closely resonated with some politicians' calls for more surveillance, arming citizens, expulsions of immigrants, and attempts at political recuperation of feminism on the far right.
\end{abstract}

Keywords: race and gender in colonial discourses, New Year's Eve in Cologne, Far Right memes, feminism and intersectionality, miscegenation

'Just as human productions cannot be divided into a desiring-production on the one hand and a 'material' production on the other, so also can men in power not be seen to have made that distinction in the process of establishing and consolidating their power. It was two aspects of a single conquest that set up white masters over the coloured nations of the world and placed the dominant male ego of the emergent bourgeoisie in a position of domination over women in his own society. He [white male - EP] would continue to employ those women as the colourful raw material for shaping the images and setting the boundaries that were so necessary to secure his domination' - K. Theweleit, Male Fantasies ${ }^{1}$

Polak, Sara, and Daniel Trottier (eds), Violence and Trolling on Social Media. Amsterdam, Amsterdam University Press 2020 DOI: 10.5117/9789462989481_CHO5 
Many of the current forms of vitriol follow a logic of biological and cultural supremacy. In the present-day European context, white supremacy discourses are informed by the colonial-era images of non-white populations' innate primitivism and deviancy. ${ }^{2}$ The present analysis reaches to historical prefigurations that determine the affective force of online violence and trolling. Recent racist and sexist images, depicting white women sexually harassed by non-white men, reflect the centrality of intersecting narratives of race and gender in articulating otherness. One of the most charged events that led to dissemination of such images online is the wave of sexual aggressions committed mainly by men of Algerian and Moroccan descent during New Year's Eve 2015/2016 in Cologne, Germany. ${ }^{3}$ Starting from a sample of images disseminated on the internet in the wake of the Cologne events, I move back to historical discourses that set deviant sexual behaviours of non-white men in contrast with a figure of a white woman. Stereotyping practices involving non-white male sexuality can be investigated from myriad angles, such as fetishization (fantasy) or stigmatization (taboo). ${ }^{4}$ This critical study of juxtaposing white femininity with non-white sexual violence epitomizes the historical preponderance of representing miscegenation in Europe as a threat. ${ }^{5}$ I focus specifically on past and present images and discourses closely resonating with the prevalent visual rhetoric after the Cologne assaults.

\section{New Year's Eve 2015/2016 in Cologne}

The sexual assaults that took place in Cologne during the New Year's Eve celebration in 2015 led to massive reactions in various media, and in political, academic and intellectual discourses. These reactions came in several waves and with varying intensity. Most online images including memes, tweets, and political cartoons, reflected the following logic: a) they denounced

2 Colonialist and imperialist preeminence of today's racist discourses is one of the most explored topics in postcolonial scholarship. On non-white rapist's representations see: Ware, Beyond the Pale.

3 The exact report regarding the events was published by Zeit Magazine on 23 June 2016. https://www.zeit.de/zeit-magazin/2016/27/silvesternacht-koeln-fluechtlingsdebatte-aufklaerung. 4 Hall, Representation.

5 'Miscegenation - marriage, cohabitation, or sexual intercourse between a white person and a member of another race' (Merriam-Webster). The term replaced 'amalgamation' and first occurred in a 1863 pamphlet written by two then-anonymous authors as an apology of mixing races, in an attempt to breed controversy around Abraham Lincoln shortly before the presidential election of 1864 . See: Miscegenation. 
presumably deliberate disinformation by the police and media, and $b$ ) they identified the perpetrators as Arabs, North Africans, Muslims, and/ or refugees. While the first narrative redirected the assaults to the matters of public security (immigrants as public threat, critique of diversity and multiculturalism), the second amounted to considerable visual racializing of the assaults. In the racially charged visual rhetoric perpetrators were framed as 'Arabs' and 'Muslims', both terms were used as synonymous with backwardness and violent behaviour, while 'rape culture' became a 'Muslim rape culture'. In mid-2015, an American anti-Muslim think-tank, Middle East Forum, published an article entitled 'Muslim rapists prefer blondes' containing claims of an 'ongoing epidemic' in Europe in which 'Muslim men sexually target white women'. ${ }^{6}$ Calls for more surveillance and collective punishment of both the Muslim population and the pro-immigration government were voiced to no-one's surprise: both are standard elements of far-right reaction to crimes committed by non-white perpetrators. However, post-Cologne trolling particularly capitalized on historical anti-miscegenation rhetoric and on the ongoing feminist ambivalence with regard to the interlocking categories of gender and race in dealing with representations of sexual violence. ${ }^{7}$

\section{'Silence hides violence'}

Since 2014, the opposition to the immigration policies introduced by the liberal German government has become part of a struggle for white supremacy. The events in Cologne sparked off numerous vitriolic reactions suggesting that the mainstream media and politicians are hiding the truth from the population. The provocative and polarizing female representations in the images and narratives after Cologne helped to redirect the question of sexism and racism to a debate on European security and cultural identity, two pillars of the far-right political programme. Postulates to save 'our' women were pronounced by organizations such as PEGIDA $^{8}$ and Alternative

6 Ibrahim, Muslim Rapists Prefer Blondes.

7 Hark and Villa, Unterscheiden und Herrschen.

8 Founded in Dresden in 2014, PEGIDA, or Patriotic Europeans Against the Islamisation of the Occident (Patriotische Europäer gegen die Islamisierung des Abendlandes) is an international political movement promoting nationalism, Christianity and denouncing Islam as a threat to 'the European values'. 
für Deutschland (AfD). ${ }^{9}$ The European Far Right - in Hungary the supporters of Victor Orban, in Poland the ruling extreme-right Law and Justice party, in France Front National, etc. - unilaterally politicized the Cologne aggressions as part of their securitization campaigns. They argued that the threat represented by the incomers was far greater than the mainstream media and politicians were willing to admit. During anti-Muslim protests following the aggressions in Cologne, PEGIDA demonstrators held a banner that read: 'silence hides violence'. The slogan targeted careful reactions uttered by German Chancellor Angela Merkel and Henriette Reker, the mayor of Cologne, following the news of the assaults. The \#einearmlänge hashtag referring to the advice given by Reker to German women to stay one arm's length away from foreigners resulted in memes accusing the female politician of betraying German women. Trending images featured white women armed against Muslim men (\#einearmlänge, \#stopIslam, \#taharrush). One of the memes depicted a fierce-looking blonde figure - adopted by the Far Right on various occasions. ${ }^{10}$ The caption reads: 'To avoid sexual assaults against women during the next Carnival of Cultures, this time I will vote AfD. That one-arm's-length distance simply does not hold'. (Figure 3). As a number of journalists and researchers acknowledged afterwards, the media's unwillingness to disclose the fact than many of the perpetrators were of North African origin legitimized the anti-immigrant far-right online outburst to a large degree. ${ }^{11}$ Much of the far-right trolling after Cologne focused on legitimizing neo-Nazi racial slurs arguing that silencing immigrant crimes and appraising the merits of multiculturalism should be interpreted as violent acts against the population. According to that rationale, the biological preservation of the white race could no longer be entrusted upon the existing power structures who fail to protect 'our' women. And inversely, white female representatives of the German society were depicted in the memes and slogans as renouncing their traditional

9 Since its foundation in 2014 out of disgruntled members and supporters of the centre-right CDU, Alternative für Deutschland has changed its anti-EU rhetoric and focused on criticising the pro-immigration policies of Angela Merkel. In 2014 AfD entered the European Parliament with 7.1 percent of votes (Vorländer et al., 2016, p. 52-53).

10 For instance, in the US Lana Lokteff and Tomi Lahren are among the white female faces of the Alt-Right. In the European politics some examples are Marion Marechal Le Pen and Marine Le Pen in France (Front National), and Corinna Miazga and Alice Weidel in Germany (AfD).

11 F. Klask, 'Die Stille nach der lauten Nacht', Zeit Online, 29 December 2017, https://www. zeit.de/2018/o1/silvesternacht-koeln-sexuelle-belaestigung-schweigen-medien; Hans-Peter Friedrich labelled the lack of news 'the Silence Kartell', https://www.tagesspiegel.de/gesellschaft/medien/kritik-an-den-medien-wegen-koeln-berichterstattung-schweigekartell-undnachrichtensperren/12797422.html. 
Figure 3 Twitter handle titled: Safety in Berlin sent from AfD twitter account

त्र-

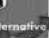

AfD Berlin

@AfDBerlin

Mehr Sicherheit für Berlin.

\section{\#agh16 \#afd}

(1) Translate Tweet

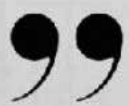

Damit es auf dem

nächsten Karneval der

Kulturen nicht wieder

zu J̈beršriffen auf Irauen

kommt, wähle ich

diesmal die AfD.

Das mit der Armlänge

Abstand haut einfach

nicht hin!

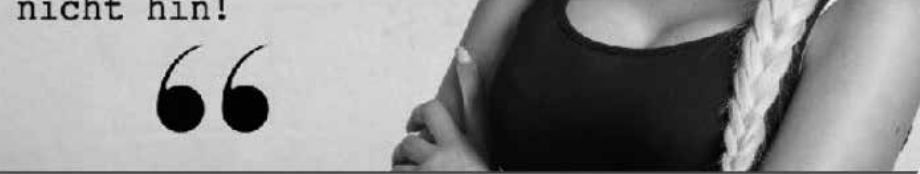

Follow

3:53 AM - 30 Jul 2016

Posted on 30 July 2016 at 03:53

role of protecting the white population. This population, embodied in an every-day regular white woman, is presented with a far-right alternative, where the government has allegedly left a void to fill.

\section{'Rapefugees not welcome'}

The far-right rhetoric aimed principally at identifying the perpetrators from Cologne as (predominantly Muslim) refugees who had been coming to Europe since July 2015. To that effect another slogan seen during PEGIDA demonstrations, 'rapefugees not welcome', went viral. One particular meme established the 'rapefugee' cliché: it is composed of two photos set together - one with three smiling girls holding a 'refugees welcome' banner and marked 'Cologne October 2015' and the second, marked 'Cologne January 2016', showing a white woman being raped by a black man. The rhetoric 
Figure 4 Meme identifying refugees/immigrants with Nazis (\#einearmlaenge)

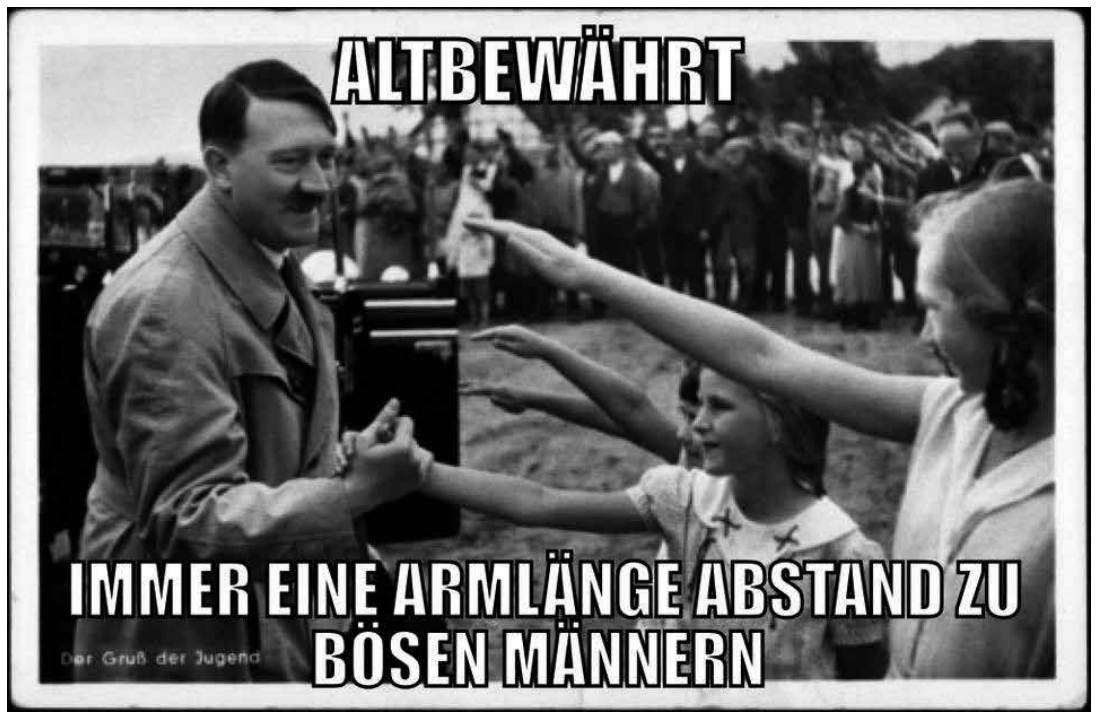

It states on top: 'Time-tested'; and underneath: 'Always stay at arm's length from evil men'. Meme inspired by \#einearmlänge, reposted on German far-right websites

of security and solidarity with women who are no longer protected by the existing power structures gained in Islamophobic tones. ${ }^{12}$ In his comment on Cologne events a Dutch far-right politician Geert Wilders named refugees 'Islamic testosterone bombs' and called for a legalization of pepper spray. ${ }^{13}$

From non-white foreigners to refugees and Muslims, the enemies of white women have been swiftly identified as beasts who would lead the population to decline. They are aided by the enemy within figure, represented by a white female 'refugee helper'. A prominent example of the ambivalent villain

12 Angela Merkel, as a symbol of 'Wilkommenskultur', has been on numerous occasions - not least on air (ARD news on 8 October 2015) - portrayed wearing an Islamic veil. A meme issued by a Zionist 'Jihad Watch Deutschland' blog run by a journalist Fred Alan Medforth shows Angela Merkel in sexy underwear and veiled, the article holding her responsible for sexual aggressions and death of German women at the hands of Muslim men. See: https://fredalanmedforth. blogspot.com/2018/o6/susanna-14-ermordet-kanzlerin-merkel.html.

13 The call for civil armament is another common narrative occurring in the aftermath of violent events involving immigrants. For instance, Donald Trump tweeted shortly after the Charlie Hebdo attacks on 7 January 2015: 'Isn't it interesting that the tragedy in Paris took place in one of the toughest gun control countries in the world?' suggesting that violence occurs because the population is not armed. See: https://twitter.com/realdonaldtrump/status/552955 167533174785 ?lang=en. 
Figure 5 Polish magazine W Sieci

\section{Alessio Fratticcioli} @fratticcioli

Left: Polish magazine @Tygodnik_Sieci, 2016. Right: Fascist Italy's poster, 1943.
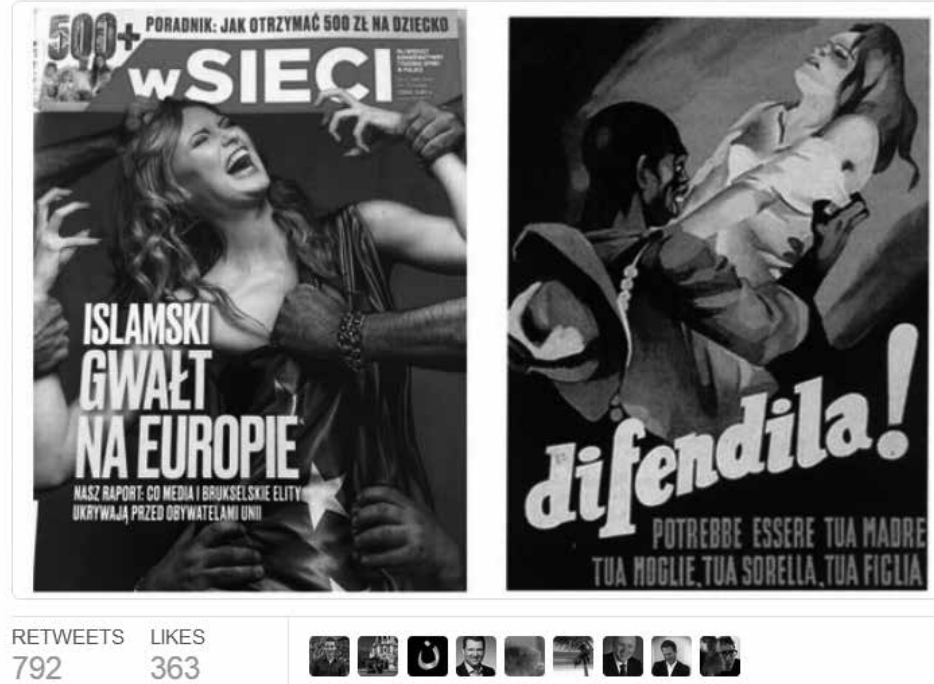

1:20 AM - 16 Feb 2016

H 52 낙 792 ○ 363

The title reads: The Islamic Rape of Europe. In his tweet, an Italian researcher Alessio Fratticcioli, likens the cover to a 1941 Italian fascist propaganda poster: "Defend her! She could be your mother, your wife, your sister, your daughter".

figure after Cologne is the use of a 1934 postcard depicting German girls saluting to Hitler in another \# einearmlänge meme (Figure 4).

The image amalgamates Hitler, an 'evil man' with a 'North African or Arab', 'Muslim' rapist. ${ }^{14}$ Women depicted in the meme are framed as supporting the powers that be, unaware (hence in need for protection) but also easily subjected (hence not trustworthy, the figures of enemy within). The \#einearmlänge memes are particularly telling, precisely due to the paradoxical message they carry. Although the Nazi postcard meme carries a warning, it simultaneously dissociates the anti-immigration propaganda from the Nazi ideology, even though both the present-day far-right parties

14 On the preponderance of labelling New Year's Eve perpetrators as 'Muslim', 'refugee', 'immigrant' and 'Arab', see: Abdelmonem et al., The Taharrush Connection. 
such as Alternative für Deutschland and the Nazis in the 1930s advocated blood purity and promoted xenophobia. ${ }^{15}$ Far-right representations of the Cologne victims drew directly on the Nazi propaganda posters in their use of an iconic image of a white woman: She is sexy, blond, slim, and helpless (Figure 5).

\section{Feminists and trolls}

Thirdly, trolling the Cologne sexual offenders as backward and violent due to their skin pigmentation and religion points to an ambiguous relationship between the feminist and the far-right rationale. While trolling after Cologne focused on the migrants, feminists had also been accused of deliberate silence. ${ }^{16}$ Alt-Right internet news outlets such as Breitbart, Euroislam, Riposte Laïque, and Politically Incorrect used ambivalent feminist reactions to the events as an opportunity to further their racist rhetoric. Although traditionally anti-feminist, these outlets seconded the feminist outcry against sexual harassment in order to gain legitimacy. Some statements made by prominent feminists enabled the articulation of racial and sexual difference. For instance, a German feminist Alice Schwarzer writes that the Cologne culprits were 'North Africans or Arabs, hence Muslims. And it is on that basis that they got in touch. Yet, they weren't just any Muslims. These were the kind of young men with no jobs or perspectives, standing on street corners and listening to pied pipers telling them for years and decades: you are not guilty of your misery - the 'infidels' are.' ${ }^{17}$

Breitbart's article from 16 January features a photo of Angela Merkel and Alice Schwarzer sitting next to each other but looking away. According to Breitbart, Schwarzer 'claimed Cologne police have been covering up Muslim rape for 20 years, and said that sexual violence was now being used as a weapon of war in Germany.' ${ }^{18}$ In her interview for a Polish anti-Muslim outlet Euroislam, another German feminist and activist Rebekka Sommer blamed Muslim culture for practicing 'sexual terrorism':

15 The AfD campaign billboards before the 2017 parliamentary election featured pregnant white women and read: 'New Germans? We will make them ourselves', https://www.welt.de/politik/ deutschland/article165297337/Was-setzt-die-AfD-gegen-Burkas-Alkohol-oder-Frauenrechte. html.

16 Prendergast, 'Why are feminists refusing'.

17 Schwarzer, Der Schock, pp. 17-18.

18 https://www.breitbart.com/europe/2016/o1/16/old-school-feminist-slams-establishmentcalls-for-debate-on-islam-without-political-correctness/. 
For the first few years I thought that the people coming here were real refugees and that they were happy to be in a safe place. So I thought they would be willing to adapt to their new surroundings here and become integrated. But as time went by, step by step I awoke to an unpleasant truth. There were so many different clues that pointed to this conclusion that I just could not go on ignoring them any longer. Certainly one of the decisive turning points was what happened on New Year's Eve 2015 in Cologne. That's when I finally had to admit to myself that that sort of behaviour is characteristic for the overwhelming majority of the Muslims I was seeing on a day-to-day basis. That's when I said to myself: 'Rebecca, now is the time to pull the emergency brake, simply because as a women's rights advocate you bear collective responsibility as a woman.' ${ }^{19}$

Other feminist activists denounced the racializing of sexual violence as part of the feminist discourse. The \#ausnahmslos movement led by a German feminist Anne Wizorek stated on its website: 'Sexualised violence must not only be addressed if the perpetrators are supposedly the "others": Muslim, Arab, black or North African men - in short, all those considered "nonGerman" by right-wing populists. ${ }^{20}$ As a result, the German Alt-Right portal Politically Incorrect attacked them as traitors, relativists, and blamed them for the assaults. Apart from feminists who denounce both sexual violence and racism, female refugee helpers were particularly subject to trolling. Contrary to the image of an innocent, helpless victim used to vilify the dark-skinned men, female refugee helpers were accused of treachery and simulating charity to mask their sexual fantasies about 'an oriental prince charming'. ${ }^{21}$

On Reddit, they were mocked as unattractive and desperate:

Is Ahmed, 20, with no job or skills, an afghan face and genetics and a quest for European wellfare money a high value male? Yeah right.

And the females in these stories, I can only speak personally for Sweden, but those women I wouldn't wanna touch with a 10 foot pole. Fat, old,

19 Rebekka Sommer's interview for Euroislam was later translated into German and English. https://arbeitsgruppefluchtundmenschenrechte.wordpress.com/2018/02/11/ interview-with-rebecca-sommer-english/.

20 http://www.ausnahmslos.org./

21 The expression comes from an article on refugee assistants published on the Islamophobic far-right German blog run by a controversial Turkish-German author Akif Pirinçci. https:// nixgut.wordpress.com/2016/12/19/studie-die-irren-flchtlingshelfer_innen/. 
ugly, left-wing, horrible scum. Let the ahmeds have them. They are using this opportunity to extort sex from young males when they can't get any other man on the planet. They are sex-offenders, pedophiles. ${ }^{22}$

\section{Historical prefigurations of anti-miscegenation campaign after Cologne}

In the visual rhetoric and narratives exploited by trolls after Cologne, the racialized sexual threat was framed as an act of terror that would eventually lead to a decline of the white population. This was not the first time such a response to the presence of non-white men on the European soil occurred. A similar outcry took place in the early 1920 s when 30,000 to 40,000 non-white soldiers from several French colonies were stationed in Rhineland. ${ }^{23}$ Xenophobic reactions to the foreign presence on the European soil had been entrenched in European mentalities even earlier, throughout nineteenth-century anti-miscegenation campaigns.

In the nineteenth century, in the attempt to assert modern states' control over colonial subjects, an emerging concept of population became interwoven with various othering strategies. The notions of a rational individual and a rational society that used to fall under all-encompassing jurisdiction were superseded by a new 'character': a population. ${ }^{24}$ According to Michel Foucault, population is 'a multiple body, a body with so many heads that, while they might not be infinite in number, cannot necessarily be counted'. ${ }^{25}$ Populations, states Foucault,

become pertinent only at the mass level. They are phenomena that are aleatory and unpredictable when taken in themselves and individually, but which, at the collective level, display constants that are easy, or at least possible to establish. ${ }^{26}$

Therefore, populations, albeit randomly manifested, are representative of their time when studied in a historical context. In addition to that, they

22 https://old.reddit.com/user/samenrofringslikeLBJ (Reddit Account is removed by user. Post no longer available); https://www.reddit.com/r/TheRedPill/comments/7dmiuu/ women_and_refugees_a_compilation/.

23 Wigger, The Black Horror.

24 Foucault, Society Must Be Defended, p. 245.

25 Ibid.

26 Ibid., p. 246. 
generate outbursts of normative functions, such as racial purity, narrated as essential for survival. The threat of miscegenation (allegedly resulting in sterility) has been one of the most prominent discourses sustaining white supremacy. The preservation of the white race has become a vital part of the far-right propaganda. These functions, due to a growing complexity of social realities (in the nineteenth century these were industrialization and centralization, today digitalization and globalization), make the 'human masses' particularly predisposed to self-regulate. ${ }^{27}$ Hence, racial regulation, embodied in anti-miscegenation rules, became imperative for the population. ${ }^{28}$

Not unlike in the past, multiculturalism embodied in the influx of refugees in 2015 was a turning point that authorized the far-right all over Europe to openly call for regulation. Backed by considerable civil movement, the European far right effectively echoed the racist undertones established in colonial-era narratives. That these narratives did not resonate with mainstream politics is not new either. Foucault argued that the specificity of the population lies also in being beyond a society. While society relies on institutions, populations will only survive through regulatory mechanisms. The more personalized character of populations makes them easier to believe in and identify with. Contrary to a population, as it is implicitly argued, a society would inevitably turn against tyrannical tendencies of the biopower. Because the population is responsible for 'the biological continuum of the [...] distinction between races ${ }^{29}$, it is determined by its biological functions rather than its individualistic capacities. By instigating racism as a norm, the population will be divided and thus easier to control, and additionally it will be made to believe that in order to live it must destroy its enemies. Destroying a degenerate race will make life healthier and purer, and by destruction Foucault does not only mean a biological annihilation of a race considered 'degenerate' - he also means 'political death, expulsion, rejection, and so on' $3^{\circ}$ This logic reveals the power of a discourse of biological preservation: dying out represents weakness and racial mixing represents degeneracy. After Cologne, older images of white women, traditionally in charge of ensuring the preservation of the white race, being sexually assaulted resurfaced in order to generate a threatening symbol of a civil society in crisis. Now as then, biopolitical narratives ceaselessly rely on symbolic 
Figure 6 This political cartoon went viral in far-right digital media following the New Year's Eve in Cologne.

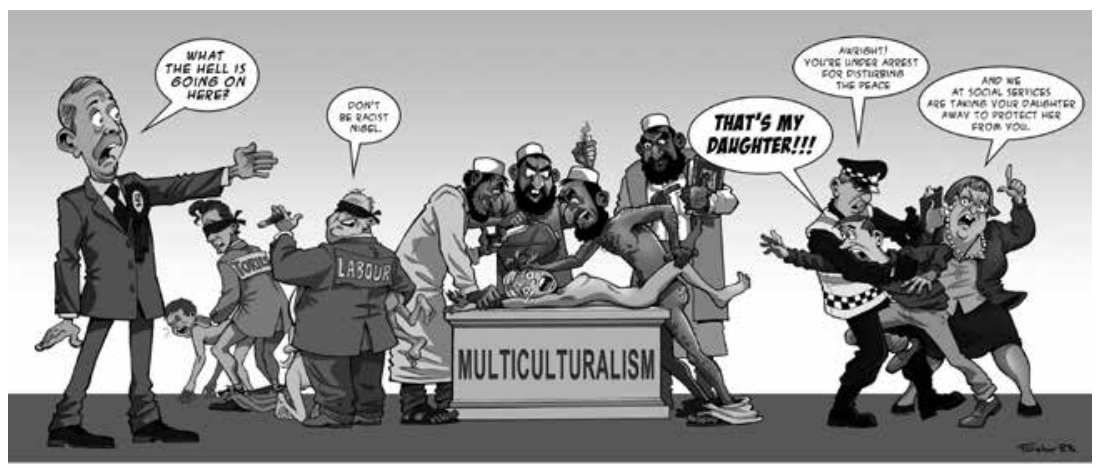

THE MOST OFFENSIVE THING ABOUT THIS CARTOON IS THAT IT IS ALL TRUE.

representations of decline blamed on abstract politics, political correctness, widespread diversity, and a too-generous welfare state. For instance, the political cartoon that went viral in Alt-Right online circles links the spread of multiculturalism and diversity to the decline of 'straight white men'. One of the Reddit users commented underneath: 'Isn't multiculturalism great! You can have sex with just about anything and you get to suppress straight white guys.' (Figure 6).

\section{Colonial discourses of racialized sexual deviancy}

How did the verbalization and shaping of sexual norms come to the fore? In order to retrace recent representations of miscegenation, researchers turned to texts and images from the nineteenth and early twentieth centuries that reveal the construction of atemporal, oversexed, and violent non-white men. ${ }^{31}$ While in the nineteenth century scientific and intellectual discourses were the dominant spaces of conceptualizing otherness, at the turn of the centuries journalism took over that role. As mass printing increased the volume of popular press, the representations of miscegenation became not only more commonplace, but also more explicitly racist.

In the nineteenth-century scientific discourse, especially in the realms of phrenology and sociology, efforts were made to identify the 'general 
characteristics of savages': $3^{2}$ narrow-mindedness, intensity of desire, unnatural physical strength, and brutality with women, ${ }^{33}$ followed by a general idiocy, unattractiveness and animal-like features:

If it is admitted that the European cannot hope to civilize the negro, and manages to transmit to the mulatto only a very few of his own characteristics; if the children of a mulatto and a white woman cannot really understand anything better than a hybrid culture, a little nearer than their father's to the ideas of the white race, - in that case, I am right in saying that the different races are unequal in intelligence. ${ }^{34}$

A French academic authority of that period and Arthur de Gobineau's friend, Ernest Renan, writes of the Semites as 'an incomplete, simplistic, and undifferentiated race'. ${ }^{35}$ In the sixth volume of his works published in 1847 , Condorcet endeavoured to scientifically prove that Islam 'seems to condemn people to eternal slavery and incurable stupidity'. ${ }^{36}$ In the period of the Third Republic, the demonization of Arabs, hitherto objects of orientalist fascination, served the purpose of reinforcing discourses of white supremacy and imperial politics. Jules Ferry, a key political figure in the French Third Republic, claimed in his speech on 28 July 1885 that 'the superior races have the right to rule over the inferior ones' and a duty to civilize them. Ferry points to the German colonial expansion and urges the French to catch up, giving as an example their successful colonization of Algeria, where 'piracy has been replaced by a controlled free exchange'.37 The press narratives in the nineteenth-century British Empire were particularly keen on reproducing reports of non-white men sexually assaulting women. In the aftermath of the Mutiny, as the American historian of the Victorian era Bernard Semmel noted, 'day after day, the newspapers told stories of massacres of British women and children, of gruesome oriental tortures and mutilations, of assaults on the virtue and honour of English women'. ${ }^{8}$ According to a researcher on mass literacy, 'no episode in British imperial

32 Pickering, Stereotyping, p. 49.

33 'They are proud and revengeful, and make war and kill each other; and among the names of honour given to them are 'the adulterer', 'the woman-stealer', 'the brain-eater", Spencer, The Study of Sociology, p. 294.

34 De Gobineau, The Inequality, p. 179.

35 Said, Orientalism, p. 149.

36 Condorcet, Esquisse d'un tableau historique, p. 124.

37 Ferry, 'Discours'.

38 Ware, Beyond the Pale, p. 39. 
history raised public excitement to a higher pitch'. ${ }^{39}$ In the French humoristic press some of those representations emphasized the exoticism of non-white men: their love of music, dance, anything referring to their accrued sensuality. Popular magazines, such as Le Sourire (1899-1940), La Vie Parisienne (1863-1970), and Fantasio (1906-1937), featured miscegenation drawings by famous draftsmen (Paul Colin, René Giffey, George Leonnec, etc.). In these aesthetically exquisite illustrations, French women were portrayed mostly as libertarians, lying down or relaxing, enjoying housework or light outdoor activities, dressed either fashionably, or as vaudeville dancers, but most often simply undressed. As a contrast, their non-white counterparts were predominantly represented with explicitly simian traits, displaying lustful looks, or else portrayed as playthings of excited and flirtatious Parisian women. ${ }^{40}$ In one of these drawings for Rire (another French humourist magazine) published in 1896 , a black tribesman is squatting on a severed body of a white woman. In the background, we can see five men representing European colonial enterprises. Ironically, colonialism is here portrayed as potentially dangerous for European populations, in case colonial transfer of human subjects changes its course. The change eventually ensued, due to shortages in the European armies.

Owing to the mass recruitment of colonial subjects during World War I, non-white presence in Europe led to a shift in visual representations. Colonial soldiers or tirailleurs (largely recruited from Sub-Saharan and Northern Africa) were now represented in the French, American, British and German press as either romantically involved with or sexually assaulting white women. For the sake of the post-Versailles Treaty status quo, some of these images strove to normalize a mixed-race couple. While the benign clichés, mimetically situated in the 'white mother' and enfant nègre register, are mostly draw on non-sexual supremacist undertones, the 'Black Shame' iconography is dominated by sexualisation and simianization of non-Europeans. In 1921, Guido Kreutzer published 'Black Shame', a novel defaming Black and Arab soldiers from the French troops who stationed in Rheinland for fifteen years following the Versailles Treaty in 1918. Kreutzer's novel contains the 'Black Horror's' standard images: cynicism and immorality of black soldiers, rape, stigmatizing mixed-race individuals, a mulatto running a brothel for non-white troops filled with

40 It is striking to what extent these representations differ from those of unattractive, old, and bossy suffragettes in the Anglo-Saxon press of that period. See Lysack, Come Buy Come Buy, p. 142 . 
white German women. The French in the 'Black Horror' narratives represent the treacherous governance and humiliation - an equivalent of the Cologne narratives' 'Wilkommenskultur'. Kreutzer's novel depicts German women as a symbol of moral integrity, honour and racial purity of the German people. Their tortured bodies, attacked by the 'savages', symbolically marked the boundaries of the German nation and the white race, injured and violated by France's 'Black Shame". ${ }^{41}$ The non-white soldiers in Rheinland, often forcefully recruited from the colonies, were accused of 'countless' rapes and other crimes. The visual representations of Black soldiers raping white women multiplied in the German press in between wars. In her analysis of the 'Black Shame' discourse, Iris Wigger points out the flexibility with which the white female figure was instrumentalized to racist, sexist and nationalist ends. ${ }^{42} \mathrm{~A}$ typical example of the animal-like rapist cliché is an illustration entitled 'the Black Shame' in the 1927 album The French in the Ruhr (Französen im Ruhrgebiet). The motive, common in the Black Shame era, depicts a simianized French soldier groping a German blonde (Figure 7). The caption reads: 'the lust of the coloured man towards a white-skinned girl, the horror of the poor creature in the deepest distress [...]. The German girl, a lamentable example of more than two hundred similar cases, symbolizes a fate threatening every white woman. Apparently, the French promised white women to black soldiers in exchange for their military service and victory'. Another influential document of that era, a pamphlet written by Edmund D. Morel, a Labour MP and specialist on Africa, depicted colonial soldiers as beasts and rapists. ${ }^{43}$ While criticizing the militarism of the French, Morel denounced Europe's lethargy (prefigurative of 'silence hides violence') that preordained a white female's doom:

From the plains and forests, from the valleys and the swamps of Africa they brought tens of thousands of savage men, and thrusted them upon us. Boys, these men raped our mothers and sisters! This, neither you, nor we, nor they, must ever be allowed to forget. ${ }^{44}$

'They' are the imperial powers that be, the enemies of the people in interbellum Europe. Not only did these and many other voices gain ground in the

41 Wigger, The Black Horror, p. 85 .

42 According to the Rheinland 'Black Horror' narrative, the white German woman 'became a coherence-generating symbol for a nation and white racial community threatened by a desecration'. See: Wigger, The Black Horror, p. 128.

43 Ibid., pp. 46-52.

44 Morel, Horror of the Rhine, p. 22. 
Figure 7 “Die Schwarze Schmach!” (The Black Shame!)

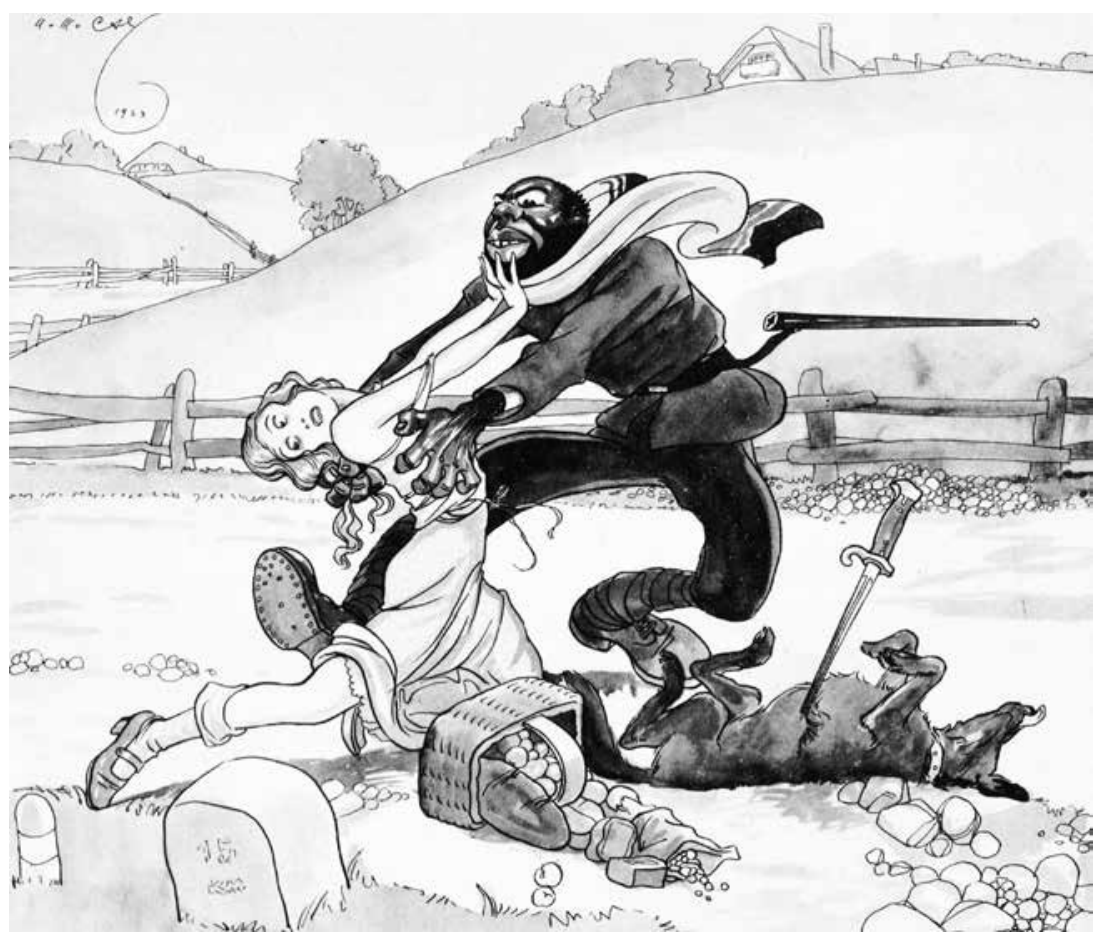

Französen im Ruhrgebiet, 10 illustrations by A.M. Cay (Alexander M. Kaizer). Reimar Hobbing Verlag Berlin, 1927. Copied from Scientific Public Library Mainz

course of the late nineteenth and early twentieth century because of the technology of power in place, they also emerged and thrived due to the popular demand to denounce miscegenation as dangerous and alien to white Europe and the United States. ${ }^{45}$

During the Second World War, fascist propaganda posters established representations of Jewish and African sex offenders depicted as spiders or monkeys reducing them, as women themselves and lower classes are often 'being reduced to the very margins of humanity'. ${ }^{46}$ These images have been increasingly reused to spread racist and sexist memes, and they continue to fuel trolling rhetoric.

45 The prominent anti-miscegenation voices in the American discourse were, for instance, Francis Galton and Madison Grant. The latter stated in his 1916 The Passing of the Great Race that 'the laws against miscegenation must be greatly extended if the higher races are to be maintained'. See. Grant, The passing of the great race, p. 31.

46 Hund, Racist King Kong Fantasies, p. 45. 


\section{Civilizing mission, miscegenation and the feminist struggle}

The emancipatory virtue of Christianity, brought by white female educators and missionaries, was another facet of nineteenth-century normative practices in the colonies. Because women were the bearers of moral goodness, their presence and active role was considered indispensable for the bettering of the ruled populations. In the French iconography of the first decades of the twentieth century, the 'white women's burden' consists in dissuading men in the colonies from having sexual relations with native women, which had earlier been widely accepted. Visual representations deprecating métissage ('miscegenation') were part of the politics of prestige - the idea according to which to better govern subalterns Frenchmen must keep 'a good distance'. 47

Another aspect concerns the attitude to native men among white women in the colonies, and their own racism. A conflict between Isabella Mayo and Catherine Impey, two prominent figures in the Anglo-American feminist anti-racist movement, reveals the scale of the problem. On the pages of the anti-racist journal 'Fraternity ${ }^{48}$ Mayo expressed her indignity at the news of Catherine Impey's desire to marry a non-white man:

There are women who will 'fancy' anything which will give them a sensation and a little passing notoriety. [...] the morbid egotists may only imagine that men fall in love with them'. Be it remembered that even this imagination, if indulged in by a 'white woman', regarding a 'nigger' in some of the States, would mean the death of the man, perhaps even more ignominious death, if he ventured to say in self-defence that the 'imagination' was wholly baseless [...]. For it must be noted that female sufferers from this diseased egotism are not necessarily young and flighty. They are often elderly, dowdy and disappointed. ${ }^{49}$

Mayo's attack on Catherine Impey demonstrates to what extent the feminist struggle was not to be confused with calling for racial mixing. On the question of race, the feminist position was thus originally in unison with the white patriarchy. ${ }^{50}$ Beyond civilizing mission and feminist activism, the function of white women overseas was to police and distract white

47 Edwards, 'Womanizing', pp. 121-123.

48 The anti-racist journal published between 1888 and 1895 in Britain, later as Anti-Caste, established by Catherine Impey (EP).

49 Ware, Beyond the Pale, p. 195.

50 See: Newman, White Women's Rights. 
men. ${ }^{11}$ Despite their merits in the service of the empire, the British colonial narratives often represented white women as passively waiting for a final decline of the colonial status quo. At times they even jeopardize the practices of the colonial enterprise (although not the Empire itself) through their emancipatory activities. As transpires from Richard Dyer's reading of a British series, The Jewel in the Crown (Granada Television 1984), white women in the Raj ultimately do nothing, even if some support civilizing mission while others strive to change things: 'The serial's focus is women, to whom it allots three narrative possibilities: doing that fails; boredom and bitchiness; or [...] transfixed listening and observing', thus condoning the ongoing violence..$^{2}$ In the end, as Dyer demonstrates through a tragic story of one of the characters who crossed the line and fell in love with the native man, ${ }^{53}$ white women take the blame and provide the spectacle of moral suffering, for the loss of empire'.54 These two short portrays of white women in British colonialism were cited to explore the challenges white feminists face, now and then, as agents of the imperial patriarchy implicated in the question of race, positing the notion of their own sexuality as part and parcel of their struggle.

\section{Conclusion}

The racialization of sexual practices that was established in the nineteenth century is historically specific and ought to be historicized in its own right. However, re-enacting the seemingly redundant clichés has been a dominant

$5^{1}$ Dyer divides the activities of white women in British colonies into two categories: imperialist and feminist. The first category generated a positive figure of white women doing missionary work and giving example of moral refinement (civilising mission) and a negative image of them being even more snobbish, more cruel to the natives than men, and while morally repressive, often adulterous (presumably due to boredom and heat). The second, feminist, is characterized by both the critique of racism and encouraging female independence. See: Dyer, White, pp. 184-187.

52 Ibid., p. 196.

53 Among the series' many characters who represent either the imperialist or the feminist type, is Daphne who questions the enterprise itself by opposing to anti-miscegenation laws, for which both she and her Indian lover are severely punished. The 'pandora's box' of racial transgression opened by Daphne according to another character (Lady Chaterjee), is used as an overarching metaphor for the fall of the British rule. Dyer concludes: 'The British withdraw because they have failed; and they have failed because of their women, who have weakened the fabric of empire with both their sexuality and their questioning of the enterprise'. Ibid., p. 199 .

54 Ibid., p. 206. 
strategy in the recent instances of online racist and sexist violence. Today's Far Right sustains the decline narrative in that it denounces the media and political establishment for concealing the truth of an ongoing 'epidemic' of 'Islamization' and 'bastardization' of Europe from its population. The struggle of Alt-Right trolls to uphold white supremacy relies on the instrumentalization of the image of white women as endangered by violent multiculturalism embodied in the invasion of lecherous non-white men. Trolls after New Year's Eve in Cologne acted as protectors of white women and simultaneously accused the 'traitors' among them of facilitating violence by their permissive approach to the influx of refugees in 2015. On the one hand their discourse resonates with the pseudo-scientific claims made in the nineteenth and early twentieth century. Yet, it has also been endorsed by public figures who usually identify as anti-racist (certain intellectuals and feminists). It is arguable that the politics of representation - practised in the pre-digitalization era, as well as the one emerging from online conflicts described above - has a factual social impact (see Chapter 5). Yet, the articulation of racist and sexist memes after Cologne and some feminist reactions to the events definitely bring forth 'some uncomfortable questions about feminism'. 55 The above analyses of some particularly popular images and narratives that pointed to racial origins of sexual deviancy in the past, reveal the reiterative quality of today's far-right argumentation. Moreover, the ties between established scientific discourses, intellectual debates and racist trolling - now and back then - signal the possibility for racializing gaze to flourish far beyond the political scope of the Far Right.

\section{Works cited}

Abdelmonem, Angie, et al. 'The Taharrush Connection: Xenophobia, Islamophobia, and Sexual Violence in Germany and Beyond', jadaliyya.com, 1 March 2016.

Burgess, Jean, et al. (eds). The Sage Handbook of Social Media. London: Sage, 2018. Condorcet, Nicolas de. Esquisse d'un tableau historique des progrès de l'esprit humain. Paris: Firmin-Didot Freres, Libraires, 1847.

Dyer, Richard (ed). White. Essays on Race and Culture. London and New York: Routledge, 1997.

Edwards, Penny, 'Womanizing Indochina: Fiction, Nation and Cohabitation in Colonial Cambodia, 1890-1930, in Domesticating the Empire: Race, Gender and 
Family Life in French and Dutch Colonialism, edited by Frances Gouda and Julia Clancy Smith. Charlottesville: Virginia University Press, 1998.

Ferry, Jules. 'Discours au sujet de la colonisation'.Journal Officiel de la République française, 29 July 1885 .

Foucault, Michel. Society Must Be Defended. Lectures at College de France 1975-76. New York: Picador, 2003.

Frank, Michael. Kulturelle Einflusssangst. Inszenierungen der Grenze in der Reiseliteratur des 19. Jahrhunderts. Bielefeld: Transcript, 2006.

Galton, Francis. Hereditary Genius. An Inquiry into its Laws and Consequences. London: MacMillan, 1869.

Gobineau, Arthur de. The Inequality of Human Races. New York: GP Putnam's Sons, 1915 .

Gouda, Frances and Julia Clancy Smith (eds). Domesticating the Empire: Race, Gender and Family Life in French and Dutch Colonialism. Charlottesville: Virginia University Press, 1998.

Grant, Madison. The passing of the great race. New York: Charles Scribner's Sons, 1916 [2020].

Hall, Stuart (ed). Representation. Cultural Representations and Signifying Practices. London: Sage, 2012.

Hark, Sabine, and Irene-Paula Villa. Unterscheiden und herrschen. Ein Essay zu den ambivalenten Verflechtungen von Rassimus, Sexismus und Feminismus in der Gegenwart. Bielefeld: Transcript, 2016.

Hund, Wulf D. 'Racist King Kong Fantasies. From Shakespeare's Monster to Stalin's Ape-Man', in Wulf D. Hund, Charles W. Mills, and Silvia Sebastiani (eds). Simianisation. Apes, Gender, Class, and Race. Racism Analysis Yearbook, 2015/2016. Wien: Lit Verlag, 2016.

R. Ibrahim, 'Muslim rapists prefer blondes'. Middle East Forum. 30 July 2015, https:/ www.meforum.org/5410/muslim-rapists-prefer-blondes. Last accessed 7 August 2019 . Lysack, Krista. Come buy, come buy. Shopping and the Culture of Consumption in Victorian Women's Writing. Athens: Ohio University Press, 2008.

Miscegenation. The Theory of the Blending of the Races Applied to the American White Man and Negro. New York: Dexter, Hamilton and Co.

Morel, Edmund D. The Horror of the Rhine. London: Union of Democratic Control, 1921.

Newman, Louise Michele. White Women's Rights. The Racial Origins of Feminism in the United States. New York and Oxford: Oxford University Press, 1999.

Phillips, Nickie D. Beyond Blurred Lines. Rape Culture in Popular Media. Lanham: Rowman and Littlefield, 2017.

Pickering, Michael. Stereotyping. The Politics of Representation. Edinburgh: University of Edinburgh Press, 2008. 
Prendergast, Lara. 'Why are feminists refusing to discuss the Cologne sex attacks?'.

The Spectator, 7 January 2016, https://www.spectator.co.uk/article/why-arefeminists-refusing-to-discuss-the-cologne-sex-attacks-. Accessed 26 August 2020.

Said, Edward. Orientalism. New York: Vintage Books, 1978.

Schwarzer, Alice. Der Shock - Silvesternacht von Köln. Köln: Verlag Kiepenheuer \& Witsch, 2016.

Spencer, Herbert. The Study of Sociology. New York: Appleton and Company, 1874.

Stoler, Ann Laure. Race and the Education of Desire. Durham and London: Duke University Press, 1995.

Theweleit, Klaus. Male Fantasies, vol. 1: Women, Floods, Bodies, History. Minneapolis: University of Minnesota Press, 1987.

Villa, Paula-Irene und Sabine Hark. Unterschieden und Herrschen. Ein Essayzu den Ambivalenten Verflechtungen von Rassismus, Sexismus und Feminismus in der Gegenwart. Bielefeld: Transcript, 2017.

Vorländer, Hans, et al. PEGIDA and New Right-Wing Populism in Germany. London: Palgrave Macmillan, 2016, 2018.

Ware, Vron. Beyond the Pale. White Women, Racism and History. London and New York: Verso, 2015.

Wigger, Iris. The 'Black Horror on the Rhine'. Intersections of Race, Nation, Gender and Class in 1920s Germany. London: Palgrave McMillan, 2017.

\section{About the author}

EWELINA PEPIAK is author of publications on European immigrant cultures and the representations of immigration. Among her research interests are cultural and literary theories, British and French postcolonial film and literature, and intersectional analysis. She is currently completing a dissertation on white femininity and métissage in French multicultural comedy at Justus Liebig University within International PhD Programme "Literary and Cultural Studies". 



\title{
6 The Case of Telefilm De Punt's Online Discussion Forum
}

\author{
Participatory Space for Societal Debate or Echo Chamber for \\ the Polemical Few?
}

Gerlov van Engelenhoven

\begin{abstract}
The Dutch direct-to-TV feature film De Punt (2009) was aimed at instigating public discussions about the collective memory of a train hijacking in the village De Punt, which was carried out by second generation DutchMoluccans, a postcolonial migrant community in the Netherlands. The filmmakers created an online discussion forum as an accompaniment to the film, in which viewers were invited to participate directly in discussions about the hijacking itself, as well as the role of the state in ending it, and the larger postcolonial context of the action. This chapter is aimed at contributing to this volume's central questions concerning online violence, by providing a comparative analysis between the film itself and the debate culture on the online forum, in which the latter will be critically assessed in terms of its intrinsic, polarizing structure.
\end{abstract}

Keywords: colonial memory, Dutch-Moluccan community, online discussion forum, group polarization, train hijacking De Punt

In what follows, I will discuss an online discussion forum that was designed to invite debate about Dutch postcolonial society. The website was active in 2009, and was an accompanying feature of telefilm De Punt. ${ }^{1}$ Telefilms, according to their website (https://telefilm.cobofonds.nl/over-telefilm/),

Polak, Sara, and Daniel Trottier (eds), Violence and Trolling on Social Media. Amsterdam, Amsterdam University Press 2020 DOI: 10.5117/9789462989481_CHo6 
'are Dutch direct-to-TV feature films that discuss current societal themes'. Since their inception in 1999, six films have been released every year. De Punt and its accompanying online discussion forum were aimed at encouraging discussions about the Dutch collective memory of a train hijacking in the village De Punt, which was carried out by second generation DutchMoluccans, a postcolonial migrant community in the Netherlands (currently around 50,000 people). ${ }^{3}$ The hijacking was a radical protest against their disadvantaged position in Dutch society, took 20 days, and ended when the military intervened, which resulted in the deaths of six hijackers and two hostages.

The main question to be explored concerns the structural limitations of an online forum as a space for societal debate. By analyzing the way in which the hijacking was remembered and discussed on De Punt's online forum, as compared to the telefilm itself, my aim is to critically assess the participatory reach and productive potential of online discussions. As such, this text to some extent recalls (and bases itself on the resource material of) Randi Marselis's article 'Remembering Dutch-Moluccan radicalism: Memory politics and historical event television' (2016). Marselis argues in favour of the discussion forum, because to her it was an example of the 'participatory culture of digital media [...], where viewers can voice opposing interpretations and express their own memory work'. ${ }^{4}$ With this point of view, she refers to a common interpretation of the internet as possessing the promise of a participatory culture (a term coined by media scholar Henry Jenkins), 5 that encourages internet users' productive participation in society, in this case by actively debating shared colonial memory.

My intent, however, is to take a less optimistic standpoint regarding the participatory effects of online discussion forums. I will study to what extent De Punt's online forum perpetuated and perhaps amplified the group polarization of opinions that is frequently seen in public discourses about the hijacking. I owe my definition of the concept of group polarization to legal scholar Cass R. Sunstein (2008), who argues that '[it] means that members of a deliberating group predictably move toward more extreme points in the direction indicated by the members' pre-deliberation tendencies' ${ }^{6}$

2 'Telefilms zijn Nederlandse speelfilms die speciaal gemaakt zijn voor televisie, en die actuele maatschappelijke thema's behandelen.' All translations from Dutch are mine, except those taken from Marselis' article.

3 Fridus Steijlen (Algemeen Dagblad, 9 February 2018).

4 Marselis, 'Remembering', p. 214.

5 See for example: Jenkins, Confronting the Challenges.

6 Sunstein, 'The Law', p. 81. 
According to Sunstein, online violence is a particularly hostile escalation of such group polarization, which occurs when 'diverse social groups are led, through predictable mechanisms, toward increasingly opposing and ever more extreme views'. ${ }^{7}$ The case study of the Moluccan hijackings will follow this emphasis on predictable mechanisms, in that it will study the quality of De Punt's online discussions as a matter of what Sunstein calls 'the architecture of the Internet'. ${ }^{8}$ As such, this text does not directly discuss online violence, but is rather aimed at exploring the structural limitations of one of the spaces that enables it, i.e. the discussion forum.

I will develop this argument through a comparative analysis of the online forum with the film itself. The first step, however, will be to give an overview of the Dutch-Moluccan community's migration history and the polarizing effects that the hijacking had on the way Dutch society perceives them.

\section{Historical context of the Moluccan migration leading up to the hijacking}

Moluccans originate from the eastern Indonesian province Maluku. During the Indonesian National Revolution (1945-1949), they took the side of the Dutch colonizers against the Indonesian nationalists, because they had hopes that the Dutch would help them establish an independent state: the RMS (RepublikMaluku Selatan: 'South-Moluccan Republic'). The state was to be independent from Indonesia, and independent from (although allied to) the Netherlands. This hope was based on a more than three-centuries-long history of Moluccan social and political privilege above other Indonesian ethnic groups. ${ }^{9}$ This privilege was the result of the importance of the Moluccan territory for Dutch colonialism. Maluku was the centre of the spice trade on which the Dutch trading company voc (Vereenigde Oostindische Compagnie: 'Dutch East India Company') held the monopoly. The spice monopoly was an important reason for the strength of the Dutch colonial empire and brought it considerable wealth in the 16oos, a century which national history still refers to as the Golden Age.

7 Ibid., p. 90 [my italics].

8 Ibid.

9 Chauvel, Nationalist, p. 41. Richard Chauvel's book provides a comprehensive account of how the history of Moluccan privilege led to their ideology of separatism, which was part of the cause for their migration. 
Indonesia became independent in 1949, initially as a federal state system (United States of Indonesia) that allowed provinces the right to self-determination. However, the new government rapidly worked toward a unitary Republic of Indonesia, leading to violent confrontations between Indonesian nationalists and Moluccan separatists. Because the Moluccan soldiers were officially still part of the Dutch army, the Dutch government was by law required to protect them. For this reason, they brought most Moluccan soldiers and their families to the Netherlands in 1951-1953 (around 12,500 migrants in total). Upon arrival, the Moluccan soldiers were fired from the army, and they were sent to camps in remote places, some of which had served during the Second World War as Durchgangslager: i.e. Nazi camps used as transit locations for prisoners before their deportation to Germany. The Moluccan camp in Dutch city Vught had served as a Konzentrationslager (i.e. a concentration camp). The reason for this isolation from Dutch society was that their residence in the Netherlands was supposed to be temporary: the original planning was for a period of six months. In the 1960 s and $1970 \mathrm{~s}$ most Moluccans were relocated to newly built, segregated neighbourhoods in the margins of cities, where many Moluccans still live today. Throughout these years the Moluccan dependence on the state was reduced gradually until they received citizenship in 1976, 25 years after the first Moluccans had arrived.

From the mid-196os, a portion of the community's second generation sought violent means to protest their continued marginalization by the Dutch government. They had perceived the slow retraction of Dutch support for their residence, and the increasing unlikelihood of their return to Maluku, as a systematic denial of responsibility from the side of the government. The hijacking at De Punt, which is the focus of the current case study, was one of the final actions in a longer history of attacks between 1966 and $1978 .{ }^{10}$ On 23 May 1977, a group of nine Moluccan youths

10 1966: attempt to set fire to the Indonesian embassy in The Hague;

1970: occupation of the residence of the Indonesian ambassador in Wassenaar (one Dutch person dead);

1975: attempt to take the Queen hostage;

1975: first train hijacking in Wijster (three Dutch people dead);

1975: occupation of the Indonesian consulate in Amsterdam (one Dutch person dead);

1977: second train hijacking in De Punt (six Moluccans and two hostages dead, all killed by the military);

1977: occupation of a primary school in Bovensmilde;

1978: occupation of a province house in Assen (two Dutch people dead).

Total deaths: fifteen, of which seven Dutch people by Moluccans, six Moluccans by the military, and two hostages by the military (accidentally). 
hijacked the train, and took 54 passengers hostage. The action was meant to re-draw attention to the Moluccan ideology of independence, and to demand that those who were involved in a previous hijacking in 1975 be released from prison. After twenty days of unsuccessful negotiations, a special task force of marines surrounded the train and ended the hijacking violently, killing six of the hijackers. They also accidentally killed two hostages. The three surviving hijackers were charged with six to nine years in prison.

The Moluccan actions have been remembered in many cultural and media representations since, and the hijacking at De Punt more than the other actions. The event has featured in literature: both fiction ${ }^{11}$ and nonfiction. ${ }^{12} \mathrm{~A}$ four-part television documentary about it, Dutch Approach, was released in 2000. Telefilms were released for both hijackings, ${ }^{13}$ of which De Punt 'became the most seen telefilm in the ten years this concept had been running, which indicated that the theme of the film was not only important to the Dutch-Moluccan community but had broader national interest'. ${ }^{14}$ A 2017 article of national news channel nos remarks that 'it has been almost forty years, but the train hijacking at De Punt still reappears in the news on an almost yearly basis'. ${ }^{15}$ The action's lasting public impact was possibly a result of the action headlining the national media for three weeks, as well as the televised live report of the military intervention. The violence of this intervention furthered the controversy of the event, which until today is unresolved. A new ongoing investigation began in 2014, when the killed hijackers' next of kin started a lawsuit against the Dutch state, accusing them of having approved the use of disproportionate violence by the military.

The continued presence of the hijacking in cultural and journalistic representations shows the event's impact on Dutch society and the ongoing need to further process this collective memory. The next part of this case study analysis will explore some of the prominent ways in which Dutch society remembers and interprets the hijacking.

11 For example Scholten, Morgenster; Dam, Dood Spoor; Pessireron, Gesloten Koffers.

12 For example Barker, Not Here; Westerman, Een Woord Een Woord.

13 Oest, Wijster; Smitsman, De Punt.

14 Marselis, 'Remembering', p. 206.

15 'Het is alweer bijna veertig jaar geleden en nog steeds komt de treinkaping bij De Punt bijna jaarlijks in het nieuws'. 


\section{Victims and perpetrators: Polarized interpretations of the hijacking}

The hijackings caused a shift in the way in which Moluccans were generally perceived in the Netherlands. In his article about the hijacking's effects on the Dutch-Moluccan community and their position in Dutch society (1986), anthropologist Dieter Bartels argues that the actions triggered

widespread abuse by Dutch civilians and indiscriminate actions by the police against younger Moluccans [...] countrywide. [...]. The immediate repercussions ranged from Dutch civilians cursing Moluccans on the streets to police harassing young Moluccans or anybody who faintly resembled them [...]. A more long-term effect resulted from stereotyping Moluccans as violence-prone, leading to widespread discrimination, particularly on the labour market. ${ }^{16}$

The stereotype of Moluccans as violent indicates one of two directions in which the hijackings polarized public opinion about them. This first direction regards them as perpetrators, the other as victims. As perpetrators, they are interpreted as aggressors, who took innocent bystanders hostage for an unreasonable cause. As victims, they are interpreted as marginalized postcolonial subjects, who were driven to despair as a result of their systematic mistreatment by the government.

The latter interpretation was to a great extent encouraged by publications appearing at the time on the role which the Dutch had played in their colonies during the last decades before independence. In 1969 a governmentinitiated investigation into archive material about the independence war led to what was called the Excessennota ('Note of Excesses'): i.e. a research report that made public a long list of war crimes committed by Dutch soldiers during this war. The Excessennota inspired many further reconsiderations of the recent colonial past. Most prominently, war veterans J.A.A. van Doorn and W.J. Hendrix released a large amount of details about the systematic cruelty of the Dutch army during decolonization in their book Ontsporing van geweld ('Derailment of Violence', 1970). These are examples of a Dutch self-critical perspective that was developing in public opinion on colonial memory around the time of the hijackings. They form an indication of the context that enabled a general interpretation of the Moluccans as victims of severe mismanagement from the side of the Dutch government during and directly after decolonization. 
This interpretation is further strengthened by the fact that the hijackers had not killed any hostages, whereas the military intervention caused eight deaths, including those of two hostages. The investigation that started in 2014 has released new controversial material to the court and the press, including tapes of recording devices that were placed under the train, which seem to indicate that the soldiers were also shooting at unarmed hijackers. The uncovering of such details has led to renewed discussions in traditional and social media about the position of Moluccans in society. These new discussions have perpetuated the polarization of public opinion about the hijacking. Fridus Steijlen, Professor of Moluccan Migration and Culture in Comparative Perspective, argued in a 2018 interview with the national press that the lawsuit is 'reducing the discussion to a case study about perpetrators and victims.' ${ }^{17}$

According to sociologist Bernard Giesen (2004), this fixation on perpetrators and victims is common for a society that is dealing with the memory of disruptive events. He argues that the two archetypes appear as the result of 'a social construction [that is] carried by a moral community defining an evil'. ${ }^{18}$ This argument informs the relevance of Giesen's theory for the current case study: i.e. victims and perpetrators do not construct themselves. Instead, their construction is in the hands of what he calls 'the public perspective', which acts as a 'universalist moral discourse that aims at impartiality and justice', and which is 'at a certain distance from the victims, as well as from the perpetrators.' ${ }^{19}$ Giesen locates this public perspective in different institutional arenas:

The public perspective can be based on the authority of [...] intellectuals, or judges or it can just refer to the majority of impartial spectators. It can be constructed in the discourse of civil society, articulated in literature and art, or brought forward by the response of the common people on the streets. ${ }^{20}$

These discourses work together to establish the moral boundaries of society, by defining deviations from its norms: 'the moral community needs deviance and perpetrators in order to construct the boundary between the good and the evil'. ${ }^{21}$

Giesen's theory provides an explanation for why these polarized interpretations occur. The hijacking, as the climax of a longer history of radical attacks 
on Dutch society, forced the reconsideration of a fragile element of Dutch collective identity: i.e. colonial memory. This reconsideration has repeatedly re-appeared into public consciousness since: through public discussions taking place in some of the institutional arenas that Giesen mentions; through the ever-expanding list of cultural and journalistic accounts of the event; and most recently, through the lawsuit. To re-stabilize itself in such situations, society has to re-determine questions of right and wrong, and decide on matters of responsibility and justice. By interpreting the hijackers as perpetrators, they are held responsible for their actions. By interpreting them as victims, their actions are seen as a desperate attempt to gain attention for their treatment as exiles by the government on arrival and ever since, despite their history of loyalty to the Dutch empire. In the latter case, major responsibility is located on the side of the state. In both cases, the hijackers are regarded as deviants who have lost their place as full members of the moral community: 'the moral community constitutes its basic tension and its fringe of restricted membership mainly by pointing to victims and perpetrators'. ${ }^{22}$

The purpose of the analysis thus far was to establish the reasons behind the polarized public interpretations of the hijackers as victims or perpetrators. The next step is to use these considerations as the basis for a close-reading of some of the contributions on the film's online forum, in order to study the kind of public debate which this platform encouraged.

\section{De Punt's online discussion forum: A platform for further polarization}

At the end of the film, a text appears on-screen, inviting the viewers to visit the accompanying online forum, in order to engage in further discussion about the topic: 'Would you like to respond? Go to www.eo.nl/depunt.'23 In her article, in which she analyzes the 363 comments that were posted on the day of the film's premiere, Marselis observes that recurring themes of the online debate were:

the perceived degree of realism of the film, personal memories of the situation in the 1970s, whether the military ending of the action was justifiable or not, wider references to postcolonial politics and so on. ${ }^{24}$ 
Especially the question concerning the degree of justification of the hijacking itself, as well as the state's response to it, were discussed at length: most of the other elements mentioned served to support this central question about justice. This interest corresponds to great extent to Giesen's argument that in the aftermath of a collective trauma, society feels the need to determine matters of responsibility and justice by identifying victims and perpetrators. Marselis mentions many forum posts accused the film of attempting 'to turn the moral positions of perpetrators and victims upside down'. ${ }^{25}$

According to some discussants, the film's approach 'downplayed the radicalism of the young Moluccans', while others protested the film's (alleged) intention to 'make the Moluccans the victims of the events', something that was at times even identified as 'part of a broader tendency in Dutch society'. ${ }^{26}$ Marselis quotes one post that provides an apt indication of this polarizing element of the online discussion: 'What a terrible shame that we the Dutch always seem to be masters at making perpetrators into victims.' ${ }^{27}$ Alternatively, there were also voices taking up the opposite opinion. For example, one discussant declared to be 'ashamed of the way the Netherlands have treated our Moluccan fellow creatures [sic]. [These] people have been treated like old trash'. Another argued that '[a] people, who have been so loyal to us in difficult times, should not be left alone with this pain and these wounds'. ${ }^{28}$

The above citations were all from Dutch participants, but Marselis also discusses Dutch-Moluccan responses. The latter often drew upon the socalled injustice frame, a phenomenon that was 'found by Beatrice de Graaf in her interviews with the radicalized Moluccans' and which states that 'the Dutch government left the Moluccan minority in the cold, ignored their struggle for independence and gave them false promises'. According to Marselis, the injustice frame was most tangible in the '[n] umerous postings [that] called for an official apology from the Dutch government [...]'. ${ }^{29}$ This points towards a Dutch-Moluccan inclination to sketch the government as being responsible for the trauma. This inclination was further communicated by discussants pointing towards 'the role of the Dutch during colonialism, [as well as] Dutch postcolonial politics in regard to the Moluccan soldier families and a free Moluccan republic'. ${ }^{30}$

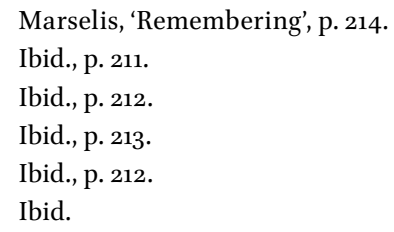


With Dutch discussants interpreting Moluccans as either victims or perpetrators, and Moluccan responses pointing towards the responsibility of the government, the forum's content can be interpreted as predominantly polarized. This polarization furthermore gained an ethnic element, because of the forum's protocol to ask discussants to state 'their afkomst ('origin'), [which] meant that many participants categorized themselves in terms of ethnic or national belongings', and which leads Marselis to conclude that the web debate served as the platform for 'a cultural encounter between people of Dutch-Moluccan and of Dutch majority background'.${ }^{11}$ With this requirement, the forum reduced the discussion to a conflict between two ethnic groups.

In short, the forum to a great extent furthered the polarization which the previous section identified as a main characteristic of public debates about the hijacking. Despite its aimed function as a platform for participatory societal debate, the forum to great extent reduced the discussion to a back-and-forth between polarized opposites: guilty and innocent, victim and perpetrator, Dutch and Moluccan. This part of the analysis was aimed at pointing out the polarizing tendencies of De Punt's online discussion forum. By way of comparison, the next step is to shift the focus from the forum to the film itself, and to provide close-readings of some of its central scenes. The aim of this comparison is to see to what extent the film achieves what the online forum could not, i.e. to bring nuance to the group polarization that is characteristic of public perspectives on the event.

\section{De Punt's fictive discourse: Complicating the possibility of polarization}

Telefilm De Punt presents a story around a fictional talk show called Met andere ogen ('With Other Eyes'), for which several people are invited that were involved with the hijacking: a surviving hijacker, the father of a killed hijacker, a hostage, a marine who was part of the special task force that ended the hijacking, and former Minister of Justice Dries van Agt, who had sanctioned the task force. These guests are all portrayed by actors, but are based on real people. Over a sequence of images that one by one introduce the main characters, a voice-over reads out the invitation letter which they all received from the television station:

For our television programme about Moluccans in the Netherlands, we would like to dedicate some time discussing the train hijacking in De 
Punt. [The hijacking] made history not only as a result of its violence, but also because of the involvement of a female hijacker, Noor Pattipamena. [...] Very little is known about this woman, who was probably the first female terrorist in the Netherlands. Together with you and four other guests, we want to try to give her a face..$^{32}$

With this approach, the film frames the hijacking as an event that is remembered differently by different parties. Every invited guest functions as a synecdoche for one of these parties, i.e. each of them represents one of the groups that were involved in the hijacking. The former hostage represents the hostages; the marine represents those who were part of the special task force; Van Agt represents the government at the time; former hijacker Koen Manuputty represents the hijackers. The father of the deceased hijacker, i.e. Noor Pattipamena, is depicted as being in an ongoing conflict with Koen Manuputty, who was not only the leader of the action, but also Pattipamena's boyfriend. The father disapproved of their relationship and blames Manuputty for his daughter's death. This conflict is shown mostly in flashbacks, but also comes out briefly during the talk show. As such, the conflict can be interpreted as a reminder that the hijacking caused a rift within the Dutch-Moluccan community, between those who supported and those who decried the action. The father, as a representative of the latter, opens up the possibility for viewers to consider the lasting, painful effects which the action has had on them.

These lasting effects, finally, are represented by the late Noor Pattipamena herself, whose absence precipitates the complicated conversations that happen between the other characters. These conversations are further provided with a sense of urgency due to the film's choice to have cast all characters, except former Minister Van Agt, as being personally related to Pattipamena. Apart from her father, and her boyfriend and co-conspirator, the other guests are the marine who killed her (which in the film is depicted as an accident in the midst of the chaos), and the hostage who became friends with Pattipamena during the hijacking and in whose arms she died (the latter element is not based in reality). Because her story is singled out and developed only in the form of flashbacks and personal memories narrated by the other characters,

32 'In het kader van een tv-programma over Molukkers in Nederland willen wij aandacht besteden aan de treinkaping bij De Punt. [De kaping] maakte niet alleen geschiedenis door de gewelddadige aanval maar ook door de aanwezigheid van een vrouwelijke kaper, Noor Pattipamena. [...] Slechts weinig is bekend over deze vrouw die waarschijnlijk de eerste vrouwelijke terrorist in Nederland was. Samen met u en vier andere gasten die destijds nauw bij haar en bij de actie betrokken waren willen wij proberen haar een gezicht te geven.' 
Pattipamena functions as a symbol for the hijacking's tragic and unresolved aftermath. This function is further strengthened by the fact that Pattipamena is based on a real person: the group of hijackers indeed included one female activist, by the name of Hansina Uktolseja. Her death is currently under investigation, because it is now assumed that she was killed despite being unarmed during the military intervention. As such, the lack of closure which her absence in the film's talk show represents, is a direct reference to a real-life lack of closure, i.e. the uncertainty about the circumstances of Uktolseja's death.

Despite the emphasis on Pattipamena's absence, one of the talk show's main aims, and by extension that of the film, is 'to give her a face', as was expressed in the letter which all invited guests received. This aim is pursued by staging her as the central topic of the other characters' conversations, accompanied by frequent flashbacks from before and during the hijackings, in most of which she plays a leading role. In these flashbacks, Pattipamena is often the one who urges her co-conspirators not to use violence against the hostages. When another hijacker argues in favour of violence ('we have nothing to lose'),33 she retorts 'we have everything to lose: not only the action, but also who we are. [...] No victims, that was the agreement'. ${ }^{34}$ Therefore, these flashbacks provide her not only with a face, but also with a voice, which she mostly uses to speak out against violence and in favour of more humane strategies of protest. These practices of giving her a face and a voice complicate her and the other hijackers' interpretations as one-dimensional victims or perpetrators, who according to Giesen, 'have no face, no voice [...], they are numbed and muted, displaced and uprooted' (53). The subjectivity which the hijackers lack in such polarized interpretations, is to some degree restored in the film.

Not only Pattipamen receives a degree of subjectivity: the same applies to the other guests, and by extension the parties they represent. By bringing all these parties into view, by giving them all a voice, and by staging a conversation between them that never happened in reality, (although it could happen), the film invites viewers to place themselves in the positions of these parties one by one and thereby to realize the complexity of the situation. Literary theorists Henrik Skov Nielsen, James Phelan and Richard Walsh (2015) call this practice fictive discourse:

Fictive discourse $[\ldots]$ invents or imagines states of affairs in order to accomplish some purpose(s) within its particular context. Those purposes

34 'Sетиа ('alles'). Niet alleen de actie, maar ook wie we zijn. [...] Geen slachtoffers, dat was de afspraak.' 
can vary widely - sometimes fictive discourse is a strategy for generating a fresh perspective; sometimes it is an implicit argument for change [...]. In this respect, fictive discourse is [...] a means for negotiating an engagement with [the] world. ${ }^{35}$

Through this approach the film complicates the polarized public interpretations which were discussed in the previous parts of this case study analysis. All guests, and by extension the parties they represent, are provided with emotional and ideological context, all of them are granted a face and a voice with which they can motivate their actions and negotiate their positions amongst each other.

The nuance that is thus offered extends to the film's depiction of the government as well. During flashbacks of political deliberation about the hijackings, Van Agt is depicted as someone who is torn between two sides. In his capacity as the Minister of Justice, he has to make decisions about what measures to take against the hijackers, whereas on the personal level, he is not at all feeling certain about these decisions. His portrayal as a reluctant mediator between his colleagues' opposing opinions about the issue at hand, urges viewers to consider that the government's involvement in the event is at least as complicated and internally conflictive as that of the other parties involved. Their sanctioning of the military intervention was the result of a group of people debating matters of life and death under time pressure and making decisions based on majority votes. This means that 'the government' as a body cannot be held unanimously responsible for the hijacking's ending, because individual people involved in the decision-making process might have opposed the measures that were eventually agreed upon.

This part of the case study was meant to explore how De Punt, unlike the accompanying online forum, achieves a degree of nuance with regard to the way it remembers and discusses the hijackings and their aftermath. Rather than trying to identify victims and perpetrators, the film uses fictive discourse in order to suggest that there were more than just two parties involved, and that all of these parties' perspectives on the hijacking are worth considering. A preliminary conclusion that can be drawn here is that the film, despite lacking the online forum's possibility of interactive participation, still seems to be a more suitable medium for breaking down the rigid polarization common in public perceptions of the hijacking. The next step is to discuss the implications of this conclusion, with regard to the perceived effectiveness of online discussion. 


\section{An echo chamber for the polemical few}

Marselis sees the online forum as a step towards 'more inclusive memory cultures, where national collective memories make room for individualized and minoritarian voices and where opposing interpretations may coexist ${ }^{\prime}{ }^{6}$ Within the context of the findings that were presented in the previous sections, this argument requires further scrutiny. During her discussion of preliminary considerations about the forum posts, Marselis states:

Obviously, the viewers who took up the invitation to respond and debate were not representative of all viewers. Rather, the comments were posted by viewers who had been especially moved by the telefilm, were especially positive towards or angry about it or already had a special interest in this part of Dutch, postcolonial history. ${ }^{37}$

What can be taken away from this consideration is that the contributors to this online discussion were viewers who had pre-existing reasons to voice their opinion about the topic. Correspondingly, Sunstein argues that the internet's influence on public debate is often

one of fragmentation, with certain people hearing more and louder versions of their own pre-existing commitments, thus reducing the benefits that come from exposure to competing views and unnoticed problems..$^{38}$

In other words, a space that allows a plurality of voices does not automatically lead to a productive discussion. Marselis points this out as well, when she argues that 'user-generated comments have strength in terms of spontaneity although they may be lacking in terms of complexity'. ${ }^{39} \mathrm{~A}$ collection of intuitive, unfiltered comments therefore does not necessarily become a productive conversation, but could instead become an echo chamber for recurring, polarized voices.

In his article, Sunstein criticizes this, to him, unconvincing general predilection for 'spontaneous' public deliberation, by asking:

Why deliberate? [Those] who emphasize the ideals associated with deliberative democracy tend to emphasize its preconditions, which include 
political equality, absence of strategic behaviour, full information, and the goal of 'reaching understanding'. In real-world deliberations, behaviour is often strategic, and equality is often absent in one or another form. ${ }^{40}$

This argument is a critical reminder that optimistic theories about the productive possibilities of the internet as a 'horizontal', participatory space, often seem to be based on the assumed possibility of a neutral starting point, devoid of pre-existing power relations that influence participation into specific directions. The online forum's contributions that were discussed previously showed that Dutch participants had a tendency to interpret the hijackers as either victims or perpetrators, while Moluccans tended to blame the government for the role they played during the migration, as well as during the colonial era at large. These tendencies are hardly surprising when taking into account the wider context of the public debate and the power dynamics in place. Not only was the hijacking to some extent a symptom of a colonially marked, historically controversial ethnic divide between Dutch and Moluccans, it also further escalated this divide. Because the hijackers were Moluccans, and the state they addressed their attack to was the Dutch state, there were pre-existing differences in place between the social and political positions of the forum's participants, which influenced the content of their debate.

Sunstein alludes to this common presence of unequal starting positions in public debate, when he argues that 'deliberation predictably pushes groups toward a more extreme point in the direction of their original tendency', which leads him to emphasize 'the importance of paying far more attention to the circumstances [...] of deliberation'. ${ }^{41}$ The circumstances of the online forum, for example, included the requirement for contributors to state their ethnic belonging, i.e. something which Sunstein directly argues against: 'when the context emphasizes each person's membership in the social group engaging in deliberation, polarization increases'. ${ }^{42}$ The point here is not so much to argue that the discussion's focus on ethnicity was purely produced by the structure of the forum: given the issue at hand, it is quite likely that contributors would have identified with one or the other ethnicity in any case. Instead, the argument concerns the question of the forum's responsibility to try to prevent, rather than strengthen, such patterns of stratification. 'In this light', says Sunstein, 'a system of checks 
and balances might be defended, not as an undemocratic check on the will of the people, but as an effort to protect against potentially harmful consequences of group discussion'. ${ }^{43}$ A thought-experiment, for instance, would be to hypothesize what would have happened to the discussions if the forum would have disallowed the possibility of stating one's ethnicity.

These considerations indicate that one of the major weaknesses of online discussion platforms is exactly the lack of moderation which proponents of the internet's participatory culture so strongly favour. This observation corresponds to Sunstein's argument that creating the possibility of non-polarizing deliberation is a matter of 'institutional design' (90). As he argues, because 'small groups of deliberators have relatively clear antecedent tendencies in one or another direction', they could benefit from the participation of 'moderators, trained to make sure that no one dominates the discussion, to ensure general participation, and to ensure a level of openness likely to alter some of the dynamics discussed here'. ${ }^{44}$ This appeal to a stronger monitored form of deliberation can be supported by considering Marselis's observation about the forum's general lack of 'aggressive or coarse language'. ${ }^{45}$ In her conclusion, she explains this fact as follows:

The tone of the debate was remarkably sober compared to other recent studies of user-generated comments discussing collective memory on YouTube, which has been described as having a harsh debate culture. Commenting on the website of a public service broadcaster might have framed the debate about De Punt so that users showed each other respect. ${ }^{46}$

Another reason she sees for the form's respectful tone is that the forum was 'influenced by the inclusive memory culture proposed by the filmmakers'. ${ }^{47}$

The argument here is that, unlike similar discussions on YouTube, the forum's discussion was guided by certain external factors, that prevented the platform from becoming a participatory free-for-all. These factors, i.e. the contextualization of the forum within a public service broadcaster, and as an accompanying feature to a film aimed at providing nuance to the topic at hand, could also very well be the main reason that, in Marselis's words, 'the user-generated reactions turned into a fruitful debate that showed 
some degree of reconciliation. ${ }^{48}$ Marselis is referring to those discussants that responded more or less in correspondence to the nuance which the film had originally intended. For example, she cites one discussant as arguing that the film 'shows that reality is more complex than a simple distinction between good and bad or perpetrator and victim'. ${ }^{49}$ However, such responses mostly adhered directly to the film, typically mentioning 'how touched they had been by the film and their appreciation for seeing the event from different perspectives..$^{\circ}$ For that reason, such reconciliation is at best a reference to the achievements of the film, rather than to those of the forum.

Moreover, even when a reconciliation is reached between several participants of a localized internet discussion, one could wonder what significance this has for the larger societal debate. After the forum discussions of this case study took place in 2009, the topic has been discussed on many other online platforms as well, especially since the 2014 lawsuit started. Further analysis of such more recent discussions would show that polarized opinion, including conflicts about the determination of victims and perpetrators, are as common as before, and very little signs of a more informed approach towards colonial memory can be observed. In some cases, especially those that come closest to the non-moderated structure which Sunstein argues against, the practice of identifying victims and perpetrators happens in more directly violent ways as compared to the respectful character of the discussions of De Punt's forum.

A 2014 article on the right-wing, predominantly nationalist-oriented news website GeenStijl may serve as an indication for such violence. ${ }^{51}$ The article was in response to the news that the hijackers' next of kin had sued the state, accusing them of having approved disproportionate violence. The article describes the indictment as 'the ceaseless whining of the Moluccan hijackers' next of kin, who, 37 years after the fact, come crawling from all corners and bullet holes, to tell us about that horrible Saturday morning

48 Ibid.

49 Ibid., p. 211.

50 Ibid.

51 For a more detailed description of GeenStijl, see Frans-Willem Korsten's contribution to this volume: '[Geenstijl] literally means 'Nostyle'; it is a pun that might be translated as Badform. Dumpert, connotes the English 'to dump'. Both were (and still are, November 2018) platforms of TMG Digital, part of the Telegraaf Media Group - part of an official right-wing media group, that is, with a turnover of 35 million Euros. Despite its being part of a journalistically oriented media group the subtitle on the GeenStijl site perverts any journalistic attitude in stating: 'insinuating, unfounded and needlessly offensive'. 
11 June 1977 from the perspective of their victim roles' (20 November 2014)..$^{2}$ The article's webpage features a large amount of responses that are all outspokenly in agreement with it. One contributor responded: 'Yet another group of lost cases cast in the role of victims. If only they would stop whining to their offspring about their 'beautiful' land of origin, there would be less collateral damage down the line. ${ }^{53}$ Another contributor adds that the leftist media 'are doing everything they can [to change] the perpetrators into victims. Disgusting. ${ }^{54}$

This is a small selection of a longer list of responses, all posted in the first few minutes after the publication of the original article, creating a massive voice of unfiltered, aggressive antagonism. Such responses support Sunstein's warning that 'when people are hearing echoes of their own voices, the consequences may be far more than support and reinforcement', including 'unjustified extremism, indeed fanaticism'. ${ }^{5}$ As such, discussion forums, depending on their degree of moderation, risk becoming echo chambers for the polemical few, which form 'a potential danger to social stability, a source of social fragmentation or even violence. $5^{6}$

\section{Conclusion}

Such extreme versions of the echo chamber, understood as escalated variants of the more modest one analyzed in the current text, to me indicate several structural dimensions of the occurrence of online violence. The limiting and stratifying structure of the online forum as a medium for societal debate, seems at best to result in localized reconciliations that have no further consequences for the larger debate taking place outside of the platform, and at worst to invite the possibility of unregulated, violent antagonism. The reason for this less than satisfying effect is that, far from representing society at large, discussion spaces such as De Punt's forum tend to attract

$5^{2}$ '[...] het onophoudelijke gejammer van de nabestaanden van de Molukse treinkapers. 37 jaar na dato komen zij uit alle hoeken en kogelgaten gekropen om vanuit een slachtofferrol te vertellen over die verschrikkelijke zaterdagochtend 11 juni in 1977.'

53 'Weer een groep dwaallichten in de slachtofferrol. Wat minder gejank over het "prachtige" land van herkomst richting je nakomelingen voorkomt later restschade.'

54 '[...] nu wordt er alles op alles gezet [...], waar of niet waar om hen zoveel jaren later te kunenen $[s i c]$ beschuldigen en de van de daders $[s i c]$ slachtoffers te kunnen maken. Walchelijk $[$ sic].'

55 Sunstein, 'The Law', p. 82.

56 Ibid. 
contributors who enter the debate with pre-existing opinions, and a desire to express themselves. If the discussion that follows is to some extent contained or directed by productive external factors, such as the film itself, a degree of reconciliation may ensue, albeit purely within the boundaries of the forum and as such relatively ineffective on a broader societal scale. Without such moderating factors, the result may well be, and often is, the occurrence of online violence.

Therefore, contrary to the still prominent interpretation of the internet as a democratizing and participatory space, I would direct my hope for a more inclusive collective identity towards a plea for an increase of precisely the 'expert-driven discussions' that Marselis wants to move away from. ${ }^{57} \mathrm{As}$ such, I follow postcolonial theorist Gloria Wekker's point of view (2016), who states that, "[judging] by curricula at various educational levels, from grade school to university level, it is the best-kept secret that the Netherlands has been a formidable imperial nation'. ${ }^{8} \mathrm{~A}$ more informed education curriculum, led by experts who are capable of moderating discussions about the shared past, seems like a better place to start a more nuanced understanding of the postcolonial present, than an unguided discussion space for polarized voices.

\section{Works cited}

Barker, Ralph. Not Here, But in Another Place. New York: St. Martin's Press, 1980.

Bartels, Dieter. 'Can the Train Ever Be Stopped Again? Developments in the Moluccan Community in the Netherlands before and after the Hijackings'. Indonesia, vol. 41, 1986, pp. 23-45.

Chauvel, Richard. Nationalists, Soldiers and Separatists: The Ambonese Islands From Colonialism to Revolt, 1880-1950. Leiden: KITLV Press, 1990.

Dam, Aart van. Dood spoor: Een vrijheidsideaal ontspoort tot terreur. Krimpen aan den IJssel: Aart van Dam Media, 2009.

Doorn, J.A.A. van, and W.J. Hendrix. Ontsporing van geweld. Over het NederlandsIndisch / Indonesisch Conflict. Rotterdam: Universitaire Pers Rotterdam, 1970.

Giesen, Bernhard. 'Victims: Neither Subjects nor Objects'. Triumph and Trauma. Boulder: Paradigm Publishers, 2004, pp. 45-73.

Graaf, Beatrice de, and Maarten van Riel. 'Hansina Uktolseja (1955-1977)'. Historisch Nieuwsblad 4, 2008, https://www.historischnieuwsblad.nl/ hansina-uktolseja-1955-1977/. 
'Hoe Nederland wekenlang zijn adem inhield bij treinkaping De Punt'. Nos, 29 May 2017, https://nos.nl/artikel/2175675-hoe-nederland-wekenlang-zijn-adem-inhieldbij-treinkaping-de-punt.html.

Jenkins, Henry. Confronting the Challenges of Participatory Culture:Media Education for the $27^{\text {st }}$ Century. Cambridge (MA): MIT Press, 2009.

‘Treinkaping De Punt 1977. Kappen nou'. GeenStijl, 20 November 2014.

Marselis, Randi. 'Remembering Dutch-Moluccan Radicalism: Memory Politics and Historical Event Television'. Memory Studies, vol. 9, no. 2, 2016, pp. 203-217.

Mee, Tonny van der. 'Van de Molukkers kunnen we zoveel leren'. Algemeen Dagblad, 9 February 2018, https://www.ad.nl/binnenland/van-de-molukkers-kunen-wezoveel-leren ab3ef2fe/.

Nielsen, Henrik Skov, James Phelan, and Richard Walsh. 'Ten Theses about Fictionality'. Narrative, vol. 23, no. 1, 2015, pp. 61-73.

Oest, Paula van der. Wijster. Hilversum: varA, 2008.

'Over Telefilm'. CoBo, https://telefilm.cobofonds.nl/over-telefilm/.

Pessireron, Sylvia. Gesloten koffers. Amsterdam: Overamstel Uitgevers, 2014.

Roelofs, René. Dutch Approach. Amsterdam: Pieter van Huystee Film, 2000.

Scholten, Jaap. Morgenster: roman in drie delen. Amsterdam: Uitgeverij Contact, 2000.

Smitsman, Hanro. De Punt. Hilversum: Motelfilms/EO, 2009.

Sunstein, Cass. R. 'The Law of Group Polarization'. Debating Deliberative Democracy, edited by J.S. Fishkin and P. Laslett. Oxford: Blackwell publishing, 2008, pp. 80-101.

Wekker, Gloria. White Innocence. Paradoxes of Colonialism and Race. Durham: Duke University Press, 2016.

Westerman, Frank. Een Woord Een Woord. Amsterdam: De Bezige Bij, 2016.

\section{About the author}

GERLOV VAN ENGELENHOVEN is a lecturer of courses on art, culture and postcolonial theory at the Universities of Amsterdam and Leiden, and at the Royal Academy of Art in The Hague. He defended his PhD dissertation at the Giessen International Centre for the Study of Culture, Justus Liebig University, in 2020. The dissertation has a focus on matters of colonial memory and identity articulation among the Dutch-Moluccan postcolonial migrant community in the Netherlands. 
Affects of Online Vitriol 



\title{
$7 \quad$ Love and Hate Online
}

\author{
Affective Politics in the Era of Trump \\ Greta Olson
}

\begin{abstract}
This chapter examines the affective politics of online vitriol in the era of Trump, the first Twitter president. Trump's use of Twitter shapes the affective resonances of his presidency by fueling experiences of love as well as indignation. These dynamics are unpacked by examining the online style of Donald Trump and Mike Cernovich, a self-appointed spokesman for MAGA and the New Right. The chapter first outlines how affect theory helps to comprehend the emotional politics of Trump's presidency in a manner that goes beyond notions of its simply invoking hatred. Second, the chapter argues that social media platforms create pleasurable in-group community experiences that function to produce collective support for Trump.
\end{abstract}

Keywords: Trump presidency, Twitter president, affect theory, affective politics, affect and social media

This chapter outlines how affect theory can help to understand the emotional politics of online hatred and its counterpart, online love. Affect describes pre-verbal experiences of feeling rather than emotions, which are experiences that have been translated into and thus already explained through words. Affective experiences include getting hot and having one's skin turn red when one feels embarrassed or getting goose bumps when one feels afraid. These feelings are deeply embodied and have little to do with rational arguments that are expressed in words. This chapter also wants to offer a bit of pushback against what I now see as a dominant narrative about the negative effects of social media. This narrative says that social media represents a 'threat to democracy' and to civility and that the main

Polak, Sara, and Daniel Trottier (eds), Violence and Trolling on Social Media. Amsterdam, Amsterdam University Press 2020 DOI: 10.5117/9789462989481_CHO7 
impetus behind online engagement and interaction is a sense of disgust or a thirst for novelty. ${ }^{1}$

The primary affects expressed in individual and group contributions to online vitriol have been described as outrage and a sense of 'fellowship' in commonly expressed grievance. ${ }^{2}$ Outrage is certainly the preferred mode of the first Twitter president Donald Trump, who likes first to berate others in his tweets and 'then escalate' whatever conflict is at hand. ${ }^{3}$ Alternatively, the desire for attention from both one's peers and perceived enemies, also through shared humour, is said to drive trolls. How does this affective economy of vitriol, including experiences of extreme anger and a desire for violence, Schadenfreude, humour, and a hunger for recognition actually operate? Why can online vitriol only be understood with reference to its opposite, online love? How do the as yet unnamed and undertheorized experiences of pleasure and feeling positively connected fit into this mixture of intense sensations? Why do we need to think about political discourse and the politics of social media differently because of affects?

This chapter starts to address these questions. It notes preliminarily that theories of political and social intercourse have traditionally described a public commons that is governed by rational discourse and exchange. This presupposes that communication occurs primarily through language, that language is used to represent a commonly agreed upon reality, and that agreements about perceptions of this reality can be made on the basis of rational exchange. This reality is then also understood to be experienced mutually and to be negotiable through a commonly understood language.

An affective theory of the political, by contrast, suggests that political sentiments are determined by viscerally experienced sentiments and a physically imagined sense of rightness or wrongness, rather than one that is worked out through rational means. This aligns with notions of persuasion that stress pathos - the evocation of feeling - as an at least as important part of rhetoric as logos and ethos - the logical/evidentiary and the communicator's conveyed sense of authority, respectively. Moreover, a sense of affective loyalty or being strongly bound to those who agree with one fuels a heightened sense of 'taking one for the team' and outdoing one another in terms of expressing online venom and eliciting strong reactions from those one vents against.

1 Cf. The Economist cover story of 4 November 2017, entitled 'Social media's threat to democracy' and Vosoughi et al., 'The Spread' on the primacy of the 'basic emotions' of disgust and novelty in the spread of false news.

2 'Politics of Outrage', p. 23.

3 Gessen, 'How Trump governs by tweet'; Baker, 'A Trump Vacation Formula'. 
More rational models have traditionally comprised deontological ethics, based on should(s) and ought(s) between subjects, or utilitarianism, based on an interest in minimizing suffering and maximizing the common good. Further, Jürgen Habermas's notion of social communication was based on a linguistic model of exchange that was grounded in the ideal that every group would be able to equally participate in the process of developing rationally agreed upon norms through discussion and coming to consensus about better, that is more rational, arguments for these norms. ${ }^{4}$ Habermas writes that: 'The concept of communicative action presupposes language as the medium for a kind of reaching understanding, in the course of which participants, through relating to the world, reciprocally raise validity claims that can be accepted or contested.' 5 Through language, speakers can convince one another discursively about the validity of their claims using rational means. In contrast to Habermas, I am arguing that we need now to take a post-linguistic approach to the political, one that accounts for what has been called the affective turn in critical theory. ${ }^{6}$

In contrast to rational-choice theories of the political or to ones based on a notion of a common consensus that can be attained through communicative means, political thinkers like Chantal Mouffe describe a political climate in which the affective has to be taken with great seriousness: 'My claim is that it is impossible to understand democratic politics without acknowledging 'passions' as the driving force in the political field'.7 In the spirit of Mouffe, I would like to move away from a poo-poohing of affectively experienced and expressed politics as the result of a vulgar populism. Rather, I wish to explore how the political is literally felt differently in our historical moment, the era of Trump, and how these feelings are expressed in social media exchanges. To look at the affects of online vitriol as well as those of what, to my mind, have been the still underdiscussed phenomena of online affection and connectivity, I want to look at Donald Trump's discourse first. Trump, it is generally agreed, has mastered the art of affective elicitation and has garnered a sense of loyalty amongst his followers that is genuinely difficult to explain rationally. Put bluntly, Trump has been able to spread a sense of hatred of his perceived enemies so effectively only because he is so talented at bringing out a sense of fierce love in his followers. After thinking about

4 Habermas, The Theory.

5 Ibid., p. 99 .

6 Clough and Halley, Theorizing the Social; Clough, 'Political Economy'; Leys, 'The Turn to Affect'; Olson, 'The Turn to Passion'.

7 Mouffe, Agonistics, p. 6. 
Trump's affective style, I wish to look more closely at the online expressions of a self-chosen spokesman for Trump and the New Right, Mike Cernovich, before finally commenting, more generally, on how affect functions online.

\section{Genealogies of affect}

Versus a history of philosophy that has favoured the rational while exiling the irrational, the felt and the embodied, affect theory favours the somatic and questions the validity of representations that are based on descriptive notational systems. This is in contradistinction to Cartesian rationality which sets up a model in which there is a strict relation of control between the mind and the objects of consciousness that are contained in that mind and are accessed through cognition. Cartesianism extends into the present in that we use linguistic and/or other forms of semiotic representation to signify something as being such a thing. Writing about the break from this kind of notational economy that is based on the semiotic sign, Karen Barad remarks that 'the belief in the ontological distinction between representations and that which they purport to represent' has been obliterated by the notion of affect. ${ }^{8}$

Affect theory has more than one genealogy. The one I follow more closely extends from Baruch Spinoza's emphasis on the irreducibility of ideas from the body in his 1677 Ethics. Considered a heretic, Spinoza directly contradicted Descartes's insistence on a dualism of mind and body as postulated in his Mediations (1641). This involves making rationality the sine qua non of existence. Descartes' 'I think, therefore I am' means that the process of cogitating precedes and is the precondition for one's being. Embodiment is a secondary state to cognition and therefore, like the environment, of a second-order status. By contrast, Spinoza writes in Ethics that 'the body cannot determine the mind to think, nor the mind the body to remain in motion or at rest'. 9 The two are inseparable.

Other anti-Cartesians have shown up within the history of Western philosophy in the work of thinkers like William James, Henri Bergson, the phenomenology of Merleau-Ponty, and in Cognitive Metaphor Theory, which espouses a theory of the embodied mind. Yet the twentieth-century philosopher Gilles Deleuze's reading of Spinoza's affectus has perhaps become the most seminal basis for theoreticians like Brian Massumi, Rosi Braidotti, 
and Mieke Bal. Deleuze describes affects as embodied states of intensity. This is according to Deleuze's and Felix Guattari's translator Massumi to be understood as 'a prepersonal intensity corresponding to the passage from one experiential state of the body to another and implying an augmentation or diminution in that body's capacity to act'. ${ }^{\prime 0}$ Leading Deleuzian figures of relation include 'intensities, machinic assemblages and their various types, bodies without organs"11 and the rhizome, which 'assumes very diverse forms, from ramified surface extension in all directions to concretion'. ${ }^{12}$ These forms provide metaphors for how things may be related without the linearity of beginning or end, subject and object, or the presence of a human.

Note that the affective is independent of individuation and personhood, denotation and consciousness. Affective relations are accordingly anti-narrative in that narrativization involves a structuring of experience through minimal narrative units that are generally set up in a linear relation to one another. Such units are for the greater part verbally processed and transmitted. Affects exist prior to their being articulated in speech or through other language-related forms. They are felt or experienced rather than related through words or other representational systems. Bodies, and not necessarily human ones, meet one another, skins touch, affects are sent forth and returned.

Another genealogy of affect theory arises from the psychologist Silvan Tompkins's notion of basic emotions, which are shared affectively when one unconsciously mimics, for instance, the happy, smiling face one has unexpectedly encountered in the subway. Affects are expressed in non-verbal reactions, and particularly in facial expressions. Tompkins's hypothesis is that basic emotions are shared through the report or representation of these emotions in affects. 'All affects, with the exception of startle, are specific activators of themselves - the principle of contagion'. ${ }^{13} \mathrm{He}$ explains this with the image of an infant who continues to cry even after the source of the tears has been alleviated: "This is because crying is as much to cry about as adequate a stimulus as is pain. [...] we are referring not simply to the response of crying, but to the awareness, or report of crying. ${ }^{14}$

Tompkins works with a notion of affect as non-verbal reaction and expression. According to Tompkins, intrinsic affects are experienced in 
the face, whose expressions are highly resonant in terms of how they are responded to, and thereby elicit emotions in others contagiously. The idea of what is alternatively termed emotional or affective contagion has been popularized in psychology to suggest that personal happiness for instance is more dependent on the equanimity of one's friends and loved ones than on one's personal material conditions. ${ }^{15}$ It has also been used to show how direct touch, for instance between mothers and their infants, positively impacts shared affects. ${ }^{16}$

Typically, models of contagion describe a three-part pattern of mimicry feedback - contagion and are based on ideas of direct interactions between persons. ${ }^{17}$ It has also been used to describe the affective work that artistic images do. Jill Bennett calls 'affect contagion' the transportation of physically felt experience through the elicited awakening of similar somatically embedded experiences. Such images 'touch the viewer who feels rather than simply sees the event, drawn into the image through a process of affect contagion,' a reaction that 'precedes the inscription of narrative, of moral emotion or empathy'. ${ }^{18}$ Bennett's work is important in this regard because the affective charges she describes in viewers are elicited through images and not through non-verbal behaviours like smiling or snarling. This plays a part in the not yet adequately understood process of how affects are spread contagiously via digital media. We know that Facebook has experimented with trying to shape its users' affective responses by manipulating users' incoming content. This resulted in the insight that ' $[\mathrm{e}]$ motions expressed by friends, via online social networks, influence our own moods, constituting, to our knowledge, the first experimental evidence for massive-scale emotional contagion via social networks.' ${ }^{19}$

Jodi Dean has suggested that online exchanges contain 'affective nugget $[\mathrm{s}]^{20}$ that take place within the frame of 'communicative capitalism' in which users are hailed into capitalist labour practices in which they act as both producers and consumers. ${ }^{21}$ Affective nuggets provide a useful alternative to the logic of narremes, that is how minimal narrative units relate to one another. The haptic quality of nuggets also allows us to think about bonds between similarly effected/affected individuals as also taking

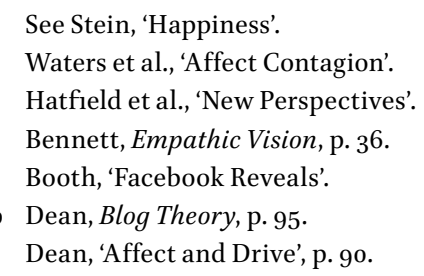


place in the body. Dean, like others, has suggested that social media can only function because it is pleasurable and its makers create it as it is. ${ }^{22}$ Let us suppose that a sense of enjoyment, titillation, pleasure in the outrageous and boundary making between an in-group and an imagined outgroup form the basis of online vitriol and online love in the Trump era. If this is the case, studying the libidinal politics of Trump's media presence as well as of one of his self-appointed knights of the round table, Mike Cernovich, may be a way to understanding the felt politics of the present.

I suggest we move away from the negatively connoted metaphors of illness and non-volition that are suggested by 'contagion' and 'going viral' and think about affective contagion in a neutral sense, as the stickiness that binds people and also pushes them apart. Why is this so effectively elicited and transmitted through digital means, and how does this digitally elicited affective contagion determine personal sentiment so strongly at present? This notion of the contagiousness of the affective, its stickiness, stands somewhat in contrast to the negative reading of virality that Sara Polak offers in this book.

\section{Trumpian affects}

One of the perplexing things about the Trump era is that many of his supporters perpetuate a pattern in which working-class people support Republican candidates whose fiscally conservative policies are to their clear economic detriment. ${ }^{23}$ This trend, which is generally dated back to the culture wars of the 1980 s, has, if anything, intensified in the polarized media economy that surrounds Trump's presidency. The more Trump is criticized, it would seem, the more his supporters insist on their loyalty to him and their belief in the verity of the version of facts he espouses. ${ }^{24}$ This affective attachment to Trump is often explained as people's having fallen prey to the appeal of an authoritarian personality whose discourse and style reduces complexity and gives the disaffected a sense of safety in what is perceived as a belligerent or unsafe environment. The appeal of authoritarianism may be one part of the equation.

Yet Trump also needs to be credited for his having cued into a new political economy of passion, excess, and the naming of subjects once considered 
unmentionable, at least by a politician on the public stage. Trump makes racist slurs, regularly incites Islamophobia and has dissed disabled people, and called immigrants 'animals' as well as 'rapists.' He has also repeatedly wagged fingers at women who have gained weight, were supposedly menstruating while questioning him, women who were lactating, women who are not loyal to their husbands, and women who fail to be as 'attractive' as Trump's wife. The list goes on. This is not to mention Trump's self-fashioning in social media, that is to say how his presentation of himself in images and central narratives has contributed to creating a newly affective online environment:

He at once defines the field through his celebrity and performances which generated outrageous, cheap-to-produce content with each news cycle, while opening this space to the pure affective intensity of the alt-right. ${ }^{25}$

Trump supporters maintain loyalty and a sense of passion towards him, because he is a master of rousing passionate responses and using these responses effectively in media expressions and reports. Trump 'is completely modern in embodying the values of affective media in eliciting the libidinal energies of his audience. ${ }^{26}$

Trump, I am coming to believe, serves as much as a blank screen as Obama once did for the projection of a variety of diverse kinds of desire. Yet he has shown himself to be uniquely qualified in calling out expressions of hate, derision, and boundary making, as well as love. It is a mistake, I think, to concentrate on the negative affects that Trump inspires without also looking at the sticky attachment and sense of love and/or loyalty that he also calls out.

Trump supporters identify with the emotional immediacy of Trump's address. He offers a sense of closeness and intensity by rhetorically breaking down the world into winners and losers, by championing the - according to him - formerly strong white men and working people who have been unreasonably weakened by Washington elites, and through his repeated attestations of love for these people. Note how he expresses a sense of shared affection at his rally in Phoenix in August 2017:

\section{CROWD: USA! USA! USA! [...]}

You always understood what Washington, D.C. did not. Our movement is a movement built on love. Our movement is a movement built on love. 
It's love for fellow citizens. It's love for struggling Americans who've been left behind, and love for every American child who deserves a chance to have all of their dreams come true. ${ }^{27}$

The rally in Phoenix was held shortly after Trump had made equivocal comments about supporting the white supremacists responsible for attacks on counter-demonstrators in Charlottesville, VA. The 'love' that he insisted on in Phoenix and which is at the basis of his movement may well sit uneasily with readers of this chapter. Yet it needs to be taken seriously as the attestation of a world view in which the in-group of Trumpians feel themselves to be passionately attached to each other and to a shared sense of felt identity. It is their 'dreams' that have been delayed, according to Trump. They, this group 'built on love,' stand in radical opposition to the haters in Washington, D.C. 'You,' as Trump addresses them in the second person, are the true lovers, dreamers, and believers.

And Trumpians do believe. On a website that charts Rustbelt Trump voters' evolving opinions about their candidate before and after the election, one finds a continuing stream of steady support. For instance, the 54-year-old Ohioan driver and former Democrat voter Geno DiFabio speaks about the continued affective appeal of his candidate. Regarding criticism of Trump's failure to get a new health-care bill through Congress and other setbacks, DiFabio's position changed little between March and November 2017. If anything, his ratings of Trump on a 1-10 scale went up.

All they're doing is solidifying the people that voted for him, believe me. Sometimes he says stupid stuff, but he's still the only one that's going to do anything for us, fight for us, actually fight for us. ${ }^{28}$

One notes the sense of affective connection, the belief that Trump is the fighter for 'us,' the people, even if 'he says stupid stuff.' And in July 2017:

I think the swamp in Washington is bigger and deeper than he thought... I pay attention enough to see that no one is helping him as far as there's no cooperation whatsoever from the Democrats and very little from the Republicans. So no, I'm not disappointed. ${ }^{29}$ 
The affective sense is that opposition shows the legitimacy and trueness of the people's candidate, the man who so nobly fights for them. This extends to Trump's tweets and his take on the news:

He's up against a lot more than I thought he would ever be up against, from both sides. The people that voted for him - and I'll bet there's more people every day - are still behind him... At first [his tweeting] made me nervous. I used to cringe - I'd say, 'Oh God, what's he going to say today?' Now, I love it. Now, if they would take it away from him, that would probably ruin his presidency because he can bring what he wants to the forefront and they jump on everything he says. So people can make their own choice: here's what Trump's saying, here's what the media is saying..$^{30}$

I want to pause over DiFabio's self-reflexivity, his awareness that aspects of Trump's utterances once made him uneasy but that he now sees them as a vital part of Trump's truth-saying in the face of media lies. DiFabio uses affectively charged words such as 'fight for us,' 'swamp' and in the last citation 'love.' He expresses certainty that more people stand behind Trump, his politics, and his tweets than during the election.

DiFabio, like others, responds to the alternative route to information these tweets provide as well as their uncensored and surely also for this reason original content. As Trump has repeatedly insisted, his tweets allow him to circumvent traditional media vehicles and coverage as well as to hit back immediately at those who criticize him..$^{31}$ Trump's tweets do offer seemingly unmediated access to the President's thoughts and affects. Their verity is attested to in their bluntness as well as their grammatical and spelling errors.

DiFabio expresses his sense of a world of 'us' - those with Trump - and a world of 'them' - the media and Trump's detractors. Affectively, the greater the intensity of disapproval, or felt hate, that is extended towards Trump, the more love his supporters shall nobly bring to his support. As DiFabio's statement about Trump reveals, the strong identification with him leads to a sense that all criticism is an effort to weaken Trump and is therefore also false. This mirrors Trump's rhetoric that all of his critics are unproductive losers that have personal vendettas against him.

Trump personalizes America's problems as his own in a manner that evokes passions. He insists that the country may excel again if it has a tough 
guy in charge to do battle for it. Making a case for his ability to go to battle, Trump stressed at the beginning of his campaign announcement speech that he would be the fighter-in-chief:

Our country is in serious trouble. We don't have victories anymore. We used to have victories, but we don't have them. When was the last time anybody saw us beating, let's say, China in a trade deal? They kill us. I beat China all the time. All the time. ${ }^{32}$

Whereas the country finds itself in a downtrodden and defeated state, also against China in terms of trade, Trump as tough commander will restore the country to its place of rightful dominance. 'I beat China' is a rallying cry: America under Trump will beat the world. Those who have been unfairly weakened will under Trump's dominant leadership return, like the country in general, to glory.

Trump performs an alternative normative order whose performance is carried out by affective means, in the call and response pattern of his rallies and the binarist logic of his speeches. This logic divides the world into losers - those who are against Trump (the media, Washington, elites) - and winners (his loving and loyal supporters). As explicated by the earlier title of his campaign memoir 'Crippled America,' Trump's dominant narrative concerns the nation's lost greatness. It elicits a nostalgic yearning for this greatness that can be won back through the election of the winner and fixer Trump. This narrative cues in with a generalized sense of lost position and dignity amongst Trump supporters. It is also expressed in Trump's Alt-Right and New Right adherents' urgent desire to recover an imagined, much longed for sense of lost masculine nobility.

Another aspect of Trumpian political affect is his certainty that any news about him is beneficial for his brand and that any negative news about him is simply untrue. As early as 1986, Trump espoused the value of negative coverage in The Art of the Deal: 'The funny thing is that even a critical story, which may be hurtful personally, can be very valuable to your business',33 an idea he repeats in Great Again. ${ }^{34}$ In a chapter from Great Again, Trump (or his ghost-writer) vilifies the press as dishonest, inaccurate, and personal in their vendetta against him: 
They [the media] hate me because they know I don't need them. I learned a long time ago how to talk directly to the people who matter - to regular Americans who are fed up with the career politicians.

That's probably you - the real Americans. ${ }^{35}$

By this view, real Americans align with Trump in despising the traditional press, believing that they are untruthful and have a personal vendetta against their candidate. Note the emphasis on hate to elicit love in the 'real Americans' Trump makes his appeal to.

\section{Mike Cernovich, masculine nobility, and basic bitches}

If Trumpian affective discourse serves as a communicative and sensational model for his online supporters, then it may be worthwhile looking at a self-appointed champion of Trump, Mike Cernovich. A defender of the Manosphere - 'the pick-up artist community [...] groups of men disillusioned with feminism in society, ${ }^{36}$ Cernovich is credited with masterminding Pizza-Gate and currently acts as an alternative news pundit and a self-appointed denouncer of fake news. In a dualistic world of winners and losers, in which Trump is the self-appointed winner, the rest are liars, weaklings, and people without enough to do. Cernovich espouses a similar philosophy: negative news is good coverage and gets attention. Cernovich does in fact possess the wherewithal to make Kellyanne Conway quote his Twitter account as 'unbiased journalism' and for Trump Jr. to retweet his posts. As he states: 'This is why the hoaxing media is so triggered by me. They can only keep saying, 'Don't listen to him; he's not legit' for so long. I'll keep saying the opposite, and I'll keep getting more views on Periscope". 37

Cernovich also acts as a powerful voice in the \#MAGA movement. With reference to Trump's campaign slogan, this movement

was tapping into the fears of voters who felt that the America they lived in, the America they loved, had gone downhill. The slogan speaks to people who desired not just for a new America, but one which takes its cues from the America of old - America updated. America V 2.o. A return 
to the past glory days, to employment, to stability, to working together to realise the American dream..$^{8}$

Note, once again, the emphasis on love, lost greatness, and the simply and accessibly expressed conviction that the country's prelapsarian ideal can be attained again.

Cernovich has recently been as much maligned by the mainstream and the non-mainstream media for his self-promotional tactics, the alleged charges of rape against him, and his presentation of himself as wealthier and more conventionally successful than he actually is..$^{39}$ One could also make the critical point that my writing about Cernovich in this context performs the same kind of academic and media overexposure of Trump that abetted his branding of himself in a celebrity culture, and which contributed to his successful campaign for the presidency. Yet I find that Cernovich's group tactics and his communicative patterns and allusions to traditional notions of masculinity and an ideal of dominance closely align with Trump's affectively resonant rhetorical practices. They are helpful in understanding how the process of expressing hatred and disrespect online occurs on a background of a shared sense of knight-like brotherly love.

Cernovich has repeatedly stated that he is particularly impressed by Trump's straight-talking brand of ostentatious masculinity, his unabashed championing of himself as The Donald, and his victories over his enemies. Trump's triumphal masculinity is not only worthy of emulation but cause for Cernovich's sense of intimate connection. As he proclaims in one Vlog during the campaign:

Trump is just doing what I am doing. He said, Fuck you. Fuck the establishment. I believe in America. Here are my beliefs. When he was confronted about mean tweets he said this is why America is losing. Right, that's the deep shame of real Americans. America used to be a masculine country. That's why America is losing. ${ }^{40}$

Real Americans are associated with a sense of lost and nostalgically longed for male heroism and noble masculinity that Cernovich refers to at the beginning of this video. There he complains of the demise of male ascendance 
due to the feminization of the United States. This imperious masculinity is associated with Trump and is counterposed with 'the establishment.'

The affective love for Trump, the in-group's support for their top dog, might be explained as an instance of hegemonic masculinity. As explicated by R.W. Connell, hegemonic masculinity privileges the top dog or the masculine hegemon. ${ }^{41}$ Yet those men who are subordinate to the hegemon nevertheless profit from their relative position within a hierarchy of masculinity. They are still closer to power than those who are marginalized, like women, those identified with women, and gays. Within a system of hegemonic masculinity, women who have successfully internalized misogyny will be rewarded to the degree that they uphold and enforce the structures of this system to the detriment of other women who are less compliant. By contrast, such women will be treated with hostility who refuse to hold up the prevalent system of male privilege..$^{42}$

Reading Cernovich in light of research on hegemonic masculinity and in reference to biographical details like his denying the existence of date rape, and his penning books on the virtues of masculine domination such as Gorilla Mindset (2015) and Danger \& Play (2016), one notes with interest that all despised persons are described as 'basic bitches'. This phrase deserves unpacking. ${ }^{43}$ The Urban Dictionary lists the top definition of 'basic bitch' as follows:

Someone who is unflinchingly upholding of the status quo and stereotypes of their gender without even realizing it. She engages in typical, unoriginal behaviors, modes of dress, speech, and likes. She is tragically/laughably unaware of her utter lack of specialness and intrigue. She believers herself to be unique, fly, amazing, and a complete catch, when really she is boring, painfully normal, and par. ${ }^{44}$

And in an etymological explanation of the term Slang by Dictionary notes that:

Basic bitch is a term used to condescendingly refer to women who have predictable or unoriginal style, interests, or behavior. [...] For many, the concept of a basic bitch is associated exclusively with middle-class white women, however, this term originated in black culture with a different 
meaning and connotations. In this entry [from Lil Duval and SpokenReason from 2009], basic bitch is defined as 'a bum-ass woman who think she the shit but really ain't.' By 2011, with the release of Kreayshawn's 'Gucci Gucci,' basic bitch had come to refer more specifically to women who rely on popular designer clothing for status: [...]. This definition of a basic bitch as a woman who likes things that are popular because they are popular began to stick. ${ }^{45}$

The term 'basic bitch' coheres with Julia Serano's analysis of 'traditional sexism' as the denigration and deprecation of everything that is associated with the feminine, including pleasure in adornment and ornamentation. ${ }^{46} \mathrm{In}$ the original meaning, 'basic bitch' referred to an uppity woman who refused to know her place. In the now more common usage, the term refers to a stereotypically feminine woman, particularly in terms of her consumerist practices and media tastes. Two forms of gender-related disparagement are carried out in the term. The first is to disdain an identified woman as a 'bitch,' a female dog - ugly, sexually unattractive, animal-like, and hyper-embodied, and the second term 'basic' as more highly so a woman. Work on verbal expressions of gender-based disdain shows that women are typically insulted for being either insufficiently attractive according to normative expectations or for their perceived sexual (over)availability. Men, by contrast, are insulted for being weak, incompetent, or for being like women. Men tend to perceive as the worst kind of insult being told that they are like gay men. ${ }^{47}$

All of this plays into Mike Cernovich's and his followers' multiple uses of the term 'basic bitches.' Significantly, he has named his book series as such. 'Basic bitches' is used as a nomenclature of disdain not only for Trump critics and leftists but also for those who are deemed insufficiently conservative. In the 2016 New Yorker profile that brought Cernovich to national and international attention, he is quoted as saying derogatorily of Hillary Clinton's PR people that:

Her social-media advisers are twenty-four-year-old basic bitches who feel triggered by us, and so they asked their boss to yell at us and make us go away. Well, we're not going away. They just made us stronger. ${ }^{48}$ 
Here the disparagement is that they are women or weak men, who are as such incompetent and unable to defend themselves. Moreover, their weakness calls out an even greater show of strength in Cernovich's army of trolls. In the same article, Cernovich is quoted as saying he shall care for his then unborn daughter 'as long as she's not a basic bitch' and referring to George Soros's son by the same term. ${ }^{49}$

In the following tweet, Cernovich responds to the furor about the comedian Kathy Griffin's 2017 photograph of herself holding the bloody decapitated head of the president:

Basic bitch conservatives go, 'Imagine if a conservative did what Kathy Griffın did.' Yawn. The New Right is calling CNN's advertisers! (@Cernovich, 30 May 2017) $)^{50}$

In this case, basic bitches are insufficiently critical and radical. This is reflected in comments on the tweet such as

Yes please. I'm tired of the right ALLOWING themselves to be bullied. Pathetic. (@sheeplemmings, 31 May 2017) 51 $^{1}$

Yet this form of abuse is also commented on negatively by one Cernovich follower who tweets that

Calling teammates basic bitches really isn't helping the situation (@chanopokes, 31 May 2017) $)^{5^{2}}$

Both responses, one of acclaim and solidarity, the other of critique of Cernovich's discourse, demonstrate how cohesion is created within the group. Group members are intimately concerned with and involved in adjudging, affirming, and editing each other's utterances. This leads to a sense of immediacy, attachment, and mutual involvement.

The pattern I am pointing out is that to be weak in any way is to be basicbitch-like. This is to be insufficiently strong, masculine, dominant, or, in Cernovich's eyes, like a woman. Similarly, the supposedly inadequately radical former House Speaker Paul Ryan is akin to a cuckolded man. Cernovich 
refers to him as 'Cuck Ryan'.53 'Basic bitch' may however also refer to the mediocre and the insufficiently radically conservative, as in the tweet about supposedly lacklustre conservatives' response to the Griffin photograph, quoted from above. Thus, Cernovich pitches his book MAGA Mindset: Making You and America Great Again with an obvious reference to Trump's campaign memoir as follows:

'Readers are tired of basic bitch content,' Cernovich told me, 'They want edge. They want pop. They want swagger. My readers are ferocious and want to stand out. Let the content serfs serve up the same undifferentiated slop. I only want savages and madmen and madwomen reading me. 54

And self-critically about his own work:

My content was getting a little basic bitch, so I had a three hour conversation with a Muslim nationalist. (@Cernovich, 11 June 2017) ) $^{55}$

I do not read Cernovich's use of 'basic bitch' necessarily as a hatred of particular women or of the female gender per se but rather a hatred of being dominated and a desire to win in any contest. The goal is making others submit to one's control. Here, the self-appointed newsmaker mimics his much-admired president. Trump reports proudly on his having beaten up his music teacher in second grade: 'I'm not proud of that, but it's clear evidence that even early on I had a tendency to stand up and make my opinions known in a very forceful way'. ${ }^{6}$ Similarly, Cernovich's supporters, like Trump's, have an affective sense of intense loyalty to and commonality with this mouthpiece of theirs, the New Right movement. This loyalty is experienced as a brotherhood that champions a nostalgic longing for a lost masculinity.

Expressions of an affectively experienced brotherhood of insiders can be found in the following online commentaries. In responses to a Cernovich YouTube teaser for a documentary on fake news called 'Hoaxed' from 8 July 2017, supporters posted comments such as

Ibid.

twitter.com/Cernovich/status/873713799513096192.

56 Trump, The Art, pp. 71-78. 
WoW..!! This is Epic..!! Your Stepping up Next Level Bro..!! Great Job !!! Thank-you \& God Bless you and the Fam Mike for Bringing Truth to the Light.! ('Dick Tracy')

YES , finally someone with balls , I'm in Lock \& Loaded !!!( not literally !!!) ('AimZ29o9')

revelutionary, ground breaking frontal attack that will promote the movement we need towards the liberty and principles this land was ment to sustain. Thank you sir Mike cernovich ('Bearcat Fierce')

I F@ \$(?ing love you Mike! That made the hairs on the back of my neck stand up. Any freedom loving person who doesn't react like I did to this challenge is fast asleep and we must wake them. I can't think of a more noble cause in the world today for anyone who hopes to leave any kind of decent future for our children. Thank you Mike Cernovich. ('Dizzy AUgustopherAG')

Yaaaaa buddy ('Tony N’)

CAPTAIN AWESOME HIT ONE OUT OF THE BALLPARK!!!!!!!!!!!!!!! THAT LAST VISUAL HAD ME LMFAO!!!!!!!!!!!!!! THIS IS THE BEST FREAKING TRAILER I'VE EVER SEEN! BRAVO! ('Texas Cat')

wow..... turn on the arthurian way of legend...enter at the darkest place... where there is no path...now enter at the darkest place... and take it back from the evil ones that left their horrible tracks in us....BRILLIANT!!!! and dangerous...true bravery...can hardly stand to watch this... maga trump... the true living arthurian king.....and YOU a contemporary knight of the round table...where angels fear to tread bro.... ('esmeralda')

Thanks Mike! I appreciate youbrother! ('Patrick Lacy')

King Kong Cernovich Biggest monkey in the JUNGLE. ('H8twoluz')

Without analyzing each comment individually, I would like first to highlight the stress on a felt sense of masculine kinship articulated in words like 'Bro..!!,' 'brother!,' and 'Yaaaaa buddy,' each expression suggesting that the speaker is a common member of a desirable closely linked group of men. Second, the respondents stress the inherent nobility of 
masculinity that is exemplified by Cernovich in creating this trailer for his documentary on fake news. This is documented in expressions such as: 'Thank you sir Mike Cernovich,' and 'maga trump...the true living arthurian king.....and YOU a contemporary knight of the round table... where angels fear to tread bro....' and 'I can't think of a more noble cause in the world today for anyone who hopes to leave any kind of decent future for our children.' In all three cases, Cernovich is portrayed as an altruistic noble who engages in battle for the honour of his king MAGA Trump. Finally, there are positive attestations of Cernovich's superior masculinity and machismo, as in 'YES , finally someone with balls , I'm in Lock \& Loaded !!!' and 'CAPTAIN AWESOME HIT ONE OUT OF THE BALLPARK!!!!!!!!!!!!!!!' and, with reference to Cernovich's earlier work on having a gorilla mindset, 'King Kong Cernovich Biggest monkey in the JUNGLE.' Here, the implication is that by being the top dog, the hardest hitter, the Captain Awesome of the fraternally bonded group, Cernovich champions and improves not only his own status but also that of his brothers. One notes the affective resonance that is conveyed by the use of shouting caps and multiple exclamation marks. These followers feel intently and deeply for their man, Cernovich.

\section{Online affect}

Affective emotions occur in physical sensations of hate, love, desire and disgust. We do not yet, I believe, have a model to explain our current political climate in which affects appear to spread differently via online media as compared to other forms of human exchange. One obvious explanation for expressions of online vitriol is the experience of deindividuation described in social psychology. This involves one's feeling oneself intensely to be anonymous and/or as a part of a group rather than being recognized and potentially also adjudged for one's actions as an individual. This decreased sense of personal responsibility and availability to critique happens in situations in which people feel a powerful sense of group unity, are focused on stimulating outward events, and have a sense of reduced individuality. Experiments on deindividuation show that when test subjects had white sacks placed over their heads they were more likely, in a simulated setting, to induce shocks in others than when their faces were uncovered and they knew that they could be seen. In this case, there are 'weakened restraints against impulsive behavior' as in expressions of online hate, and an 'inability 
to regulate [one's] own behavior'. ${ }^{57}$ In descriptions of motivations behind the Alt-Right and the New Right movements, one finds an obvious gratification in winning and in being outrageous, a sense of pleasure in outsmarting the other side. As Andrew Anglin explains in his guide to the Alt-Right: 'One of the unifying marks of the Alt-Right sensibility is the assumption that no speech act is beyond the pale..$^{8}$ One also finds an expressed sensation of happiness in belonging to a brotherhood with a common purpose. As Angela Nagle has discussed, in-group online subcultures are violently defended through displays of superior skills in manipulating digital forums. 59 Deindividuated, one acts with lessened self-awareness and restraint in what are felt to be the interests of the group.

When groups pile on hate or copy-cat each other's vitriol towards a given person, deindividuation may be at work. Another theory borrowed from social psychology suggests that people are more likely to help others in trouble when they are alone and in direct face-to-face encounters than when they are in groups of bystanders or do not have direct contact with the person in need.$^{60}$ Processes of deindividuation and the diffusion of responsibility when multiple bystanders are present lead to acute concerns about the effects of drone warfare, for instance, about the sense of responsibility in the person operating the drone: what happens when targets are sighted on screen rather than in direct forms of combat? Similarly, anxieties grow about the oversharing that occurs between people who interact digitally rather than in person. The very anonymity of the exchange - the non-touching - appears paradoxically to invite highly personal exchanges, sometimes with painfully experienced consequences that occur in flaming, revenge porn, or other misuses of shared material.

Metaphors of contagion have also been used to describe what happens when people strongly empathize with anonymous others online in what might be described as online love rather than vitriol. Cassandra Sharp describes how a sense of vulnerability was affectively shared and enlarged upon per tweets after the terrorist attacks in Paris and elsewhere. ${ }^{61}$ Reading tweets added to users' immediate perceived sense of their own threat from a possible terrorist attack, however safe their locality and position there actually was. What is counterintuitive here,

59 Nagle, Kill All Normies.

60 Atkinson et al., Introduction to Psychology, pp. 633-636.

61 Sharp, '\#Vulnerability'. 
is that touch is not involved in these experiences of spread sensation caused by interactions with others on social media. Nor is emotional intimacy based on face-to-face social interaction with another or others necessary to co-experience or even co-witness sentiments expressed on Twitter, Reddit, or Facebook.

How then do we explain the shared affects of online exchanges and responses, the expressions and sensations of hate and love? Applying affect theory to online exchange, Dean has argued that, similar to the distinction that game theorists have made between what happens in games and descriptions of gaming in narratology, it is not the imposition of a linear tale that arouses, but the iterative and the participatory. ${ }^{62}$ To create content and to comment on the content of others or on their commentaries is to contribute to building something. The time one spends in specific online forums relates directly to one's affective commitment, sense of purpose, and pleasure in being there. When a group that is experienced as unique and as subject to its own code is attacked, then the defence of this group becomes a passionately important pursuit. Face-to-face interaction is rendered irrelevant given group members' experience of mutual banded togetherness. In a similar vein, Susanne Paasonen argues that a taste for affective or 'sticky intensity' of all kinds drives trolls and non-trolls alike. ${ }^{63}$ This intensity increases in scale in online conflicts.

\section{Conclusions}

Attributing Alt-Right and now New Right internet hate to misogyny alone is too monocausal. Trump's rhetoric and self-fashioning is not fuelled by misogyny alone, nor is that of his knight-in-waiting Cernovich. Rather, Trump has been uniquely successful in creating an us versus them narrative that includes an antagonism towards traditional journalism and supposedly elitist sources of knowledge. This narrative focusses on the intrinsic greatness and largeness of Trump, \#MAGA America, and those who believe in these entities. It also espouses the supposed virtues of hegemonic masculinity. Online hate functions in part through experiences of deindividuation and perhaps also through a diffusion of responsibility caused by actors' ability to inflict pain and not be held directly accountable for it. Yet these explanations of online vitriol prove too simple. The real affective charge that is spoken

62 Dean, 'Affect and Drive'.

63 Paasonen, 'A Midsummer's Bonfire'. 
about by Cernovich and his compatriots results out of exchanges with their in-group community that can be regarded as expressions of a libidinal economy. In meticulous commentaries about each other's messages, group members pat each other on the back for what is perceived as their having won online battles not only individually but also for the glory of the group.

To begin to understand online hate during the age of Trump and other populist authoritarians, we need to understand the love that binds those who feel themselves to be passionately fighting for common cause in their support of him. What motivates Trump's supporters is in parts a nostalgically longed for, phantasmagoric image of lost American glory and an ideal of noble manhood that, for many of us, went out of fashion with medieval knights or Braveheart. Yet it is also intensely experienced love. We need to attend seriously to the stickiness involved in expressions of hate and vitriol on online platforms and their background in a shared sense of commonality and affection. This means taking affect seriously. We may also have to critically adjust our continuing attachments to the power of rational arguments and our sense that others should be convinced by these arguments as well.

\section{Works cited}

Anglin, Andrew. 'A Normie's Guide to the Alt-Right'. The Daily Stormer, 31 August 2016.

Atkinson, Rita et al. Introduction to Psychology. New York: Harcourt Brace College Publishers, 1996.

Baker, Peter. 'A Trump Vacation Formula: Work Hard, Play Hard, Tweet Hard'. The New York Times, 7 August 2017.

Barad, Karen. 'Posthumanist Performativity: Toward an Understanding of How Matter Comes to Matter'. Signs: Journal of Women in Culture and Society, vol. 28, no. 3, 2008, pp. 801-831.

'Basic Bitch'. Dictionary.com, https://www.dictionary.com/e/slang/basic-bitch/. Accessed 1 March 2020.

Bennett, Jill. Empathic Vision: Affect, Trauma, and Contemporary Art. Stanford: Stanford University Press, 2005.

Booth, Robert. 'Facebook Reveals News Feed Experiment to Control Emotions'. The Guardian, 30 June 2014, https://www.theguardian.com/technology/2014/ jun/29/facebook-users-emotions-news-feeds. Accessed 1 March 2020.

Cernovich, Mike. 'Mike Cernovich Breaks Twitter Records as His Trump Book Launch Approaches'. Dangerandplay.com, 13 October 2016. Accessed 1 March 2020 . 
—. '1o Ways to Reclaim Masculinity'. YouTube, 3 March 2017. Accessed 1 March 2020.

—. 'Mike Cernovich Press Conference to Address Fake News'. YouTube, 4 April 2017. Accessed 1 March 2020.

—. 'HOAXED by Mike Cernovich - Kickstarter'. YouTube, 8 July 2017. Accessed 1 March 2020.

Clough, Patricia Ticineto, and Jean Halley. The Affective Turn: Theorizing the Social. Durham: Duke University Press, 2007.

Clough, Patricia Ticineto. 'The Affective Turn: Political Economy, Biomedia and Bodies'. Theory, Culture \& Society, vol. 25, no. 11, 2008, pp. 1-22.

Connell, R.W. Masculinities: Second Edition. Berkeley and Los Angeles: University of California Press, 2005.

Dean, Jodi. Blog Theory: Feedback and Capture in the Circuits of Drive. Cambridge (UK): Polity Press, 2010.

-. 'Affect and Drive', in Networked Affect, edited by Ken Hillis, Susanna Paasonen, and Michael Petit. Cambridge (MA): MIT Press, 2015, pp. 89-101.

Deleuze, Gilles, and Felix Guattari. A Thousand Plateaus: Capitalism and Schizophrenia. Minneapolis: University of Minnesota Press, 1993.

DiFabio, Geno. 'Geno DiFabio, Youngstown Ohio'. Bloomberg Politics, 2017, https:// www.bloomberg.com/features/2017-trump-heartland-sentiment/\#DiFabio.

'Donald Trump Announces Presidential Campaign'. YouTube, uploaded by Wall Street Journal, 16 June 2015, https://www.youtube.com/watch?v=bx6V-e2DQWo. Accessed 1 March 2020.

'Donald Trump Defends Twitter Use, Says Social Media Key to White House Victory'. ABC News, 22 October 2017.

Frank, Thomas. What's the Matter with Kansas? How Conservatives Won the Heart of America. New York: Henry Holt, 2004.

Gee, Cee. 'Basic Bitch'. Urban Dictionary, 1 May 2014, https://www.urbandictionary. com/author.php?author=Cee\%2oGee. Accessed 1 March 2020.

Gessen, Masha. 'How Trump Governs by Tweet: Start with Outrage, Then Escalate'. The New Yorker, 11 October 2017.

Habermas, Jürgen. The Theory of Communicative Action, vol I. Boston: Beacon Press, 1984 [1981].

—. The Structural Transformation of the Public Sphere. Cambridge (MA): MIT Press, 1989 [1962].

Hatfield, Elaine, et al. 'New Perspectives on Emotional Contagion: A Review on Classic and Recent Research on Facial Mimicry and Contagion'. Interpersona: An International Journal on Personal Relationships, vol. 8, no. 2, 2014, pp. 159-179. 'How the World Was Trolled'. The Economist, 4 November 2017, pp. 21-24. James, Deborah. 'Gender-linked Derogatory Terms and Their Use by Women and Men'. American Speech, vol. 73, no. 4, 1998. pp. 399-420. 
Jutel, Olivier. 'Donald Trump's Libidinal Entanglement with Liberalism and Affective Media Power'. Boundary 2 Online, vol. 2, no. 1, 2017.

Leys, Ruth. 'The Turn to Affect: A Critique'. Critical Inquiry, no. 57, 2011, pp. 434-472. Manne, Kate. Down Girl: The Logic of Misogyny. Oxford: Oxford University Press, 2008.

Marantz, Andrew. 'Trolls for Trump: Meet Mike Cernovich, the Meme Mastermind of the Alt-Right'. The New Yorker, 31 October 2016.

—. 'Can a Pro-Trump Meme Maker Get a Real News Scoop?' The New Yorker, 6 April 2017, https://www.newyorker.com/news/news-desk/can-mike-cernovich-a-protrump-meme-maker-get-a-real-news-scoop.

Mouffe, Chantal. Agonistics: Thinking the World Politically. London \& New York: Verso, 2013.

Nagle, Angela. Kill All Normies: Online Culture Wars from 4 Chan and Tumblr to Trump and the Alt-Right. New York: Zero Books, 2017.

Nuzzi, Olivia. 'Mike Cernovich Pivots From Pizzagate to Not-So-Fake News'. New York Media, 8 August 2017.

Olson, Greta. 'Nur Emotionen können Amerika vereinen'. Frankfurter Rundschau, 27 December 2017.

—. 'The Turn to Passion: Has Law and Literature Become Law and Affect?' Special Issue on 'Legal Personhood', edited by Frans-Willem Korsten and Yasco Horstmann, Law and Literature, vol. 28, no. 3. 2016, pp. 335-353.

Paasonen, Susan. 'A Midsummer's Bonfire: Affective Intensities in Online Debate', in Networked Affect, edited by Ken Hillis, Susanna Paasonen, and Michael Petit. Cambridge, (MA): MIT Press, 2015, pp. 27-42.

Pedwell, Carolyn. 'Mediated Habits: Images, Networked Affect and Social Change'. Subjectivity 10.2, 2017, pp. 147-169.

'The Politics of Outrage: Do Social Media Threaten Democracy?'. The Economist, 4 November 2017.

Serano, Julia. Whipping Girl: A Transsexual Woman on Sexism and the Scapegoating of Femininity. Berkeley: Seal Press, 2007.

Sharp, Cassandra. '\#Vulnerability - the Visualisation of Terror and Justice through Stories on Twitter'. Presentation at the Fifth Biennial Literature + Law Conference 'Visualizing Justice', 28 October 2017.

Spinoza, Baruch. The Collected Works of Spinoza, vol. 1, ed. and transl. by Edwin Curley. Princeton: Princeton University Press, 1985.

Stack, Liam. 'Who Is Mike Cernovich? A Guide'. New York Times, 5 April 2017.

Stein, Rob. 'Happiness Can Spread Among People Like a Contagion, Study Indicates'. The Washington Post, 5 December 2008.

Tompkins, Silvan. Affect Imagery Consciousness: Volume I: The Positive Affects. New York: Springer, 2008. 
Trump, Donald J., with Tony Schwartz. Trump: The Art of the Deal. New York: Ballantine Books, 1987.

—. Crippled America: How to Make America Great Again. New York: Simon \& Schuster, 2015.

Vosoughi, Soroush, Deb Roy, and Sinan Aral. 'The Spread of True and False News Online'. Science, vol. 359, 2018, pp. 1146-1151.

'WATCH: President Trump holds rally in Phoenix'. YouTube, uploaded by PBS Newshour, 22 August 2017, www.youtube.com/watch?v=8Y-iMgsDrAk.

Waters, S.F., et al. 'Affect Contagion Between Mothers and Infants: Examining Valence and Touch'. Journal of Experimental Psychology: General, vol. 146, no. 7, 2017, pp. 1045-1051.

'What made Trump's 'Make America Great Again' Slogan So Powerful?' The Journal, 9 November 2016, https://www.thejournal.ie/trump-slogan-make-americagreat-again-3071552-Nov2016/.

\section{About the author}

GRETA OLSON is Professor of English and American Literary and Cultural Studies at the University of Giessen and general editor of the European Journal of English Studies (EJES). She is interested in overlaps between politics, and aesthetic and academic expression and works in the areas of feminism, sexuality studies, media, and Law and Culture and American Studies. She has just finished a book on Law and Affect and is embarking on a project on the emotional politics of sexual cultures. Recent publications include Beyond Gender: Futures of Feminist and Sexuality Studies (2018), How to Do Things with Narrative (2017), and three special issues of EJES: 'Law Undone: De-humanizing, Queering, and Dis-abling the Law' (2017), 'Law's Pluralities: Arguments for Cultural Approaches to Law' (2017), and 'The Politics of Form' (2016). 



\title{
8 Satire and Affect
}

\author{
The Case of Stefanie Sargnagel in Austria
}

\author{
Ann-Marie Riesner
}

\begin{abstract}
This chapter analyzes the case of the Austrian writer Stefanie Sargnagel focusing on the hateful reactions to a 2017 fictional travelogue published in the Austrian newspaper Der Standard. Her case is exceptional because she did not only live through, but also publicly commented on the outburst of hate she faced. Moreover, Sargnagel - as an astute observer of the mechanisms of social media-exposes the logics of hate speech in social media and shows how they work in triggering the reactions she wants to turn the readers' attention to. Sargnagel's reactions and reflections, the chapter argues, shed light on the phenomenon of hate as an affective network that runs through the online and the offline world.
\end{abstract}

Keywords: affect and media, social media, online literature, Internet culture

'She needs the same treatment as what the Americans did to those bitches in Vietnam.' These words, written as a reaction to a provocative newspaper article written by the Austrian writer Stefanie Sargnagel seem completely out of proportion, but are quite familiar to us as users and observers of social media. Thousands of similar threats and insults are likely to appear whenever a woman, and sometimes a man, posts politically or sexually

1 'die braucht gleiche Behandlung wie Amis haben gemacht in Vietman krieg mit solchen Nutten.' Wegrzyn, Ryszard, Facebook Post, Posted as a screenshot in Stefanie Sargnagel's Facebook Album: 'Richard Schmitt wishes you a Happy Women's Day', 9 March 2017, https://www.facebook. com $/ \mathrm{media} / \mathrm{set} /$ ?set=a.10154578674413037-1073741857.711248036\&type $=3$.

Misspellings in the original German quotations from Twitter and Facebook are not rectified here. Translations of all posts by Ann-Marie Riesner.

Polak, Sara, and Daniel Trottier (eds), Violence and Trolling on Social Media. Amsterdam, Amsterdam University Press 2020 DOI: 10.5117/9789462989481_CHo8 
provocative or ambiguous content in any other way on the Internet. Jarett Kobek, for instance, has dedicated his novel I Hate the Internet to the problem of online vitriol in the USA. One of the narrative threads of the book is the history of Adeline, a graphic novel artist from San Francisco who has lived through the worst series of harassment and death-threats after carelessly making statements in public and, without knowing it, online: 'Being a kind of famous woman who expressed unpopular opinions in a culture that hated women was in itself a serious mistake, but neither it nor its constituent parts were the big one.'2 As the reader learns several pages later: 'She neglected to notice that someone was recording every word that she said.3

If the main pillar of the Internet project back in the days of its inception was to create a space of free speech, it is worth noting that hate speech or revenge projects are also among the oldest practices of online communities. ${ }^{4}$ The relative anonymity and the lack of technical barriers in social media leads to an ever increasing amount of online vitriol, as the case of Stefanie Sargnagel demonstrates. Her case is noteworthy for at least two reasons which are deeply linked. The first is that Stefanie Sargnagel is one of the most astute observers of the mechanisms of social media in the German speaking world. I would argue that a significant part of her posts is actually about the relentless logic of social media which makes the unrestricted expression of spontaneous euphoria and hate possible. To analyze her case seems promising because she not only underwent but also consciously lived through and commented on the outburst of hate - what one might call a shitstorm - that occurred to her. Generally, Sargnagel not only comments on but exposes the logic of hate in social media, plays with connotations and shows how they work in triggering the reactions she wants to turn the readers' attention to. She employs a couple of very particular strategies, sometimes through bold provocation, sometimes by playing with identities, with fact and fiction and with changing frames. The way she 'manipulates' the readers and triggers hate comments allows many insights into the phenomenon of hate as an affective network that runs through the online and the offline world.

This chapter analyzes one of her newspaper articles which elicited a furious shitstorm, titled 'Three Authors in Morocco: Now We Have a Horse

2 Kobek, I Hate the Internet, p. 3.

3 Ibid., p. 34.

4 The News Group Alt.Revenge e.g. was founded in 1983 already, when the world wide web was not even launched. 
and Hashish'. ${ }^{5}$ In what follows, I will first introduce Stefanie Sargnagel as an author and focus on her particular interest in the mechanisms of affect in social media. I will then present the case of the harassment she experienced after the publication of her newspaper article in Der Standard. The analysis is grounded in theories of media and theories of affect, and employs analytical methods originating from literary studies. Through the analysis, this chapter aims to untangle the inner dynamics of online vitriol and elucidate on the functioning mechanisms of online hate speech.

\section{The author: Stefanie Sargnagel}

Stefanie Sargnagel (1986) is an emerging Austrian author writing almost exclusively on social media like Facebook, Twitter and Instagram and regularly publishing selections of her best posts in print anthologies. ${ }^{6}$ Sargnagel started posting on Facebook in 2007 and initially did not have many followers. In 2013, the newspaper Wiener Zeitung stated that she had only 1300 followers. ${ }^{7}$ By contrast, in 2016, the newspaper TAZ counted already 20,000 followers. ${ }^{8}$ The publication of her forth book Statusmeldungen ('Status Updates') in 2017 by the renowned publishing house Rowohlt in Germany brought her vast attention and more than $5^{0.000}$ followers ${ }^{9}-\mathrm{a}$ considerable number in the German speaking context. Her posts embrace a broad range of topics from very harmless observations on the everyday life in Vienna, in the tram line 6, or at the supermarket, to sensitive political issues like Austrian (cultural) politics, being a feminist, a 'bohemian' and a female author and on the mechanisms of social media, be they good or bad.

On 7 October 2017, Sargnagel writes on Facebook: 'Everything written here is fictional, in reality my name is Lara and I work at the graphics department of an NGO. ${ }^{10}$ Whereas integrity and authenticity are usually among the most defended issues on social media, Stefanie Sargnagel plays with identities and with the boundaries between fact and fiction. That does not only account

5 Haider et al., 'Drei Autorinnen'.

6 These publications are: Sargnagel, Binge Living; Sargnagel, In der Zukunft sind wir alle tot; Sargnagel, Fitness; Sargnagel, Statusmeldungen.

7 'Die Wohlstands-Verwahrloste'.

8 'Urarg', p. 13.

9 dieschreibmaschine.net.

10 'Alles was ich hier schreibe ist fiktiv in wirklichkeit heiß ich lara und arbeite in der grafikabteilung einer ngo.' Sargnagel, Stefanie, Facebook-Post 10 July 2015, https://www.facebook. com/stefanie.sargnagel/posts/10153055927808037. 
for scenes from her daily life that she sometimes turns into fiction, even fantasy, but also for highly explosive political topics. On the one hand, it is obvious that she stands for left-wing politics, for feminism, the freedom of art and speech. On the other hand, she also ironically comments on the positions she herself supports. One of the topics she ironically reflected on was the movement for help for the refugees in Vienna in the fall of 2015. As we can read from her posts, she was involved in smuggling refugees from Hungary to Austria and worked devotedly at the refugee camp Traiskirchen near Vienna. During that time, she clearly pushed forward the debate around responsibilities for refugees in Austria by critically commenting on Austrian politicians being passive and leaving the actual work to volunteers. ${ }^{11} \mathrm{Si}-$ multaneously, she ironically reflected on the pride and self-righteousness that often underlies the altruism of the volunteers: 'is there a Traiskirchen sticker album out there where you can glue in the refugees you snapped while bringing them charitable donations?'12 This critique goes naturally also against herself, and precisely that is the intention. Sargnagel's aim is to constantly provide the readers with new lines of interpretation and to show the complexity, sometimes inconsistence, of the issues she addresses. She explicitly claims to not be afraid to provoke harsh reactions, as stated in September 2015 'I don't know what everybody has against shitstorms. I love shitstorms' ${ }^{13}$, and a month later: 'I am my own shitstorm.' ${ }^{14}$

I argue that her pronounced interest in 'shitstorms' comes from her deep understanding of the nature of affect in political and social relations that becomes most visible in discussions and comments on social media. As she correctly assumes, the topic of the refugee crisis in Austria cannot be grasped, nor pushed forward, without taking note of the affects that the experience triggers in Austrians of all political beliefs and in the refugees. Instead of being concerned to create a neutral, unemotional setting of

11 On 18 August 2015 for instance, Sargnagel writes: 'It is nice to see how many people just naturally provide Traiskirchen with groceries and sanitary products, but it is also totally absurd how politics simply rely on that.' ('Schön zu sehen wieviele leute selbstverständlich traiskirchen mit lebensmitteln und hygieneartikeln versorgen, aber auch vollkommen absurd, wie sich die politik darauf verlässt.'), https://www.facebook.com/stefanie.sargnagel/posts/10153141457198037. 12 '20.8.2015: Gibt es eigentlich schon ein Traiskirchen-Stickeralbum, in das man seine Flüchtlinge einkleben kann, die man beim Spendenbringen knipst?', Sargnagel, Statusmeldungen, p. 30. (This post is not available on Facebook any longer).

13 'Ich weiß nicht was alle gegen shitstorms haben ich liebe shitstorms', Sargnagel, Stefanie, Facebook-Post 23 September 2015, https:/www.facebook.com/stefanie.sargnagel/ posts/10153217794643037.

14 'Ich bin mein eigener shitstorm' Sargnagel, Stefanie, Facebook-Post 22 October 2015, https:// www.facebook.com/stefanie.sargnagel/posts/10153263895963037. 
discussion, she intentionally, through provocation and contradiction, creates a space that sets free not only opinions but also affects and emotions. This strategy has led to several escalations, sometimes to her temporary exclusion from Facebook, ${ }^{15}$ and in the case to be examined here to a name and shame on different media that affected Sargnagel seriously.

\section{The case Sargnagel}

Stefanie Sargnagel and five other emerging authors, among them Lydia Haider and Maria Hofer, travelled to Morocco in January 2017. The purpose of the trip was to finish their current book projects. Two of them, Sargnagel and Haider, received partial funding from the Austrian Ministry of Culture (Bundesministerium für Bildung, Kunst und Kultur). Several weeks later, on 25 February 2017, the Austrian newspaper Der Standard published the article 'Three Authors in Morocco: Now We Have a Horse and Hashish', ${ }^{16}$ a travelogue that the three authors had written collectively. The travelogue, a harmless 'byproduct' of the trip, as Lydia Haider describes it, ${ }^{17}$ is split into short fictional diary entries that each of the women wrote every day during the stay. Not surprisingly, the text as a whole is marked by satire, exaggeration and provocations, as well as by a mixture of facts and fiction. Again, Sargnagel and her co-authors address highly explosive topics in a provocative manner, and the three most provocative ones, that triggered the biggest part of comments, were the following:

1 Violence against animals, especially cats: most unbearable for selfproclaimed cat-lovers were the fictional accounts about Lydia Haider hating and assaulting animals. On 5 January, Sargnagel writes in the travelogue: 'Lydia is the only vegetarian in the group, but in contrast to other vegetarians I know she is a vegetarian not because she loves animals but because she deeply hates them. Today she kicked a baby kitten aside, claiming it had rabies, after which she complacently took a bite from her vegetarian crêpe. ${ }^{18}$ Lydia Haider confirms a few days

15 In April 2016, her fictional account about Alina Wychera, a politician focusing on identity politics, triggered so many hate comments that the author's account was blocked during a couple of days, cf. Der Standard, 2016.

16 Haider et al., 'Drei Autorinnen'.

17 'Wirbel um Marokko-Reisebericht'.

18 'Lydia ist die einzige Vegetarierin der Gruppe, aber im Unterschied zu den anderen VegetarierInnen, die ich kenne, ist sie es nicht, weil sie Tiere liebt, sondern weil sie Tiere zutiefst 
later: 'I do hate all animals, profoundly, but doves are really nature's worst creation.' ${ }^{\prime 19}$

2 Sexual provocation and challenging 'the Austrian Angst' of North Africans: Already in the fall 2015, Sargnagel had posted very provocative content on tensions that came up when suddenly many refugees came to Austria. On the one hand, many left-wing and liberal Austrians welcomed the refugees with enthusiasm; on the other, the concerns of more conservative voices, namely that many refugees were young single men and would try to get in touch with, sometimes to harass, Austrian women, were not completely groundless. Multiple debates about the role allocation of perpetrators and victims flared up, and Sargnagel's contribution was pinpointing the blind spots:

'so difficult to distinguish on Facebook those guys who send you 'you are beautiful' messages from those who are the refugees you actually met... ${ }^{20}$

For the trip to Morocco, Sargnagel addressed the same topic, this time again blurring the roles of perpetrator and victim:

The trip is great. However, as women in our prime, we are slightly disappointed about how people react on us. Miniskirt, going out with no bra and red lipstick forces Essaouira's inhabitants to do nothing more than to say an indifferent 'bon jour' from time to time. And whenever we, willingly, sit down with them at the beach late at night, they want to get stoned and play Uno. Cologne Central Station has promised too much. ${ }^{21}$

3 Arts, idleness and tax money: The use and abuse of tax money for the life of emerging artists is one of the most controversial and explosive

hasst. Heute hat sie eine Babykatze zur Seite getreten mit der Behauptung, sie habe Tollwut, danach biss sie selbstzufrieden in eine vegetarische Crêpe', Haider et al., 'Drei Autorinnen'.

19 'Ich hasse ja Tiere, von Grund auf, aber Möwen sind wirklich das Letzte vom Allerletzten in dieser unserer Schöpfung', ibid.

20 'urschwer zu sagen welche auf facebook jetzt diese typen von denen man 'you are beautiful' messages im 'others' ordner hat sind und welche die flüchtlinge, die man kennengelernt hat....' Sargnagel, Stefanie, Facebook-post 13 September 2015, https://www.facebook.com/stefanie. sargnagel/posts/10153198958428037.

21 'Dieser Urlaub ist toll. Als Frauen in den besten Jahren sind wir aber etwas enttäuscht über den Umgang mit uns. Minirock, Rausgehen ohne BH, roter Lippenstift ringen den Bewohnern Essaouiras nur hin und wieder ein desinteressiertes 'Bon jour' ab, und wenn wir uns spätnachts willig zu ihnen an den Strand setzen, wollen sie eingraucht Uno spielen. Der Kölner Hauptbahnhof hat echt zu viel versprochen', Haider et al., 'Drei Autorinnen'. 
topics Sargnagel often reflects on. On purpose, she often enacts her life as an artist as pure leisure paid by the state, as exemplified by the Morocco trip: 'From time to time we hire poncy quads and, stoned, altogether speed around the idyllic beach with loud engine noises. That is what they call freedom. The BMUKK has given me a travel grant for that. (For the literature). If the FPÖ only knew.'22

These examples, again, shed a light on Sargnagel's humour that works essentially through the spontaneous transgressions of the boundaries between fact and fiction and through sudden turns to irony. The fact that the reader must be alert at all time as Sargnagel's text can turn into fiction or irony any moment, makes for an enjoyable yet demanding read that forces readers to leave their comfort zone. Moreover, the texts require a lot of knowledge on the part of the reader and they even work through the pleasurable exclusion of those who do not understand the transgressions and the insider jokes. Just take the comment on 'Cologne Central Station' that actually refers to a series of assaults made by young, mainly north African men on a considerable number of women during the night of New Year's Eve in 2015 in front of Cologne central station. The events lead to a heated debate about migration, sexism and Western liberal values in which the conflicting roles of Muslims as victims of war and expulsion, but also as sexual perpetrators were widely discussed. Sargnagel not only nonchalantly refers to 'Cologne Central Station' without explaining the reference but also introduces the provocative point of view of Muslims as the target of harassment through sexually frustrated Austrian women.

To be at eye level with the text, Sargnagel's texts require readers to never easily settle in a comfortable line of thought, but to always consider the complexity and the unpleasant aspects of the topic in question. Far more than to elaborate on her own thoughts about specific topics at length, Sargnagel's activism consists in destabilizing deep-rooted patterns of thought and comfortable explanation patterns. The success of her texts results from the reader's satisfaction of being able to understand the references, the irony and the provocations and to stay cool vis-à-vis the affective reactions that Sargnagel's provocations might cause in people without the required flexibility of mind.

This is also how the article about the Morocco-journey works. Instead of conveying any reliable information on the trip, her travelogue is a Molotov

22 'Immer wieder mieten wir uns prollige Quads und zischen eingraucht mit lauten Motorengeräuschen zu sechst über den idyllischen Strand. Das ist Freiheit. Das Bmukk hat mir dafür einen Reisekostenzuschuss gewährt. (Für die Literatur.) Wenn das die FPÖ wüsste', ibid. 
cocktail of explosive topics that are piled up onto each other. It could not be more obvious that combining cats, sex, Muslims and the waste of tax money in one article has only one aim: to trigger reactions; the article is a trap. Its mechanism is very simple: a person who affectively reacts to the content of the article has automatically disqualified him- or herself as a critical reader who understands satire. On the contrary, he or she belongs to those who are excluded by Sargnagel's sense of irony, to those who are led through the Internet by affect instead of reflection. Imagining those who seethe with anger at Sargnagel's provocations then becomes part of the pleasure for those readers who consider themselves on equal terms with the texts' requirements. The trap did catch its 'victims'. Although the satirical format was more than obvious and despite the fact that Der Standard had published the article in the section Culture/Literature, thereby hinting to the possibility of fiction or irony. Nevertheless, many Austrian media took everything to be real, fell into the trap, and started one of the biggest shitstorms that the Austrian cultural scene had ever seen.

The reactions came in two steps, the first being the article 'Literary Journey - Drinking and Smoking Weed on the Taxpayers' Expenses', published by Die Krone on 8 March 2017. Die Krone is Austria's most popular newspaper, a tabloid newspaper that usually supports the course of FPÖ, Austria's right-wing party. The article cites original passages from the Standard article, although ripped out of context, and mentions the fact that the women in question are authors. However, the responsible journalist Richard Schmitt does not account for the context of fiction or satire and takes the content of the travelogue for real, at least he pretends to do so. Vis-à-vis the very obvious markers of satire in the text and the paratext of the Standard article, and considering Schmitt's experience as a journalist and as the Krone's chief editor, it is not probable that Schmitt missed the satirical and fictional character of the text. It is rather likely that the article was already a kind of 'revenge' for a coverage on Sargnagel and her so-called 'fraternity hysteria' that the TV channel ORF had aired the day before. ${ }^{23}$

The article by Die Krone can be read as a first step of the shitstorm because it was actually the newspaper which made the topic of Sargnagel's travelogue available to an audience and to social networks that would not read the article in Der Standard. In that function, the Krone can be seen as an intermediary between the Austrian intellectual, left-wing class that

23 In the coverage, broadcasted within the news format 'Kulturmontag', ORF reports how the group Hysteria had disturbed the 'Akademikerball', a ball traditionally attended by ultra conservatives, FPÖ members and by (former) fraternity members, cf. Wienerin.at, 2017. 
reads Der Standard and the right-wing, FPÖ-oriented, conservative, often misogynistic and islamophobic readership of Die Krone. As the newspaper Der Kurier wrote on 10 March 2017, the effect of that contact is 'as if two worlds collide that should not have touched each other. ${ }^{24}$ From there, in a second step, the content spread within minutes to readers who would not even read Die Krone, but far more conspiracist newspapers or not even newspapers but only comments by (online) hate commentators.

Within the next hours and days, a couple of articles in clearly populist media went an important step further than the Krone article. Not only did these all pretend the details from the travelogue were real, calling the trip a 'drug-journey' and Sargnagel's writings 'the confessions of an animal abuser,', ${ }^{25}$ they also 'enriched' the story with details that make the perfect enemy and target for hate out of Stefanie Sargnagel. The article 'HoferHater Does Drug-Journey on the Taxpayer's Expenses', ${ }^{26}$ published on the 9 March 2017 by the online platform wochenblick.at, does this already in the title, which characterizes Sargnagel mainly through her activism against Norbert Hofer, the president of FPÖ. A second but even more important strategy of the same article is the creation of the cover image: it is a montage of the prototypical picture of a joint, a photograph of Stefanie Sargnagel wearing her 'against nazis' pullover and a screenshot from a post by Sargnagel that she made as a cynical reaction to the beginning of the shitstorm: 'If the Krone knew that we did not only kick kittens' asses but that we also fucked puppies to death...'

The online platform unzensuriert.at, again an FPÖ-friendly conspiracist organ, published a similar article on 11 March 2017: 'Kicking baby kittens, smoking weed and drinking: 'Literary journey' on the tax payer's expenses'. ${ }^{27}$ The article not only presumes the 'Literary journey' to be only a pretext for a scandalous trip, but also characterizes Sargnagel as 'a left-wing extremist' and as 'essentially an FPÖ-hater'. From Sargnagel and the $€ 1.500$ that were taken from the taxpayers, the article moreover quickly moves on to the Austrian Ministry of Culture's 'abominable and corrupt' principles of attributing stipends to artists. It thus ties a network of emotive terms and 'hot topics' that it knows will make the readers' blood boil. In the context of that hate campaign, it is not only interesting to observe the increasing distance of this article from the original text, but also the development of 
the comments in newspaper forums and social media that accompanied the articles.

If we consult the comment forum of Der Standard in the days after the publication of the travelogue, we find a rather high amount of comments, almost 230 comments in the days before Die Krone publishes its article. It is astonishing that almost all comments in the Standard forum are adequate reactions to Sargnagels text. Criticism comes only from those who do not appreciate that the journey has been funded by a stipend from tax money. But no matter if people find the text 'boring, immature, pointless ${ }^{28}$ or if they appreciate the 'mix of literary journal and Dschungelcamp-Satire' as 'really funny', ${ }^{29}$ no commentator actually doubts the satirical and fictional character of the travelogue. Some even reflect on the mechanisms the text wants to trigger and make valid points in their analysis:

I think that's what they wanted. Just shit-talk as much as possible and wait for the reactions. The product is not the text but the discussion after. I mean, they didn't leave out any thing: infantile behaviour, sex tourism, bohemian life style, tax misspending, drugs, André Heller... they did not even stop at kicking kittens. That is what makes me smile about the forum discussion..$^{30}$

Several vitriolic comments like: 'You find kicking kitten is funny?????? Are you crazy????'31 that found their way into the Standard forum all came in after the publication of the Krone article, supposedly by Krone readers, and are rare exceptions.

In comparison to that very homogeneous discussion on the Standard forum, things got far more heated on the Twitter profiles of Stefanie

28 'unglaublich unnötig von denen niemand was zu sagen [...] gar nix langweilig, unreif, sinnarm_diese worte kommen mir beim Lesen dieses TB in den Sinn.' Comment at the Standard Forum by 'smily record', 25 February 2017, 15:26:19, Haider et al., 'Drei Autorinnen'.

29 'Ich fand das wirklich lustig. Offenbar als Einzige hier. Eine Mischung aus literarischem Tagebuch und Dschungelcamp-Satire.' Comment at the Standard Forum by 'lizboa, don', 26 February 2017, o8:06:09, ibid.

30 'Ich denke das ist so gewollt. Fleißig shit talking betreiben und schauen was zurück kommt. Das Produkt ist nicht der Text sondern die Diskussion danach. Sie haben ja wirklich nix ausgelassen: infantil, Sextourismus, Bobotum, Steuerverschwendung, Drogen, Andre Heller [...] Ja, sogar vor dem Katzentreten haben sie nicht zurückgeschreckt. Deshalb schmunzle ich gerade besonders über das Forum. :)' Comment at the Standard Forum by 'Ich mag Züge', 26 February 2017, 12:31:13, ibid.

31 'Also Babykatze treten witzig finden?????? Geht's noch????' Comment at der Standard Forum by 'de-fake-news-gitti', 9 March 2017, 09:49:46, ibid. 
Sargnagel and Richard Schmitt, the author of the Krone article, after the publication of his article. However, although the debates here are much more controversial than on the Standard forum, they are still rather equilibrated in the sense that both Sargnagel and Schmitt receive support and critique and in the sense that actual arguments are exchanged. Schmitt shared his article eleven times with different headers, on 8 March at 07:48am with the words 'Drinking, smoking weed, kicking kitten - that deserves a travel grant. From our tax money. ${ }^{2}$ This post on Twitter and the attached article led to different reactions, some of them being defamatory and irrespective towards Sargnagel, for example: 'Sargnagel is the dumbest creature under the African sun. The living proof that the left is stupid. ${ }^{33}$ But Schmitt received also a lot of critique for the post and the article, pointing to his own use of tax money (how much tax money does the Krone actually get as press subsidy?'34) or to his incapacity to detect satire: 'being a 'journalist' you, theoretically, earn your money through writing but you don't recognize satire?'35 The same applies for Stefanie Sargnagel's Twitter profile, where she also gains lots of support on the one hand, as well as defamatory comments on the other. These 'virtual' debates have 'real' consequences: in another article by Die Kärntner Krone, a local newspaper owned by Die Krone, the journalist Fritz Kimeswenger published Sargnagels's current address in Klagenfurt, mentioning in the same sentence that Sargnagel was 'willing' and thus brought her in actual danger ${ }^{36}$ As a countermovement, the Austrian press council initiated legal proceedings for issues of media ethics against Die Krone. ${ }^{37}$ In addition, an online petition called for Fritz Kimeswenger's dismissal, and different celebrities from Austria's media industry spoke up for Sargnagel. ${ }^{8}$

32 'Saufen, kiffen, Babykatzen treten - dafür gibt's ein Reisestipendium. Mit unserem Steuergeld.' Twitter-post by @richardschmitt2, 8 March 2017, 07:48, https:/twitter.com/RichardSchmitt2/ status/839551599785582592.

33 ‘RichardSchmitt2 Die Sargnagl, das dünmste Geschöpf unter der Sonne Afrikas. Der lebende Beweis, das Links dumm ist.' Twitter-post by @Maxx_Heidegger, 8 March 2017, https:// twitter.com/Maxx_Heidegger/status/839514949596692480.

34 ‘RichardSchmitt2 wieviel steuergeld kriegt die krone eigentlich als presseförderung? @ stefansargnagel @CLangOnline'. Twitter-post by @ChristianMock, 8 March 2017, https://twitter. com/ChristianMock/status/839595136732524550.

35 '@RichardSchmitt2 als 'journalist' zumindest theoretisch schreibend sein geld verdienen u dann keine satire erkennen.' Twitter-post by @nopulse, 11 March 2017, https://twitter.com/ nopulse/status/840650400768356352.

36 For a screenshot of the article 'Ex-LH Dörfler tritt zurück', cf. Wienerin.at, 2017.

37 Österreichischer Presserat, OTS.at, 'Presserat'

38 'Fall Sargnagel'. 
Still, although these articles and comments entail important consequences, one has to consider that the Twitter and Facebook profiles of Sargnagel and Schmitt were not the actual setting of the 'core' hate campaign. Although Richard Schmitt with his Krone article clearly initiated the hate campaign, and Stefanie Sargnagel even denunciates him ('Just read the comments you trigger with such a misogynist article. Happy women's Day.'39), the pure hate comments are spread on other walls, i.e. in reaction to other individuals sharing the articles published at Die Krone, wochenblick.at and unzensuriert.at. Mediated and torn through multiple biased intermediaries, the content that reaches these Internet communities and their readership has nothing to do with the original text anymore. The whole campaign is now oriented around Sargnagel as the target of an irrational hate, the details of the initial story are not only forgotten but do not matter at all.

As it is pointless to present a plethora of totally disconnected death and rape threats here, I will give only some examples, all of which can be found as a collection of screenshots that Stefanie Sargnagel compiled into the Facebook album 'Richard Schmitt Wishes you a Happy Women's Day' on Facebook. ${ }^{40}$ Whereas some hate comments were 'at least' related to facts from the Sargnagel case, mainly on the animal abuse topic, ${ }^{41}$ on the waste of taxpayers' money ${ }^{42}$ and on Muslim men ${ }^{43}$ many others simply insulted her as a 'dirty cunt' or 'genetic waste' and wished her 'generally speaking' death and rape: 'she needs the same treatment as what the Americans did to those bitches in Vietnam' or 'frustrated old women's libber. They should be pushed in a hole with rapists in it."44 What we can see from these extremely hateful and disrespectful comments is that vitriolic comments on the Internet are only rarely the result of the study of arguments. Instead of engaging with the actual content a person provides, vitriolic comments react

39 'lesen sie mal die kommentare die sie mit so einem frauenhasser-artikel produzieren. fröhlichen frauentag.' Twitter-post by @stefansargnagel, 8 March 2017. https://twitter.com/ stefansargnagel/status/839570421762637826.

40 A compilation of 32 comments has been collected as screenshots by Stefanie Sargnagel and can be found in the Facebook-album 'Richard Schmitt wishes you a Happy Women's Day', 9 March 2017, https://www.facebook.com/media/set/?set=a.10154578674413037.1073741857.7112 $48036 \&$ type $=3$.

41 'that monstrosity is a shame for every animal lover, vegetarian, vegan...', 'that animal torturer should be in a psychiatric institution', ibid.

42 'put her into a labour camp', 'why would these betrayers of the nation not be put up against a wall? I could make a good job as an executioner', ibid.

43 'I hope one of her beloved nafris (my apologies if that term is forbidden by now) does her really hard against her will in the staircase', ibid.

44 All comments: ibid. 
in a generally refusing manner in order to unload frustration, strengthen their own position, or the one of their group, and humiliate the victim. ${ }^{45}$ The level of debate and argument then gets completely out of sight.

As I have explained before, Stefanie Sargnagel is not afraid of 'shitstorms' and even harsh reactions for they illustrate the affects that she wants to show. The first reaction of Die Krone was thus more or less what she intended. In order to stoke the flames, immediately after the publication of the Krone article, she writes on Facebook: 'If Die Krone knew that we did not only kick kittens' asses but that we also fucked puppies to death... ${ }^{46}$ That comment was again included in the wochenblick.at article as 'the confessions of an animal abuser, ${ }^{47}$ which pushed Sargnagel to write the following post:

Now that another right-wing medium has picked up on the point that we fucked puppies to death, I surrender and tell you the whole truth: [...] we also whipped baby camels, while we, laughing, ate little patés from baby dolphins. ${ }^{4}$

For many readers of the debate, that comment was the drop that caused the barrel to overflow. After people complained about the author, her Facebook account was closed for a month. The events finally led to a point where Sargnagel herself changed the tone back to argument. For instance, she had a very serious discussion with Richard Schmitt on Twitter. ${ }^{49}$ On 12 March 2017, she even wrote a two-page statement where she mentions

45 In her analysis of online hate speech from a psychological perspective, Josephine B. Schmitt names four motives pertaining to hate comments: exclusion of the other in order to reach a positive understanding of the self; intimidation of those who threaten the self; demonstration of dominance and power; fun and thrill, Schmitt, 'Online Hate Speech'.

46 'wenn die krone wüsste, dass wir nicht nur babykatzen getreten, sondern, dass wir auch welpen zerfickt haben...' Sargnagel, Stefanie, Facebook-post 8 March 2015, https://www.facebook. com/stefanie.sargnagel/posts/10154574558763037.

47 'Hofer-Hasserin'.

48 'nachdem ein weiteres rechtes medium nun auch aufgegriffen hat, dass wir welpen zerfickt haben, gebe ich mich geschlagen und rücke mit der ganzen wahrheit raus: wir haben in marokko nicht nur babykatzen getreten und welpen zerfickt. wir haben auch kleine babykamele ausgepeitscht, während wir lachend faschierte laberl aus babydelfinen gegessen haben. dabei saßen wir auf baby schildkröten und dekoriert war das ganze szenario mit baby hamstern die wir auf palmen aufgehängt haben, nachdem wir sie mit unseren haschsspritzen betäubt haben. beim rückflug haben wir menschenbabys aus dem fenster geworfen auf eine babyinsel auf der nur babys leben, die von den andern babys erschlagen wurden.' Sargnagel, Stefanie, Facebook-post 9 March 2015, https://www.facebook.com/stefanie.sargnagel/posts/10154577761988037.

49 Cf. the discussion under a twitter post by Richard Schmitt on the 8 March 2017, https:// twitter.com/RichardSchmitt2/status/839551599785582592. 
that she was usually not easily intimidated but that, after the publication of her address, she felt uneasy at Klagenfurt..$^{0}$

To sum up, it can be said that the hate campaign Sargnagel experienced consists of two phases: the first is the act of translation of provocative content from Sargnagel's text into realms of a right-wing readership through Die Krone. As I have argued, it is very unlikely that journalists like Richard Schmitt do not understand the satirical frame of Sargnagel's text. But he knew what some of her quotations would trigger in the Krone's readership: affects like hate and anger, which means attention, clicks and money. In the second step, the content starts to circulate in total disconnection from its source and becomes the plaything of very aggressive online networks centred around the collective celebration of hate. Although these sorts of reaction were initially intended by Sargnagel, Hofer and Haider, the reach and the intensity of the hate comments and threats transgressed by far their expectations - while also affecting their personal resilience.

\section{Affect and hate online}

As I have said in the beginning of this case study, I argue that hate on the Internet is not a phenomenon of single actors sitting frustrated in front of their screens. Instead, it is a powerful dynamics of affect of a whole network of people. Affects like hate (be it against strangers, Muslims, women, etc.) is a constant affection that accompanies and pushes people through the online and the offline world, while they are at work, at home, in their couple or family, in private gatherings or on social media. ${ }^{11}$ Hate is constantly there, as a 'movement of emotions and feelings in and out of the cyberspace, through bodies, psyches, texts and machines, $5^{2}$ but cannot always be expressed as it is not tolerated in all contexts. The affect outbursts in protected realms and in exchange with like-minded people. That is why the network of hate and the network of the Internet largely overlap, as people find their platform of exchange and agency online, act out their hate, affect and offend each other, and also find new targets for their hatred, as the case Sargnagel shows: delivered in an already biased way by Die Krone, the Molotov cocktail that Stefanie Sargnagel, Lydia Haider and Maria Hofer prepared with their

$5^{0}$ Twitter-post by @stefansargnagel, 12 March 2017, https://twitter.com/stefansargnagel/ status/840884161518960640.

$5^{1}$ See, for example, Bargetz and Sauer, 'Der Affective Turn'.

$5^{2}$ Karatzogianni and Kuntsman, Digital Cultures, p. 2. 
travelogue is only one of many contents that make their way into a network of hate consisting of right-wing Austrians who strongly react to anything loosely connected to Islam, women, feminism, left-wing ideology, intellectualism, certain elements of social injustice and other adjacent topics. Through intermediaries like Richard Schmitt, Fritz Kimeswenger and Die Krone, and even more through conspiracist organs like wochenblick.at and unzensuriert.at, the content is filtered and arranged in the most effective way to appeal to people's hate. These articles are orchestrated in a way that aims not at intellectual persuasion through argument but at the provocation of affects, ${ }^{53}$ that is 'potential bodily responses, often autonomic responses, in excess of consciousness'. ${ }^{4}$ The software that is needed for these techniques to function is so easily accessible that even absolute beginners can create web content which at first glance (and often that is quite enough) looks confidential. Often, the exponential logic of algorithms is on the side of those who express hate because the posts with the highest number of clicks are the most visible ones.

Thus the Internet and social media can be seen as an important playground for people whose life is entangled with networks of hate. Hate posts and conspiracist articles play an important role because 'the movement of violent words in online domains can intensify hatred and hostility'. 55 For those who are members of online communities centred around hate, media technologies allow them 'both to 'see' affect', through the behaviour of other users, 'and to produce affective bodily capacities beyond the body's organic and physiological constraints ${ }^{56}$, that is to extend the (felt) realm of agency. As the Internet and social media thus become a space for self-empowerment, they 'insert the technical into the felt vitality, the felt aliveness given in the pre-individual bodily capacities to act, engage, and connect - to affect and be affected. 57

Still, the case of Sargnagel shows exactly that the Internet and social media alone cannot be blamed for the mechanisms of hate. Instead, the case shows that different communities create their own networks within the same medium and within the same social media platforms. Furthermore,

53 By reframing content and taking it out of its context, by using collage techniques as we have seen it on wochenblick.at, content is moulded into the shape that affects the most. Claire Wardle explains these techniques in a very insightful article on the construction of Fake News: Wardle, 'Fake News'.

54 Clough, 'Introduction', p. 2.

55 Karatzogianni and Kuntsman, Digital Cultures, p. 2.

56 Clough, 'Introduction', p. 2.

57 Karatzogianni and Kuntsman, Digital Cultures, p. 2. 
the clash of these networks as demonstrated in this case, the integration of information from the intellectual, left-wing network around Der Standard into the right-wing network of hate, leads to escalation. Hence, filter bubbles and echo chambers create the effect that different networks, almost different 'Internets', coexist, making the Internet for some users a space of hate, for others a space of tolerant exchange (and even support against such attacks).

\section{Conclusion}

The merit of Sargnagel's text is to show what happens when the border between mutually exclusive networks and virtually closed communities is crossed. Her text is thus transgressive for several reasons. First, it is a transgression of the limits of 'good taste' but also a transgression of the discourse limits of the realms of different networks that rarely touch each other. Second, the text functions as a boycott in the sense that it wants to go beyond the borders of closed communities and reach out to a broader readership in order to affect people and push the debates further. Although it entailed a disaster for Sargnagel including death and rape threats, she did not change her provocative writing style - perhaps the best proof of her persistency is that a year after the whole scandal, she went to Morocco again and published another travelogue 'Morocco Travel Journal II: 'Steffi Got Married to Hassan" again in Der Standard..$^{8}$ The article already counts more than 1,00o comments in the Standard forum.

\section{Works cited}

Bargetz, Brigitte, and Birgit Sauer. 'Der Affective Turn. Das Gefühlsdispositiv und die Trennung von öffentlich und privat'. Femina Politica, vol. 1, 2015, pp. 93-102.

Clough, Patricia Ticineto. 'Introduction'. The Affective Turn: Theorizing the Social, edited by Patricia Ticineto Clough and Jean Halley. Durham: Duke University Press, 2007, pp. 1-33.

'Die Wohlstands-Verwahrloste'. Wiener Zeitung, 29 November 2013, https://www.wienerzeitung.at/nachrichten/politik/wien/590898_Die-Wohlstandsverwahrloste. html. Accessed 1 March 2020. 
'Fall Sargnagel. Online-Petition fordert Kündigung des 'Krone'-Journalisten Kimeswenger'. Wienerin, 13 March 2017, https://wienerin.at/petition-fordertkundigung-des-krone-journalisten-kimeswenger. Accessed 1 March 2020.

Haider, Lydia, Maria Hofer, and Stefanie Sargnagel. 'Drei Autorinnen in Marokko: Jetzt haben wir ein Pferd und Haschisch'. Der Standard, 25 February 2017, https:// www.derstandard.at/story/2000053157304/drei-autorinnen-in-marokko-jetzthaben-wir-ein-pferd-und. Accessed 1 March 2020.

—. 'Marokko-Reisetagebuch II: 'Steffı hat Hassan geheiratet." Der Standard, 17 March 2018, https://www.derstandard.at/story/2000076277310/marokkoreisetagebuch-ii-steffi-hat-hassan-geheiratet. Accessed 1 March 2020.

'Heldenplatz, reloaded: Krone gegen Stefanie Sargnagel'. Der Kurier, 10 March 2017, https://kurier.at/kultur/heldenplatz-reloaded-krone-gegen-stefaniesargnagel/250.828.150. Accessed 1 March 2020.

'Hofer-Hasserin macht Drogentour auf Kosten des Steuerzahlers!'. Wochenblick, 9 March 2017, http://www.wochenblick.at/hofer-hasserin-macht-drogentourauf-kosten-des-steuerzahlers/. Accessed 1 March 2020.

Karatzogianni, Athina, and Adi Kuntsman. Digital Cultures and the Politics of Emotion: Feelings, Affect and Technological Change. New York: Palgrave Macmillan, 2012. Kobek, Jarett. I Hate the Internet. Los Angeles: We Heard You Like Books, 2016. "Literaturreise' Saufen und kiffen auf Kosten der Steuerzahler'. Die Krone, 8 March 2017, https://www.krone.at/557951\#comment-list. Accessed 1 March 2020.

'Presserat zum “Babykatzengate.” OTS, 12 May 2017, https://www.ots.at/presseaussendung/OTS_20170512_OTSo041/presserat-zum-babykatzengate. Accessed 1 March 2020.

Sargnagel, Stefanie. 'Babykatze treten, kiffen und saufen: 'Literaturreise' auf Kosten der Steuerzahler'. unzensuriert.at, 11 March 2017, www.unzensuriert. at/content/oo23401-Babykatze-treten-kiffen-und-saufen-Literaturreise-aufKosten-der-Steuerzahler.

—. Binge Living: Callcenter Monologe. Vienna: Redelsteiner Dahimène, 2013.

—. In der Zukunft Sind Wir Alle Tot. Neue Callcenter-Monologe. Berlin: Mikrotext, 2014.

—. Fitness. Vienna: Redelsteiner Dahimène, 2015.

—. Statusmeldungen. Reinbek bei Hamburg: Rowohlt, 2017.

Schmitt, Josephine B. 'Online Hate Speech: Definition und Verbreitungsmotivationen aus psychologischer Perspektive', in Online Hate Speech. Perspektiven auf eine neue Form des Hasses, edited by Kai Kaspar et al. Düsseldorf, München: Kopaed, 2017, pp. 51-56.

'Schmöker: 'Ein Abend mit Stefanie Sargnagel." dieschreibmaschine.net, 14 November 2017, https://dieschreibmaschine.net/2017/11/14/schmoeker-ein-abend-mitstefanie-sargnagel/. 
'Stefanie Sargnagel nach Identitären-Posting von Facebook blockiert'. Der Standard, 19 April 2016, https://www.derstandard.at/story/2000035208517/ stefanie-sargnagel-nach-identitaeren-posting-von-facebook-blockiert.

'Urarg, urschlecht, urschade'. Tageszeitung, 15 March 2016, p. 13.

Wardle, Claire. 'Fake news. It's Complicated'. First Draft, 16 February 2017, https:// firstdraftnews.org/latest/fake-news-complicated/. Accessed 1 March 2020.

'Wirbel um Marokko-Reisebericht von Sargnagel, Haider und Hofer: Der Einfachheit erlegen', Der Standard, 10 March 2017, https:/www.derstandard.at/ story/2000053969916/wirbel-um-marokko-reisebericht-von-sargnagel-haiderund-hofer-der.

\section{About the author}

ANN-MARIE RIESNER is a research associate at the Heinrich Heine University in Düsseldorf, Germany, at the department of Modern German Literature. She is currently completing her PhD Project titled Imaginations of the Internet in Contemporary German Literature, 1999-2019 at Justus Liebig University in Giessen, Germany, where she also has worked at the Center for Media and Interactivity. She studied German and Romance literatures at Albert Ludwig University Freiburg, Université de Paris Sorbonne Nouvelle, Technical University Dresden, École normale supérieure de Lyon, and Washington University in St. Louis, Missouri. Ann-Marie Riesner has published on contemporary German literature, online writing projects, actor-networktheory, science, technology and media studies, and modernism. 


\title{
9 Ethical Implications of Onlife Vitriol
}

\author{
Katleen Gabriels and Marjolein Lanzing
}

\begin{abstract}
This chapter explores onlife vitriol from an ethical perspective. Traditional offline/online dualisms hinder in-depth understanding because online and offline violence are deeply interconnected, hence onlife. We discuss three cases of onlife vitriol: revenge rape and slut shaming, body shaming, and cyberbullying. Onlife vitriol opens up unprecedented forms of harm enabled, and often amplified, by the technology. We argue that this form of violence is currently inadequately addressed. Existing legal measures are not (yet) effective for preventing or ensuring sufficient reparation in cases of onlife vitriol. Societal debates about how to handle onlife vitriol lag behind despite implicit acknowledgement of its harmful effects. Greater media literacy and more research concerning the boundaries of monitoring are needed now that it has become increasingly easy to surveil, coveil, and sousveil.
\end{abstract}

Keywords: online vitriol, onlife vitriol, surveillance, coveillance, sousveillance, violence

This chapter explores ethical concerns related to onlife vitriol. Online vitriol can be narrowly conceived. The Cambridge Dictionary for instance, defines vitriol as 'violent hate and anger expressed through severe criticism.' $\mathrm{We}$, however, take a broader approach by suggesting that instances of online vitriol can be conceptualized as onlife violence: violence that transgresses and affects both the offline and online world. While there is not a clear-cut, all-encompassing definition of violence, ${ }^{2}$ we conceptualize violence as the intentional physical or psychological, including reputational, harm inflicted on a person and/or

1 See https://dictionary.cambridge.org/dictionary/english/vitriol.

2 See Vorobej, The Concept.

Polak, Sara, and Daniel Trottier (eds), Violence and Trolling on Social Media. Amsterdam, Amsterdam University Press 2020 DOI: 10.5117/9789462989481_CHO9 
their property. In this conception, specific instances of hate speech can be understood as onlife violence because of their actual impacts, such as causing psychological harm. We discuss a number of cases that we consider as violent forms of onlife vitriol. Cases we zoom in on include revenge rape and slut shaming (cf. the 187 exposed snitches \& bitches case), body shaming (cf. the Dani Mathers case), and cyberbullying (cf. the Amanda Todd case).

Our chapter draws upon the claim that traditional offline/online dualisms hinder our understanding of online violence exactly because online and offline violence are deeply interconnected, hence onlife. Modern information and communication technologies tether actions committed in the offline world to the online and vice versa. Both online and offline acts of violence are part of one experienced and ongoing reality. The acts of violence at stake in our cases of vitriol cannot be reduced to virtual harm or regarded as separate from the offline realm. We argue that online vitriol is a new dimension of real violence that is ethically problematic because it opens up unprecedented forms of harm enabled, and often amplified, by the technology. Moreover, we argue that this form of violence is currently not adequately addressed in our society. As we will illustrate, existing legal measures are not (yet) effective for preventing or ensuring sufficient reparation in cases of onlife vitriol. At the same time, we argue that the societal debate about how to handle onlife vitriol lags behind even though there is implicit acknowledgement of its harmful effects.

Nowadays, the technological features of mobile computing facilitate new manifestations of surveillance, such as coveillance (peer monitoring), through new technological possibilities for immediate, cheap, and long-term recording. ${ }^{3}$ One of the first cases and an example of how peer monitoring can become a pernicious form of visibility and Internet vigilantism is the infamous Dog Poop Girl case from 2005. Photographs - taken with camera phones - of a young woman who refused to clean up after her dog had defecated on the subway train, were shared online after which the woman was harassed and threatened relentlessly. ${ }^{4} \mathrm{~A}$ second interesting case of the perniciousness of an online memory is the one of the late Ilse Uyttersprot, former mayor of the Belgian city Aalst, who was secretly recorded while having sex in a public space. Four years later, she was confronted with the material, which had spread like wildfire across various social network sites and websites, compromizing her position as mayor. ${ }^{5}$ New technological 
features problematize acts of violence in a worrying way. Technologies allow victims to be haunted and (repeatedly) harmed by violence in perpetuity, which affects their off and online lives. ${ }^{6}$

We will unfold our arguments in the following way. First, we elaborate on our basic conceptual assumption that offline/online dualisms hinder our understanding of online violence (and vitriol) by drawing from the literature. ${ }^{7}$ Second, we propose that modern ICTs provide a new, ethically problematic dimension to violence because their features allow ongoing repetitive violence. Users carry their camera-equipped smartphones with access to online platforms with them and can instantly upload photos, films, and other data to millions of users. ${ }^{8}$ In so doing, we introduce and discuss three specific cases of onlife vitriol. First, the case Amanda Todd (2012), a Canadian girl who was severely cyberbullied and bullied at school, and eventually committed suicide. Second, the case Dani Mathers (2016) on body shaming: Mathers posted a nude picture of a woman showering at her local gym online, which subsequently went viral. Finally, the case on 187 exposed snitches \& bitches (2017-2018) on slut shaming and revenge rape.

All cases have female victims, which is not to say that men cannot suffer from onlife vitriol. In fact, awful cases of onlife vitriol, including the suicide of Tyler Clementi in 2010, who was filmed with a webcam, installed by his roommate, while exploring his gay sexuality, happen to men as well. While onlife vitriol affects many different user groups - becoming a victim of onlife vitriol can happen to anyone - we recognize that some user groups are more vulnerable because of their gender, ethnicity, and sexuality. One such user group consists of (young) women, who are particularly vulnerable because of their gender and (sometimes) intersecting ethnicity. ${ }^{9}$

We conclude that new ICTs have given rise to onlife vitriol: a form of violence that transgresses and affects both the offline and online world. We advocate for greater media literacy among users but also for more research into questioning and regulating the boundaries of monitoring now that it has become increasingly easy to surveil, coveil, and sousveil through our smartphones and connected online platforms. ${ }^{10}$ Not only can companies and governments track and watch consumer or citizens behaviour from

6 Fox et al., 'Perpetuating Online Sexism'.

7 Dibbell, 'A Rape'; Dibbell, My Tiny Life; Gabriels, 'Ethics and Morality'; Henry and Powell, 'Embodied Harms'.

8 Blanchette and Johnson, 'Data Rentention'.

9 Fraser, 'Sex, Lies'; Dugan, 'Online Harrassment'.

10 Citron and Franks, 'Criminalizing Revenge Porn'; Huff et al., 'Virtual Harms'; Marwick and Miller, 'Online Harassment'. 
above, or surveil, but new technologies enable coveillance, that is, the multidirectional type of peer monitoring found on social network sites. They allow users to watch each other's posts and re-share or copy them. Moreover, new technologies enable users to sousveil: to track and watch those in power from below, for instance, by using mobile or wearable devices to record protests or police action. ${ }^{11}$ When we discuss monitoring throughout this chapter, we mainly focus on coveillance since this form of monitoring is particularly interesting from the perspective of vigilantism.

\section{Onlife vitriol: Coveillance and pernicious memory}

In this first part, we address the conceptual underpinnings of the notion onlife and its specific repercussions for online vitriol and harm. Because online acts of vitriol are likely to have actual-world impacts, such as psychological harm, we emphasize the reality status of online settings, which fall within the scope of ethical consideration. It is important to underscore the hybridization of online and offline, among others in terms of identity and sociality.

In the early days of the World Wide Web, the first-generation theorists of the 1990s approached the online-offline relation in terms of an ontological dualism rather like a mind-body split, hereby emphasizing how the virtual is radically divorced from the real. ${ }^{12}$ The Internet was looked upon as a walled-off space where actual-world rules did not apply and where people could leave behind their emotional embodied selves. A dualism was at play between "virtuality", which is associated with information, the mind, and fantasy, and "reality", which is associated with materiality and the body'. ${ }^{13}$

At the end of the 1990s this ontological dualism was gradually disproven by empirical research and phenomenological approaches, showing more of a merging between online and offline identities. An interesting example is Markham (1998) who started from a clear-cut dichotomy in her empirical study. She eventually destabilized the dichotomy when her findings revealed that users conceive virtual experiences as real ones and do not operationalize a dualism. ${ }^{14}$ People do not start their online lives from a blank slate, as they are always rooted in autobiographical, social, moral, and cultural contexts. Both online and offline experiences are part of one continuous everyday reality. 
It also became clear that crossing moral boundaries in online settings could have actual-life impacts. A seminal text, based on a true event, in this context, is 'A rape in cyberspace.'. Julian Dibbell chronologically reports on how Mr. Bungle raped Legba and Starsinger in the text-based social virtual world LambdaMOO. The victims reported to be distressed by the events, such as crying behind their computer screen. Many residents supported the victims and condemned Mr. Bungle's actions. They argued to decide on what would be a proper punishment for the wrongdoer. As there were no explicit rules against rape, the community gathered for a public meeting in the online environment of LambdaMOO. Although community members had deviating views on the severity of the incident, many of them believed that the harm-doer could not escape sanctioning. This event revealed that LambdaMOO was a meaningful environment for its residents, and that online practices are enacted within a moral framework. This way, they fall within the consideration of ethics. Online harm should not be easily dismissed with arguments such as: 'it only took place online' or 'just go offline, shut down your computer'. Dibbell's depiction of the online rape also forced Internet researchers to acknowledge the reality status of online experiences. In Buchanan's phrase, 'this incident was seminal in pushing the boundaries of online experiences into human subjects research. ${ }^{16}$

Virtual space has to be understood as an embodied space in which actual-life selves, practices, and norms continue to exist. Subsequently, dualist views in terms of virtual versus actual selves were deconstructed and brought about a view on virtual selfhood in terms of an extension, rather than a disruption of actual self. This turn in conceptual thought led to new notions of the self as an onlife self, ${ }^{17}$ to highlight the hybridization of both selves, and a smeared-out self to emphasize that the self is distributed across multiple communication networks. ${ }^{18}$ The self stretches out over the online and offline world: these worlds are interwoven, instead of distinct. Online and offline forms of social, moral, and cultural life mutually influence each other and are deeply interwoven. Therefore, dualisms hinder our understanding of online vitriol. In the next section we discuss three cases of onlife vitriol that we subsequently build on to further develop our theoretical perspectives.

Dibbell, 'A Rape'.

Buchanan, 'Internet Research Ethics', p. 89.

Floridi, 'The Informational Nature'.

Ess, 'The Embodied Self'. 


\section{Cases of onlife vitriol}

Vitriol in online settings is a new dimension of real violence that opens up unprecedented forms of harm that are enabled, and often amplified, by the technology. Technological features play an important role in mediating and shaping the violence and its impact. The immediacy, speed of dissemination, the scope (scale), the easiness to share and copy the information inherent to many new ICTs give rise to new feature-related practices such as coveillance, which can turn into social policing or even vigilantism.

A good example of onlife vitriol is bullying. Classical bullying was confined to face-to-face settings. Nowadays, bullying moves between online and offline contexts. The impact has worsened because, among other things, an anonymous (invisible) audience can witness the bullying. Even though more research is needed on the effects and impacts of cyberbullying versus in-person bullying, there is evidence that technology has amplified the effects of classical bullying in the case of cyberbullying. ${ }^{19}$

An example of bullying that shows the onlife impact on victims' lives is the case of the Canadian teenager Amanda Todd. Between 2009-2010, a picture of her breasts was circulated online after she was blackmailed. As a result, Todd was bullied at school and online. Despite the decision of her family to move several times, Todd could not escape the onlife vitriol because the information that harmed her was disseminated online. Eventually, in 2012, Amanda posted a YouTube video in which she disclosed the harassment and how this harmed her. A week after, she committed suicide.

The second case of onlife vitriol we discuss is the Dani Mathers case. In 2016, Dani Mathers, a former Playboy model, publicly posted a picture that she made with her smartphone of a 70-year-old naked woman showering at her gym in Los Angeles on Snapchat, with the words 'If I can't unsee this, then you can't either.' Mathers also posted a selfie with her hand before her mouth, depicting herself in mock shock. The picture subsequently went viral and several newspapers and (news) websites published it (although partly blurred) as well. People worldwide criticized Mathers for body shaming. Mathers was charged with invasion of privacy and eventually sentenced in 2017 to thirty days of community service and a probation period of three years. ${ }^{20}$ This case is a good illustration of onlife vitriol, though there was, just like in the aforementioned example of LambdaMOO, no actual physical harm. The victim's privacy was violated and she was humiliated in front of 
the world's eye. Although it is debatable that Mathers could foresee that her picture went viral, she intentionally uploaded it on Snapchat, together with harsh words, and subsequently caused psychological harm to the victim. ${ }^{21}$

Our final case is ' 187 exposed snitches \& bitches'. The Dutch Broadcast Organization (NOS) uncovered and researched slut shaming app-groups on Telegram, a smartphone communication application that is the equivalent of the more popular WhatsApp. These app-groups aim to expose and shame women of Turkish and Moroccan backgrounds who are perceived to have transgressed cultural behavioural norms of sexuality. This ranges from pictures in which a girl is not wearing a headscarf to explicit nudes. One way of proof includes sharing names and phone numbers along with nude photos or videos, including photos of minors. These app-groups are titled ' 187 exposed snitches \& bitches' or 'headscarfs 18+' and include thousands of users. The app-groups intentionally aim to harm the reputations of women by exposing their (sexual) behaviour. ${ }^{22}$ The social consequences of being mentioned in these app-groups are extreme, including rejection (of the girls' family) by the community. Young women whose pictures are shared on these apps are often oblivious and will only later suffer from the consequences of a destroyed reputation and honour. This example of online shaming has been referred to as a form of honour killing. ${ }^{23}$

New features of ICTs afford new forms of problematic violence, because they allow and facilitate repetitive violence. In the next section we continue our analysis about how these features problematize and amplify acts of violence in a worrying way from the perspectives of pernicious memory and coveillance.

\section{Dustbin to freezer: The importance of forgetting in a world of increasing surveillance}

The problem of onlife vitriol stems from a more general problem regarding the continuous visibility of users and the coveillance and pernicious memory that new technological features afford. Until fifteen years ago it would have been a reasonable expectation that one's history was a personal and private matter. Dredging up and displaying your past behaviour would have cost a great deal of effort and, therefore, would have been highly unlikely. Formerly, 
when teenagers would transfer schools they experienced something that most teenagers today perhaps no longer experience: a fresh start. New technologies, such as social network sites, enable the constant recording of one's personal information, including selfies, YouTube clips, live-streams, Facebook posts, and Instagram posts and tweets. Starting with a clean slate and building a new life can become difficult, because past and current actions are now equally easy to access: 'Electronic accessibility renders past and current events equally knowable. The very ideas of 'past' and 'present' in relation to personal information are in danger of evaporating. ${ }^{24}$

Following new possibilities of technology, our expectations regarding the privacy of our past have changed accordingly. New technologies mediate our expectations from different social contexts. Information about a person that was once contained to the classroom can now end up at one's workplace. It has become increasingly difficult to separate social contexts and to control the information that spills over into different social contexts through the use of ICTs. Not reviewing what turns up on Google when you enter your name before going to a job interview or not expecting your employer to review your online presence is now considered to be naïve and even negligent. Yet, distancing ourselves, at the very least from the mistakes, diversions from, or transgressions of the social norm, we wish to put behind us seems a reasonable demand from a psychological, social, and ethical perspective. We first discuss the first two reasons, before raising the underlying ethical rationale.

\section{The psychological function of forgetting}

Forgetting has a psychological function. Memories can terrorize one's life and chill one's actions. Imagine suffering from hyperthymesia; a condition of perfect autobiographical memory. People who suffer from hyperthymesia are incapable of reconstructing or reinterpreting personal narratives because the memories are unusually accurate and complete. ${ }^{25}$ One can imagine several mental health hazards that accompany the impossibility of forgetting past experiences such as the inability to process traumatic experiences. Many psychological strategies are aimed at distancing the subject from her experiences in order to move on, to make room for new 
experiences, or to forgive themselves or others for past actions. ${ }^{26}$ In the case of Amanda Todd, she was unable to distance herself from her traumatic experiences. This was largely due to the pernicious online memory, but also because her harasser, a (suspected) Dutch man who controlled her information, continued to monitor her actively at a distance. New ICTs enabled him to repeatedly harm her reputation at every new school by posting her nude pictures online and distributing them among her new social contacts.

The fading, reinterpretation, or blocking of memories with the passing of time or specific therapy is necessary for placing distance between the past and the present, for being able to look upon an experience from a more detached perspective. Imagine having to relive the emotions one felt after a past break-up with the same intensity ten years later or imagine re-experiencing the psychological effects of being humiliated, bullied, or shamed on a daily basis.

The victim of the Dani Mathers case experienced severe loss of control when she was humiliated before an international audience. The wide dissemination of the picture is still obvious today, as it can still be found online. Also, people can easily save it to their computer, so it is impossible to estimate how widely the picture was actually disseminated. Going to the gym was a trivial event that nonetheless put the victim before the public eye and made her a news topic. While she expressed that she would like to move on, this has been made impossible. The ability to move past victimhood or trauma largely depends on the ability to forget.

\section{The social function of forgetting}

The socio-legal perspective on the importance of forgetting is tightly wound up with the psychological value of forgetting and, as we will see, the ethical considerations with regard to the value of privacy and forgetting. The right to be forgotten received special attention. In 2014, Google Spain lost a case against Mario Costeja González, a Spanish citizen who requested the removal of an Internet link. The link led to a newspaper article from 1998 in which the foreclosure of his house was announced, as well as its auction, which was related to a debt he owed at the time. He had since paid off his debt and reasoned that he had the right to have this information removed since all

26 An example is eye movement desensitization and reprocessing (EMDR) treatment: a therapeutic method for severely traumatized patients basically enables an accelerated process. 
matters had been resolved. ${ }^{27}$ The European Court of Justice ruled in favour of Costeja González and asked Google to comply with the right to be forgotten and remove the link. Costeja Gonzálezs claim set a precedent for 12.000 requests for the removal of personal data on the first day of compliance only.

While the recent court decision regarding the right to be forgotten has sparked international debate, the concept of social forgetfulness is far from controversial. It has been institutionalized in our society as an important value. Examples are policies and legislation including bankruptcy law, juvenile crime records, and credit reporting that protect social forgetfulness and, relatedly, the chance to start over. ${ }^{28}$ After all, forgiveness and forgetting are very closely related. Social forgetting may allow people to try again without the constant burden of their past. To be freed from ones past behaviour and to be granted a clean slate may cause people to feel trusted and to trust themselves again.

While these socially institutionalized forms of forgetfulness are oriented towards perpetrators, the right to be forgotten is interesting also from the perspective of victims of onlife vitriol. For instance, Google has committed to this forgetfulness by removing links to pictures and videos that include revenge rape or revenge porn. ${ }^{29}$ Nevertheless, the Dani Mathers case clearly shows how challenging it is to grasp, act on, and control acts of onlife vitriol in order to mitigate its impact on victims. The impact of the viral picture taken by Mathers was amplified because of present-day ICTs. Twenty-five years ago, using a reflex camera, it would have been more difficult to secretly take a picture. Also, the speed to disseminate it online was significantly slower in the early days of the World Wide Web. Mathers's behaviour was mediated and co-shaped by technology: a smartphone camera, a mobile Internet connection, an account on a social network site, and so forth. All of these were immediately within reach by merely pressing some buttons.

Moreover, Mathers's behaviour was shaped by shifting norms on sharing information online and coveillance: making and uploading pictures and videos without obtaining consent has become a daily habit. In the past years there have been shocking cases, such as the real-time streaming of murder on Facebook Live and rape on Periscope. $3^{0}$ While we often discuss

Blanchette and Johnson, 'Data Retention'. 
the meaning of privacy in a digital age, there is too little public discussion regarding the consequences of coveillance as a form of vigilantism.

Even though in the Mathers case the perpetrator was legally prosecuted and sanctioned, the human costs remain high. The victim only spoke through her attorney, expressing her wish to leave the case behind her. ${ }^{31}$ But, as we discussed in the previous section, the psychological harm that the victim suffered from and continues to suffer from due to the fact that her pictures can still be found online today and cannot be removed, is done. From a legal point of view, it is not easy to compensate for all these consequences.

Finally, legal steps against perpetrators generally are incredibly difficult to take. In the Amanda Todd case, the perpetrator was only investigated, identified as a Dutch man and sentenced to prison in March 2017, long after her death. In the ' 187 exposed snitches \& bitches' case, the harassers are anonymous groups of men that are difficult to investigate. The Telegram app-groups that they use are not publicly accessible. One can join only when one is invited and these app groups are exclusive to men. Also, Telegram allows for anonymous participation. This makes it more difficult to do research. Moreover, online revenge rape is a murky legal terrain..$^{32}$ The police expresses that it experiences difficulty in classifying the victims of onlife vitriol. In the Netherlands, Minister Grapperhaus (Justice and Safety) is working on a modernization of the law regarding revenge rape as a form of onlife vitriol. 33

\section{The ethical perspective on forgetting}

Granting people the opportunity to start over and not to be burdened by the past is something that we intuitively seem to find the right or kind thing to do, because this opens up space to develop oneself. ${ }^{34}$ Without forgetfulness, society would become a suffocating place. Allen (2008) argues that new ICTs raise concerns with regard to an everlasting, objective memory and the effect of the continuous possibility of dredging up the past. Burkell (2016) reiterates these concerns, claiming that digital systems that remember everything threaten our personal, narrative identity and human flourishing. 
Along with Dodge \& Kitchin (2007) and Mayer-Schönberger (2009), Burkell argues that forgetting is a psychological necessity and that, therefore, we are in need of an ethics of forgetting.

The ethical importance of forgetting lies in the right to change. The underlying value is autonomy and, more specifically, the ability to express and thus develop the self freely. Self-expression and self-development are inhibited when one worries about being confronted with one's expressions, through image and text, in the future and when one adapts one's behaviour according to a perceived social norm. Often this is referred to as the chilling effect. ${ }^{35}$ The chilling effect resonates nicely with Anita Allen's dustbin-freezer analogy (2008). Posting information through new ICTs, Allen argues, should be compared to storing something in a freezer, rather than throwing it out into the dustbin. In the past our behaviour and actions would have been forgotten for the most part; they would have ended up in the proverbial dustbin. Today, however, all information, however briefly present on the web, is instantly and automatically copied, shared, and stored on multiple servers, either by users or by corporations. Whether your actions are offline or online, your behaviour is more likely to be frozen and kept fresh in the digital freezer, ready to be defrosted sometime in the future. The problem that has been exacerbated and, therefore, has become more harmful with new ICTs, is that one can be confronted with a copy of her past or a combination of copies of her past at any given time. While the bits and chunks of information or data posted and stored on the Internet of course do not instantly constitute a memory, we agree with Burkell that a digital record 'constitutes an array of potential memories, the very existence of which may compromise our ability to forget, or move on'. ${ }^{36}$ One's digital(ized) behaviour may become an eternal reminder of and potential confrontation with the (bad) choices and actions one once made or became the victim of. This may result in a form of repetitive and ongoing violence.

The possibility of being confronted with one's past behaviour alone has a chilling effect on one's behaviour. Moreover, who is monitored and, consequently, whose information is shared and stored, is susceptible to biases, including gender. ${ }^{37}$ For instance, young women express that they should be more careful than their male counterparts about how they present 
themselves online. ${ }^{8}$ They report that they are judged more harshly. Moreover, as exemplified in the 187 exposed snitches \& bitches case, they are not only vulnerable to social control and onlife vitriol from the perspective of gender but also from the perspective of their ethnicity and corresponding cultural backgrounds.

Coveillance, which has become a normalized practice across social network sites, and pernicious memory enable and increase the impact of behavioural policing or vigilantism. The ' 187 exposed snitches \& bitches case' illustrates this as well. Pictures and videos from the Telegram-apps were also shared on other social network sites such as Facebook, Twitter, and YouTube, creating a collective memory with which the victims are confronted every day. One victim, Ouahiba, stated in a video on YouTube that pictures and videos she shared three years ago with a trusted partner, that do not represent her now, were circulated across multiple forms of social network sites every day for three years after and destroyed her life. ${ }^{39}$

Onlife vitriol impacts career opportunities and personal relationships. Ouahiba stated that her employer was informed about her pictures, which affected her work. She also stated that she lost her friends because of her tainted reputation. Clearly, the fact that this all plays out on social network sites does not mean that the wishes or the trauma and suffering of the victims are less real. One mother posted a heart-breaking message on the NOS news webpage in which she pleads the app groups to delete her daughter's pictures..$^{40}$ Ouahiba also asks her audience on YouTube whether, even if she deserved social punishment, it is fair and reasonable to punish someone every day for three years in a row. ${ }^{41}$

The combination of coveillance and pernicious memory enables social policing and vigilantism, which has a detrimental effect on experimentation, creativity, and invention. Taking risks or deviating from the (perceived) social norm may have dire consequences because one's actions will be saved forever and therefore liable to public scrutiny forever. Importantly, this causes a problem for the free and dynamic shaping of one's identity. In sum, modern ICTs afford new, ethically problematic dimensions to violence because of their technological characteristics.

38 Steeves and Bailey, 'Living in the Mirror'.

39 See 'Mijn verhaal - Ouahiba', published 17 November 2017 on YouTube, https://www.youtube. com/watch?v=EMdcv7kBIDo Accessed 27 August 2020.

40 Pruis et al., 'Vrouwen online exposed'.

41 For the link, see footnote 39. 


\section{Concluding thoughts}

In this chapter, we sought to broaden the notion of (online) vitriol by conceptualizing it as onlife violence: violence that transgresses and affects both the offline and online world. In doing so, we elaborated on three cases to illustrate how violence has changed with the affordances of new technologies. Both greater media literacy among users and more empirical and conceptual research are required, amongst others on regulating the boundaries of monitoring since it has become increasingly easy to coveil with present-day ICTs. We are never cut off from the network: we are in fact always and already on, making it impossible to log out. In the past, only children born into royal families or children of celebrities grew up in front of cameras and in front of the public eye. Yet, nowadays virtually every child in the West grows up in front of multiple cameras: a baby monitor with a camera at home, surveillance cameras on the street, personal smartphone cameras, dashcams, recreational drones, and so on.

It is our contention that onlife vitriol is a form of violence that is inadequately addressed at the moment in our society. While intuitively we agree that cases of onlife vitriol as presented in this chapter are forms of violence, the means society has at her disposal to combat this violence are limited. This clearly comes to the fore in the Dani Mathers case, in which the victim could not be offered adequate reparation (her photos are still online today); the '187 exposed snitches \& bitches' case, in which victims reported to the police but the police did not know what to do with these reports and which only after this case has stirred a debate in the Netherlands about adequate legislation; and the Amanda Todd case in which only after her death the alleged perpetrator (who harassed many other girls at the same time) was arrested $^{42}$. The law is, of course, not the only tool for combatting onlife vitriol. We suggest that a societal debate about the meaning, harm, and solutions regarding onlife vitriol is important in order to raise awareness and to educate users and citizens. Moreover, we are in need of adequate policies regarding onlife vitriol that recognize its dynamic and crossover nature, as well as the actual-life impact of it. We are already always on, but in a society that is increasingly becoming smart (cf. the Internet of Things and smart cities), the ethics of onlife vitriol should be a crucial societal debate.

42 Although it has been argued that the US and Canada have adequate laws to combat this type of harassment, it has also been argued that the cultural mores prevented the law from being successfully invoked. See also: https://www.newyorker.com/culture/culture-desk/ the-story-of-amanda-todd. 


\section{Works cited}

Allen, Anita L. 'Dredging up the Past: Lifelogging, Memory, and Surveillance'. The University of Chicago Law Review, vol. 75, no. 1, 2008, pp. 47-74.

Bennett, Steven C. 'Right to be Forgotten: Reconciling EU and US Perspectives'. The Berkeley Journal of International Law, vol. 30, 2012, pp. 161-169.

Blanchette, Jean-François, and Debora B. Johnson. 'Data Retention and the Panoptic Society: The Social Benefits of Forgetfulness'. The Information Society, vol. 18, 2002, pp. 33-45.

Buchanan, Elizabeth A. 'Internet Research Ethics: Past, Present, and Future', in The Handbook of Internet Studies, edited by Mia Consalvo and Charles Ess. West Sussex: Wiley-Blackwell, 2013, pp. 83-108.

Burkell, Jacquelyn. 'Remembering Me: Big Data, Individual Identity and the Psychological Necessity of Forgetting'. Ethics and Information Technology, vol. 18, no. 1, 2016, pp. 17-23.

Campbell, Marilyn A. 'Cyber Bullying: An Old problem in a New Guise?'. Australian Journal of Guidance and Counselling, vol. 15, no. 1, 2005, pp. 68-76.

Citron, Danielle Keats, and Mary Anne Franks. 'Criminalizing Revenge Porn'. Wake Forest Law Review, vol. 49, 2014, pp. 345-391.

Dibbell, Julian. 'A Rape in Cyberspace. How an Evil Clown, a Haitian Trickster Spirit, Two Wizards, and a Cast of Dozens Turned a Database into a Society'. The Village Voice, 23 December 1993, pp. 36-42.

-. My Tiny Tife: Crime and Passion in a Virtual World. New York: Owl Books, 1999.

Dodge, Martin, and Rob Kitchin. 'Outlines of a World Coming into Existence: Pervasive Computing and the Ethics of Forgetting'. Environment and Planning B: Planning and Design, vol. 34, no. 3, pp. 431-445.

Dugan, Maeve. 'Online Harassment: Summary of Findings'. Pew Research Center Internet \& Technology, 22 October 2014, https://www.pewresearch.org/internet/2014/10/22/online-harassment/. Accessed 15 March 2018.

Edwards, Lilian. 'Revenge Porn: Why the Right to be Forgotten is the Right Remedy'. The Guardian, 29 July 2014, https:/www.theguardian.com/technology/2014/ jul/29/revenge-porn-right-to-be-forgotten-house-of-lords. Accessed 15 March 2018.

El Abdouni, Nora. 'Er is een seksualiteitsoorlog gaande'. $N R C$, 18 December 2017, https://www.nrc.nl/nieuws/2017/12/18/er-is-een-seksualiteitsoorlog-gaandea1585379. Accessed 15 March 2018.

Ess, Charles. 'The Embodied Self in a Digital Age: Possibilities, Risks and Prospects for a Pluralistic (Democratic/Liberal) Future?'. Nordicom Information, vol. 32, no. 2, 2010, pp. 105-118. 
—. 'Self, Community, and Ethics in Digital Mediatised Worlds', in Trust and Virtual Worlds. Contemporary Perspectives, edited by May Thorseth and Charless Ess. New York: Peter Lang, 2011, pp. 3-30.

Floridi, Luciano. 'The Informational Nature of Personal Identity'. Minds and Machines, vol. 21, no. 4, 2011, pp. 549-566.

Fox, Jesse, et al. 'Perpetuating Online Sexism Offline: Anonymity, Interactivity and the Effects of Sexist Hashtags on Social Media'. Computers in Human Behavior, vol. 52, 2015, pp. 436-442.

Fraser, Nancy. 'Sex, Lies and the Public Sphere: Some Reflections on the Confirmation of Clarence Thomas'. Critical Inquiry, vol. 18, no 3, 1992, pp. 595-612.

Gabriels, Katleen. 'Ethics and Morality in Virtual Space', in Vice City Virtue:Moral Issues in Digital Game Play, edited by Karolien Poels and Steven Malliet. Leuven: Acco Uitgeverij, 2011, pp. 33-50.

-. Onlife. Hoe de digitale wereld je leven bepaalt. Tielt: Lannoo, 2016.

'Google Spain SL v. Agencia Española de Protección de Datos'. Harvard Law Review, vol. 735, 2014, https://harvardlawreview.org/2014/12/google-spain-sl-v-agenciaespanola-de-proteccion-de-datos/. Accessed 15 March 2018.

'Grapperhaus: meer doen tegen exposen'. NOS, 8 March 2018, https://nos.nl/ artikel/2221246-grapperhaus-meer-doen-tegen-exposen.html. Accessed 15 March 2018.

Hartzog, Woodrow, and Evan Selinger. 'Google's Action on Revenge Porn Opens the Door on Right to be Forgotten in US'. The Guardian, 25 June 2015. https:// www.theguardian.com/technology/2015/jun/25/googles-revenge-porn-opensright-forgotten-us. Accessed 15 March 2018.

Hauser, Christine. 'Dani Mathers, Former Playboy Model, Gets Community Service for Snapchat of Woman in Gym'. The New York Times, 25 May 2017, https:// www.nytimes.com/2017/05/25/us/dani-mathers-body-shaming.html. Accessed 15 March 2018.

Henig, Samantha. 'The Tale of Dog Poop Girl Is Not So Funny After All'. Columbia Journalism Review, 7 July 2005, http://archives.cjr.org/behind_the_news/ the_tale_of_dog_poop_girl_is_n.php.

Henry, Nicola, and Anastasia Powell. 'Embodied Harms: Gender, Shame, and Technology Facilitated Sexual Violence'. Violence Against Women, vol. 21, no. 6, 2015, pp. 758-779.

Huff, Charles, Deborah G. Johnson, and Keith W. Miller. 'Virtual Harms and Real Responsibility'. IEEE Technology and Society Magazine, vol. 22, 2003, pp. 12-19. Kowalski, Robin M., et al. 'Bullying in the Digital Age: A Critical Review and MetaAnalysis of Cyberbullying Research among Youth'. Psychological Bulletin, vol. 140, no. 4, 2014, pp. 1073-1137. 
Mann, Steve, Jason Nolan, and Barry Wellman. 'Sousveillance: Inventing and Using Wearable Computing Devices for Data Collection in Surveillance Environments'. Surveillance \& Society, vol. 1, no. 3, 2003, pp. 331-355.

Markham, Annette N. Life Online. Researching Real Experience in Virtual Space. Walnut Creek: AltaMira Press, 1998.

Marwick, Alice E., and Ross Miller. 'Online Harassment, Defamation and Hateful Speech: A Primer of the Legal Landscape'. Fordham Center on Law and Information Policy Report, 2, 2014.

Mayer-Schönberger, Viktor. Delete. Princeton, NJ: Princeton University Press, 2009. McPhate, Mike. 'Teenager is Accused of Live-Streaming a Friends Rape on Periscope'. The New York Times, 18 April 2016, https://www.nytimes.com/2016/04/19/us/ periscope-rape-case-columbus-ohio-video-livestreaming.html. Accessed 15 March 2018.

Monahan, Torin. 'Dreams of Control at a Distance: Gender, Surveillance, and Social Control'. Cultural Studies Critical Methodologies, vol. 9, no. 2, 2009, pp. 286-305. Pruis, Anna, Nisrine Sahla and Roel van Niekerk. 'Vrouwen online exposed: Bangalijsten zijn hierbij kinderspel'. NOSop3, 2017, https://nos.nl/op3/artikel/2207855vrouwen-online-exposed-bangalijsten-zijn-hierbij-kinderspel.html. Accessed 15 March 2018.

Schladebeck, Jessica. 'Woman Body-Shamed by Former Playboy Model Dani Mathers Speaks out about Humiliating Incident'. New York Daily News, 9June 2016, http:// www.nydailynews.com/news/national/woman-body-shamed-dani-mathersspeaks-time-article-1.3234115. Accessed 15 March 2018.

Schneier, Bruce. Data and Goliath: The Hidden Battles to Collect Your Data and Control Your World. London, New York: W.W. Norton \& Company, 2015.

Schultze, Ulrike and Julie Rennecker. 'Reframing Online Games: Synthetic Worlds as Media for Organizational Communication'. Virtuality and Virtualization, IFIP International Federation for Information Processing, vol. 236, edited by Kevin Crowston, Sandra Sieber and Eleanor Wynn. Boston: Springer, 2007, pp. 335-351.

Steeves, Valerie, and Jane Bailey. 'Living in the Mirror: Understanding Young Women's Experiences with Online Social Networking', in Expanding the Gaze: Gender, Public Space and Surveillance, edited by Emily Van De Muelen. Toronto: University of Toronto Press, 2016, pp. 56-83.

Vorobej, Mark. The Concept of Violence. New York: Routledge, 2016.

Yar, Majid. 'The Novelty of 'Cybercrime': An Assessment in Light of Routine Activity'. European Journal of Criminology, vol. 2, 2005, pp. 407-427. 


\section{About the authors}

KATLEEN GABRIELS is a moral philosopher, specialized in philosophy and ethics of technology. She works as an Assistant Professor at Maastricht University. Previously, she was an Assistant Professor at Eindhoven University of Technology and she also held a chair at the faculty Engineering Sciences at Vrije Universiteit Brussel (VUB). She holds an MSc in Germanic Philology from KU Leuven, an MSc in Moral Sciences from Ghent University, and a doctoral degree in Philosophy and Moral Sciences from VUB. Katleen is an executive board member of INSEIT, a steering committee member and the deputy chair of ETHICOMP, and an affiliate member of 4TU Centre for Ethics and Technology. She is the author of Rules for Robots. Ethics \& Artificial Intelligence (VUBPRESS, 2020) and Onlife (Lannoo, 2016).

Marjolein LAnzing is Assistant Professor Philosophy of Technology at the University of Amsterdam. Previously, she worked as a post-doc on the 'Googlization of Health' within the ERC project 'Digital Good' at the Interdisciplinary Hub for Security, Privacy and Data Governance (Radboud University). She finished her PhD-research 'The Transparent Self': A Normative Investigation of Changing Selves and Relationships in the Age of the Quantified Self at the 4TU Center for Ethics and Technology (University of Technology Eindhoven). Marjolein is board member of Bits of Freedom, an NGO that protects online freedom and (digital) civil rights, and the Amsterdam Platform for Privacy Research. 


\section{Activism and Online Vitriol}





\title{
10 'I Wasn't Chastised Properly'
}

\author{
On Trolls and Misogyny
}

Sophie Schwarz

\begin{abstract}
The following chapter provides an insight into feminist activism by presenting reactions to a poster campaign conducted in 2017. The campaign aimed at finding out whether and why feminism is still needed in today's society by asking people to share their reasons for why they need feminism on the poster printouts that were put up at a university campus. It documents and critically reflects on serious reasons people wrote down on the posters by means of semantic and statistical analysis. Furthermore, it discusses the offline vitriol the campaign received, such as the hateful treatment of the poster printouts and the misogynist comments on them, and thus demonstrates that trolling is a phenomenon that is not only limited to online social media platforms.
\end{abstract}

Keywords: feminism, feminist activism, vitriol, misogyny, trolls

Aranya Johar's wake-up call 'A Brown Girls' Guide to Gender' (2017), in which she publicly shares her personal experiences with the discrimination of Indian women, went viral on the Internet. A year before, during the United States presidential election, not only Donald Trump's slogan 'Make America Great Again' was promoted by the media but also his discriminating statement from 2005 'Grab 'em by the pussy' that accompanied the rest of his campaign. Aside from the by now old-fashioned argument that 'feminism has reached its goals', these contrasting examples show that there are new waves of misogyny as well as new radical intersectional forms of feminism arising. As a reaction to this polarized status quo, I conducted a poster campaign in 2017. It aimed at finding out whether and why feminism is still needed in today's society by asking people to share their reasons for why

Polak, Sara, and Daniel Trottier (eds), Violence and Trolling on Social Media. Amsterdam, Amsterdam University Press 2020 DOI: 10.5117/9789462989481_CH10 
they need feminism on the poster printouts. This chapter provides insight into one form of feminist activism and focuses on the vitriolic reactions that the campaign received. These reactions demonstrate that trolling is a phenomenon that is not only limited to online social media platforms. In addition to categorizing and evaluating people's reactions to the campaign by means of semantic and statistical analysis, the chapter furthermore focuses on the interrelation between trolling and misogyny ${ }^{1}$.

\section{Background}

The 2017 campaign was inspired by a social media photo campaign conducted in 2012 by students at Duke University, Durham, NC called 'Who Needs Feminism?'. With this campaign, 16 female students 'decided to fight back against [...] popular misconceptions surrounding the feminist movement', such as the 'man-hating, bra-burning, whiny liberal', the 'Feminazi or slut'. ${ }^{2}$ They state that

[o]ur class was disturbed by what we perceive to be an overwhelmingly widespread belief that today's society no longer needs feminism. In order to change this perception, we have launched a PR campaign for feminism. We aim to challenge existing stereotypes surrounding feminists and assert the importance of feminism today. ${ }^{3}$

It is important to say that the initiators did not provide any definitions of feminism. On the contrary, they wanted to find out what people perceive feminism to be with their campaign. The students asked people to write down reasons for why they need feminism. A picture of each participant was taken while holding up a sign with their personal reason on it and then posted on the official campaign's blog. ${ }^{4}$ The campaign itself was a huge success and quickly went viral on the Internet. The people taking part in the campaign gave a variety of different reasons for why they need feminism, including body shaming, inequality concerning their profession,

1 Sophie Schwarz is a pseudonym. I would like to thank Sara Polak and Greta Olson for inviting me to contribute my experiences to the discussion on which this book is based. Also, I would like to thank Maren Walinski for her helpful thoughts and comments on the campaign as well as Julia Sorokin for revising and Elaine Gurich for proofreading the chapter.

2 https://www.facebook.com/WhoNeedsFeminism.

3 Ibid.

4 https://whoneedsfeminism.tumblr.com/. 
discrimination, misogyny as well as social, political or cultural reasons. The campaign conducted in 2017, however, differs in some ways from the original campaign, as is explained in the following section.

\section{The campaign}

Unlike the original online campaign, the campaign in 2017 was designed to be an offline campaign. ${ }^{5}$ This was for two reasons: First, the intention was to limit the campaign to an academic context, namely a university, since the students' opinions on feminism should be focused on. The underlying assumption was that students at the Humanities, in Cultural Studies in particular, are familiar with Gender Studies and Feminism, since a variety of lectures and seminars are offered in these fields and popular among students. Thus, it can be assumed that many students are reflective on issues such as discrimination or misogyny. An online campaign, on the other hand, would not have prevented the campaign from spreading throughout the Internet and, thus, would have left the academic context. Second, the campaign should be protected from trolls, as trolling is a common phenomenon that can mainly be seen on social media platforms on the Internet, which means sowing discord on the internet by starting quarrels or upsetting people, by posting inflammatory, extraneous, or off-topic messages in an online community with the intent of provoking readers into an emotional response or of otherwise disrupting normal, on-topic discussion.

For this reason, the 2017 campaign differs from the original campaign with regard to anonymity. While in the original campaign, people could decide whether or not to send in a picture of themselves holding up a sign with their reason on it, the students in the offline campaign were completely anonymous when filling out the poster printouts. Since trolling can be motivated by the opportunity to stay anonymous on the Internet in the sense of using fake accounts that do not reveal the troll's real life identity, it nonetheless cannot be ruled out that a similar type of behaviour can occur in the offline campaign as well. This assumption is represented by Gabriels and Lanzing and will be focused on in more detail in the analysis of the reactions to the offline campaign (see section 4). As the initiator of the campaign, I too decided to stay anonymous. In fact, several people had warned me of revealing my identity, as feminists and feminist activists are still being confronted with threats and insults, especially on the Internet, as the possibility of anonymity has

5 The campaign was initiated and conducted solely by Sophie Schwarz but was promoted by Greta Olson. 
probably given more leeway to such expressions than there existed before. This is why I put the posters up secretly before the university had closed one evening before the summer semester started. As is shown in the analysis of the reactions, it was a wise decision to stay anonymous.

People who wanted to take part in the poster campaign had to complete the sentence 'I need Feminism because...'. Following the example of the original campaign, I did not provide any definitions of feminism on the posters. There were both English and German versions of the posters to make sure that both native speakers of German as well as students from abroad could take part in the campaign. The English version was printed on white paper, the German version on pink paper as a reference to the pink pussy hats worn at the Women's March on Washington in 2017 and also in the hope that the colour would raise more attention to the campaign. The posters contained links and QR codes to the original website of the campaign for further information. In addition, it also contained an e-mail address, created for the campaign, that could be used to send in reasons in case someone did not want to write down a reason on the poster in public.

In total, 6o posters were put up at the Humanities department's building of the University of Giessen in the beginning of the summer semester 2017. The campaign lasted for one month. Another reason for this very limited space and time was the opportunity to control what was happening to the posters. It would have been impossible for me alone to supervise a campaign that was widely spread to different parts of campus, some of which are across town. However, it would have been interesting to see reactions from students of other departments such as sciences, business or law. What happened to the posters was regularly documented with a camera with the intention to analyze the comments by means of statistical and semantic analysis after the campaign had ended. The first poster that was put up had my very personal reason on it: '[I need feminism] because men keep telling me that feminism is not needed anymore in today's society! 'What else do you want?' is a question I have to hear too frequently when the topic switches to feminism'. After one month, the reactions to the campaign, the comments on the posters as well as the e-mails were analyzed in a data-driven, survey-like approach to collect opinions on feminism.

\section{The reactions}

Although the poster campaign did not confirm any leading hypothesis or theory, it was rather motivated by current political events as described in 
Figure 8 Reactions to the posters (a)

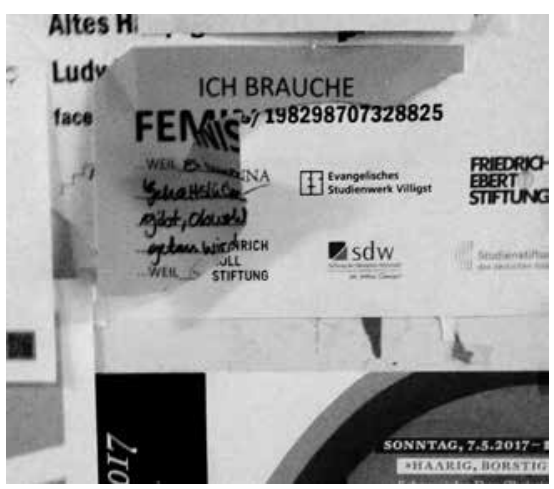

Figure 9 Reactions to the posters (b)

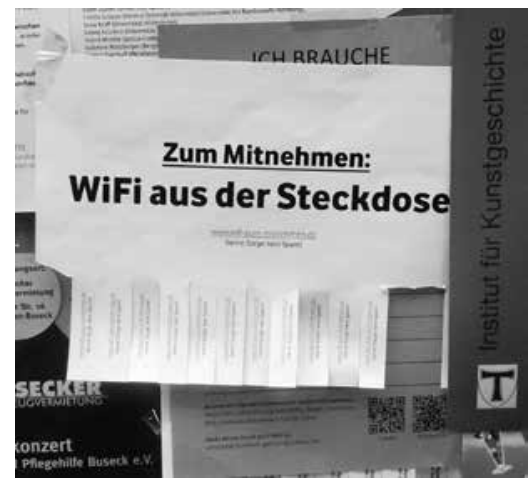

section 1; the reactions to the campaign were illuminating and shocking. They were illuminating because people's comments show the necessity of feminism in today's society and also provide insight into what people perceive feminism to be, and shocking because the campaign received a lot of aggressive and vitriolic reactions as well. Due to the complete anonymity that people were given when taking part in the offline campaign, the intention to protect the campaign from trolls failed.

Adding up the comments on the poster printouts that were documented ( 38 comments) and the comments received via e-mail (four e-mails), the campaign received 42 comments in total after one month. Out of the 60 posters that were put up in the beginning of the semester, only 12 posters were still hanging at the end of the month. All posters were checked on a daily basis. However, it was not possible to document each comment on the posters, as many of them were simply ripped off the wall. Some of them were pasted over by other posters, as is exemplified by Figures 8 and 9 .

While it is common that posters are posted over during the course of a semester due to a lack of space in the humanities building, it is not common that posters are ripped down. Quite obviously, this was due to the topic of feminism that some people felt the need to physically 'delete' it. In fact, the posters with the troll comments on them were not the ones being ripped off, but rather the ones with serious reasons on them. For example, the poster in Figure 8 dealt with the pay gap between men and women. However, since the poster was ripped off, the comment could not be documented in its full length. The vitriolic reactions to the posters resulted not only in a physical attack on the posters; the hatred of feminism was also verbalized in many of the comments as is shown in the semantic analysis. What happened to the posters is not the default case and does not represent the attitude of every 


\section{Figure 10 Types of comments}

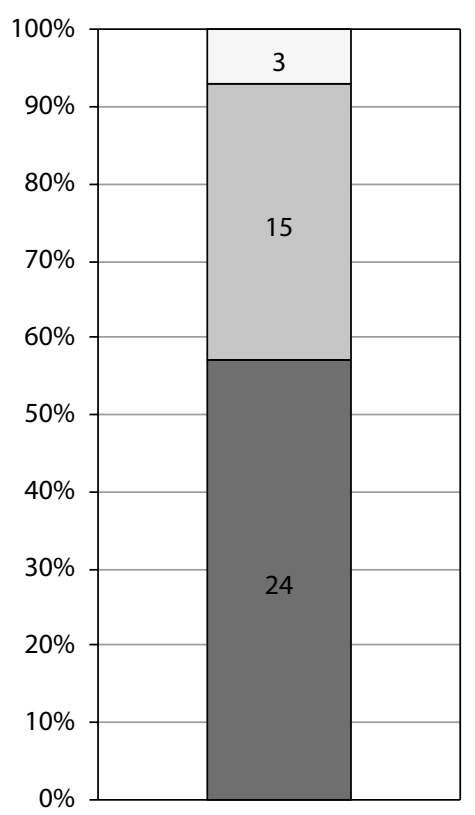

$\square$ Serious $\square$ Trolling $\square$ Generalizing statements

student at the humanities department. Neither does it represent the attitude of the humanities department and the university in general. Seminars and lectures on gender studies and feminism are being attended with a high frequency and lots of interest. The University of Giessen promotes equality and stands up against any kind of discrimination, which is protected by an official university law. ${ }^{6}$

In a first step, all comments were categorized into three types (see Figure 10). All upcoming comments are presented as they were originally written down on the posters, meaning that the original spelling (capitals, crossed out parts, etc.) will be maintained. German comments are translated into English: (a) generalizing statements ('FEMINISM IS INTERNATIONAL!')

(b) troll comments ('I am fat and need to blame it on someone other than me')

(c) serious comments ('genital mutilation is still being practiced')

Generalizing statements as in (a) did not complete the sentence 'I need feminism because...' but rather stated a general opinion. Hence, they missed 
the purpose of the posters but are still included in the statistics. Troll comments as in (b) did complete the sentence, however, the comments did not contain serious reasons for why feminism is needed. On the contrary, the trolls intentionally wrote about comments representing clichés surrounding the feminist movement, which were articulated in an assaulting and misogynist manner. Serious comments as in (c) completed the given sentence and also contained a reason for why feminism is needed. As Figure 10 shows, $57 \%$ of all the comments received were serious comments. However, $36 \%$ were troll comments, which is quite striking when considering the small amount of comments that were received in total. Only $7 \%$ of the comments were generalizing statements.

Having categorized the comments into three types in the first step, it was then possible to categorize all of them in terms of their specific content. Since the comments touched on a variety of topics, it seemed necessary to come up with rather broad categories to avoid an unnecessary amount of categories with less than three comments. Concerning their content, the comments were classified into five subcategories: I. discussion, II. culture and religion, III. politics, economy and law, IV. shaming and social discrimination, V. misogyny.

There is no clear cut boundary between the categories, as they are connected to each other in certain aspects (except for category I.). However, the comments that were sorted into the categories contained specific keywords (e.g. 'honour killing' or 'pay gap'), which can be seen as misogynist and discriminating; still, honour killing is a practice that is mainly performed in a religious context, while the pay gap mainly belongs to the field of politics and economy. The categories are, of course, debatable. Nonetheless, in this specific analysis, they fulfil their purpose of providing an insight into the many fields that were referred to in the comments.

As can be seen in Figure 11, 10\% were replies to the comments on the posters, which belong to the category of discussion and were not separately analyzed by the means of semantics. Only $10 \%$ of all comments named cultural and religious reasons for why feminism is needed; comments concerning politics, economy and law are represented with $14 \%$. Most comments concern the topic of shaming and social discrimination as well as misogyny, which are equally represented with $33 \%$.

When compared to the first categorization of types of comments in Figure 10, it is striking that - except for one comment ('I don't need feminism') - the troll comments match the misogynist comments in Figure 10, meaning that 14 out of 15 comments were not only troll comments but also insulting and misogynist ones. 


\section{Figure 11 Semantic categorization}

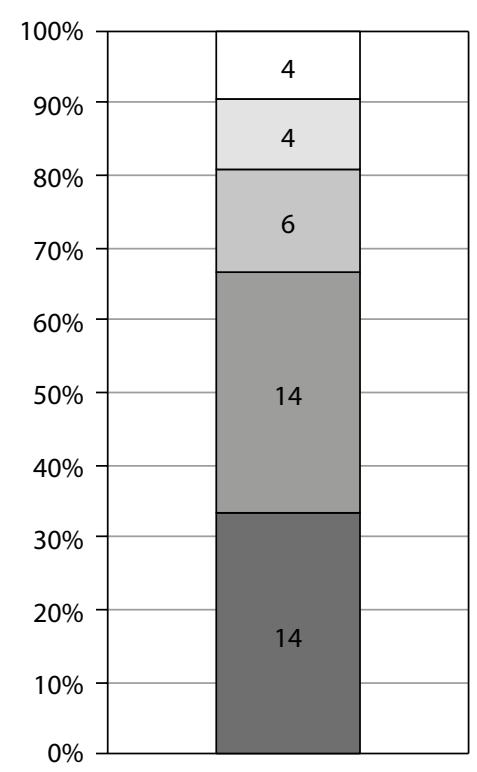

Misogyny

$\square$ Shaming and social discrimination

$\square$ Politics, economy and law

$\square$ Culture and religion

$\square$ Discussion

To give examples, a selection of two comments per category are listed below. Since I am focusing on the vitriolic aspect in this chapter, this category is represented by ten misogynist comments, including e-mails. Due to the limited space of this chapter, not every single comment can be mentioned.

\section{Discussion}

In four cases, people actively engaged and replied to comments on the posters. The comments in Figures 12 and 13 refer to troll comments:

The troll comment in Figure 12 refers to the cliché of feminists being over-weight by saying: 'I am fat and need to blame it on someone other than me'. Another person marked the comment that s/he was referring to and asked the troll to look up the meaning of feminism on the Internet: 'seriously? google “feminism” please.' 
Figure 12 Reply to a troll comment (a)

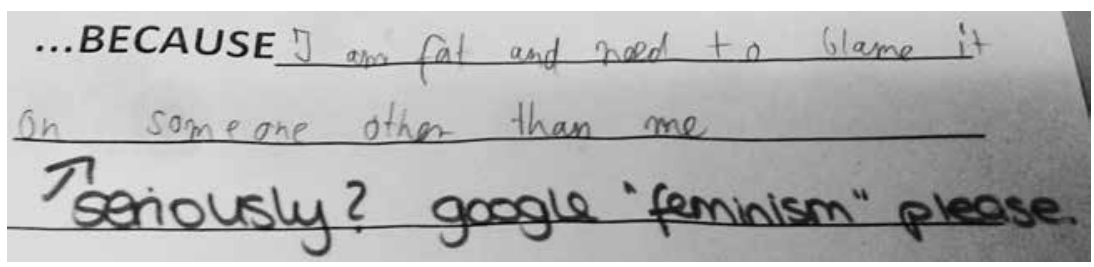

Figure 13 Reply to a troll comment (b)

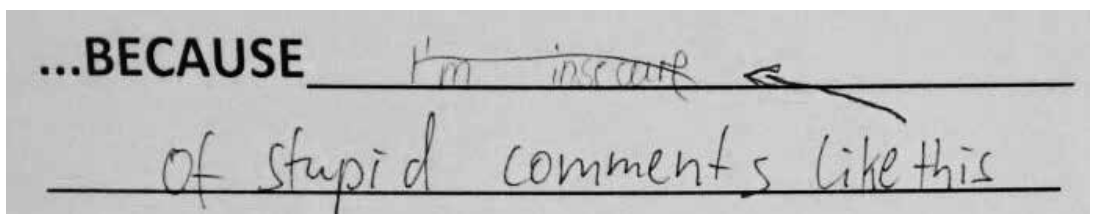

In Figure 13, the troll claimed that people needed feminism because they are insecure. Another person crossed out the troll's comment ('F'm insecure') and stated that feminism is needed because 'of stupid comments like this'.

\section{Culture and religion}

In this category, participants showed their concern about cultural and religious practices that violate a woman's body. For example, they claimed that feminism is needed because 'it is still acted on a woman's 'virtue' which can, if it is violated, in the worst case result in murder ('honour killing')' and because 'genital mutilation is still being practiced'.

\section{Politics, economy and law}

Besides mentioning Donald Trump as a reason for why our society needs feminism, it was also stated that 'there is still a huge pay gap in many professions although the same work is being done'. Additionally, participants mentioned the lack of rights for homosexuals: 'homosexuals still don't have the same rights as heterosexuals.' When the campaign was conducted, same-sex marriage had not yet been legalized. Only later, in June 2017, did the German parliament announce that same-sex marriage will be legalized. 


\section{Shaming and social discrimination}

When it comes to shaming and social discrimination, participants mostly mentioned that feminism is needed because 'women are still being discriminated internationally' but also claimed to 'Stop body shaming!. Furthermore, someone stated that feminism is needed because 'bullying in school is very often triggered by sexism (for example slut-shaming) $\rightarrow$ see the series 13 reasons why! and'. Apparently, the writer of the comment contemplated an additional comment, however, the 'and' was crossed out and the comment was not finished.

\section{Misogyny}

In addition to the troll comments that were already listed in I. that claimed that women need feminism because they are 'fat' and 'insecure', another troll referenced the cliché of the supposedly sexually frustrated feminist by saying: 'I want some dick!'. The comments get even more disturbing on a poster that was written by only one person (as can be seen by the handwriting) who can be named the biggest troll of the campaign (see Figure 14): ${ }^{7}$

I need feminism because...

- 'I was hit by the ugly stick'

- 'because I'm hoping for a forced distribution of men so that I can have one too for once'

- 'I don't have anything else except for type II diabetes'

- 'a common concept of the enemy strengthens the society's solidarity'

- 'I wasn't chastised properly'

- 'because real problems like poverty or war are too complex for my brain.'

This was the only case in which a troll took the time to fill out a whole poster. As the comments show, the person came up with nearly every cliché about feminism: women are ugly, women desperately seek for a man in their life (with the underlying premise that every woman is heterosexual), women are fat, women see men as the enemy (while at the same time they want one in their life), women need to be chastised, women are stupid (with the premise that fighting for feminism is of no concern, while poverty and war are).

During the time the campaign was conducted, four e-mails were sent in on the same day. All of them were troll e-mails and three of them referred to

7 For further information on online and offline violence, see Gabriels and Lanzing 'Ethical Implications of Onlife Vitriol'. 


\section{Figure 14 Misogynist comments}

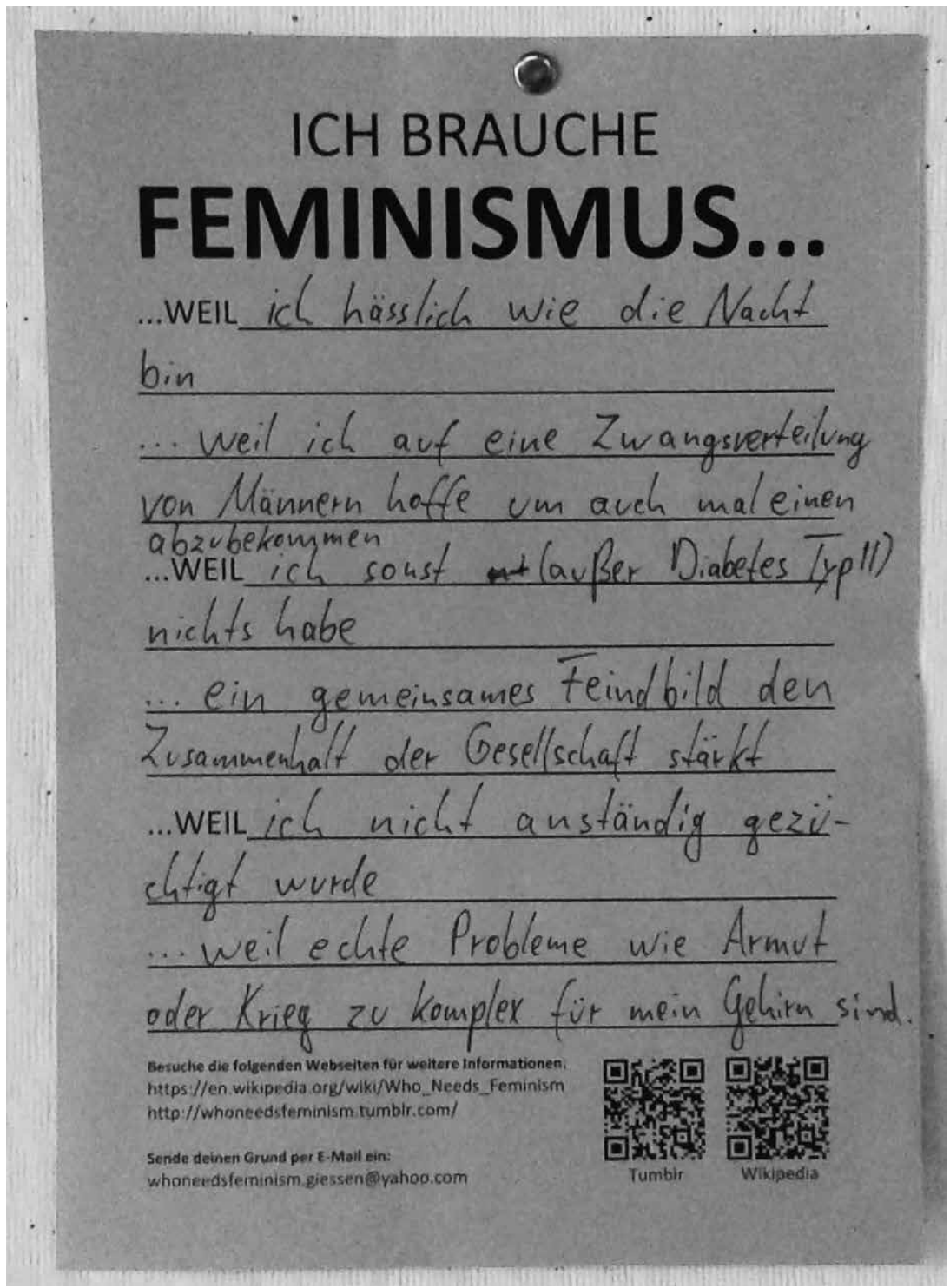

the cliché of the sexually frustrated woman, as can be seen on the screenshot of the inbox (see Figure 15).

The person abused the official campaign's e-mail address and used it to create three accounts on porn websites by using the names 'ineedfem' and 'ineedfeminism'. A search on Google showed that one of the websites even promotes rape, abuse and child pornography. The information on this 


\section{Figure 15 Troll e-mails}

\begin{tabular}{|c|c|}
\hline Instagram & Willkommen bei Instagram, qweas 16791 Bitte bestätige deine E-Mail-Adresse. Willkommen bei Instagram, \\
\hline - accounts@motherless.com & Your motherless.com registration Welcome to motherless.com ineedfeminism, Click the link below to ven \\
\hline - Pornhub & Activate your new Pornhub account You're nearly there! Your Pornhub account ineedfeminism has been \\
\hline
\end{tabular}

website was simply taken from Google entries that appear when typing the name of the website into the Google search bar. Clicking on any of those entries might not have been legal. Thus, no further information on this website is provided. Since the person used the official campaign's e-mail address to register on the websites and did not send any e-mail by using his or her personal e-mail account, there is no personal data to trace the person. Additionally, the troll created an Instagram account. Since the person who created the account is not the owner of the e-mail address, the account could not be verified and no pictures could be uploaded. The number in the username 'qweas1679' does not seem to be chosen randomly and might refer to $\S 1679$ of the Civil Code of Germany of 1896 that says: 'The parental violence of the father ends when he is found dead, ${ }^{8}$ This possible reference - if it really was intended by the troll - fits the comment on the poster 'I wasn't chastised properly' perfectly. Since the person already put effort into filling out a whole poster, it might be possible that it is the same person who also created the accounts on the porn websites. However, these assumptions remain unverified. The troll comments listed above are now being focused on more closely.

All in all, the trolls portray feminists in a negative and nasty way. To them, feminists are fat, ugly, stupid, insecure and sexually frustrated women who need to be chastised. Emma A. Jane uses the concept of 'e-bile' to describe these '[...] extravagant invective, the sexualized threats of violence, and the recreational nastiness that have come to constitute a dominant tenor of Internet discourse'. 9 In her analysis of vitriolic communication on the Internet, Jane found out that '[e]-bile targeting women commonly includes charges of unintelligence, hysteria, and ugliness' and furthermore that '[f]emale targets are dismissed as both unacceptably unattractive man haters and hypersexual sluts who are inviting sexual attention or sexual 
attacks'. ${ }^{10}$ This definition describes the trolls' vitriolic behaviour in the offline campaign perfectly. ${ }^{11}$

Instead of staying silent, the trolls were triggered and decided to demonstrate their hatred, although it seems that there was no need for them to participate in the campaign because it looks like they apparently do not need feminism. With every comment, they completely ignored the fact that many women do need feminism as they (still) suffer from discrimination, assault or the lack of rights. Thus, the trolls did not show any empathy at all. On the contrary, they intentionally ignored the 'rules' of the campaign (to write down a reason for why feminism is needed) and rather wrote down comments with the intention to insult, provoke and upset possible readers. They did not give any serious reasons for why feminism is needed; neither did they use rational arguments to explain why they think it is not needed. Therefore, they did not deem it worthy of consideration. In addition, they did not comment on any of the serious comments written down on the posters and thus refused to take part in a serious discussion altogether. This phenomenon is also mentioned by Jane who is stating that '[e]-bile episodes may be triggered by disagreements over divisive subjects [...] but participants rarely engage substantively with each other's positions. ${ }^{12}$

Moreover, the trolls did not only refuse to take part in the discussion but also avoided that other people could take part in the campaign by ripping off the posters from the walls and, thus, making feminism disappear. This is where an offline campaign differs from an online campaign: while it is possible to comment on posts on the Internet (e.g. on Twitter), it is not possible to simply edit or delete an original post from another person (unless the account is hacked or the name and password of the account are shared with another person), since editing and deleting requires administrative rights. Yet, on some platforms it is possible to report or downvote someone else's post, which may also impact their visibility and appearance. Participants of the offline campaign, on the other hand, had the chance to edit comments and 'delete' the posters. Therefore, by conducting an offline campaign, I unintentionally provided participants with even more opportunities to troll, which they made use of: not only did they insult women on the posters but they also silenced those who wrote down a serious comment and made sure their voice could not be heard.

10 Ibid., p. 3 .

11 For further information on how to deal with personal vitriolic attacks, see Kemekenidou, 'r/ChokeABitch'.

12 Jane, "Your a Ugly, Whorish, Slut...", p. 3. 
As the results of my offline campaign show, trolling (including vitriolic communication and actions) is not only limited to online social media platforms; the trolls show a similar behaviour offline as they do online. Thus, the trolls' offline behaviour can furthermore be connected to the concept of 'onlife violence', which, as Gabriels and Lanzing propose in chapter 9 , means that 'online and offline violence are deeply interconnected, hence "onlife". According to this assumption, violence is defined as 'the intentional physical or psychological (including reputational) harm inflicted on a person and/or their property', which describes the troll's behaviour in the offline campaign perfectly, as they intentionally tried to cause psychological harm by insulting participants with their hateful comments as well as by abusing the official e-mail-address; additionally, they physically destroyed the poster printouts.

By analyzing the form of the troll comments, it is quite striking that every comment begins with 'I'. Apparently, the trolls adapted to the structure of the given sentence on the posters 'I need feminism because' and took the perspective of a woman to complete the sentence, pretending to give a real reason for why they need feminism. What the trolls are really saying is: if women were chastised properly, they would not need feminism; if women were intelligent enough, they would not need feminism; if women had enough sex or a man in their life, they would not need feminism. According to the trolls, feminism is not needed at all and they see feminism as an excuse for women to blame their alleged problems or discontent on someone else. While the trolls seem to have found the solution for each of these alleged problems, they ignore the fact that many women suffer from being chastised, assaulted or abused; that many women still have no access to education; that not every woman is heterosexual and does not need a man in her life. Only one troll spoke for himself or herself by saying 'I don't need feminism'. In contrast to the trolls, participants who wrote down serious comments mainly used the passive or the third person rather than the first person and thus did not only speak for themselves but spoke in a more generalizing societal manner.

It seems that anonymity and affect are important when it comes to trolling. It is unlikely that the trolls ripped off the posters or wrote down troll comments if the posters were supervised by a video camera and if they knew that they were being filmed. However, this was not the case and the given anonymity made them feel safe, so that they could happily enjoy their trolling without it having any consequences. The fact that the trolls did not use rational arguments to discuss feminism but rather expressed 
their feelings (mainly hatred) towards feminism in a vitriolic manner shows that they got triggered and acted in the heat of the moment. ${ }^{13}$

\section{Conclusion}

What started out as a simple idea to find out whether and why feminism is still needed in today's society resulted in a both illuminating and shocking way. It was illuminating because the analysis of the serious comments provides an insight into what people believe feminism to be and also what kind of topics they associate with it; the participants did not only point out the discrimination of women in particular but also the discrimination of homosexuals in general that is still being practiced in many fields, ranging from culture and religion to politics, economy and law. It was shocking because the vitriolic reactions to the campaign prove that feminism is still a divisive topic that raises the attention of trolls. The analysis of the troll comments shows that they use existing stereotypes to insult women in a misogynist manner while at the same time they avoid dealing with feminism in a serious way. By ripping the posters off the walls, they did not only keep people from taking part in the campaign but also silenced those who stated their opinion. While the given anonymity prevented participants from personal confrontations or threats when writing down serious reasons on the poster printouts, it also allowed people to troll without it having any consequences.

It is naive to think that trolling is a phenomenon that is only limited to online social media platforms. Be it online or offline, there is no place that is safe from trolls; not even the humanities department of a university, in which critical thinking, tolerance and the freedom of speech are highly valued. Becoming an activist taught me that even in today's society it can still be dangerous to out yourself as a feminist or to contribute to feminism in any way, even if it is only putting up posters to collect opinions. This is why I salute every feminist activist who is not afraid of personal confrontations or threats and has the courage to publicly fight against sexism and all sorts of discrimination. In conclusion, the results of the campaign, including both the serious comments as well as the troll comments and especially the vitriolic reactions, prove that feminism is still needed in today's society. 


\section{Works cited}

“A Brown Girl's Guide to Gender'. Aranya Johar (Women's Day Special)'. YouTube, uploaded by UnErase Poetry, 10 March 2017, https://www.youtube.com/ watch?v=75Eh5OnNeoY. Accessed 1 March 2020.

Civil Code of Germany, 1896. http://www.koeblergerhard.de/Fontes/BGB/ BGB1896_RGBl_S.195.htm. Accessed 6 March 2018.

Gabriels, Katleen and Marjolein Lanzing. 'Ethical Implications of Onlife Vitriol', in Violence and Trolling on Social Media. History, Affect, and Effects of Online Vitriol, edited by Sara Polak and Daniel Trottier. Amsterdam: Amsterdam University Press, 2020, pp. 197-214. DOI: 10.5117/9789462989481_CHog.

Jane, Emma A. 'Your a Ugly, Whorish, Slut. Understanding E-Bile'. Feminist Media Studies, vol. 14, no. 4, 2014, pp. 531-546.

Kemekenidou, Penelope: 'r/ChokeABitch', in Violence and Trolling on Social Media. History, Affect, and Effects of Online Vitriol, edited by Sara Polak and Daniel Trottier. Amsterdam: Amsterdam University Press, 2020, pp. 233-249. DOI: 10.5117/9789462989481_CH11.

Olson, Greta. 'Love and Hate Online' in Violence and Trolling on Social Media. History, Affect, and Effects of Online Vitriol, edited by Sara Polak and Daniel Trottier. Amsterdam: Amsterdam University Press, 2020, pp. 153-177. DOI: 10.5117/9789462989481_CHo7.

—. 'Loving Feminism: Negotiating Differences in the Classroom', in Beyond Gender: Futures of Feminist and Sexuality Studies - An Advanced Introduction, edited by Greta Olson et al. Abingdon: Routledge, 2018, pp. 156-178.

'Who Needs Feminism'. Facebook. https://www.facebook.com/WhoNeedsFeminism/ about/?ref=page_internal. Accessed 6 March 2018.

'Who Needs Feminism'. Tumblr, https://whoneedsfeminism.tumblr.com/. Accessed 6 March 2018.

\section{About the author}

SophIE SchWARz is a PhD candidate at the Giessen Graduate Centre for Humanities (GGK) of the University of Giessen, Germany. She also holds an MA in German Linguistics and Anglophone Literary, Cultural and Media Studies from the University of Giessen. In her research, she focuses on representations of gender in different media including comic books, film and video games. Besides her academic research, she is strongly interested in Queer Studies and feminist activism in all of its facets. 


\title{
11 r/ChokeABitch
}

\section{Feminist Tactics Against Hate Speech in Capitalist Social Media Platforms*}

Penelope Kemekenidou

\begin{abstract}
This chapter discusses tactics on how to cope with online hate from an activist perspective, based on personal experiences of the author as a feminist in Germany. Violence and hate speech are part of online culture, its victims sharing very much the same demographic as offline victims, for example women and/or minorities. The first section focuses on online hate, and on how and why it affects us emotionally, followed by examples of effective campaigns against it. The second section discusses how the fight of online hate is inextricably linked to the question on what platforms it takes place and why. Fighting online hate is ultimately linked to the basic fight against the capitalist, sexist, racist, and classist roots of our Western society.
\end{abstract}

Keywords: activism, feminism, social media, capitalism, misogyny, patriarchy

When in 2012 Forbes asked Alexis Ohanian, one of the two founders of Reddit, what the Founding Fathers might have thought of his invention, he answered: 'A bastion of free speech on the World Wide Web? I would love to imagine that 'Common Sense' would have been a self-post on Reddit, by Thomas Paine, or actually a redditor named T_Paine.'

Reddit is an online platform founded by Steve Huffman and Ohania in 2005, when they were still roommates at the University of Virginia. It is infamous

* This essay is written in March/April 2018.

$1 \quad$ Marantz, 'Reddit and the Struggle', p. 61.

Polak, Sara, and Daniel Trottier (eds), Violence and Trolling on Social Media. Amsterdam, Amsterdam University Press 2020 DOI: 10.5117/9789462989481_CH11 
for its collection of weird topics, but also for the hate groups that it hosts. From sodomy, rape and torture threats, to anti-Semitic and racist content, Reddit is well known for its unregulated, extreme and often illegal content.

In 2011, when journalist Anderson Cooper mentioned the subreddit 'Jailbait' on CNN, it was possibly the first time some people even heard the term 'subreddit' at all. The channel 'Jailbait', which Cooper mentioned, in Reddit language spelled 'r/Jailbait', was a channel dedicated to sexualized pictures of young women. Although the channel claimed that everyone was at least 18 , the pictures told a different story. The subreddit was banned, but the user $\mathrm{u}$ /Violentacrez, who had opened the channel, was not, just like any of his other hundreds of channels, among them subreddits called ' $r / J$ Jewmerica or r/ChokeABitch. 'Yes, it gets worse', as the journalist from the New Yorker pointed out. Unlike to what one might expect, Reddit's reaction to the case was not one of portraying shock or a form of disapproval regarding what was happening on its platform. On the contrary, Yishan Wong, the then CEO of Reddit, stated that $\mathrm{r} / \mathrm{Jailbait}$ was only banned because it violated U.S. law, not because of any moral standards Reddit might have: 'We stand for free speech, [and] it would not do if, in our youth, we decide to censor things simply because they were distasteful. ${ }^{2}$

This chapter primarily discusses tactics on how to cope with online hate from an activist perspective, based on my personal experiences as a feminist activist in Germany. Violence and hate speech are obviously part of our online culture, its victims sharing very much the same demographic as offline victims, for example women, children or minorities. The case of 'r/Jailbait' though, showcases how the discourse of tackling violence and online hate is not only inextricably linked to the question how to tackle the creators of this violent content. It is also raising the question on which platforms this hate speech and violence takes place.

A definition of online activism for this chapter will be followed by a brief introduction of my activist background, since this chapter is thought as a guideline from an activist's point of view.

The first section of this chapter focuses on online hate, and on how and why it affects us emotionally, followed by examples of effective campaigns against online hate. A first set of rules will focus on how to deal with online hate on these platforms. The second section discusses how the fight of online hate is inextricably linked to the question on what platforms it actually takes place. Current social media platforms belong to unregulated private companies, and while the technology to gather and sell information about 
us is increasing, the networks seem simultaneously overwhelmed, or rather indifferent to the rise of violence and hate on their platforms. ${ }^{3}$ The second set of advice therefore concerns itself with aspects of our relationship to social media and self-care. As a German feminist activist and student of American history, I will mostly use examples from the German and American context. Since this chapter focuses on online violence and hate speech on social media networks, I chose to focus on Facebook, Twitter and Reddit as the primary examples, and the aspect of online hate speech and trolls on a verbal level.

\section{Clicktivism vs. effective online activism}

With regard to the Arab Spring, WikiLeaks or the Black Lives Matter movement, it becomes quite clear that online activism has a wide scope, ranging from hacking to organizing people online on a greater scale. The form of online activism discussed in this chapter, which primarily takes place on platforms like Facebook or Twitter, has often been criticized as clicktivism or slacktivism. These terms describe the often aimless political gestures online, such as likes' on Facebook or futile online petitions, which only aim to gather email addresses rather than effecting actual change. Critics regard them as pointless or meaningless moves, which I fully agree with. Supporting statements, petitions, or movements online, or liking a sharepic with a political message does not make one an activist.

However, effective activism on social media is, since we are concerned with communication platforms, mainly based around spreading and sharing information. Meredith Clark is a professor at the Mayborn School of Journalism at the University of North Texas; her research includes the establishment of a theoretical framework for exploring Black Twitter. 'Black Twitter' is a widely used term in the US for the black community on Twitter. The \#Ferguson \#MikeBrown campaign was largely responsible for raising awareness to the killing of Mike Brown in Ferguson, Missouri on 9 August 2014. She defines three levels of connection on Black Twitter, a concept which I find useful for defining fields of activism on social media in general: personal community, thematic notes and conversations about the networks themselves:

I break Black Twitter down into three levels of connection: personal community, and that reflects the people that you are connected with in some other dimension other than Twitter. And I take that personal community from Barry Wellman's work. The second level I find is thematic notes, and 
that's where individuals specifically tweet together about certain topics, so they keep returning to this subject matter. And those thematic notes could be any thing from television shows, to ideologies, topics of religion. They might be centric to where these individuals are in a certain part of the country. It just kind of all depends on what topic we're interested in. And then that third level of connection, where we see a lot of conversation about these networks and how they're linked, is when those personal communities and the thematic notes kind of intersect around a specific topic. And generally you see that, \#SolidarityIsForWhiteWomen, \#AskRKelly, those sort of things. That's where you see the meta-network at work. ${ }^{4}$

The effectiveness of social media activism can be made visible by evaluating how popular the topic is online, which Clarke defines as 'affirmation'. A discussion which enters offline spaces like private conversations or panels, or other media like newspapers or talk shows, is a step further, 're-affirmation': \#metoo has found its way into our everyday language and culture. Clarke identifies 'vindication' as another step in this scenario, which is the process of looking for some kind of change in the physical world.' Examples here are people who lose their jobs or have to publicly apologize as a direct effect of a Twitter topic. In this way, social media activism can break its limitations insofar as it can reach out to communities and groups who do not have access to, or the media literacy to engage in, these online discussions.

From a feminist perspective, speaking out is an activist element in itself. Feminist history is basically a history of speaking out one's own truth. Women's realities were mostly seen as second to men's stories. History is literally hisstory, written by and for white privileged men. Hashtags like \#WhyIStayed or years later \#metoo let women share realities, while pushing forward experiences that otherwise were kept hidden from mainstream society. Social Media can, with some restrictions, function as a connection for marginalized groups and can thus be a cathartic, liberating experience. In this case it becomes important how we are emotionally connected to our digital environment.

\section{Affect and the power of massive-scale emotional contagion on Facebook}

What happens online affects us offline: people are wired to feel the emotions of others. This effect, called emotional contagion, means that we copy the 
emotions that we see in others, and it happens regardless of whether we want it to. Nicolas A. Christakis, a physician and social scientist, and James H. Fowler, a social scientist and researcher in the field of social networks, discuss online emotional contagion in the context of hyperconnectivity in Connected: The Surprising Power of Our Social Networks and How They Shape Our Lives. They state that the mirror neuron system in our brains lets us copy the mood of another person, through first mimicking expressions, and then feeling them:

Emotions spread from person to person because of two features of human interaction: we are biologically hardwired to mimic others outwardly, and in mimicking their outward displays, we come to adopt their inward states. If your friend feels happy, she smiles, you smile, and in the act of smiling you also become happy. ${ }^{5}$

Emotional contagion has also been proven to work without two people having to face each other. In a sound experiment, subjects had to listen to recordings of nonverbal vocal reactions. The subject's reactions were monitored via a magnetic resonance (MRI) machine. There were two positive emotions and two negative ones to listen to, and the people were told not to react to them. Still the MRI detected that although the subjects did not react as told, it stimulated the parts of their brains that are connected to commanding the corresponding facial expressions. ${ }^{6}$

Emotional contagion is possible solely through online communication, and one of the most striking findings may still be a study conducted by Facebook itself. Facebook tested emotional contagion on 689,003 of its users, notably without their consent. The results were published as an article, 'Experimental Evidence of Massive-Scale Emotional Contagion Through Social Networks', in the journal Proceedings of the National Academy of Sciences of the United States of America, on 18 June 2014. While initially stating that automated testing 'was consistent with Facebook's Data Use Policy, to which all users agree prior to creating an account on Facebook, constituting informed consent for this research,' a Forbes article published in 28 June 2014, states that 'Facebook conducted their research four months before adding "research" to their data use policy'. 
Facebook's aim in this research was discovering whether users did have an influence on their connected users' emotions. The procedure was simple: a programme identified positive and negative words in the users feeds; in some cases they then reduced the positive, in some the negative content. The people who had a reduced negative content in their feed, started posting more positive status updates themselves, and vice versa. The scientists concluded that

[t]hese results suggest that the emotions expressed by friends, via online social networks, influence our own moods, constituting, to our knowledge, the first experimental evidence for massive-scale emotional contagion via social networks and providing support for previously contested claims that emotions spread via contagion through a network. ${ }^{8}$

Greta Olson elaborates in her chapter 'Love and Hate Online' how affect, described as 'pre-verbal experiences of feeling rather than emotions' are a predecessor to emotions, which are 'experiences that have already been translated into and thus already explained through words.' Affective experiences include for example bodily reactions to feelings that are 'deeply embodied and have little to do with rational arguments', like getting goosebumps when feeling scared or aroused, reactions which can also result from reading tweets or messages online. ${ }^{9}$ The fight against online hate takes place on two levels, and although often neglected, the fight against the negative emotional effects are just as relevant as the fight against misinformation, when it comes to fighting hate speech and trolls. Olson concludes that ultimately, we will have to say goodbye to our belief that rational arguments are the answer to online hate. ${ }^{10}$

\section{A redditor named T_Paine - free speech and online hate}

When it comes to defending violent or hateful content, as an activist I often encounter the argument that we all have the right to state our opinion. Online social media communication often blurs the line between political and personal statements, we rather engage in conversations when it affects us personally. When we talk about online vitriol or online hate, we primarily

8 Ibid.

9 Olson, 'Love and Hate', p. 153.

10 Olson, 'Love and Hate', p. 174. 
mean toxic or otherwise socially harmful speech acts. The definition of hate speech agreed upon for this publication is (online) speech that intentionally or effectively harms, diminishes, or upsets others (usually on categorical grounds). I would additionally define attacks in private messages, per email or per phone as cyber-harassment, which should be dealt with in another way than publicly posted hate speech. The question when we defend our rules as a society, and when we are silencing voices, is often the main argument when we are talking about regulating hate speech online. Since social media platforms are unable or unwilling to make this distinction, and as hate speech has become more organized online, various initiatives have formed to combat online vitriol collectively.

In 2017, a German group began to fight online vitriol on Facebook through counter speech. Facebook had failed to act quickly and effectively to the racist comments that started to add up under German news concerning what commenters called the 'refugee-crisis'. Organized hate groups and trolls had started to comment under news articles which were connected to refugees, and news about crimes was linked to refugees or immigrants without any proof or clue. \#ichbinhier, translated as 'I am here', started to organize people in a Facebook group, where they started posting links to posts that were attacked by trolls, or contained hate speech. The group members simply have to follow the link to the original article, and either react by writing comments that correct the misinformation, or simply directly react to troll comments, telling them they are lying. The \#ichbinhier responses are then linked back to the news post in the group channel, where a bigger amount of members can simply like the posts. The idea is simple, but effective. In 2017 the group received the Online Grimme Award, a German award for journalistic quality online. At this time, the group had over 35,000 active members. ${ }^{11}$

'Hass hilft', 'hate helps', is an 'involuntary fundraising campaign', and another creative strategy against online hate. The project turns every hate speech comment into a one-euro donation for the refugee programmes of 'Aktion Deutschland Hilft' and 'EXIT-Deutschland', an initiative against the far right. The concept originated in the 'Rechts gegen Rechts' [right-wing against rightwing] campaign, which was founded by the Zentrum Demokratische Kultur (ZDK) gGmbH, against neo-Nazi marches. Without the consent or knowledge of the neo-Nazis that attended a march on 15 November 2014, sponsors donated 10 euros for every walked metre. In this way they collected 10,000 Euros to fight right-wing extremism. With the support of Facebook, 'Hass Hilft' started in 
2015 and is still active today. In this initiative, people call attention to certain hate posts or comment. 'Hass Hilft' then responds to the according post with a congratulation message, if the post fits the criteria: the post was chosen as an example of hate speech, and will therefore be used to donate one Euro to the group, the post attacked. For the moment the hate expressed on social media networks is very real, and I would not argue against the importance of systems and groups who are trying to fight, or at least contain it. From a feminist perspective, cyberspace has often been disputed as a second battleground, where the fights of our social realities are just extended to another platform. If we take a look at current events, this theory is hard to dismiss.

My personal advice is mainly shaped by the context of feminist activism in Germany. I began with campaigns against 'date coaches' or 'pick up artists' like Julian Blanc, who make a fortune with publishing videos, books, or giving seminars to men who would nowadays be called 'involuntary celibates' (incels). Men like Julien Blanc and his group Real Social Dynamics or Roosh V, give misogynist advice on how to intimidate women to make them submissive, or treat them badly to crush their self-esteem. During his tour in 2014, Blanc was forced to leave Australia, after his visa had been revoked due to his misogynist content, which could also be plainly called advice for rape. ${ }^{12} \mathrm{His}$ tour in Germany had not been cancelled, since, oddly enough, the German government, unlike the Australian government, did not see a way to intervene in this matter. Social Media helped us to organize protest very quickly, and was our main connection to our supporters. During the demonstration, some guys started filming us, and after a while my picture could be found online on incel websites in the 'rape' section, together with some basic information such as my email address, Facebook name and residential area. After that, I continued my work in the campaign StopBildSexism, which was founded by Kristina Lunz and started off as a sister campaign of NoMorePage3. StopBildSexism is a campaign against the daily sexism of Germany's (still) biggest selling tabloid newspaper, the Bild Zeitung. The campaign became larger, and in October 2015 Kristina Lunz, Sophia Becker, and I founded Gender Equality Media e.V., our own organization against media sexism in Germany. GEM is currently working on studies on media sexism, creating feminist media, organizing feminist events and targeting sexism in German media on a daily basis, by contacting the journalists and responsible decision makers directly. ${ }^{13}$

13 Politicians and media personalities who directly support the patriarchy in Germany, and/ or are unwilling to change sexist behavior, are collected on our page unfollowpatriarchy.com to make patriarchy visible and thus combatable. 
During this time, my team and me experienced various forms of personal harassment as feminists online, since our work at $S B S / G E M$ is mainly based online. We learned a great deal about online hate speech and trolls, but also about the role social media platforms themselves play in this scenario. These five rules are our basic procedure to counteract online hate.

\section{Our rules for counteracting violence and trolls online}

\section{Always take screenshots}

Either for further investigation or to show it to other people: Always take screenshots of the harassing messages or pictures you received in private or public threads, ideally before answering to them. Never delete anything, as embarrassing as the content might be. Just because you do not see it, does not mean that its existence is erased, after all.

\section{Know your rights}

For serious cases of cyber harassment, doxing and bullying, check the law in your country. Screenshot incidents, and report the perpetrator's behaviour to legal authorities. Taking things into your own hands is seldom a good idea when it comes to personal threats. Seeking revenge or fighting back in form of posting personal information of the harasser online, is a crime in itself almost in every country. If you want to do that as a political statement though, seek legal advice first.

\section{Make your fights visible}

Trolls seldom make the smartest decisions. More often than not, it suffices to look back into their accounts and just offer to send their (publicly posted) comments to their friends, family or workplace. I once experienced a case in which I sent the screenshot back to the troll, who had a real picture and his workplace listed. I told him that his boss would surely be very happy to see what he was up to at the weekend. The post was very quickly erased.

\section{Seek allies - and the media}

If it is not personal harassment but online vitriol you want to fight, it is smart to form alliances. To combat hate in the long run, I would recommend joining 
an existing group, rather than to fight isolated on your own. If someone attacks you in a greater political context, seek public support. When you think it is newsworthy, contact the according groups or organizations who are active on this matter in the social media platforms. Journalists are the final option, when what happened is really outstanding and/or newsworthy.

\section{If nothing helps: block, mute, report, repeat}

Ultimately, if you cannot use the online hate for a political debate, or if the troll simply will not let go, the smartest move might just be to delete this account from your timeline. Blocking or muting certain accounts is sometimes the healthiest and most sustainable way to react to online hate. The only reason I would not block a harassing account, would be needing more evidence or screenshots for my case.

This set of rules is vital if you want to engage in social media activism, and function similarly to concepts like \#ichbinhier, mainly through counter speech and forming alliances, which can sometimes even be fun. Concepts like Hass Hilft are also very popular, since it gives those involved a sense of control and empowerment. From a quick glance we seem to win the fight against trolls, ridiculing them and feeling good in our formed alliances. What we often fail to address is that projects like Hass Hilft are dependent on potent sponsors, and thus, ultimately, are playing into the hands of the system they so desperately are trying to change, as will be explained in the following section. ${ }^{14}$ If we do not address the issue where these forms of online hate take place, we will always stay defensive, which will ultimately change nothing at all.

\section{Facebook is not your friend - online hate and capitalist interests}

In 2012, Ohanian was sure that the Founding Fathers would see Reddit as the defendant of free speech in America. However, in a post from 2015, co-founder Huffman saw things quite differently. He stated, contrary to Ohanian, that 'neither Ohanian nor he had created Reddit to be a bastion of free speech.' ${ }^{15}$ When the CEOs of Reddit announced, in August 2017, close to the date that the University of Virginia was overrun by white nationalists, that Reddit would expand its rules concerning the definition of hate speech, 
the outcry was enormous. Reddit had erased channels before, when they violated American law, or when the media attention became too big. Whereas before most channels operated in an undefined grey area concerning morals, for some the newly set rules declared the official death of free speech on Reddit. The opinion regarding free speech had changed; disenchantment seemed to set in for both the users and the founders. The New Yorker quotes a user, who argued that the only reason for the new bans was to attract advertisers: 'They don't actually want to change anything. It was, in fact, never about free speech, it was about money. ${ }^{16}$ Social media networks seem to be quite inconsistent when it comes to speaking out for free speech or simply deleting unwanted content on their own terms.

\section{Free speech and existence: Nontransparent algorithms}

In January 2018 Twitter banned the then Green politician Jörg Rupp, after a tweet that - taken out of context - seemed racist. It was clear that this ban was a mistake, likely executed by a machine, since the tweet was followed by an explanation, and Rupp's account was in itself proof that the tweet was meant as a joke. Although he tried contacting Twitter repeatedly, nothing happened. He was astonished at how impossible it was to contact Twitter, he stated in an article on netzpolitik.org. ${ }^{17}$ While Rupp's account was never restored, it seems that the same rules do not apply to everyone. When Trump threatened North Korea in a tweet in September 2017, Twitter did not react at all. The algorithms of social media platforms are not transparent: Why a user is banned or deleted, why a tweet is erased or why a post is blocked, is sometimes hard to trace back. Julia Krüger, social scientist and journalist at netzpolitik.org, suggests that we need an extension of fundamental rights regarding social media platforms. She argues that if it is private companies that provide public spaces in which we exchange political views, they also have to be taken into accountability when it comes to who they let in. However, most people are already using these networks, and private companies will always be more likely to create more attractive platforms and apps for the user. We rely on platforms of private companies to communicate, leaving the power of who can speak, and when, in the hands of private investors. ${ }^{18}$ 


\section{Boys clubs/the value of hate}

Social media networks are mainly media platforms which do not generate media, but use peoples' content for profit. Social Media networks are thus mainly looking for traffic, which equals profit. What is trending is good, initially regardless of its content. That is why sexist or racist comments or groups on Facebook, when kept at a (for Facebook) moderate level, spread as easily as fake news, and why Twitter's algorithm is apparently having such a hard time to detect and erase misogynist slurs, ${ }^{19}$ or anti-Muslim videos retweeted by Trump, ${ }^{20}$ while deliberately erasing accounts of less famous people. Sexism and racism do indeed sell, not only to people, but to advertisers as well.

In the case of Facebook, a New York Times article states that 'a report from ProPublica, a non-profit news site, revealed that Facebook enabled advertisers to seek out self-described 'Jew haters' and other anti-Semitic topics. ${ }^{21}$ Facebook is not only making money off hate from users, but is also helping advertisers to make profit from the active hate community. To gain more profit, Facebook is promoting hateful content, or helping advertisers to find the right hate group.

However, material that is too extreme has still to be taken out of the mainstream feed. Facebook and Twitter are interested in our well-being insofar as this means making us spending more time on their platforms. The reason extreme rape or violence are sometimes erased from these platforms is not out of goodwill, but because it would repel most people to stay online longer. For the task of erasing this content, Facebook, like many others, uses low wage workers. In 2014 Facebook outsourced a lot of its moderators to the Philippines who often quit after some months, due to the traumatizing material they have to deal with. After some time, the workers exhibited symptoms of PTSD, as a Wired article mentions. ${ }^{22}$ In 2017 Facebook opened its first content moderation office in Berlin, from where most of the moderation of the European traffic takes place. The location might have changed, the problem remains the same; one woman stated: 'I personally did not have much faith in humankind beforehand, and now I virtually do not have any.23 
Apart from the financial aspect mentioned above, the origins of social media platforms need to be discussed as well. The online sexism and racism minority groups and women face today, has a lot to do with the corporations within which the harassment takes place. Facebook's now infamous origin cannot be repeated enough: it was a frat boys' rating system of female students on campus, not a campus page to connect with one's friends. Reddit had subreddit channels named $\mathrm{r} /$ ChokeABitch, and Twitter favoured far right tweets on many occasions, bending the rules for Trump, while deleting politically critical voices. Ultimately, social media platforms are from their origin, to the way they function, a culmination of our white, patriarchal, racist and sexist elite, which dominates the online market.

The first section of advice concerned itself with the defence; how to cope with hate speech and violence when we are using these platforms. The second section is not so much advice on how to cope with hate as it discusses how we at Gender Equality Media view our relation to social media networks. Ultimately, the question is not whether to pick a fight as a private person or as an activist online, but in which relation you view yourself and your activist work in this context. What we try, although we are primarily an online based campaign, is to not let social media networks become too dominant in our everyday lives.

\section{Self-care and perspective}

\section{Pick your fights wisely}

Be aware of what you want to achieve: The most you will obtain from a public fight is informing other people who will read the thread. It will seldom be the case that you will convince a troll. We are not saying that it is not important or not worth it to express your opinion. However, consider in which context it happens, and if it is worth it to fight on your own, or if you can outsource it to programmes fighting hate speech. As we have seen, online emotions affect you whether you want them to or not, and you should learn to save your energy when a fight is not necessary.

\section{Tell your own story}

Studies show that lies spread fast and that it is almost impossible to correct them. Most political trolls know that, and far right extremists don't care if you correct fake news afterwards. It has been proven to circulate 
uninhibited in their bubble, and that is all what they wanted to achieve in the first place. ${ }^{24}$ Instead of spending all our energy on trying to correct this misinformation, we would rather focus on creating content and campaigns which tell our own story, and inform the public on the things we consider to be important, rather than staying the commentators on the narrative the enemy has chosen to tell.

\section{Have a squad!}

Even if it seems hard because of the (assumed) humiliating content, or the hurtful words, always confide in someone when a bad feeling won't let go. In cases where you are being threatened, I have already mentioned that you should tell another person and go together to the police. When it comes to hate speech and criticism though, people still feel hesitant to confide in others. Acknowledge your feelings, regardless of what caused them. We often screenshot the situation and share it in our group chats. We assure you that in many cases this takes half the weight of it.

\section{Some anti-capitalist feminist perspectives}

Facebook and Twitter are a necessary (though often fun) evil for online activism. Even so, you should distance yourself from these platforms as much as possible. These platforms are based on capitalist, white patriarchal, sexist, and racist ideas. In the end there is no way to 'correct' them, other than by supporting fair alternatives. As a group, but also regarding our interaction with followers, we try to outsource our communication to alternatives like Signal or Threema and not feed these platforms with more content than necessary.

\section{Define your own value}

Whether as an individual or as a group - we rely way too much on selfassurance through acknowledgment on forms of likes or retweets in these networks. In activism we have seen people losing track of what is important: yes, your speech was not that popular online, your riot did not resonate as expected. So what? If you do not free yourself of this social media evaluation system, emotionally and strategically, your work and relevance will suffer. 


\section{Be critical of criticism}

In our experience, most hate and unconstructive criticism we encountered came from people who did not have any alternative to offer themselves. Your ideas, your actions, your position will never be enough for some. Constructive criticism, on the other hand, always contributes something to the movement or the idea, instead of just boycotting and hurting what is already there. Someone who wants change as well, will not want to break you. Most unconstructive criticism or hate speech however, does not offer any better solution, and is mostly trying to discourage already existing initiatives. People feel better when they can say that something is not (good) enough, because in their minds it shifts the conversation away from them, and their guilt of doing nothing at all. There are people who want to change something, and people who want to be always right. If you belong to the first, accept that making mistakes is part of the deal. Always being right is reserved to the ones who do nothing at all.

As a final note, if we want to fight online hate, we will not only need to reconsider how we evaluate emotions in comparison to facts. If we do not address the root of the problem, that we are talking about racist and sexist platforms, based in a white patriarchal, capitalist tech industry, we will always stay on the defence, rather than actually changing the narrative. Fighting online hate is ultimately linked to the basic fight against the capitalist, sexist, racist, and classist roots of our Western society. In the long run we will have to talk about strategies to free our online communication from the influence of private companies, while focusing on the issue of surveillance capitalism. Until then, we should definitely not lose sight of effective strategies to combat online hate strategically.

\section{Works cited}

Chen, Adrian. 'The Laborers Who Keep Dick Pics and Beheadings Out of Your Facebook Feed'. Wired, 23 October 2014, https://www.wired.com/2014/10/ content-moderation/.

Christakis, Nicolas A., and James H. Fowler. Connected: The Surprising Power of Our Social Networks and How They Shape Our Lives. New York, Boston, London: Little, Brown, and Company, 2009.

Davey, Melissa. 'US 'Pick-up Artist' Julien Blanc Forced to Leave Australia after Visa Cancelled'. The Guardian, 7 November 2014, https://www.theguardian.com/ 
australia-news/2014/nov/o7/protesters-force-us-pick-up-artist-julien-blanc-toquit-australian-tour. Accessed 1 March 2020.

Denkena, Wiebke. 'Überwachungskapitalismus: Wir steuern auf digitale soziale Kontrolle zu'. Netzpolitik.org, 28 September 2018, https://netzpolitik.org/2018/ ueberwachungskapitalismus-wir-steuern-auf-digitale-soziale-kontrolle-zu/. Accessed 1 March 2020.

'Grimme Online Award 2017: \#ichbinhier'. Grimme Online Award, 2017, https:// www.grimme-online-award.de/archiv/2017/preistraeger/p/d/ichbinhier-1/. Accessed 1 March 2020.

Hasshilft.de/

Kemp, Nicola. 'Facebook, Twitter and Google Slammed for Monetising Hate Speech'. Campaign, 15 March 2017, https://www.campaignlive.co.uk/article/ facebook-twitter-google-slammed-monetising-hate-speech/1427422. Accessed 1 March 2020.

Krüger, Julia. 'Kommentar: Das Recht auf den Tweet'. Netzpolitik.org, 6 January 2018, https://netzpolitik.org/2018/kommentar-das-recht-auf-den-tweet/. Accessed 1 March 2020.

Larson, Selena. 'Twitter Has a New Reason for Why It Didn't Delete Trump's antiMuslim Retweets'. CNN.com, 1 December 2017, https://money.cnn.com/2017/12/01/ technology/twitter-reason-trump-delete-anti-muslim-tweets/index.html. Accessed 1 March 2020.

Lomas, Natasha. 'UK Study Quantifies Twitter's Misogyny Problem'. Techcrunch. com, 26 May 2016, https://techcrunch.com/2016/05/26/uk-study-quantifiestwitters-misogyny-problem/?guccounter=2. Accessed 1 March 2020.

Maheshwari, Sapna and Alexandra Stevenson. 'Google and Facebook Face Criticism for Ads Targeting Racist Sentiments'. NYTimes.com, 15 September 2017, https:// www.nytimes.com/2017/og/15/business/facebook-advertising-anti-semitism. html. Accessed 1 March 2020.

Marantz, Andrew, 'Reddit and the Struggle to Detoxify the Internet'. The New Yorker, 19 March 2018, https://www.newyorker.com/magazine/2018/03/19/reddit-andthe-struggle-to-detoxify-the-internet. Accessed 1 March 2020.

McNeal, Gregory S. 'Facebook Manipulated User News Feeds to Create Emotional Responses'. Forbes, 28 June 2014, https://www.forbes.com/sites/gregorymcneal/2014/06/28/facebook-manipulated-user-news-feeds-to-create-emotionalcontagion/\#478c2e8b39dc. Accessed 1 March 2020.

Olson, Greta. 'Love and Hate Online. Affective Politics in the Era of Trump', in Violence and Trolling on Social Media: History, Affect, and Effects of Online Vitriol, edited by Sara Polak and Daniel Trottier. Amsterdam: Amsterdam University Press, 2020, pp. 153-177. DOI: 10.5117/9789462989481_CHO7. 
Ramsey, Donovan X. 'The Truth About Black Twitter Complex, influential, and far more meaningful than the sum of its social justice-driven hashtags'. TheAtlantic. com, 10 April 2015, https://www.theatlantic.com/technology/archive/2015/04/ the-truth-about-black-twitter/390120/. Accessed 1 March 2020.

Rechts-gegen-rechts.de. Accessed 1 March 2020.

Reuter, Markus. 'Moderation nach Gutsherrenart: Wie Twitter Accounts ohne Einordnung des Kontexts sperrt'. Netzpolitik.org, 15 January 2018, https:// netzpolitik.org/2018/moderation-nach-gutsherrenart-wie-twitter-accountsohne-einordnung-des-kontexts-sperrt/. Accessed 1 March 2020.

Schade, Marvin. ‘\#ichbinhier: Tausende Facebook-Aktivisten organisieren sich im Kampf gegen Hate Speech'. Meedia, 30 January 2017, http://meedia.de/2017/01/30/ ichbinhier-tausende-facebook-aktivisten-organisieren-sich-im-kampf-gegenhate-speech/. Accessed 1 March 2020.

Sokolow, Andrej. "No More Faith in Humanity': A Day in the Life of Berlin Facebook Moderators'. The Local.de, 11 July 2017, https://www.thelocal.de/20170711/thefirst-beheading-video-made-me-weep-a-day-in-the-life-of-facebook-moderators. Accessed 1 March 2020.

Vosoughi, Soroush, et al. 'The Spread of True and False News Online'. Science, vol. 359, no. 6380, 2018, pp. 1146-1151, https://science.sciencemag.org/content $/ 359 / 6380 / 1146$.full.

\section{About the author}

Penelope Kemekenidou has finished her M.A. in American, History, Society and Culture at the Ludwig-Maximilians-Universität in Munich, Germany. Her M.A. focused on the "Ersatzdiskurs" of pedophilia in U.S. American media and politics. She has taught on black feminism and radical activism and has also published on empathic hyperconnectivity in social media networks. She is also co-founder of Gender Equality Media, an organization which is fighting against sexist media coverage in Germany. The group is primarily known for its \#unfollowpatriarchy campaign, tackling sexist media publishers. 



\section{Index}

Note:

Page numbers in italic refer to images.

Page numbers in the form $116 n 15$ refer to footnotes.

'187 exposed snitches \& bitches' appgroup 198-99, 203, 207, 209-10

4Chan 71

8Chan 71

Abbott, Diane $49,52,54-55$

abuse $13,19,49,54,56,60-61,227$

accountability 50, 243

Achterhuis, Hans 91

activism

clicktivism vs. effective online activism $\quad 235^{-3} 6$

feminist tactics against hate speech $\quad 233-47$

free speech and online hate $\quad 238-41$ miscegenation and feminist struggle $\quad 125$

overview 17,19

self-care and perspective on online hate $245-47$

trolls and misogyny $\quad 19,217-31$

and vigilantism 39

advertising $\quad 79,243-44$

AfD see Alternative für Deutschland affect

definition 153

emotional contagion on Facebook $236-38$

genealogies of $156-59$

and hate online $\quad 192-94$

online affect $\quad 171-73$

Sargnagel as author $\quad 182-83$

and satire $\quad 179-94$

Trumpian affects $\quad 159-64$

weaponization of 15

affect theory $18,153,156,173$

affective contagion $\quad 158-59$

affective politics $\quad 153-74$

Cernovich, masculine nobility, and basic

bitches 164-71

genealogies of affect $\quad 156-59$

online affect $\quad 171-73$

overview 18-19, 153-56, 173-74

Trumpian affects $\quad 159-64$

affects of online vitriol

affective politics in Trump era 18-19, 153-74

ethical implications of onlife vitriol 19 , 197-210

overview $\quad 17-19$

satire, affect and Sargnagel $\quad 19,179-94$

Africa $70,72-73,75,80,123-24$

Agamben, Giorgio 104 agon (conflict) 104

Agt, Dries van 140-41, 143

'Aktion Deutschland Hilft' 239

Alberti, Leon Battista, Momus 89-91, 93

Algerians 110, 121

algorithms $\quad 26,193,243-44$

Allen, Anita 207-08

Alternative für Deutschland (AfD) 111-12, 113, $116,116 n 15$

Alt-Right

affective politics in Trump era 160,163 , 172-73

historical prefigurations of vitriol $\quad 18,88$

platforms 27

Trump on Twitter and Ebola $\quad 71-72,79-81$ white femininity and trolling $112 \mathrm{n} 10$, $116-17,120,127$

ambivalence $12-13,28,116$

anarcho-capitalism 102

anger $59-60,105,154,186,192$

Anglin, Andrew 172

animal abuse $\quad 30,183-84,187-88,190-91$

anonymity

app-groups 207

feminist poster campaign $\quad 219-21,230-31$

historical prefigurations of vitriol 89,95

limits of free speech $48-49,56,60$

satire and Sargnagel 180

speed of vitriol spread 16

antagonism 98,148

anti-miscegenation $111,118-20,124 n_{45}, 126 n_{53}$

anti-Semitism 71, 121, 234, 244

apologies 35,236

app-groups 203, 207, 209

Arab Spring $\quad 235$

Arabs 111, 115, 115n14, 116-17, 121

archetypal stranger $\quad 76,79$

Arendt, Hannah

On Revolution 59

On Violence 59-6o

Areopagitica (Milton) 48, 50

arguments $57,190-91,238$

artists $\quad 184-85,187$

Ash, Timothy Garton $\quad 5^{1-52,61}$

Free Speech $48,5^{1}$

attention $15,26,67,79,154,192$

\#ausnahmslos movement 117

Austin, J.L. 13

Austria $182,184,186-87,193$

authoritarianism 159, 174

avian influenza 77 
bad talk 95

Baidu Tieba 33-34

Bal, Mieke 157

Banfield, Ashleigh 68

Bannon, Steve 88,91

Barad, Karen 156

Bartels, Dieter 136

'basic bitches' 18, 166-69

Becker, Sophie 240

Benjamin, Walter 87,105

Bennett, Jill 158

Bergson, Henri $\quad 15^{6}$

Biddle, Sam 9-10

Bild Zeitung (newspaper) 240

Birther movement $\quad 68-69,72,77-78$

'Black Horror' narratives $122-24$

Black Lives Matter 235

'Black Shame' illustration 123,124

Black Twitter 235-36

Blanc, Julien 240

blocking $56,242-43$

boards of shame 37

body $156-57,193,200,225,238$

body politic $78,98,104$

body shaming $\quad 52,198-99,202-03,218,224,226$

bots 43

Bourdieu, Pierre 101, 103

Braidotti, Rosi $\quad 156$

Breitbart 116

Brexit 26

British Empire $\quad 121,126$

Brown, Mike 235

Brown, Victoria 90

Bruno, Giordano 92-93

The Expulsion of the Triumphant Beast 92

Buchanan, Elizabeth A. 201

Buck-Morss, Susan 102

bullying 10-11, 56-57, 199, 202, 205, 226, 241

Bunker, Pamela Ligouri 103

Bunker, Robert J. 103

Burkell, Jacquelyn 207-08

bystanders 172

Calvinists $\quad 98,99$

camera phones 198-99, 206, 210

Canada 210n42

capital 103-04

capitalism 101-02, 104-05, 158, 242-43, 246-47

Cartesianism $\quad 156$

cartoons $99,110,120,120$

'cat bin woman' 30

Catholic church 92

Caucasus 38-39, 42

celebrities $55,165,210$

censorship 40, 43, 100

Cernovich, Mike

affective politics in Trump era 156,159 , 164-71, 173-74

Danger \& Play 166
Gorilla Mindset 166

'Hoaxed' documentary 169-70

MAGA Mindset $\quad 169$

masculine nobility, and basic bitches 164-71

Trump, Twitter and Ebola $\quad 80-81$

chaos 88, 92

charivari 30

Charlie Hebdo attacks $114 \mathrm{n} 13$

Charlottesville demonstrations $\quad 161$

Chauvel, Richard 133ng

Chechens 39

child abuse $\quad 30,227,234$

chilling effect 208

China 27, 32-36, 65, 73, 163

'ChokeABitch' subreddit 234, 245

Christakis, Nicolas A. $\quad 237$

Christianity 94,125

citizenship 36,199

civic engagement 27

Civil Rights Act 50

civility $53-54$

civilizing mission $\quad 121,125-26$

Clark, Meredith 235-36

class 105,247

Clementi, Tyler 199

clicks 79, 192-93

clicktivism 235

Clifton, Jacob 71

climate change 73,103

Clinton, Hillary $\quad 69,80-81,167$

CNN 81, 234

cognition $\quad 156$

collective identity 138,149

collective memory $135,139,144,146,209$

collective responsibility $\quad 5^{0-51}$

collective talk 93-95, 99

collectives 17-18, 70-71, 101

Cologne, New Year's Eve assaults $18,110-20$, $127,184-85$

colonial memory $\quad 18,132,136,138,147$

colonialism

civilizing missions and feminist struggle $\quad 125^{-2} 6$

De Punt film and discussion forum $132-33$ $136,138-39,145,147$

discourses of racialized sexual deviancy 120-24

historical prefigurations of anti-miscegenation $\quad 118-19$

white femininity and trolling 110, 118-26

comment culture

expanding public sphere $\quad 53-55$

limitless free speech $\quad 58-60$

overview $17,47-50,60-61$

problems of enforcement $55-58$

right to hate $50-5^{2}$

social media and limits of free speech $\quad 47-61$ see also comments 
comments

affective politics in Trump era $\quad$ 169-70, 173

bullying and trolling 11

De Punt online discussion forum 144 , 146-48

feminist poster campaign

reactions 220-31

German counter speech 239

mediated visibility and vigilantism $\quad 34-35$, 43

online communities as constituencies 100 satire and Sargnagel $188,190,191 \mathrm{n} 45,194$

see also comment culture

common knowledge 94

communicable disease $\quad 74-75,77$

communication $\quad 154-55$

communicative capitalism $\quad 158$

communism 101

communities

affective politics in Trump era 174

Black Twitter and online activism $\quad 235^{-36}$

collectives 71

and constituency $\quad 95-100$

fama 93-94

historical prefigurations of vitriol $\quad 88-89$, 93-102, 104

online communities as constituencies 100-02

satire, affect and Sargnagel $\quad 190,194$

community talk 93-95

Competitive Enterprise Institute 103

computer viruses 78

concentration camps 134

Condorcet, Nicolas de 121

conflict 53-54, 104, 154

Connell, R.W. $\quad 166$

consensus 60,155

consent 13, 206, 237

conservatives $\quad 167-69$

conspiracists 193

constituency

communities and constituency $\quad 95-100$

historical prefigurations of vitriol $88-89$, 95-102, 105

online communities as constituencies 100-02

contagion metaphors

affective politics in Trump era $\quad 157-59$, 172

emotional contagion $\quad 158,236-38$

genealogies of affect $\quad 157-59$

online affect 172

Trump, Twitter and virality $74,78-80$

conversation norms $\quad 11,49,57,60$

Conway, Kellyanne 164

Coolidge, Calvin 68

Cooper, Anderson 234

Costeja González, Mario 205-06

counter speech $\quad 28,239,242$ courts 94,104

coveillance (peer monitoring) 198-99, 200-03, 206-07, 209-10

'covfefe' 67

credit records 206

crime $34,103,206,239,241$

critical theory, affective turn in 155

criticism 246-47

Cruz, Ted 69

cultural hegemony 94

cultural identity 111

culture 101-02, 104, 110-11, 203, 210n42, 224-25

culture wars 98,159

cyber vigilantes 30

cyberbullying $\quad 57,198-99,202,241$

cybercrime 34,69

cyber-harassment $\quad 57,239,241$

cyberspace 240

data collection and use $16,26,237$

date coaches 240

date rape $\quad 166$

De Correspondent (Dutch online news) $\quad 88-89$

De Punt (film) 131-49

fictive discourse of De Punt telefilm $\quad 140-43$

historical context 133-35

online discussion forum as echo chamber $144-48$

online discussion forum as polarization $\quad 138-40$

online discussion forum overview $\quad 148-49$

overview 18, 131-33, 148-49

polarized interpretations of hijacking 136-38

de Witt brothers 95-99

Dean, Jodi $\quad 158-59,173$

death threats $9,49,54,180,190,194$

debate $58,60,89,96,98,132,146-47$

defamation laws $\quad 5^{8}$

deindividuation $\quad 171-73$

deleting accounts/content $\quad 229,242-45$

Deleuze, Gilles $\quad 156-57$

deliberation $144-46$

democracy $101,144,154$

denunciation $15,26-28,30-34,36,41-42,58-61$

deontological ethics 155

Derrida, Jacques 92

Descartes, René, Meditations $\quad 156$

deviancy 110

Dibbell, Julian, 'A rape in cyberspace' 201

DiFabio, Geno $\quad$ 161-62

digital media $\quad 16,26,30,119,132,15^{8}$

digital vigilantism ('digilantism') 17, 27-29, 38-39

DiNucci, Darcy, 'Fragmented Future' 14

disability $\quad 30-32,160$

discrimination $58,136,217,219,222-23,226$, 229, 231 


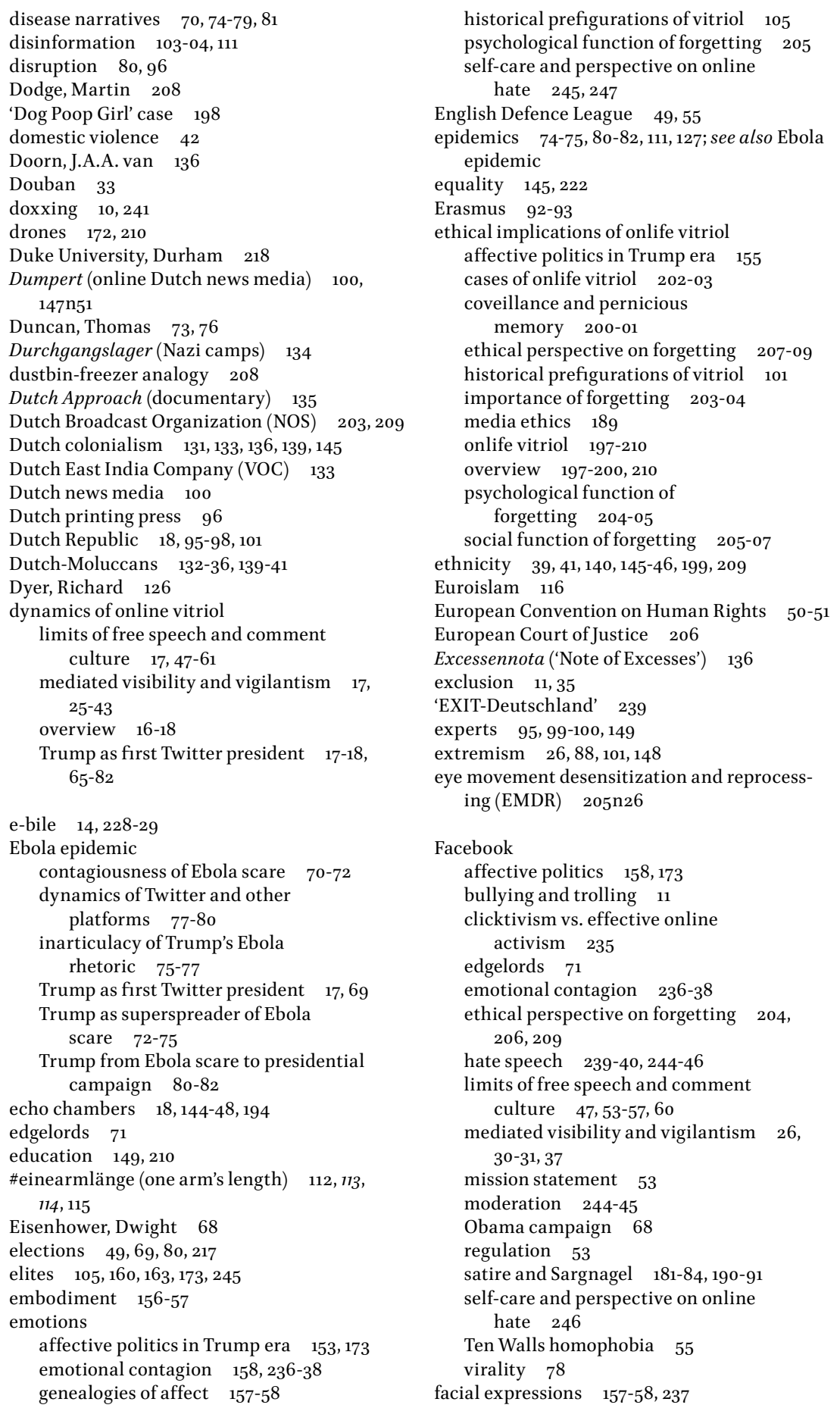


facts $94,104,247$

fake news $43,66 \mathrm{n} 4,95,164,169,171,193 \mathrm{n}_{53}$, 244-45

fama (voice of community) 93-95, 98-99, 104

far right $111-16,119,127,239,245$

fascism $87,101-02,115,124$

fear $74,78-80$

feeder platforms $\quad 71$

feeling $153-55,158,238$

felt identity 161,193

femininity 167 ; see also white femininity, and trolling

feminism 111, 116-18, 125-27, 164; see also feminist activism

feminist activism

affect and emotional contagion on Facebook 236-38

boys clubs and value of hate $\quad 244-45$

civilizing missions and miscegenation $\quad 125^{-2} 6$

clicktivism vs. effective online activism 235-36

feminist tactics against hate speech 233-47

free speech and online hate $\quad 238-41$

hate speech overview $\quad 233-35$

nontransparent algorithms 243

online hate and capitalist interests $\quad 242-43$

poster campaign $\quad 218-20$

poster campaign reactions $\quad 220-31$

rules for counteracting violence and trolls online 241-42

self-care and perspective on online hate $245-47$

trolls and misogyny $\quad 217-31$

trolls and misogyny overview $\quad 19,217-18,231$

Fenster, Thelma 94

Ferguson, Missouri 235

Ferry, Jules 121

fictive discourse $\quad 142-43$

filming $28,37-38,199$

films $18,131-32,135,140-43$

filter bubbles 194

Fireside Chats 68

flaming 172

forgetting

ethical perspective on 207-09

importance in world of surveillance 203-04

psychological function of 204-05

social function of 205-07

forgiveness 205-06

Foucault, Michel 118-19

Fowler, James H. 237

FPÖ $\quad 185-87$

fragmentation 14,144

France 112, 114n13, 118, 121-23, 125, 172

Französen im Ruhrgebiet (The French in the

Ruhr, album) 123, 124
'Fraternity' journal $\quad 125$

Fratticcioli, Alessio 115

free speech

expanding public sphere $\quad 53-55$

historical prefigurations of vitriol 93,95

Internet inception 180

limitless free speech $\quad 58-60$

limits of $\quad 47-61$

nontransparent algorithms 243

and online hate $238-41$

overview $17,47-51,60-61$

Reddit 233-34, 242-43

right to hate $50-5^{2}$

strong model $48,5^{0}-53,5^{8}, 60$

unruly spaces and problems of

enforcement $55^{-} 5^{8}$

Freeland, Chrystia 102-03

French colonies 118

The French in the Ruhr (Französen im

Ruhrgebiet, album) 123, 124

French Revolution $\quad 51,59$

Friedrich, Hans-Peter 112 n10

Front National 112

Fürstenspiegel (mirror of princes) 89-90

Gab $\quad 27$

Galton, Francis $\quad 124 n 45$

game theory 173

Gamergate 72

GeenStijl (online news website) 13, 100-01, $147-48$

gender

affective politics and 'basic

bitches' 166-67

ethical implications of onlife vitriol 199, 208-09

fama as community talk 94

gender-specific vitriol $35,41,57$

white femininity, trolling, and Cologne assaults 110-11

Gender Equality Media (GEM) 240-41, 245

gender studies 219, 222

genealogies of affect $\quad 15^{6-59}$

genital mutilation $\quad 222,225$

Germany 111, 116, 121, 123, 239-40; see also

Cologne

Giesen, Bernard $\quad 137-39,142$

Gilman, Nils 103

global village 77

global warming 73

globalization $74,105,119$

Gobineau, Arthur de 121

Goode, Luke $\quad 55,57$

Google 204-06

gossip 94

government role $\quad 33-34,199$

Graaf, Beatrice de 139

Grant, Madison 124n45

Griffin, Kathy 168-69 


\author{
group formation 11, 101 \\ group polarization $\quad 132-33,136-40$ \\ Guattari, Felix 157 \\ gun control 114n13
}

Habermas, Jürgen $\quad 54-55,155$

hacking 229, 235

Haider, Lydia $\quad 183-84,192$

harassment

cyber-harassment $\quad 57,239,241$

ethical implications $202,205,207,2104_{42}$

Facebook moderation 245

free speech and online hate 239,241

limits of free speech $\quad 5^{6-57}$

mediated visibility and vigilantism $\quad 27,42$

rules for counteracting violence and trolls online 241-42

satire and Sargnagel $\quad 180-81,184-85$

white femininity and trolling 110, 116 harm

ethical implications $198,200-03,207,210$

offline and online campaigns 230

online mobilization $\quad 28$

online vitriol defined 15

psychological harm 198, 200, 203, 207, 230

reputational harm 230

social harm $\quad 28$

speed of spread $\quad 16$

'Hass Hilft' ('hate helps') campaign $\quad$ 239-40, 242 hate

affective politics in Trump era $\quad 153,155$, $162,164-65,169,171,173$

boys clubs and the value of hate $\quad 244-45$

and denunciation 59

edgelord jokes 71

feminist poster campaign reactions 231

feminist tactics against hate speech 234 , 239

online vitriol and weaponization $\quad 15$

right to hate $5^{0-52}$

satire and Sargnagel $180,190-94$

hate speech

affect and emotional contagion on

Facebook 236-38

affective politics in Trump era 174

boys clubs and the value of hate $\quad 244-45$

clicktivism vs. effective online activism 235-36

definition 239

ethical implications 198

feminist tactics against hate speech $\quad 233-47$

free speech and online hate $\quad 238-41$

laws 49

limits of free speech and comment culture $48-52,54-56,58-61$

moderation 56

nontransparent algorithms 243

online hate and capitalist interests $\quad 242-43$ online vitriol defined 13

overview 19, 233-35

rules for counteracting violence and trolls online 241-43

satire and Sargnagel $\quad 180,191 \mathrm{n} 45$

self-care and perspective $\quad 245-47$

Hatreon 27

'headscarfs 18+' group 203

health 77,204

health care 161

hegemonic masculinity 166,173

hekeldicht 95; see also satire

Hendrix, W.J. 136

Hertzberger, Rosanne 100

hijacking, De Punt train $132-35,136-43,145$, 147

historical prefigurations of vitriol $\quad 87-105$

communities and constituency $\quad 95-100$

functions of masks and rumour's force $89-95$

online communities as constituencies 100-02

overview $18,87-89$

speed in plutocracies and subversion of power 102-05

histories of online vitriol

De Punt's online discussion forum 18 , 131-49

historical prefigurations of vitriol 18 , 87-105

overview $\quad 17-18$

white femininity, trolling, and Cologne assaults 18, 109-27

Hitler, Adolf 114,115

HIV/AIDS 77

Hofer, Maria $\quad 183,192$

Hofer, Norbert 187

homophobia $10,48-49,55$

homosexuality $167,199,225,231$

honour 93-94, 203

honour killing $203,223,225$

Hoover, Herbert 68

Hoover, J. Edgar 91

Hopkins, Katie $\quad$ 52, 58-59

Hrushi Protiv [Piglets Against] $37-40$

Huffman, Steve 233, 242

human rights $\quad 5^{0-51}$

humour $48,81,91,122,154,185$

Hungary 112

hyperbole 59-6o

hyperthymesia 204

Hysteria 186n23

\#ichbinhier ('I am here') campaign $\quad$ 239, 242

ICTs see information and communication technologies

identity

affective politics $\quad 161$

anonymity 219 
collective identity $\quad 138,149$

cultural identity 111

ethical perspective on forgetting 207, 209

felt identity 161,193

limits of free speech $\quad 48-49$

national identity 101

offline/online dualism 200

Sargnagel as author 181

social identity 48

images

affective work of $15^{8}$

ethical perspective on forgetting 206-207, 209

spread of 13

white femininity and Cologne assaults $110-$ $12,115-16,119-20,122,124,127$

see also photographs

immigrants $26,39,58,75,111-16,160,185,239$

imperialism 121, 126, 149

Impey, Catherine 125

incels (involuntary celibates) 240

Indian women 217

individual rights $48,5^{\circ}$

Indonesia $\quad 133-34$

inequality $105,218,225$

information and communication technologies

(ICTs) 198, 202-10

informed consent 237

in-groups $11,159,161,172,174$

injustice frame 139

Innocent III, Pope 93

Instagram $78,181,204,228$

insults $60,100-01,167,190,219,223,228-29$

insurgencies 103

internet

architecture of 133

bullying and trolling 11

De Punt's online discussion forum $132-33$, 144-46, 149

ethical implications $\quad 200,205^{-06}, 208$

feminist activism, trolls, and

misogyny 219, 228-29

limits of free speech $\quad 51,54-55$

satire, affect and hate online $180,192-94$

virus metaphors 80

Internet of Things 210

Internet Police 34

intimidation 100, 192

involuntary celibates (incels) 240

Ipso $5^{8}$

irony $\quad 185-86$

Islamophobia $\quad 114-15,117 \mathrm{n} 21,121,127,160$

'Jailbait' subreddit 234

James, William $\quad 156$

Jane, Emma A. 14, 57, 228-29

Jenkins, Henry 132

Jewel in the Crown, The (TV series) 126

Jews $71,124,234,244$ jobs $\quad 204,236$

Johar, Aranya, 'A Brown Girl's Guide to

Gender' 217

Johnson, Lyndon 91

jokes $49,70-71,89,185$

journalism

affective politics 173

colonial discourses 120

free speech and online hate $\quad 239-40$

mediated visibility and vigilantism 27 , 31,41

online communities as constituencies 100

rules for counteracting violence and trolls online 242

and social media $\quad 10,12$

Trump as first Twitter president $\quad 66-67$

justice $39-40,60,137-39$

Die Kärntner Krone (newspaper) 189

Kek 88-89

Kennedy, John F. 68

Kimeswenger, Fritz $\quad$ 189, 193

Kitchin, Rob 208

Kjellberg, Felix 71

Knight, Sarah 90

knowledge 94, 173

Kobek, Jarett, I Hate the Internet 180

Koch brothers 103

Kraut, Alan 74-75

Kreayshawn $\quad 167$

Kreutzer, Guido, 'Black Shame' 122-23

Die Krone (newspaper) 186-93

Krüger, Julia 243

Der Kurler (newspaper) $\quad 187$

labour 104-05

Lahren, Tomi 112 n10

LambdaMOO 201

language $\quad 65-68,92,104,154-57$

laughter $49,70,89,91$

Law and Justice party 112

law and legal system $30,34-35,49,58,94,198$, 207, 210, 241

Le Pen, Marine $112 n 10$

Le Pen, Marion Marechal $112 n 10$

libel laws $\quad 58$

liberals $\quad 5^{1-52}$

likes $40,79,235,246$

Lil Duval $\quad 167$

Limbaugh, Rush 80

Lincoln, Abraham 110n 5

literacy 121; see also media literacy

literature 92

Locke, John, 'A Letter Concerning

Toleration' $\quad 5^{0}$

Lokteff, Lana 112 n10

love $153-55,159-62,164-66,172-74$

loyalty $154-55,159-60,163,169$

'lulz' (jokes) 49, 70 


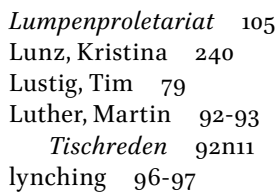

Machiavelli, Nicolo, The Prince gon6 \#MAGA movement (Make America Great Again) 66, 164, 173, 217

Mal Estacionado [Bad Parking] $40 n_{40}$ male privilege 166,236

male sexuality 110

Maluku 133-34

malware $\quad 78-79$

Manchester terror attack $\quad 5^{2}$

Mann, Michael 103

Manosphere 164

Manupatty, Koen 141

Marantz, Andrew $80-81$

Markham, Annette N. $\quad 200$

Marselis, Randi $\quad$ 132, 138-40, 144, 146-47, 149

Marx, Karl 105

masculinity $163,165-66,168-71,173$

masks 89-95

Massumi, Brian 156-57

Mathers, Dani 198-99, 202-03, 205-07, 210

Mayer-Schönberger, Viktor 208

Mayo, Isabella 125

McCarthy, Joseph 101

McGowan, Rose 57

Medforth, Fred Alan $\quad 114 n 12$

media

affective politics $\quad 162-65$

elections 49

feminist tactics against hate speech $\quad 240$

mediated visibility and vigilantism 33-37, $39,41-42$

online communities as constituencies 101-02

satire and Sargnagel $\quad 186-87,189$

sexism 240

and Trump 14, 66, 70, 162-64

white femininity and Cologne assaults $\quad 110-12$

media literacy $199,210,236$

mediated visibility $\quad 25-43$

China and female train passenger $\quad 32-36$

definition 25

overview $17,40-43$

Russia and collectively mediated vitriol $\quad 36-40$

UK and disability $\quad 29-32$

vigilantism, visibility and vitriol $\quad 25-29$

medicalized nativism $\quad 74,76$

medieval communities $\quad 89,93-94,99,104$

Mees, Heleen 100

memes $18,72,79,81,88-89,93,110,112-14$,

127

\author{
memory \\ collective memory $135,144,146,209$ \\ colonial memory $18,132,136,138,147$ \\ coveillance and pernicious memory 200- \\ 05, 209 \\ De Punt and online discussion $132,137-38$, \\ 144,146 \\ dustbin-freezer analogy 208 \\ ethical implications of onlife vitriol 198, \\ 200-09
}

ethical perspective on forgetting 207-09

importance of forgetting in world of surveillance 203-04

psychological function of forgetting 204-05

social function of forgetting $\quad 205^{-0}$ men

Cernovich and masculine nobility 164 , 167,170

ethical implications of onlife vitriol 199, 207

meninism 18

in power 109

Merkel, Angela $112,114 \mathrm{n} 12,116$

Merleau-Ponty, Maurice 156

métissage (miscegenation) 125

\#metoo movement $\quad 236$

Miazga, Corinne 112 nio

migrants

affective politics in Trump era 160

De Punt's online discussion forum 132-33, 145

free speech and online hate $\quad 239$

limits of free speech $\quad 5^{8}$

mediated visibility and vigilantism 26 , 38-39

Moluccan migration history $\quad$ 133-35

outbreak narratives 75

Trump and Ebola scare $\quad 74$

white femininity, trolling, and Cologne assaults $111-16,185$

Mikal, Jude P. 48

Milner, Ryan 12-13

Milton, John, Areopagitica $\quad 48,5^{\circ}$

mime 90

mimicry $157-58,237$

mind-body split 156,200

minorities 12, 234, 245

mirror neurons 237

mirror of princes $\quad 89-90$

miscegenation $110-11,118-20,122,124-25$

misinformation $\quad 238-39,245-46$

misogyny

affective politics in Trump era $18,166,173$

boys clubs and the value of hate 244

bullying and trolling 12

e-bile 14, 228-29

feminist activism, trolls, and misogyny 217-31 
feminist poster campaign $\quad 219,223-24$, 226-28

feminist tactics against hate speech $\quad 240$ limits of free speech $\quad 57$

online communities as constituencies 100 online vitriol defined $\quad$ 13-14

satire and Sargnagel 190

trolls and misogyny overview $19,217-18,231$

missionaries $125,126 \mathrm{n}_{51}$

mobile devices 198,200

mobilization $\quad 27-28,52,80$

moderation $\quad 48,55-58,60,67,146,148-49,244$

Moluccans $132-37,139-40,145,147-48$

Momus $18,88,89-93,95,100$

monitoring 146,199-200, 205, 210

morals $35-36,41,101,126 n_{51}, 137-38,201,243$

Morel, Edmund D. 123

Moroccan men 110

Moroccan women 203

Morocco $183-85,194$

Mouffe, Chantal $\quad 97$ n23, 155

mulattos 121-22

multiculturalism 111-12, 119-20, 127

mummers 90

murder 206, 225

Muslims 42, 111, 113-17, 185-86, 190

Nagle, Angela $\quad 172$

narratology 173

narremes $72,76,157-58$

Nashi [Ours] (Russian youth movement) 37

national identity 101

nationalism $26,33,74,123$

Nazism 101, 114, 115-16, 134

neoliberalism 89, 101-02,104-05

neo-Nazism 112, 239

Netherlands, The

De Punt train hijacking $\quad 133-38,140,149$

Dutch colonialism $\quad 131,133,136,139,145$

Dutch-Moluccans $\quad 132-36,139-41$

Dutch Republic 18, 95-98, 101

legislation 210

news media 100

printing press $\quad 96$

netizens (net citizens) 33-36, $5^{2}$

netzpolitik.org 243

New Right $\quad 163,168-69,172-73$

New Yorker, The 80, 167, 234, 243

news media $\quad 66,100,162-64$

newspapers $\quad 31-32,36,41,66,98,121,236$

Nielsen, Henrik Skov 142

NoMorePage 3 campaign 240

non-verbal behaviours $\quad 157-58,237$

North Africans $115-17,122,184-85$

North Korea 243

NOS (Dutch Broadcast Organization) 203, 209

nostalgia $163,165,169,174$

NRC Handelsblad (newspaper) 100

nude photos 13,199, 202-03, 205
Obama, Barack $\quad 68-69,72-74,77-78,16$ o

objectification $14,70,74$

offence $12,15,27-28,5^{2}, 56,190,192$

offline behaviour $10,19,49,60,234,236$

offline campaigns $\quad 219,221,229-31$

offline/online dualisms $\quad 198-200,210$

Ohanian, Alexis $\quad 233,242$

Oldenbarnevelt, Johan van 96

Olson, Greta $219 n_{5}$

O'Neill, Brendan $\quad 5^{2}, 5^{8-59}$

onlife violence $\quad 197-98,210,230$

onlife vitriol

cases of 202-03

coveillance and pernicious memory 200-03

definitions 198

ethical implications $\quad$ 197-210

ethical perspective on forgetting 207-09

ethics overview $19,197-200,210$

importance of forgetting in world of surveillance 203-04

and offline behaviour 230

psychological function of forgetting 204-05

social function of forgetting $205^{-0} 7$

online activism $\quad 234-36,245-47$

online affect $\quad 171-73$

online campaigns $\quad 218-19,229-31$

online communities $11,51,71,100-02,180$, 193,219

online discussion forum, De Punt film 131-33, 138-40, 143-49

Online Grimme Award $\quad 239$

online hate

and affect $\quad 192-94$

affective politics in Trump era 153,171, 173-74

boys clubs and the value of hate $\quad 244-45$

capitalist interests $\quad 242-43$

definition 239

emotional contagion on Facebook 238

feminist tactics against hate speech $\quad 234-35$

and free speech $\quad 238-41$

nontransparent algorithms 243

rules for counteracting violence and trolls online 241-42

satire and affect $191 \mathrm{n} 45,192-94$

self-care and perspective on online hate $245-47$

online love $153-54,159,172$; see also love

online/offline dualisms 198-200, 210

online self $\quad 201$

online shaming 9-10,29, 203; see also shaming

online violence $110,133,148-49,198-99,235$,

241-42; see also online vitriol; violence

online vitriol

affective politics in Trump era $\quad 153-74$

definitions 13-16, 197

De Punt's online discussion forum $\quad 131-49$

ethical implications of onlife

vitriol $\quad 197-210$ 
feminist activism, trolls, and misogyny $217-31$

feminist tactics against hate speech $233-47$

historical prefigurations of vitriol $\quad 87-105$

limits of free speech and comment culture 47-61

mediated visibility and vigilantism $\quad 25-43$

overview 9-19

satire, affect and Sargnagel $\quad 179-94$

Trump as first Twitter president $\quad 65-82$

white femininity, trolling, and Cologne assaults $\quad 109-27$

opinions $43,52,54-55,238$

Orangists $\quad 95,97$

Orban, Victor 112

ordeal, as mode of proof 94,104

orientalism 121

othering $39,78,91,110,117-18$

outbreak narratives $\quad 74-78,82$

outrage $61,70,154$

oversharing 172

Ovid, Metamorphoses 93

Paasonen, Susanne 173

paedophilia 30,37

Paine, Thomas 233

pamphlets $18,95-96,98,100-02,123$

pandemics $73-74,76$

Paris attacks $114 \mathrm{n} 13,172$

participatory culture $132,145-46$

participatory web 14

Passeron, Jean-Claude 103

past 204-05, 207-08

pathos 154

'Patient Zero' myth $\quad 75^{-7} 6,79$

patriarchy $125-26,240 n 13,245-47$

pay gap 221, 223, 225

Peacock, James 79

peer monitoring see coveillance

PEGIDA 111-13

Pepe the Frog 88,89

performativity $11,13,78,104$

Periscope 164, 206

pernicious memory 203-05, 209

perpetrators, and victims $137-40,142-43,145$,

$147-48,184-85,206-07,210$

personal community $\quad 235-36$

personal information $26,34,203^{-04}, 206,241$

petitions 235

Phelan, James 142

Philippines 244

Phillips, Whitney $\quad 12-13,48-49$

Phoenix rally $160-61$

photographs

ethical implications of onlife vitriol 19899, 202-03, 205-07, 209-10

feminist campaigns $\quad 218-19$

'Jailbait' subreddit 234 mediated visibility and vigilantism $\quad 30-31$ removal of images 206-07

spread of images 13

virality 79

phrenology 120

pick up artists 240

pile-ons 10, 172

pillory 9-10, 29

Pirinçci, Akif 117 n21

Pizza-Gate 164

plutocracies 103, 105

Poland 112

polarization

De Punt and polarized interpretations of hijacking 136-38

De Punt forum as echo chamber $144-45$, 147

De Punt forum as platform for polarization $138-40$

fictive discourse of De Punt telefilm 140-43

policing $32,34-35,57,67,210,246$

politeness $53-54,5^{8}$

Politically Incorrect (German portal) 116-17 politics

and affect $\quad 154-55,159,171$

affective politics in Trump era $\quad 153-74$

feminist poster campaign reactions 223, 224,225

fragmentation 14

historical prefigurations of vitriol 89,91 , 103-04

mediated visibility and vigilantism $\quad 27$

political violence 59

satire and Sargnagel $\quad 182$

Trump as Twitter president $\quad$ 17-18

weaponization of vitriol 15

politics of prestige $\quad 125$

Pollock, Griselda 102

popularity 26,57

populations 118-19

populism 26-27, 155, 174

pornography $100,206,227-28$

postcolonialism 110n2, 131, 136, 139, 149

power

bullying and trolling $\quad 11$

historical prefigurations of vitriol 93, 95, 97, 102-05

limits of free speech 59

men in power 109

online vitriol defined $\quad$ 11-13

participatory space $\quad 145$

soft power 67

speed in plutocracies and subversion of power 102-05

vigilantism 40

Powers, Elizabeth $\quad 5^{1}$

precariate 105

prejudice $41,53,55,60$ 


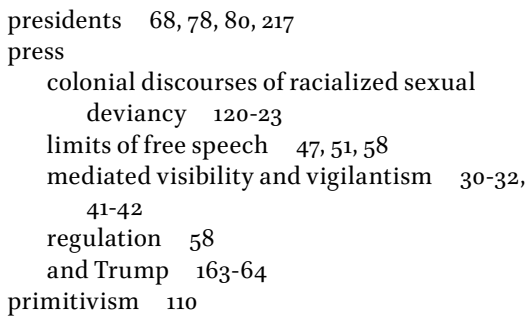

feminist tactics against hate speech $\quad 234$,

$$
240
$$

GeenStijl site 100

incels 240

limits of free speech $49,54,57$

Reddit 234

satire and Sargnagel 190, 194

threats $49,54,57,100,190,194,234$

white femininity, trolling, and Cologne

$$
\text { assaults } 111,113,115-16,122-23
$$

rationality $59,118,155^{-} 56,238$

Real Social Dynamics 240

reality 200-01

'Rechts gegen Rechts' [right-wing against right-wing] campaign 239

Reddit 11, 27, 71-72, 81, 117, 120, 233-35, 242-43, 245

refugees $18,111,113-15,117,119,127,182,184,239$

regulation $53-54,57-58,60,119,172$

Reijmer, Loes 100

Reker, Henriette 112

religion 92, 97, 101, 116, 223, 224, 225

Renan, Ernest 121

reparation 198,210

reporting $56-57,60,242$

representation 127,156

reputation $15,39,203,209$

respect 57,60

responsibility $16,5^{0-51}, 67,138-40,145,171-73$

retaliation $37,39-40$

revenge 180,241

revenge porn 172,206

revenge rape 198-99, 206-07

Rheinland (Rhineland) 118, 122-23, 123n42

rhetoric 154

rhizome 157

right wing 100-01, 117, 192-94, 239; see also Alt-Right; New Right rights

human rights $5^{0-} 5^{1}$

individual rights $48,5^{\circ}$

limits of free speech $\quad 48,5^{0-52,59}$

nontransparent algorithms 243

plutocracies and power 105

right to change 208

right to hate $5^{0-52}$

right to opinion 238

rules for counteracting violence and trolls online 241

women's rights 117,229

Riposte Laïque 116

Rire (magazine) 122

Ronson, Jon 9-10

Roosevelt, Franklin D. 68

Roosh V 240

rough music 30

Rumor 18, 88-91, 93

rumour $88 \mathrm{n} 1,89-95,96,100,102$

Rupp, Jörg 243 
Russia 27, 36-40, 41-42, 67, 102

Ryan, Paul $\quad 168-69$

Sacco, Justine 9-10

same-sex marriage $\quad 225$

Sarah's law 30

sarcasm 31, 35

Sargnagel, Stefanie

affect and hate online $\quad 192-94$

as author $\quad 181-83$

case of $\quad 183-92$

'Morocco Travel Journal II: Steffi Got

Married to Hassan' 194

satire and affect 19, 179-80, 194

Statusmeldungen ('Status Updates') 181

'Three Authors in Morocco: Now We Have a Horse and Hashish' $\quad 180-81,183,185-86$

SARS 77

satire

and affect $\quad 179-94$

affect and hate online $\quad$ 192-94

Dutch Republic history 95

overview 19, 179-81

Sargnagel as author $\quad 181-83$

Sargnagel case $\quad 183-92$

savages 121,123

schimpdicht genre 95; see also satire

Schmitt, Josephine B. 191n 45

Schmitt, Richard $\quad 186,189-93$

schools 11, 199, 202, 204-05, 226

Schwarzer, Alice $\quad 116$

scientific discourse 120,127

scold's bridle $29-30$

screenshots 241-42, 246

Second World War 124

self 201

self-care $19,235,245-47$

self-censorship 43,100

self-expression $\quad 28,53,57,208$

selfies 202, 204

self-policing $\quad 32,34$

semiotics 156

Semmel, Bernard 121

Serano, Julia $\quad 167$

sex offenders 30,124

sexism

'basic bitches' $\quad 167$

boys clubs and the value of hate $\quad 244-45$

feminist activism, trolls, and misogyny 226, 231

GeenStijl site 13

limits of free speech and comment culture $48-49,52$

satire and Sargnagel $\quad 185$

self-care and perspective on online hate $246-47$

StopBildSexism 240

white femininity and trolling $\quad 110-11$,

$$
123-24,127
$$

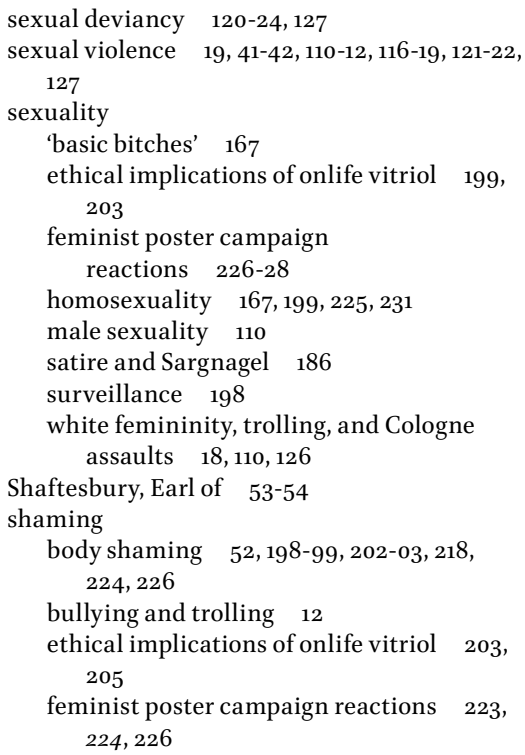

historical prefigurations of vitriol 93

mediated visibility and vigilantism 29, $37-38,41$

public shaming $\quad 9-10,12,38$

slut shaming $\quad 198-99,203,226$

sharing $26,40,79,235$

Sharp, Cassandra 172

shitstorms $9,14,19,93,180,182,186-88,191$

Silicon Valley 27

Simberg, Rand 103

simianization $\quad 122-24$

Simonides, Simon $\quad 97 \mathrm{n} 22$

Sina Weibo 33-34

slacktivism $\quad 235$

slavery $\quad 5^{6}$

slut shaming $\quad$ 198-99, 203, 226

Smail, Daniel Lord 94

smartphones 199, 206, 210

Snapchat 202-03

social capital 104

social communication 155

social discrimination $\quad 223,224,226$

social disruption 80,96

social exclusion $\quad 11,35$

social forgetfulness 206

social identity 48

social justice 40,60

social media

activism 241-42

affect and emotional contagion on

Facebook 237-38

affective politics in Trump era $\quad 153-55$, 158-60

boys clubs and the value of hate $\quad 244-45$ bullying and trolling 11 
clicktivism vs. effective online activism $\quad 235-36$

dynamics of Twitter and other platforms $77-80$

ethical implications of onlife vitriol 200 , 204, 206, 209

expanding public sphere $\quad 53-55$

feminist poster campaign $\quad 219$

feminist tactics against hate speech 234-35

free speech and online hate $\quad 238-41$

group formation 11

history of Trump as Twitter president $\quad 68-69$

limits of free speech and comment culture $\quad 47^{-61}$

mediated visibility and vigilantism $\quad 26$, $33 n 16,40$

moderation 244-45

nontransparent algorithms 243

online hate and capitalist interests $\quad 242-43$

online vitriol defined $\quad$ 13-16

public shaming 9-10

regulation $53-54,57$

responsibility of 67

rules for counteracting violence and trolls online $\quad 241-42$

satire and Sargnagel $\quad 179-82,188,192-93$

Trump as first Twitter president $\quad 65-82$

unruly spaces and problems of enforcement $55^{-5} 8$

virality $\quad 78-81$

see also Facebook; Reddit; Twitter; YouTube

social norms 53,209

social policing $\quad 202,209$

social psychology $\quad 11,171-72$

social web 14

sociality 12,19

socio-symbolic capital 89, 104-05

Sommer, Rebekka 116-17

Sontag, Susan 101

Soros, George 168

sousveillance 199-200

Soviet Union 36,40

speculum principes $89-90$

speech acts $13-14,239$

speed of vitriol spread $\quad 18,88-89,93,96,99$, 102-05, 206

Spencer, Herbert $\quad 121 n 33$

Spinoza, Baruch $\quad 156$

Ethics 156

Spivak, Gayatri Chakravorty $105^{\mathrm{n}} 4 \mathrm{O}$

spyware 78

Stacey, Peter 9on6

Der Standard (newspaper) $\quad 181,183,186-89,194$

state role $29,94,103$

state-owned media $\quad 33-34,36$

Steijlen, Fridus 137

stereotyping $110,136,166-67,218,226-27,231$ stigmatization $74,110,122$

StopBildSexism (SBS) campaign $\quad 240-41$

StopXam [Stop a Douchebag] 37, 39-40

Stormzy 55

stranger, archetypal $\quad 76,79$

subcultures 15,172

subreddits $71,234,245$

suggestion 93,96

suicides 199, 202

Sunstein, Cass R. $\quad$ 132-33, 144-48

super-spreaders 76,79

surplus value 104-05

surveillance $\quad 28,32,111,198-200,203-04,210,247$

suspended accounts $\quad 56-57$

symbolic capital $103^{-05}$

'Syndrome Syndrome' 79

tabloid press $\quad 30-31,47,51,60$

talk 93-95, 99, 102, 104

technologies 198-99, 202-04, 209-10, 247

telefilms $18,131-32,135,140-43$

Telegram 203, 207, 209

television $\quad 66,68$

Ten Walls 55

terrorism $42,52,118,141,172$

Theweleit, K. 109

thread logic $48,58,60$

threats

death threats $9,49,54,180,190,194$

feminist activism, trolls, and misogyny 19 , 219

GeenStijl site 100-01

online vitriol defined $\quad 13-14$

rape threats $49,54,57,100,190,194,234$

Reddit 234

rules for counteracting violence and trolls online 241

satire and Sargnagel $\quad 179-80,190,192,194$

self-care and perspective on online hate 246

Tianya 33

tirailleurs (colonial soldiers) 122

Todd, Amanda $\quad$ 198-99, 202, 205, 207, 210

Tompkins, Silvan $\quad 157$

traffic violations $37-38,40$

train hijacking, De Punt $132,134-38,140-43$

train travel $30-32,34-35,40-41$

Traiskirchen refugee camp $\quad 182$

transgender people 13,66

trauma 204-05, 209, 244

trends 79,244

trolling

affect and emotional contagion on

Facebook 238

affective politics in Trump era 154,168 , 173

and bullying 11

Cologne New Year's Eve assaults 18 , 110-20, 127 
feeding the trolls $17,49,56,60$

feminist activism, trolls, and misogyny $\quad 217-31$

feminist poster campaign $\quad 219,221-30$

feminists and trolls $116-18$

feminist tactics against hate speech $\quad 235$, 239, 241

free speech and online hate $\quad 239,241$

historical prefigurations of anti-miscegenation $\quad 118-20$

limits of free speech and comment culture $17,48-49,56,60$

problems of enforcement 56

and public shaming 10

'rapefugees' 113-16

rules for counteracting violence and trolls online $\quad 241-42$

self-care and perspective on online hate 245

thread logic 48-49

trolls and misogyny overview $\quad 19,218,231$

Trump as first Twitter president $\quad 71,81$

and white femininity $\quad 109-27$

Trolls for Trump 18,80

Trump, Donald

affective politics in Trump era $153-74$

affective politics overview $19,154-56$, 173-74

and Alt-Right messages/memes $\quad 81$

The Art of the Deal 163

boys clubs and the value of hate $\quad 244-45$

Cernovich, masculine nobility, and basic bitches 164-66, 168-69, 171

Charlie Hebdo/Paris attacks $114 \mathrm{n} 13$

'cofveve' 67

dynamics of Twitter and other platforms $\quad 77-80$

from Ebola scare to presidential campaign $\quad 80-82$

feminist activism, trolls, and misogyny 217,225

first Twitter president $\quad 17-18,65-82$

'Grab 'em by the pussy' comment $\quad 66,217$

Great Again 163-64

history of Trump as Twitter president $\quad 68-69$

inarticulacy of Ebola rhetoric $\quad 75-77$

Make America Great Again $66,164,173,217$

and media $\quad 14,66,70,162-64$

nontransparent algorithms 243

@realdonaldtrump account $\quad 67-68,72-74$

retweetable inarticulacy $\quad 65-68$

as superspreader of Ebola scare $\quad$ 72-75

transgender military ban 66

Trumpian affects $\quad 159-64$

Twitter and hate speech $\quad 244-45$

'unpresidented' error $\quad 65-67$

Trumpians (Trump supporters) 159-61, 163-64, 174
Turkish women 203

Twitter

affective politics in Trump era 154, 162, $164,168,173$

Black Twitter $\quad 235-36$

bots 43

boys clubs and the value of hate $\quad 244-45$

bullying and trolling 11

Cernovich and masculine nobility 164 , 168

clicktivism vs. effective online activism 235-36

contagiousness of Ebola scare $\quad 70-72$

dynamics of Twitter and other platforms $77-80$

edgelord jokes 71

history of Trump as Twitter president $\quad 68-69$

inarticulacy of Trump's Ebola rhetoric $75^{-} 77$

limits of free speech and comment culture $47,49,5^{2-60}$

mediated visibility and vigilantism $\quad 27,43$

mission statement 53

nontransparent algorithms 243

online vitriol defined 13

public shaming 9-10

regulation 54,57

retweetable inarticulacy of Trump's language $\quad 65^{-68}$

satire and Sargnagel $\quad$ 181, 188-91

self-care and perspective on online hate 246

Trump as a superspreader of the Ebola scare $\quad 72-75$

Trump as first Twitter president $\quad$ 17-18, $65^{-82}$

Trump from Ebola scare to presidential campaign $\quad 80-82$

virality 78

Uktolseja, Hansina 142

unfollowpatriarchy.com $240 n 13$

United Kingdom (UK) 26, 29-32, 49, 52, 55, $58-59,121,126$

United States (US)

affective politics in Trump era $\quad 164-65,174$

legislation $210 \mathbf{n}_{42}$

Trump as Twitter president $\quad 68,70,74-75$, $77-78$

\#unpresidented hashtag $\quad 65-67$

unzensuriert.at $187,190,193$

user-generated content $14-15,26,144,146$

utilitarianism $\quad 155$

utopian thinking $\quad 91$

Uyttersprot, Ilse 198

Valleywag 9

value $104-05,246$ 
Veblen, Thorstein $\quad 105$ victims

De Punt train hijacking and forum 137-40, $142-43,145,147-48$

ethical implications of onlife vitriol 199, 201-03, 205-07, 210

female victims 13,199

feminist tactics against hate speech $\quad 234$

functions of forgetting $\quad 205^{-07}$

limits of free speech $56,5^{8}$

online vitriol and fragmentation 14

public shaming 9-10

satire and Sargnagel $\quad 184-86$

videos

ethical implications of onlife vitriol 199, 203, 206, 209

mediated visibility and vigilantism 34 , $37-40$

online communities 100

Trump retweets 81,244

virality 79

Vienna 182

vigilantism

China and female train passenger $\quad 32-36$

ethical implications $198,200,202,207,209$

and mediated visibility $\quad 25-43$

mediated visibility overview $\quad 17,40-43$

Russia and collectively mediated vitriol $\quad 36-40$

UK and disability $\quad 29-32$

visibility and vitriol $\quad 25-29$

village pacts 32

violence

animal abuse 183

definitions 197-98, 230

De Punt train hijacking and forum 133, $136,142,147-48$

domestic violence $\quad 42$

ethical implications of onlife vitriol 197$99,202-03,208,210,230$

limits of free speech $59-60$

lynching of de Witt brothers 96-97

online hate speech $\quad 234$

online violence $110,133,148-49,198-99$, $235,241-42$

online vitriol defined 10,12

and public shaming 10

sexual violence $19,41-42,110-11,116-18,127$

value of hate 244

white femininity and Cologne as-

virality saults $110-13,127$

affective contagion $\quad 159$

computer viruses 81

Ebola epidemic $\quad 70,75,77$

ethical implications of onlife vitriol 20203, 206

historical prefigurations of vitriol 88,102 social media and Trump $\quad 78-81$ virtuality 200-01

visibility $\quad 25-29,41$

Visser, Arnoud $92 n 11$

visual rhetoric, and Cologne attacks $\quad 18,110-12$ $118,122,125,127$

vitriol

affective politics 154,174

communities and constituency $\quad$ 95-100

definitions 13-16, 197

ethical implications $\quad 197-98$

etymology 14

function of 105

functions of masks and rumour's force 89-95

historical prefigurations of $\quad 87-105$

historical prefigurations overview $\quad 87-89$

limits of free speech $\quad 59$

masks $\quad 87-89$

mediated visibility and vigilantism $\quad 25-29$, 41

online communities as constituencies 100-02

speed in plutocracies and subversion of power 102-05

vigilantism, visibility and vitriol $\quad 25-29$ see also online vitriol

VKontakte 37

Voat 27

VOC (Dutch East India Company) 133

De Volkskrant (newspaper) 100

Vorstius, Conrad 97n24

Vught camp 134

W Sieci magazine $\quad 115$

Wald, Priscilla $\quad 76-77,79-80,82$ Contagious 74

Walsh, Richard 142

Wardle, Claire $193 n_{53}$

wars $87,122,124,136$

Washington elites $\quad 160-61,163$

wealth 105

wearable devices 200

Web $2.0 \quad$ 14, 77

webcams 199

WeChat 34

Weibo 34

Weidel, Alice $\quad 112$ n1o

Weinstein, Harvey 57

Wekker, Gloria 149

Welch, Joseph 101

Wellman, Barry 235

West Africa $\quad 70,73,77$

West, Caroline $\quad 5^{2}$

WhatsApp 203

whipping pole 9

white femininity, and trolling $\quad 109-27$

civilizing missions and miscegenation $\quad 125^{-2} 6$

Cologne New Year's Eve assaults $\quad 110-20,127$ 
colonial discourses of racialized sexual deviancy $120-24$

feminists and trolls $\quad 116-18$

historical prefigurations of anti-miscegenation $\quad 118-20$

overview $18,109-10,127$

'rapefugees' 113-16

silence and violence $\quad 111-13$

white nationalism $\quad 72,242$

white patriarchy $125,245-47$

white supremacy $72,110-12,119,121-23,127,161$

'Who Needs Feminism?' campaign 218

\#WhyIStayed hashtag $\quad 236$

Wigger, Iris 123

WikiLeaks 235

Wilders, Geert 114

'Wilkommenskultur' 114n12,123

William III of Orange $\quad 95-96$

Witt, Cornelis de 96-98, 99

Witt, John de 95-98, 99

Wizorek, Anne 117

wochenblick.at 187, 190-91, 193

women

affective politics in Trump era 18,160 , 166-68

Cernovich, masculinity, and 'basic bitches' 166-68

e-bile $14,228-29$

edgelord jokes 71

ethical implications of onlife vitriol 199, 202-03, 208-09

female victims $\quad 30-31,199$

feminist activism, trolls, and misogyny $217-31$

feminist tactics against hate speech 236,240

gender-specific vitriol

$35,41,57$ mediated visibility and vigilantism 30-31, $35,41-42$

satire and Sargnagel $\quad 179-80,184-85$

scold's bridle 30

value of hate 245

white femininity, trolling, and Cologne assaults $18,109,112,115,121-22,125^{-2} 6$ women's rights 117,229

\#WomenBoycottTwitter hashtag 57

Women's March on Washington 220

Wong, Yishan 234

working class $\quad 159-60$

World War I 122

World War II 124

World Wide Web 200, 206

Wychera, Alina $\quad 183 n 15$

xenophobia 116,118

Xinjingbao 33,36

YouTube

Alt-Right $\quad 71$

'Broadcast Yourself' slogan 54

Cernovich documentary $\quad 169$

debate culture 146

ethical implications of onlife vitriol 202, 204, 209

free speech and comment culture 17,47 , 50, 53-57,6o

mission statement 53

moderation $\quad 55^{-} 57$

Russia and collectively mediated vitriol 37,40

virality $\quad 78-79$

Zentrum Demokratische Kultur (ZDK) 239

\#ZombieHillary hashtag $80-81$ 